\title{
Vitamin D as an immune modulator in multiple sclerosis
}

Citation for published version (APA):

Smolders, J. J. F. M. (2011). Vitamin D as an immune modulator in multiple sclerosis. [Doctoral Thesis, Maastricht University]. Datawyse / Universitaire Pers Maastricht. https://doi.org/10.26481/dis.20110512js

Document status and date:

Published: 01/01/2011

DOI:

10.26481/dis.20110512js

Document Version:

Publisher's PDF, also known as Version of record

\section{Please check the document version of this publication:}

- A submitted manuscript is the version of the article upon submission and before peer-review. There can be important differences between the submitted version and the official published version of record.

People interested in the research are advised to contact the author for the final version of the publication, or visit the DOI to the publisher's website.

- The final author version and the galley proof are versions of the publication after peer review.

- The final published version features the final layout of the paper including the volume, issue and page numbers.

Link to publication

\footnotetext{
General rights rights.

- You may freely distribute the URL identifying the publication in the public portal. please follow below link for the End User Agreement:

www.umlib.nl/taverne-license

Take down policy

If you believe that this document breaches copyright please contact us at:

repository@maastrichtuniversity.nl

providing details and we will investigate your claim.
}

Copyright and moral rights for the publications made accessible in the public portal are retained by the authors and/or other copyright owners and it is a condition of accessing publications that users recognise and abide by the legal requirements associated with these

- Users may download and print one copy of any publication from the public portal for the purpose of private study or research.

- You may not further distribute the material or use it for any profit-making activity or commercial gain

If the publication is distributed under the terms of Article $25 \mathrm{fa}$ of the Dutch Copyright Act, indicated by the "Taverne" license above, 


\section{Vitamin D as an immune modulator in multiple sclerosis}


Financial support for the publication of this thesis was kindly provided by: Bayer HealthCare, Biogen Idec International B.V., Merck Serono the Netherlands B.V., Sanofi Aventis Netherlands B.V., Stichting MS Research, and TEVA Nederland B.V.

\section{ISBN 9789461590459}

(C) Joost Smolders, Maastricht 2011.

All rights reserved. No part of this thesis may be reproduced, stored in a retrieval system of any nature, or transmitted in any form or by any means, electronic, mechanical, photocopying, recording or otherwise without prior written permission of the author.

Printed by Datawyse/Universitaire Pers Maastricht 


\title{
Vitamin D as an immune modulator in multiple sclerosis
}

\author{
PROEFSCHRIFT \\ ter verkrijging van de graad van doctor \\ aan de Universiteit Maastricht, \\ op gezag van de Rector Magnificus, Prof. Mr. G.P.M.F. Mols, \\ volgens het besluit van het College van Decanen, \\ in het openbaar te verdedigen \\ op donderdag 12 mei 2011 om 14.00 uur \\ door \\ Joost Josephus Franciscus Maria Smolders \\ geboren te Tilburg op 28 maart 1983
}

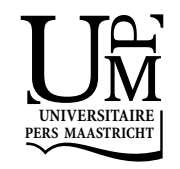




\section{Promotores}

Prof. dr. R.M.M. Hupperts

Prof. dr. J.W. Cohen Tervaert

\section{Copromotor}

Dr. J.G.M.C. Damoiseaux

\section{Beoordelingscommissie}

Prof. dr. M.H. de Baets, voorzitter

Prof. dr. H. van Loveren

Prof. dr. C.H. Polman, Vrije Universiteit Medisch Centrum, Amsterdam

Prof. dr. H.W.M. Steinbusch

Prof. dr. R. Vieth, Mount Sinai Hospital, Toronto (Canada) 
How manifold it is, what thou hast made!

They are hidden from the face of man.

Hymn to the sun god Aten,

attributed to pharaoh Akhenaten (1351 - 1333 BC)

(translation in Pritchard, 1958). 



\section{Contents}

$\begin{array}{ll}\text { Abbreviations } & 9\end{array}$

$\begin{array}{lll}\text { Chapter } 1 & \text { General introduction and aims } & 11\end{array}$

Chapter 2 Vitamin D as an immune modulator in multiple sclerosis 19

Chapter 3 Association of vitamin D metabolite levels with relapse rate and disability in patients with multiple sclerosis 43

Chapter $4 \quad$ Vitamin D status is positively correlated with regulatory T cell function in patients with relapsing remitting multiple sclerosis

Chapter 5 Regulatory T cell function correlates with 25-hydroxyvitamin $D$, but not with 1,25-dihydroxyvitamin D, parathyroid hormone, and calcium levels in patients with relapsing remitting multiple sclerosis

Chapter 6 Safety and T cell modulating effects of high dose vitamin $D_{3}$ supplementation in relapsing remitting multiple sclerosis

Chapter 7 Fok-I vitamin D receptor gene polymorphism (rs10735810) and vitamin D metabolism in multiple sclerosis

Chapter 8 Design of a randomized, controlled clinical trial on add-on therapy with vitamin $D_{3}$ in Interferon Beta-treated patients with relapsing remitting multiple sclerosis

Chapter 9 General discussion

Chapter 10 References

Chapter 11 Summary

Chapter 12 Dutch summary (Nederlandse samenvatting)

Acknowledgements (Dankwoord)

Publications

Curriculum Vitae 



\section{Abbreviations}

\begin{tabular}{|c|c|}
\hline $1,24,25(\mathrm{OH})_{3} \mathrm{D}$ & 1,24,25-trihydroxyvitamin D \\
\hline $1,25(\mathrm{OH})_{2} \mathrm{D}$ & 1,25-dihydroxyvitamin D \\
\hline 25(OH)D & 25-hydroxyvitamin D \\
\hline 7AAD & 7-aminoactinomycin D \\
\hline Apa-I & Acetobacter pasteurianus restriction enzyme \\
\hline APC & Antigen presenting cell \\
\hline APC & Allophycocyanin \\
\hline BMD & Bone mineral density \\
\hline Bsm-I & Bacillus stearothermiphilus restriction enzyme \\
\hline$C D$ & Cluster defining molecule \\
\hline CFSE & Carboxy fluorescein diacetate succinimidyl ester \\
\hline CNS & Central nervous system \\
\hline CTLA-4 & Cytotoxic T lymphocyte antigen 4 \\
\hline CYP & Cytochrome P \\
\hline DBP & Vitamin D binding protein \\
\hline DC & Dendritic cell \\
\hline DNA & Desoxyribonucleic acid \\
\hline $\mathrm{EAE}$ & Experimental autoimmune encephalomyelitis \\
\hline ED50 & Half-maximal proliferation point \\
\hline EDSS & Expanded disability status scale \\
\hline FITC & Fluorescein isothiocyanate \\
\hline Fok-I & Flavobacterium okeanokoites restriction enzyme \\
\hline FoxP3 & Forkhead box P3 \\
\hline GM-CSF & Granulocyte macrophage-colony stimulating factor \\
\hline IFN- $\beta$ & Interferon beta \\
\hline IFN- $\gamma$ & Interferon gamma \\
\hline $\lg$ & Immunoglobulin \\
\hline IL- & Interleukin \\
\hline IR40 & Inhibitor ratio for $40 \%$ suppression \\
\hline MBP & Myelin Basic Protein \\
\hline $\mathrm{MHC}$ & Major Histocompatibility Complex \\
\hline MRI & Magnetic resonance imaging \\
\hline mRNA & Messenger ribonucleic acid \\
\hline MS & Multiple sclerosis \\
\hline
\end{tabular}




\begin{tabular}{|c|c|}
\hline NGF & Nerve Growth Factor \\
\hline PBMC & Peripheral blood mononuclear cells \\
\hline PE & R-Phycoerythrin \\
\hline PEcy7 & Conjungate of PE and cyanine dye 7 \\
\hline PerCP & Peridinin chlorophyll protein \\
\hline PHA & Phytohaemagglutinin \\
\hline PMA & Phorbol 12-myristate 13 -acetate \\
\hline PPMS & Primary progressive multiple sclerosis \\
\hline PTH & Parathyroid Hormone \\
\hline Rag & Recombination activating genes \\
\hline RNA & Ribonucleic acid \\
\hline RRMS & Relapsing remitting multiple sclerosis \\
\hline RXR & Retinoid $\mathrm{X}$ receptor \\
\hline SNP & Single Nucleotide Polymorphism \\
\hline SPMS & Secondary progressive multiple sclerosis \\
\hline Taq-I & Thermus Aquaticus restriction enzyme \\
\hline TGF- $\beta$ & Tumour growth factor beta \\
\hline Th1 & T helper cell type 1 \\
\hline Th17 & T helper cell type 17 \\
\hline Th2 & T helper cell type 2 \\
\hline TNF- $\alpha$ & Tumour necrosis factor alpha \\
\hline $\operatorname{Tr} 1$ & T regulatory cell type 1 \\
\hline Treg & Regulatory T cell \\
\hline Tresp & T responder cell \\
\hline UVB & Ultra violet $\mathrm{B}$ radiation \\
\hline VDR & Vitamin D receptor \\
\hline VDRG & Vitamin D receptor gene \\
\hline VLA-4 & Very late antigen 4 \\
\hline
\end{tabular}




\section{General introduction and aims}

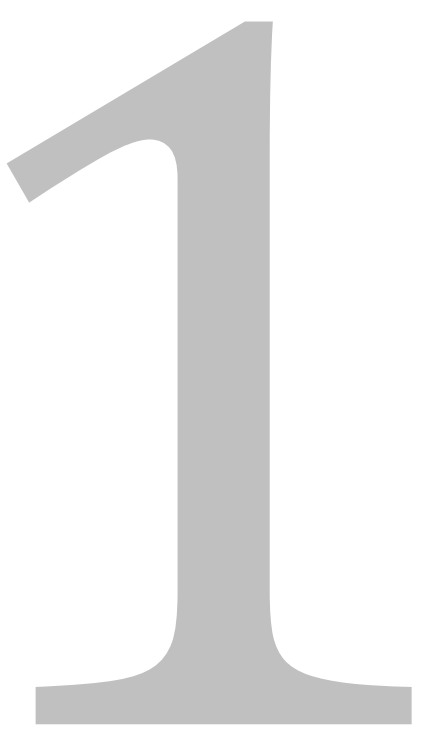

Adapted from: Joost Smolders, Jan Damoiseaux (2011). Vitamin D as a T cell modulator in multiple sclerosis. In: Litwack $G$ (ed.), Vitamins and hormones volume 86: vitamins and the immune system (Chapter 18, pp. 401-428), Elsevier, London (United Kingdom). 



\section{Multiple sclerosis}

Multiple sclerosis is an inflammatory disease of the central nervous system (CNS). The prevalence of MS in the Netherlands is about 100 per 100.000 subjects. Similarly to most other autoimmune diseases, MS affects more females than males. The female/male-ratio has increased during the past decades, and is now estimated to be about 3.0 (Orton et al., 2006). The age at disease onset is typically between 20 and 50 years of age, although MS can also sporadically have its onset during childhood $(\approx 5 \%)$ or in the elderly (Compston and Coles, 2008). The exact cause of MS is uncertain, but MS has been argued to arise from an unlucky interplay of several genetic and environmental risk factors. Several risk alleles within different genes have been identified in genome wide association studies, but the most prominent remain within the $\mathrm{MHC}$ class II region (International Multiple Sclerosis Genetics Consortium et al., 2007). Many environmental risk-factors for MS have been proposed. The most well-consolidated, is the Epstein Bar Virus (EBV) infection. MS patients experienced prior to MS onset two times more symptomatic EBV infections (infectious mononucleosis) when compared with healthy individuals (Handel et al., 2010). Higher anti-EBV antibody titers were found in MS patients prior to MS onset versus matched healthy controls (Ascherio et al., 2010). Interestingly, EBV-negative MS patients were not to be found (Levin et al., 2010). Additionally, smoking has been shown to increase the risk on MS especially in subjects with high anti-EBV titers (Simon et al., 2010). Besides identification of new risk-factors, exploration of the exact interactions between these different genetic and environmental riskfactors is an important issue in MS research.

The diagnosis of MS was, until recently, exclusively based on clinical manifestations with the Schumacher and later the Poser criteria (Poser et al.,1983; Schumacher et al., 1965). Recently, newer diagnostic criteria became in use, integrating newer diagnostic modalities as MRI in the diagnosis of MS (McDonald et al., 2001; Polman et al., 2005). However, the keystone in the diagnosis of MS is the dissemination of symptoms arising from CNS dysfunction in space and time. At onset, patients most frequently experience sub-acute attacks of neurological impairment, which resolve spontaneously after several weeks. At this stage, the disease is called relapsing remitting MS (RRMS) (Figure 1). Although impairment resolves completely at disease onset, in later stages of disease recovery is not complete and impairment accumulates. Although some patients only experience a limited amount of disability throughout their disease course of MS, many will in time develop a gradually worsening of symptoms without attacks. In this stage the disease is called secondary progressive MS (SPMS). A small proportion of patients experiences progressive disability from disease onset onwards without exacerbations, and in these patients the disease is called primary progressive MS (PPMS) (Compston and Coles, 2002). At disease onset, there have been only few tools identified to predict the severity of 
the clinical course of an individual patient. The impairment which patients experience is diverse in quantity and quality, and can arise from dysfunction of any component of the CNS. Although loss of motor function and subsequent loss of mobility are most well recognized, symptoms can also include visual impairment, sensory impairment, balance disorders, bowel dysfunction, sexual dysfunction, cognitive dysfunction, etc (Compston and Coles, 2002). Several clinimetrical scales have been developed to monitor disability of MS. Although having clear limitations, the most widely used scale to express MS severity is the Expanded Disability Status Scale (EDSS) (Kurtzke 1983). This scale rates neurological impairment due to MS in a scale of 0 to 10 (Table 1).

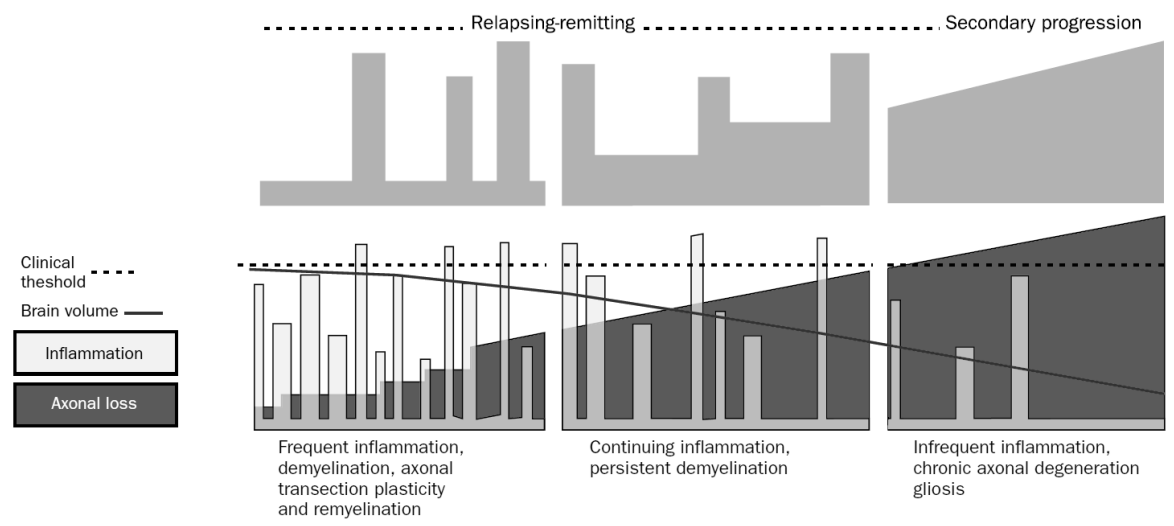

Figure 1 Multiple Sclerosis disease course

Schematic presentation of the disease course of MS. During the relapsing remitting phase, the disease is mostly characterized by inflammation. In the later stages of MS, axonal loss and loss of brain volume are predominant features (Adapted with permission of Elsevier from: Compston A, Coles A. Multiple Sclerosis. Lancet 2002;359:1221-1231). 
Table 1 Kurtzke's Expanded Disability Status Scale (EDSS)

0.0 Normal neurological examination

1.0 No disability, minimal signs in one functional system

1.5 No disability, minimal signs in more than one functional system

2.0 Minimal disability in one functional system

2.5 Mild disability in one functional system or minimal disability in two functional systems

3.0 Moderate disability in one functional system, or mild disability in three or four functional systems. Fully ambulatory

3.5 Fully ambulatory but with moderate disability in one functional system and more than minimal disability in several others

4.0 Fully ambulatory without aid, self-sufficient, up and about some 12 hours a day despite relatively severe disability; able to walk without aid or rest some 500 meters

4.5 Fully ambulatory without aid, up and about much of the day, able to work a full day, may otherwise have some limitation of full activity or require minimal assistance; characterized by relatively severe disability; able to walk without aid or rest some 300 meters

5.0 Ambulatory without aid or rest for about 200 meters; disability severe enough to impair full daily activities

5.5 Ambulatory without aid or rest for about 100 meters; disability severe enough to preclude full daily activities

6.0 Intermittent or unilateral constant assistance required to walk about 100 meters with or without resting

6.5 Constant bilateral assistance required to walk about 20 meters without resting

7.0 Unable to walk beyond approximately five meters even with aid, essentially restricted to wheelchair

7.5 Unable to take more than a few steps; restricted to wheelchair; may need aid in transfer

8.0 Essentially restricted to bed or chair or perambulated in wheelchair, but may be out of bed itself much of the day

8.5 Essentially restricted to bed much of day

9.0 Confined to bed; can still communicate and eat.

9.5 Totally helpless bed patient

10.0 Death due to MS

Adapted from: Kurtzke JF. Rating neurologic impairment in multiple sclerosis; An expanded disability status scale (EDSS). Neurology 1983;33:1444.

\section{The $\mathbf{T}$ cell compartment in multiple sclerosis}

Pathological and radiological studies of the CNS of MS patients revealed that pathogenesis is characterized by two phenomena: i) focalized inflammation of CNS tissue, and ii) loss of neurons (Compston and Coles, 2002). Although the causality of these phenomena has often been disputed, there is increasing consensus that inflammation is the primary driver of the disease process of MS. T cell-mediated inflammation in the CNS is most prominent at disease onset (Figure 1), and evidence of a 
disturbed peripheral T cell homeostasis in MS patients at disease onset is mounting (Venken et al., 2010). Additionally, large genetic screens revealed almost exclusively immune-related risk alleles for developing MS (International Multiple Sclerosis Genetics Consortium et al., 2007). Furthermore, even in patients with progressive disease, compartmentalized inflammation of the CNS remains a key characteristic in the pathological image of MS (Frischer et al., 2007). Many clinical and experimental studies have addressed the immune-pathogenesis of MS (reviewed in Bar-Or 2007; Goverman, 2009).

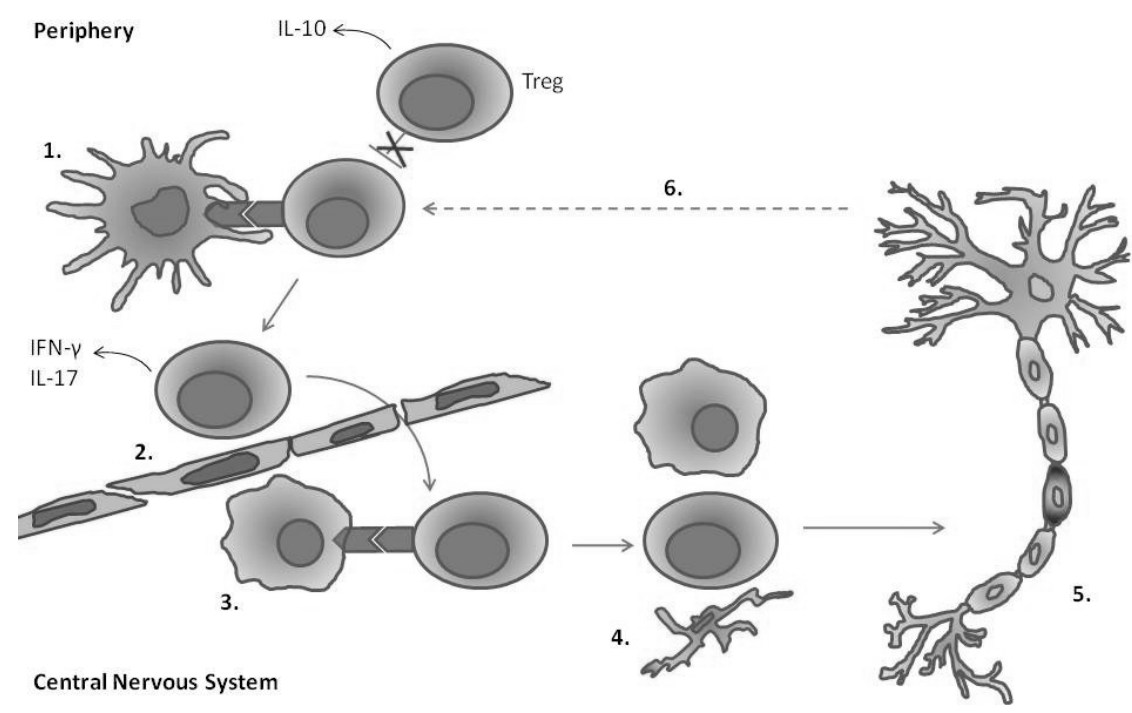

Figure 2 T cell response in MS.

Symplified model of the T cell response in patients with MS. Regulatory T cells (Treg) fail to maintain peripheral tolerance, and naïve T cells are primed in the periphery (1). Subsequently, activated auto-reactive T cells enter the circulation and cross the blood brain barrier (2). In the central nervous system, they are reactivated by APC (3), and contribute to the activation of several pro-inflammatory cells including other lymphocytes, macrophages and microglia cells (4). This activation results in an inflammatory response which attacks the myelin sheet surrounding the neurons. This inflammation results in loss of neuronal function and ultimately in loss of neurons (5). It has been postulated that fragments of degraded myelin fragments are presented again in the periphery to maintain the immune cascade (6).

The attack of the immune system on the CNS starts in the peripheral lymphoid organs, where antigen presenting cells (APC) present an epitope to naïve T cells (Figure 2). The nature of this epitope is uncertain, but a viral protein mimicking CNS proteins, soluble factors leaking from the CNS, and CNS proteins actively transferred by dendritic cells (DC) from the CNS have been proposed. Auto-reactive CD4 ${ }^{+} \mathrm{T}$ cells loose there tolerant state for self-antigens, are primed, and enter the circulation. These cells adopt a pro-inflammatory cytokine profile, including production of interferon gamma (IFN- $\gamma$ ) by T helper type 1 (Th1) cells, and interleukin 17 (IL-17) by 
Th17 cells. Patient-control studies revealed that peripheral regulatory mechanisms to maintain T cell tolerance are impaired in MS patients. In a healthy T cell compartment, regulatory $\mathrm{CD}^{+} \mathrm{T}$ cells (Tregs) are capable of controlling the quality and quantity of the immune response (Sakaguchi et al., 2008). In patients with a number of autoimmune diseases, including MS, these Tregs have been found to be less effective suppressors of T-cell responses, while their number in the circulation is not affected (Constantino et al., 2008; Venken et al., 2005; Viglietta et al., 2004). This defective control mechanism enables the activation of auto-reactive $T$ cells. The auto-reactive $T$ cells attach to adhesion molecules on the endothelium of the the blood brain barrier (including very late antigen 4 (VLA-4) receptors), and actively enter the CNS by secreting metalloproteinases. In the CNS, they are re-activated by resident $A P C$, including macrophages and microglia cells. Subsequently, the T cells contribute to a focalized inflammatory reaction, in which the myelin sheet surrounding axons is degraded. This process leads to neuronal dysfunction, neuronal damage, and ultimately loss of neurons.

\section{Treatment of multiple sclerosis}

MS cannot be cured. The registered MS drugs so far are mostly either modulators or suppressors of the peripheral T cell compartment. Beta Interferons and Glatiramer Acetate skew the balance between pro-inflammatory Th1 and anti-inflammatory Th2 cells towards a Th2 phenotype, and promote the suppressive function of Tregs as well as the induction of naïve Tregs (Schrempf and Ziemsen, 2007; de Andres et al., 2007). Therapies like mitoxantrone and cyclophosphamide are cytotoxic for $T$ cells in the periphery (Neuhaus et al., 2005). The newer therapy Nataluzimab (antiVLA-4 antibodies) prevents activated T cells from entering the CNS (Miller et al., 2003). Efficacy of these MS disease modulating therapies has only been shown in RRMS patients. Additionally, treatment with Interferon Beta was more efficacious when started early after the diagnosis of MS (Kappos et al., 2007). Longitudinal studies show that patients vary in time-course until an EDSS-score of 3, but that the progression from EDSS-score 3 to 6 shows few variation between patients (Leray et al., 2010). Therefore, modulation or suppression of the peripheral T cell compartment appears to be most efficacious at the start of MS, when disability is limited. Therapeutic trials in progressive MS patients have not delivered efficacious treatments so far. Regarding the severe side effects of the immune suppressive therapies, most patients start with immune modulating drugs. These drugs reduce the number of MS exacerbations with $30 \%$, but at the cost of several side effects, including influenza-like illness, headache, nausea, and injection-site erythema. The last years, attention has been drawn on vitamin D as a potential therapy in MS. 


\section{Aim of this thesis}

The aim of this thesis is to assess whether vitamin D supplementation can be developed as an additional treatment modality in MS. Therefore, this thesis addresses two main questions: i) is vitamin $D_{3}$ a modulator of MS disease activity? ii) which biological processes underlie this modulation?

\section{Outline of this thesis}

Chapter 2 describes a review of literature as was available at the start of the project, with some later updates on the experimental work. We show that vitamin $D$ is a potent modulator of the adaptive immune response in vitro and in animal models of MS, but that it is uncertain whether vitamin $D$ is also an in vivo modulator of the immune system in patients with MS. To address this problem, we firstly assessed in chapter $\mathbf{3}$ an association of vitamin D status with disease severity/ activity of MS in our MS population in South Limburg, The Netherlands. Subsequently, we tested in chapter 4 whether peripheral T cell homeostasis correlated in these patients with their vitamin D status, and extended these data in chapter $\mathbf{5}$ by exploring the role of calcium homeostasis in this association. Additionally, the effect of supplementation of high doses of vitamin $D_{3}$ on the peripheral $T$ cell compartment was assessed in the pilot study presented in chapter 6 . In the pilot study, the safety of vitamin $D_{3}$ supplementation was also analyzed. As an addition to these studies, we explored in chapter 7 the effect of a genetic polymorphism of the vitamin D receptor with structural and functional consequences on the risk on developing MS and vitamin D status per se. The results of these studies were all combined in the design of a large randomized placebo-controlled clinical trial, of which the study design is shown in chapter 8. The most important conclusions of this thesis will be discussed in chapter 9 . 


\section{Vitamin D as an immune modulator in multiple sclerosis}

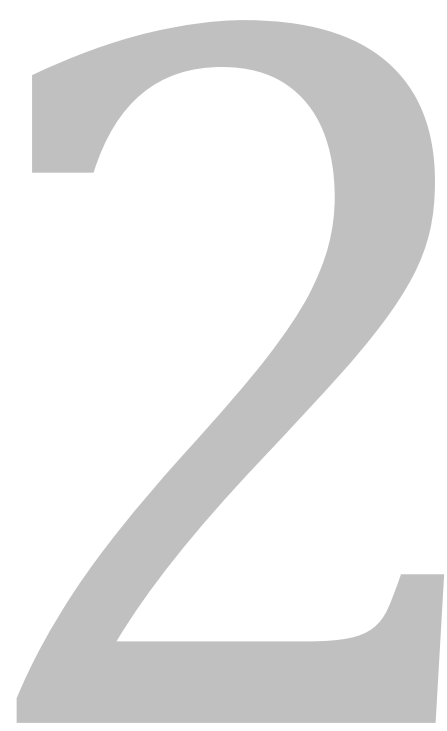

Adapted from: Joost Smolders, Jan Damoiseaux, Paul Menheere, Raymond Hupperts. Vitamin $D$ as an immune modulator in multiple sclerosis, a review. Journal of Neuroimmunology 2008;104:7-17, and Joost Smolders, Jan Damoiseaux (2011). Vitamin D as a $T$ cell modulator in multiple sclerosis. In: Litwack $G$ (ed.), Vitamins and hormones volume 86: vitamins and the immune system (Chapter 18, pp. 401-428), Elsevier, London (United Kingdom). 


\begin{abstract}
The role of vitamin D in calcium homeostasis is well known. More recently vitamin D has become a topic of interest in immune regulation and multiple sclerosis. The main reason for this is the observed geographical distribution of multiple sclerosis. Areas with high sunlight exposure, the principal inducer of vitamin D synthesis, have a relatively low prevalence of multiple sclerosis and vice versa. Furthermore, low levels of the principal vitamin D metabolite (25-hydroxyvitamin D) in the circulation are associated with a high incidence of multiple sclerosis. Other epidemiological evidence also supports the view that vitamin $D$ metabolites have an immune and disease modulating effect in multiple sclerosis. Experimental research in vitro and in animal models has further clarified the interaction of vitamin D metabolites with the immune system. The evidence obtained from these studies strongly supports a model in which vitamin $D$ mediates a shift to a more anti-inflammatory immune response, and in particular to enhanced regulatory T-cell functionality. In the current review we link the basic knowledge on vitamin $D$ and immune regulation with the vitamin D related observations in multiple sclerosis. We conclude that there is a sound basis on which to initiate double-blind placebo-controlled trials that not only address the effect of vitamin D on the clinical outcome of multiple sclerosis, but also on the regulatory $\mathrm{T}$-cell compartment.
\end{abstract}




\section{Introduction}

Multiple sclerosis (MS) is a chronic inflammatory disease of the central nervous system (CNS) of unknown aetiology (Compston and Coles, 2006). Although a genetic susceptibility for the development of MS is well known, exposure to as yet undefined environmental risk factors is also required (Hauser and Oksenberg, 2006). Apart from viral infections and geographical variation in food intake, environmental supplies of vitamin $D$ have been proposed as a possible risk factor for developing MS (Goldberg et al., 1986). There is geographical, biological and immunological evidence that exposure to low environmental supplies of vitamin $D$ is associated with an increased risk of developing MS. Although vitamin D is best known as a modulator of calcium homeostasis, it also has strong immune modulating potential. When considering MS as an autoimmune disorder, the idea of a beneficial immune modulating effect of vitamin $D$ is logical. This has been investigated in vitro, in experimental allergic encephalomyelitis (EAE), an animal model of MS and in vivo, in MS patients.

The aim of this article is to review the evidence for the potential immune modulating effect of vitamin D in MS. We will take into account not only observations in the human MS population, but also experimental research in vitro and in animal models. A possible therapeutic application of vitamin D in MS patients will be discussed.

\section{Vitamin D}

Vitamins are defined as substances of whom we are dependent upon our environment and which are vital for biological processes in the body, apart from their caloric value. While most vitamins are acquired via dietary intake, vitamin $D$ is a unique vitamin in this perspective. The largest part is synthesized in the skin under the influence of ultraviolet B (UVB) radiation (Ohmdahl et al., 2005). Out of 7dehydrocholesterol, UVB radiation forms pre-vitamin $D$, which transforms spontaneously as a result of body temperature to cholecalciferol or vitamin $D_{3}$. The vitamin $D$ which is acquired via the diet contains both cholecalciferol, derived from animal products, and ergocalciferol (vitamin $D_{2}$ ), which is derived from plant products. It is uncertain whether these forms of vitamin D differ in biological function. The contribution of dietary vitamin $D$ intake to the total daily amount of vitamin $D$ acquired is modest. Total body sun exposure easily provides the equivalent of an oral intake of $250 \mu \mathrm{g}$ (10 $000 \mathrm{IU})$ vitamin $D_{3}$, whereas the Office of Dietary Supplements of the National Institute of Health (USA) indicates $5 \mu \mathrm{g}$ (200 IU) as an adequate daily oral intake for adults (Vieth, 1999). However, depending on the geographical latitude, the amount of vitamin D effective UVB radiation is limited through winter in large 
areas on the globe (Kimlin 2008). In British children and elderly, it was shown that vitamin $D$ intake only predicts vitamin $D$ status during winter, and not in the other seasons (Bates et al., 2003; Davies et al., 1999).

In the circulation, only small amounts of vitamin $D$ are present. This molecule has a biological halflife of 12-16 hours (Smith and Goodman 1971), and fluctuates depending on the exposure to either sunlight or dietary intake (Hollis et al., 2007). It is entirely bound to a specialized carrier protein, vitamin D binding protein (DBP). The vitamin $D$ is almost instantly hydroxylated in the liver by 25-hydroxylases (CYP2R1, CYP27A1, and CYP3A4) towards 25-hydroxyvitamin D (25(OH)D) (Figure 1). This is the most abundant metabolite in the circulation and is most accepted to reflect the overall vitamin D status of an individual. It has a half-life of 20-90 days and is bound for about 90\% to DBP (Smith and Goodman 1971; Mawer et al., 1969). The other $10 \%$ is primarily bound to other serum proteins including albumin and only a small fraction of about $0.40 \%$ is freely available. Although $25(\mathrm{OH}) \mathrm{D}$ is the most abundant vitamin $D$ metabolite, it is not biologically active. Another hydroxylation step by 1- $\alpha$ hydroxylase (CYP27B1) is required to form the biologically active metabolite of vitamin $\mathrm{D}, 1,25$-dihydroxyvitamin $\mathrm{D}\left(1,25(\mathrm{OH})_{2} \mathrm{D}\right)$. The serum levels of $1,25(\mathrm{OH})_{2} \mathrm{D}$ are mostly dependent on expression of 1 - $\alpha$-hydroxylase in the kidneys upon signals from calcium metabolism (Jongen et al., 1984). The biological effects of $1,25(\mathrm{OH})_{2} \mathrm{D}$ result from either direct actions at the cell membrane, or via modulation of gene transcription via intracellular binding to the vitamin $D$ receptor (VDR). When bound to $1,25(\mathrm{OH})_{2} \mathrm{D}$, the VDR forms heterodimers with the retinoid $X$ receptor $(\mathrm{RXR})$, and moves to the nucleus of the cell. Here, it binds to a vitamin D response element, and causes transcription or transrepression of vitamin responsive genes (Figure 2) (reviewed in Smolders et al., 2009c). 


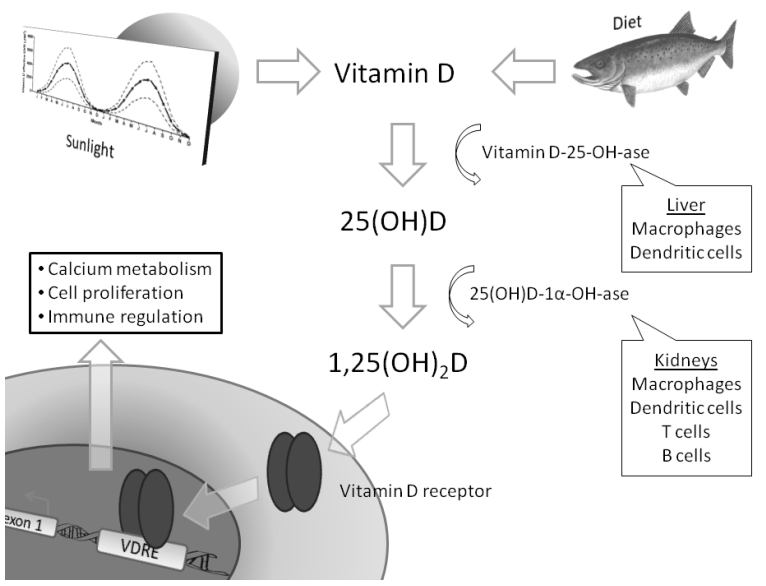

Figure 1 Vitamin D metabolism.

Vitamin $D$ is acquired via diet and via photosynthesis in the skin, dependent on the amount of intake and sun-exposure, respectively. In the body, vitamin D is instantly hydroxylized in 25hydroxyvitamin $\mathrm{D}(25(\mathrm{OH}) \mathrm{D})$, the most abundant vitamin $\mathrm{D}$ metabolite. This metabolite can be further hydroxylized in the biologically active form, 1,25-dihydroxyvitamin $D\left(1,25(\mathrm{OH})_{2} \mathrm{D}\right)$. This metabolite interacts with the vitamin $D$ receptor, which binds to vitamin response elements (VDRE) in the nucleus and induces transcription or transrepression of vitamin $D$ responsive genes. This interaction affects calcium metabolism, cell proliferation and immune regulation.

A

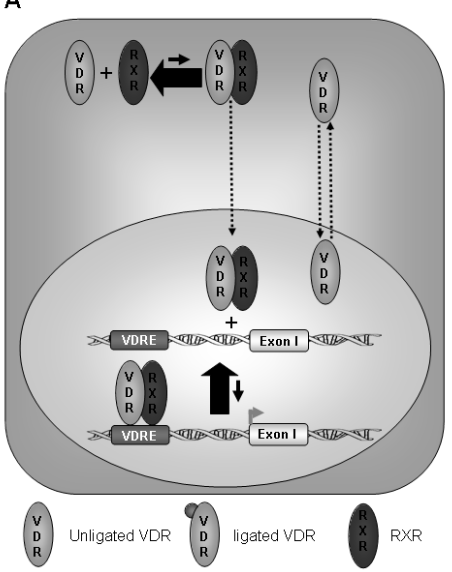

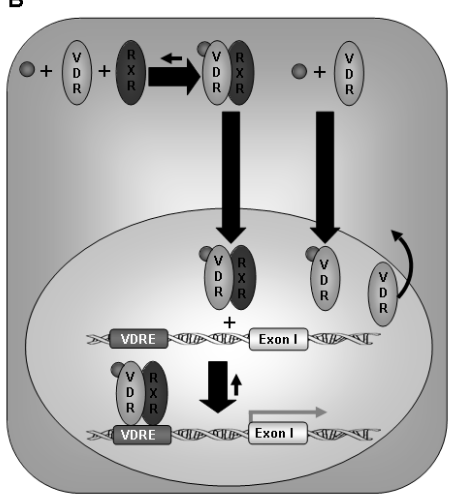

$1,25(\mathrm{OH}) 2 \mathrm{D} 3$

Figure 2 Intracellular organisation of the VDR.

A) In the absence of $1,25(\mathrm{OH})_{2} \mathrm{D}$, VDR shuttles between cytoplasm and the nucleus. The VDR can dimerize with RXR, but the formed heterodimer is not stable and has a low affinity for the VDRE. This results in basal regulation of target gene transcription. B) Upon binding $1,25(\mathrm{OH})_{2} \mathrm{D}$, VDR is activated and translocated to the nucleus. The VDR/RXR heterodimer is stabilised, giving it a high affinity for the VDRE, which results in an increased transactivation or transrepression of the genes. The size of the arrows indicates the degree of the respective processes (dimerization, translocation, DNA binding or transcription). VDR: vitamin D receptor; RXR: retinoid X receptor (Adapted from: Smolders et al. 2009c). 


\section{Vitamin D and calcium homeostasis}

The role of vitamin D in calcium metabolism is most well known. During the Industrial Revolution in the nineteenth century, rickets reached almost epidemic proportions in ill-fed children living in cities with little sunlight, in the northern countries. A beneficial effect of sunlight and cod-liver oil was observed, but it was not until the 1930's that vitamin D was identified as the therapeutic element in those therapies (Bouillon, 2005). Vitamin D is an essential component for maintaining a stable calcium level in the circulation. If the serum calcium level drops, chief cells in the parathyroid gland start secreting parathyroid hormone (PTH). Besides some direct effects on bone metabolism, PTH predominantly catalyses, via CYP27B1, the hydroxylation of $25(\mathrm{OH}) \mathrm{D}$ to $1,25(\mathrm{OH})_{2} \mathrm{D}$ in the kidneys. Elevated serum $1,25(\mathrm{OH})_{2} \mathrm{D}$ levels lead to an increased uptake of calcium from the intestines, increased resorbtion of calcium in the proximal tubules of the kidneys, and an increased osteoclast activity. The subsequent rise of serum calcium restores the balance between serum calcium and PTH. The availability of too little of the precursor 25(OH)D to be hydroxylized in $1,25(\mathrm{OH})_{2} \mathrm{D}$ results in a decompensation of this system. Since a stable serum calcium level is vital for many processes in the body, calcium is retrieved from the skeleton to compensate for the loss of calcium via kidneys and intestine. Therefore, a poor vitamin D status has been associated with loss of bone mineral density (BMD) (Bisschof-Ferrari et al., 2004), and increased risk of fractures (Lopes et al., 2009; Cauley et al., 2010). Supplementation of vitamin D with or without calcium has been shown to improve BMD (Tang et al., 2007) and to decrease fracture risk (Bisschof-Ferrari et al., 2005) in the elderly. The latter effect may be due to an increased BMD, but additionally supplementation of vitamin $D$ also decreases the risk of falling (BisschofFerrari et al., 2009). The decreased risk of falling may be attributable to a favorable effect of vitamin D on muscle strength (Stewart et al., 2009).

Both the concentration where serum PTH concentration just starts to rise above normal values and the level at which effective fracture prevention is achieved, have been suggested as reliable measurements for the level of 25(OH)D required for a normal bone metabolism. An estimated optimal plasma 25(OH)D value of $50-80$ $\mathrm{nmol} / \mathrm{L}$ has been proposed (Dawson-Hughes et al., 2005). Although these levels are required for a normal bone homeostasis, it has been argued that a higher 25(OH)D level is required to optimise other biological functions of vitamin D (Vieth, 2006).

\section{Vitamin D in the central nervous system}

In the CNS, expression of VDR has been described in different cell types (Garcion et

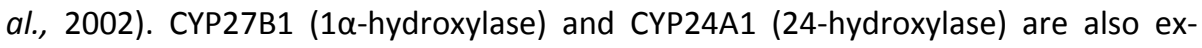
pressed in the CNS (Overbergh et al., 2000; Zehnder et al., 2001). Therefore, the 
CNS may be a site of action, metabolism and catabolism of vitamin D. Intra-uterine vitamin $\mathrm{D}$ depletion leads to brain development disorders and reduced levels of nerve growth factor (NGF) at birth in rats, underlining the importance of vitamin D in the brain (McGrath et al., 2004). A rise in VDR transcription and NGF transcription and synthesis by astrocytes on $1,25(\mathrm{OH})_{2} \mathrm{D}$ stimulation has been reported (Garcion et al., 2002; Neveu et al., 1994). In microglial cells, APC's within the CNS, an inhibition of TNF- $\alpha$, IL- 6 and Nitric Oxide production was observed in vitro (Lefebvre d'Hellencourt et al., 2003). These data suggest a paracrine function of vitamin D in the CNS.

\section{Vitamin D and the immune system}

\subsection{Vitamin D receptor expression by immune cells}

Numerous immune cells express the vitamin $D$ receptor. Firstly, the expression of VDR mRNA by monocytes and activated $B$ and $T$ cells was recognized (Provvedini et al., 1983). Measured by ELISA, both $\mathrm{CD}^{+}$and $\mathrm{CD}^{+}{ }^{+}$T cells expressed VDR protein, which was up-regulated upon activation and exposition to $1,25(\mathrm{OH})_{2} \mathrm{D}$ (Veldman et al., 2000). In resting naïve T cells, VDR protein levels were absent, but up-regulated on stimulation with anti-CD3 and anti-CD28 via the p38 TCR-signaling pathway (Von Essen et al., 2010). In purified resting CD4+ T cells, VDR mRNA expression was almost absent, but was up-regulated upon activation with phytohaemagglutinin (PHA) or anti-CD3 (Correale et al., 2009). Addition of 1,25(OH) 2 D further up-regulated VDR mRNA expression. Resting mature myeloid and plasmacytoid DC's, as well as immature myeloid DC's and monocytes, expressed similarly high levels of VDR mRNA, which were not further enhanced by addition of $1,25(\mathrm{OH})_{2} \mathrm{D}$ (Penna et al., 2007). Others observed low, but detectable levels of VDR expression in monocytes, which were instantly up-regulated by a DC differentiation cocktail comprising granulocyte macrophage-colony stimulating factor (GM-CSF) and IL-4 (Széles et al., 2009). Resting $B$ cells express undetectable amounts of VDR mRNA, but after activation or exposure to $1,25(\mathrm{OH})_{2} \mathrm{D}$, expression of the VDR is up-regulated (Chen et al., 2007)

It can be concluded that APC express the receptor for $1,25(\mathrm{OH})_{2} \mathrm{D}$, irrespective of activation or $1,25(\mathrm{OH})_{2} \mathrm{D}$ exposition, while resting lymphocytes express very low amounts of VDR, which is up-regulated on activation or exposition to $1,25(\mathrm{OH})_{2} \mathrm{D}$. Therefore, immune cells appear to be a target for $1,25(\mathrm{OH})_{2} \mathrm{D}$. Additionally, lymphocytes appear to become more susceptible for the actions of $1,25(\mathrm{OH})_{2} \mathrm{D}$ when activated.

\subsection{Metabolism of vitamin D by immune cells}

The largest proportion of the vitamin $D$ metabolites present in the circulation, lymphoid organs, and tissues, comprises $25(\mathrm{OH}) \mathrm{D}$. Only a small part $(0.1 \%)$ consists of 
the biologically active metabolite $1,25(\mathrm{OH})_{2}$ D. Numerous immune cell types, however, have the ability to express 25(OH)D-1 $\alpha$-hydroxylase (CYP27B1) and actively form $1,25(\mathrm{OH})_{2} \mathrm{D}$. Activated T cells up-regulate the expression of CYP27B1, either on activation with anti-CD3 and anti-CD28 in a T cell/DC co-culture (Sigmundsdottir et al., 2007), or on activation with PHA in a $\mathrm{CD}^{+} \mathrm{T}$ cell monoculture (Correale et al., 2009). In vitro, this up-regulation also results in the formation of $1,25(\mathrm{OH})_{2} \mathrm{D}$ out of 25(OH)D (Sigmundsdottir et al., 2007; Correale et al., 2009). Several APC, including macrophages and DC, also express high levels of CYP27B1. Resting blood DC's synthesize limited amounts of $1,25(\mathrm{OH})_{2} \mathrm{D}$, which is dramatically up-regulated by activation with LPS, accompanied by an up-regulation of CYP27B1 expression (Fritsche et al., 2003). The presence of $1,25(\mathrm{OH})_{2} \mathrm{D}$ inhibits the expression of CYP27B1. In addition, human resting monocytes do not express CYP27B1, whereas in vitro differentiated macrophages and DC do express CYP27B1 and subsequently form 1,25(OH) ${ }_{2} \mathrm{D}$ out of 25(OH)D (Gottfried et al., 2006; Széles et al., 2009). B-cells are also able to form $1,25(\mathrm{OH})_{2} \mathrm{D}$ out of $25(\mathrm{OH}) \mathrm{D}$ upon activation with several activation cocktails (Chen et al., 2007; Heine et al., 2008). Additionally, B cells express 1,25(OH) 2 D-24hydroxylase (CYP24A1) on exposure to $1,25(\mathrm{OH})_{2} \mathrm{D}$ when in an activated state (antiIgG/anti-CD40/ IL-21) (Chen et al., 2007; Heine et al., 2008). Also, monocytes, macrophages and DC (Gottfried et al., 2006; Penna et al., 2007), as well as T cells (Correale et al., 2009) express CYP24A1 upon exposure to $1,25(\mathrm{OH})_{2} \mathrm{D}$. To evoke catabolism of $1,25(\mathrm{OH})_{2} \mathrm{D}$, activation of these cells is not mandatory.

In summary, activation of an immune response is accompanied by a local induction of $1,25(\mathrm{OH})_{2} \mathrm{D}$ synthesis out of the locally available $25(\mathrm{OH}) \mathrm{D}$ (Figure 3). When $1,25(\mathrm{OH})_{2} \mathrm{D}$ is abundantly present, both activated and resting immune cells catabolize this metabolite. The observations that almost all immune cells carry the VDR and metabolize its ligand upon activation, suggest that vitamin D might have an important autocrine function for immune regulation. Interestingly, CYP27A1, the enzyme which catalyzes the vitamin D-25-hydroxylation, is also expressed by macrophages and DC's upon activation, resulting in a local formation of 25(OH)D (Gottfried et al., 2006; Sigmundsdottir et al., 2007). The relevance of this mechanism in the periphery, where $25(\mathrm{OH}) \mathrm{D}$ is abundantly available, is probably limited. However, in the skin, where vitamin $D_{3}$ itself is mostly present, this mechanism is important to induce effective $1,25(\mathrm{OH})_{2} \mathrm{D}$ synthesis.

\subsection{In vitro effects of $1,25(\mathrm{OH})_{2} \mathrm{D}$ on the immune response}

Since activated immune cells synthesize $1,25(\mathrm{OH})_{2} \mathrm{D}$ and express the VDR, $1,25(\mathrm{OH})_{2} \mathrm{D}$ is likely to affect the immune response. Several studies investigated the effect of $1,25(\mathrm{OH})_{2} \mathrm{D}$ exposition on the immune response in vitro. Studies on lymphocytes can be divided in studies which assessed the effect of $1,25(\mathrm{OH})_{2} \mathrm{D}$ on proliferation, cytokine production, and the phenotype of cells. Unless stated otherwise, all data concern studies with human cells. Results are summarized in table 1. 


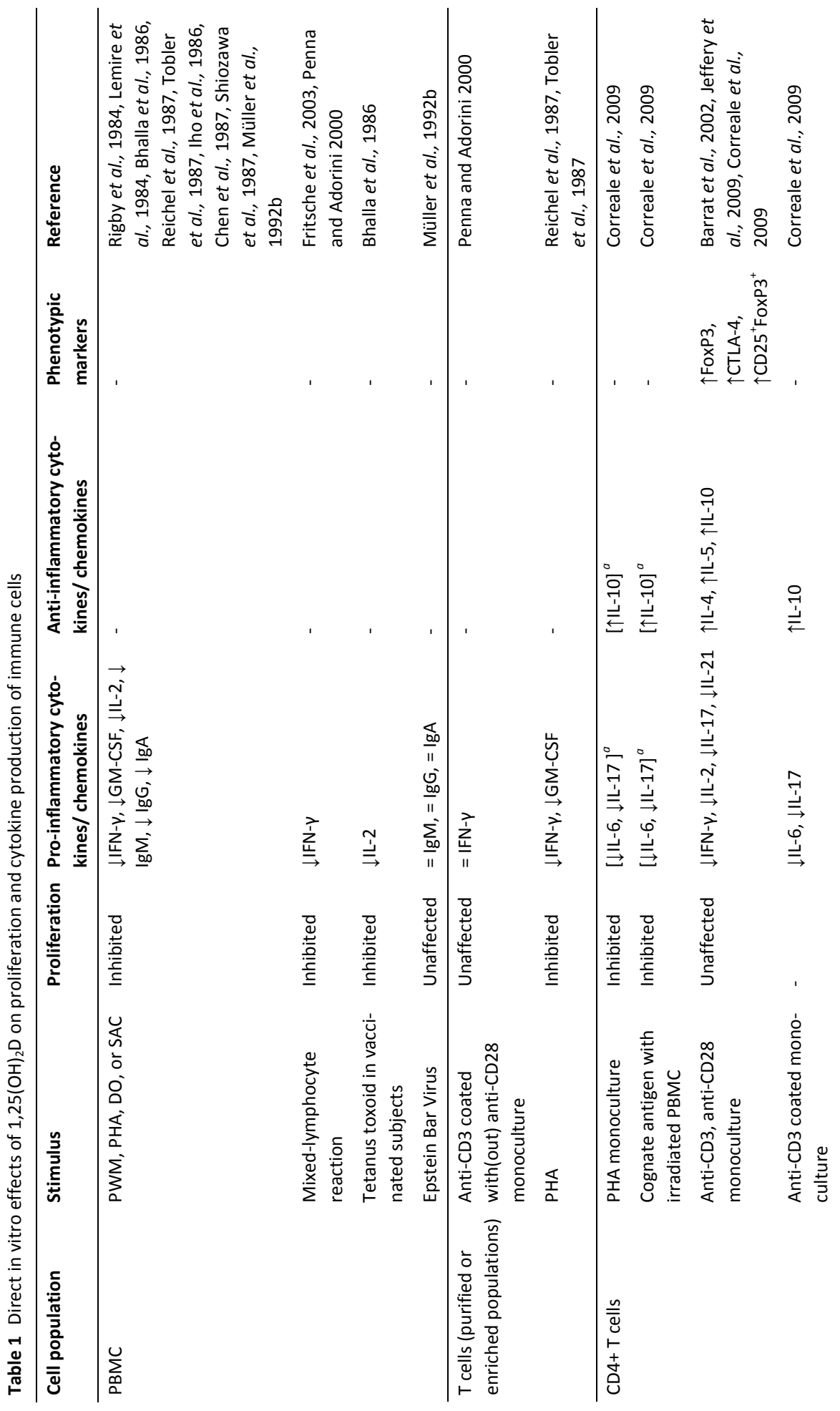




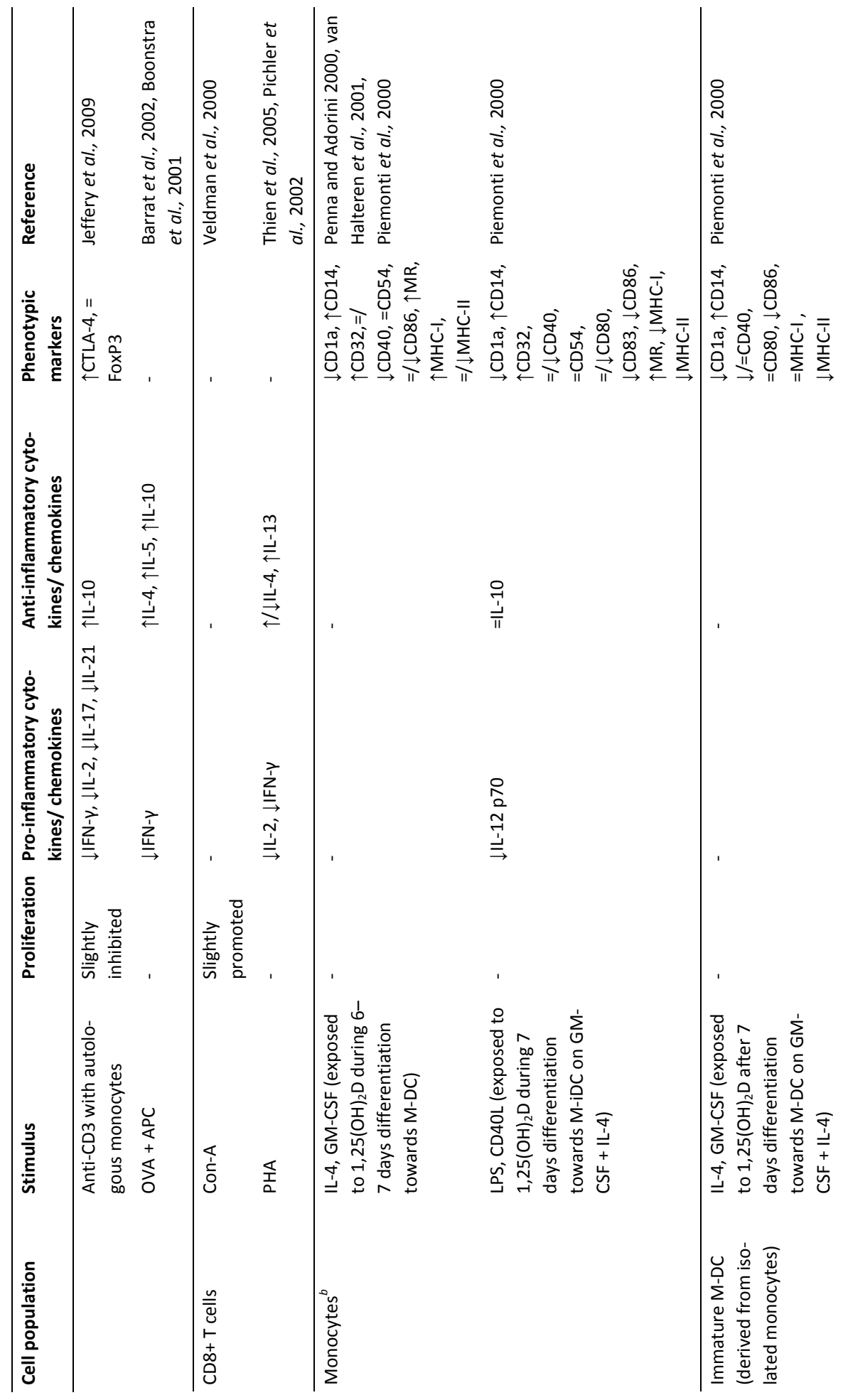




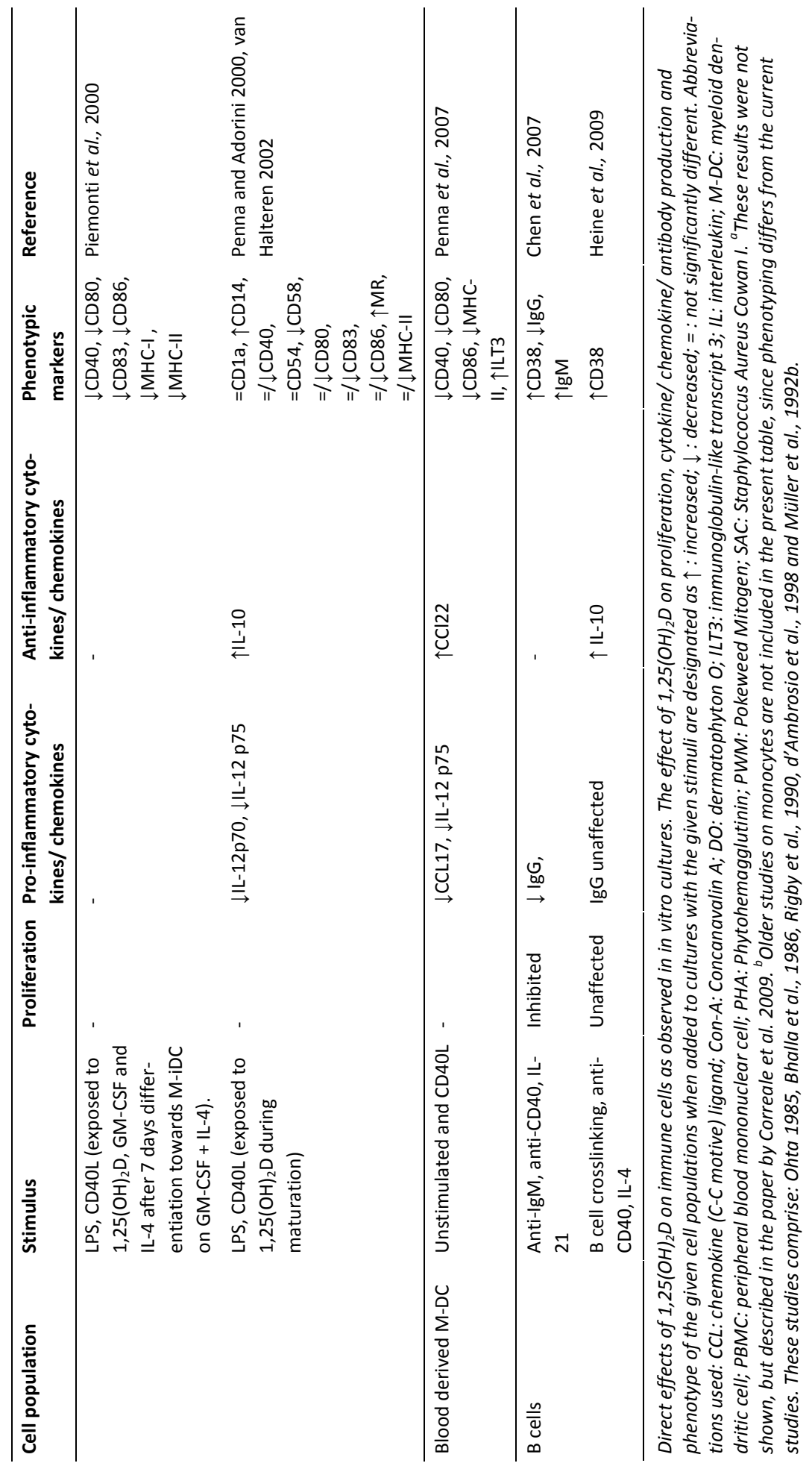


Addition of $1,25(\mathrm{OH})_{2} \mathrm{D}$ to cell cultures directly inhibits proliferation of peripheral blood mononuclear cells (PBMC), T cells and $\mathrm{CD}^{+} \mathrm{T}$ cells on several mitogenic (Rigby et al., 1984; Lemire et al., 1984, Correale et al., 2009, Fritsche et al., 2003) and antigen-specific stimuli (Correale et al., 2009). Purified CD45RO ${ }^{+}$T cells were more re-

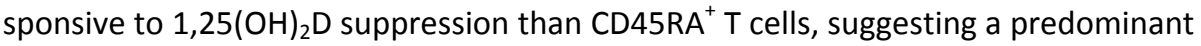
suppression of memory T cells (Müller and Bendtzen, 1992a). Interestingly, monocultures of T cells stimulated with anti-CD3 and anti-CD28 could not be suppressed directly by $1,25(\mathrm{OH})_{2} \mathrm{D}$ (Penna and Adorini, 2000; Jeffery et al., 2009). Additionally, proliferation of purified naïve $T$ cells of chronic haemodialysis patients on anti-CD3 and anti-CD28 has even been reported to be promoted by $1,25(\mathrm{OH})_{2} \mathrm{D}$ (Von Essen et al., 2010). It can be concluded that $1,25(\mathrm{OH})_{2} \mathrm{D}$ can directly suppress proliferation of $\mathrm{PBMC}$ and $\mathrm{CD}^{+} \mathrm{T}$ cells unless the stimulus is too strong (anti-CD3 and anti-CD28), and rather suppresses proliferation of memory than naïve $T$ cells. Addition of the precursor 25(OH)D also suppresses proliferation of PBMC in mixed-lymphocyte reactions (Fritsche et al., 2003), and PHA-driven proliferation of $\mathrm{CD}^{+} \mathrm{T}$ cells in monoculture (Correale et al., 2009). The metabolism of 25(OH)D by CYP27B1 upon activation therefore seems to have autocrine effects, modulating the functional behavior of the lymphocytes. Since $25(\mathrm{OH}) \mathrm{D}$ is also the most abundantly available vitamin $\mathrm{D}$ metabolite in vivo, the latter experimental model might also be the most relevant for studying vitamin $\mathrm{D}$ and lymphocyte interactions. Catabolites of vitamin $\mathrm{D}, 24,25(\mathrm{OH})_{2} \mathrm{D}$ and $25,26(\mathrm{OH})_{2} \mathrm{D}$ do not induce suppression of proliferation (Correale et al., 2009).

Much attention has been paid to the effects of $1,25(\mathrm{OH})_{2} \mathrm{D}$ exposition on the cytokine production by activated T cells in vitro. Addition of $1,25(\mathrm{OH})_{2} \mathrm{D}$ suppressed pro-inflammatory cytokine production in cultures of PBMC, T cells or $\mathrm{CD}^{+} \mathrm{T}^{-}$cells stimulated with mitogens (Rigby et al., 1984, Reichel et al., 1987; Tobler et al., 1987; Müller et al., 1991), with T cell receptor agonists (Correale et al., 2009), or specific antigens (Boonstra et al., 2001; Jeffery et al., 2009). Cytokines suppressed by $1,25(\mathrm{OH})_{2} \mathrm{D}$ included IFN- $\gamma$, IL-2, IL-6, IL-17, IL-21, and GM-CSF. In addition to the suppression of pro-inflammatory cytokines, the production of anti-inflammatory cytokines seemed to be promoted. Addition of $1,25(\mathrm{OH})_{2} \mathrm{D}$ to T cell monocultures or DC co-cultures, stimulated with T cell receptor agonists (Boonstra et al., 2001; Barrat et al., 2002, Correale et al., 2009) or specific antigens (Boonstra et al., 2001; Barrat et al., 2002) resulted in increased production of IL-4, IL-5, and IL-10. These studies show that exposition of activated T cells to $1,25(\mathrm{OH})_{2} \mathrm{D}$ results in a skewing of pro-inflammatory towards anti-inflammatory cytokine production. The effects seen in monocultures reveal that there is a direct interaction between vitamin $D$ and $T$ cells.

The shift in proliferation and cytokine production of $\mathrm{CD}^{+} \mathrm{T}$ cell, has also been reflected in phenotypic changes. Culture of PBMC in the presence of $1,25(\mathrm{OH})_{2} \mathrm{D}$ resulted in a dramatically increased proportion of functionally active Tregs 
(CD25 ${ }^{+}$FoxP3 $^{+} \mathrm{CD}^{+}{ }^{\mathrm{T}}$ cells) (Correale et al., 2009). In addition, in an anti-CD3 and anti-CD28-driven monoculture of $\mathrm{CD}^{+} \mathrm{T}$ cells, $1,25(\mathrm{OH})_{2} \mathrm{D}$ treatment induced FoxP3 and CTLA-4 expression (Jeffery et al, 2009), again suggesting the induction of Tregs. Interestingly, the up-regulation of FoxP3 was completely abrogated by the stimulation with autologous monocytes and anti-CD3, which was again restored by addition of IL-2 (Jeffrey et al., 2009). Altogether, $1,25(\mathrm{OH})_{2} \mathrm{D}$ appears to induce a regulatory $\mathrm{T}$ cell phenotype in activated $\mathrm{CD}^{+} \mathrm{T}$ cells. The combination of proliferation, cytokine production and phenotypic analysis shows that vitamin $D$ induces directly a more tolerogenic $\mathrm{CD}^{+} \mathrm{T}$ cell compartment (Figure 3).

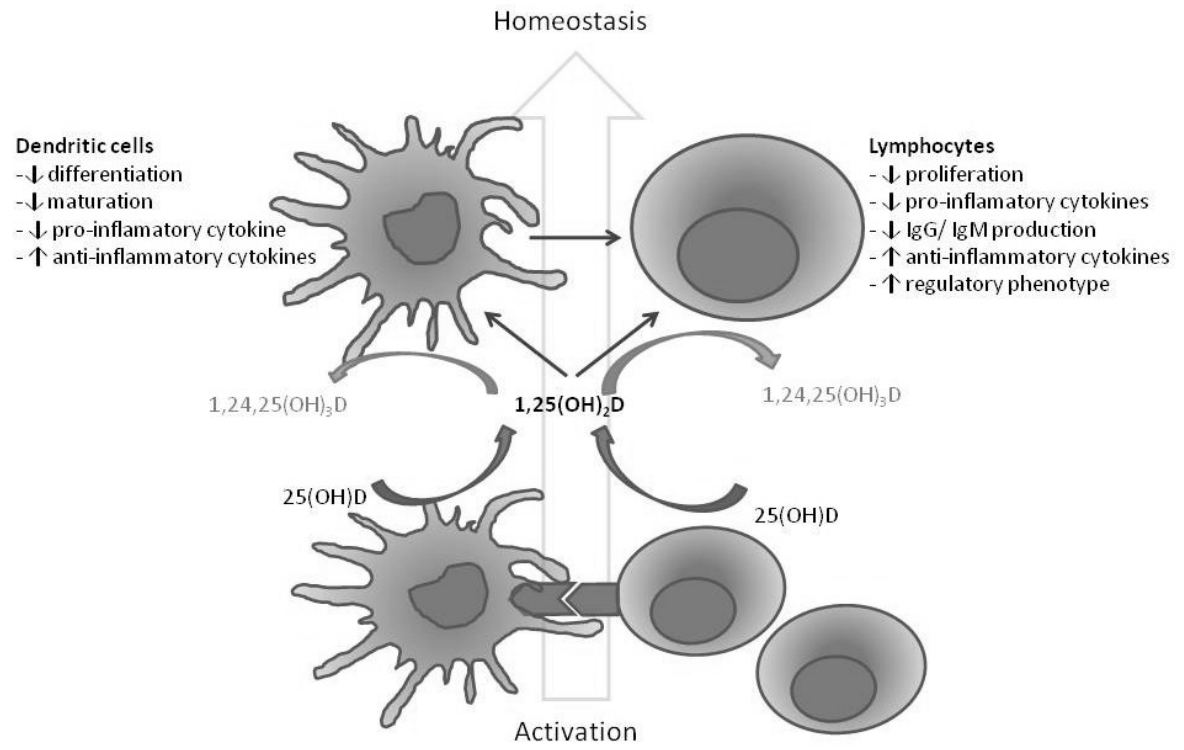

Figure 3 Vitamin D and the adaptive immune response

At sites of immune activation, expression of CYP27B1 and subsequent formation of $1,25(\mathrm{OH})_{2} \mathrm{D}$ out of $25(\mathrm{OH}) \mathrm{D}$ is induced in activated immune cells. This results in a micro environment of high local levels of $1,25(\mathrm{OH})_{2} \mathrm{D}$. Binding of $1,25(\mathrm{OH})_{2} \mathrm{D}$ to the VDR, which is present in almost every immune cell, results in a functional modulation of APC/DC and activated $B$ and $T$ cells. Vitamin $D$ exerts its effects on lymphocytes both directly and via modulation of APC/DC. When exposed to $1,25(\mathrm{OH})_{2} \mathrm{D}$, lymphocytes and DC's express CYP24A1, catalyzing the inactivation of $1,25(\mathrm{OH})_{2} \mathrm{D}$. Altogether, activation of the adaptive immune response is accompanied by local activation of $25(\mathrm{OH}) \mathrm{D}$, subsequently establishing increased levels of homeostasis.

Direct effects of $1,25(\mathrm{OH})_{2} \mathrm{D}$ on $\mathrm{CD}^{+} \mathrm{T}$ cells are uncertain. $\mathrm{CD} 8^{+} \mathrm{T}$ cells do express the VDR protein and, in contrast to $\mathrm{CD}^{+} \mathrm{T}$ cells, exposition to $1,25(\mathrm{OH})_{2} \mathrm{D}$ modestly improved proliferation rate (Veldman et al., 2000). However, the cytotoxicity of $\mathrm{CD}^{+} \mathrm{T}$ cells, as measured in a ${ }^{51} \mathrm{Cr}$ release assay, was inhibited by $1,25(\mathrm{OH})_{2} \mathrm{D}$ (Meehan et al., 1992). The effects on cytokine production match these of the CD4 ${ }^{+} \mathrm{T}$ cells, with an inhibition of IL-2 and IFN- $\gamma$ and promotion of IL-4 and IL-13 (Thien et al., 
2005). In cord blood samples cultured under the same conditions, however, IL-4 production by $\mathrm{CD}^{+} \mathrm{T}$ cells was suppressed by $1,25(\mathrm{OH})_{2} \mathrm{D}$ (Pichler et al., 2002). It can be concluded that the effect of $1,25(\mathrm{OH})_{2} \mathrm{D}$ on $\mathrm{CD} 8^{+} \mathrm{T}$ cells has not been very consistent so far, probably because $\mathrm{CD} 8^{+} \mathrm{T}$ cells have received only little attention yet.

Besides the direct effects on the T cell compartment, $1,25(\mathrm{OH})_{2} \mathrm{D}$ also affects the maturation and cytokine production of APC. In older studies, monocytes cultured with pro-inflammatory stimuli and $1,25(\mathrm{OH})_{2} \mathrm{D}$ display a VDR-dependent loss of maturation markers (Rigby et al., 1990; Griffin et al., 2000) and a loss of IL-6, IL12 , and tumor necrosis factor $\alpha$ (TNF- $\alpha$ ) production (d'Ambrosio et al., 1998, Müller et al., 1992b). Treatment with 25(OH)D gives the same effects, albeit to a lesser extent. Alternatively, however, treatment of monocytes and macrophages with only $1,25(\mathrm{OH})_{2} \mathrm{D}$ has been reported to increase the production of the pro-inflammatory cytokine IL-1 and cathelicidin antimicrobial peptide (Bhalla et al., 1986; Gombart et al., 2005). A promotion of monocyte proliferation has also been reported (Ohta et al., 1985). Therefore, regarding monocytes and macrophages, the effects of vitamin $D$ seem to depend on the way these cells are challenged. However, when monocytes are cultured supporting DC differentiation, the effect of $1,25(\mathrm{OH})_{2} \mathrm{D}$ becomes more consistent. Addition of $1,25(\mathrm{OH})_{2} \mathrm{D}$ to monocyte cultures hinders their differentiation to immature myeloid DC (Penna and Adorini 2000; van Halteren et al., 2002; Piemonti et al., 2000). Additionally, fully differentiated immature myeloid DC can also lose their DC phenotype after exposition to $1,25(\mathrm{OH})_{2} \mathrm{D}$, reflected by a loss of CD1a and upregulation of CD14 (Piemonti et al., 2000). Different maturation protocols of immature myeloid DC to mature DC are also inhibited by $1,25(\mathrm{OH})_{2} \mathrm{D}$, as reflected by surface markers of maturation (Griffin et al., 2001; Penna and Adorini 2000; Piemonti 2000; van Halteren et al., 2002). Interestingly, functional consequences have also been described. As suggested by the preservation of the mannose receptor and $\mathrm{CD} 32$, the antigen uptake capacity of the $1,25(\mathrm{OH})_{2} \mathrm{D}$-matured myeloid DC is improved (Piemonti et al., 2000). DC which reach a mature stage under $1,25(\mathrm{OH})_{2} \mathrm{D}$, produce almost no IL-12 and more IL-10 (Penna and Adorini 2000; van Halteren et al., 2002). 1,25(OH $)_{2} \mathrm{D}$ treatment also induces apoptosis in mature myeloid DC (Penna and Adorini 2000). It can be concluded that $1,25(\mathrm{OH})_{2} \mathrm{D}$ dramatically hampers maturation and affects function of myeloid DC. However, the phenotype and functionality of blood isolated plasmacytoid DC is not affected by 1,25(OH) $)_{2}$ D (Penna et al., 2007).

Therefore, besides direct effects of $1,25(\mathrm{OH})_{2} \mathrm{D}$ on the T cell compartment, vitamin D might also modulate the T cell response via the APC compartment. Indeed, pre-treatment of monocytes with $1,25(\mathrm{OH})_{2} \mathrm{D}$ inhibited proliferation of $\mathrm{T}$ cells on tetanoid toxin in a co-culture (Rigby et al., 1990). Interestingly, 25(OH)D pretreatment also induced inhibition of proliferation, albeit to a lesser extent. Pretreatment of P-DC with $1,25(\mathrm{OH})_{2} \mathrm{D}$ did not affect $\mathrm{T}$ cell function in a subsequent co- 
culture (Penna et al., 2007). Maturation of myeloid DC in the presence of $1,25(\mathrm{OH})_{2} \mathrm{D}$ reduced the level of allogenic $\mathrm{T}$ cell activation by mature $\mathrm{DC}$ in a mixed lymphocyte reaction (Griffin et al., 2000; Piemonti et al., 2000; Penna and Adorini 2000). Pre-treatment of antigen-loaded immature myeloid DC with $1,25(\mathrm{OH})_{2} \mathrm{D}$ completely blocked the subsequent production of cytokines by auto-reactive $\mathrm{T}$ cell clones, although proliferation was not affected (Van Halteren et al., 2002). Culture of mature $1,25(\mathrm{OH})_{2} \mathrm{D}$-treated myeloid $\mathrm{DC}$ with $\mathrm{T}$ cell clones and their specific antigen reduced both $\mathrm{T}$ cell cytokine production and proliferation, and stimulated apoptosis of T cells, when compared to culture with untreated DC (van Halteren 2002). When $\mathrm{T}$ cells were, after co-culture with $1,25(\mathrm{OH})_{2} \mathrm{D}$-treated myeloid $\mathrm{DC}$, reexposed to mature myeloid DC, a large proportion appeared to have become hyporesponsive (Piemonti et al., 2000; Penna and Adorini, 2000). In conclusion, the effects of $1,25(\mathrm{OH})_{2} \mathrm{D}$ on myeloid DC also affect their capacity to evoke an (autoreactive) immune response. Besides direct effects on the $\mathrm{CD}^{+} \mathrm{T}$ cell compartment, $1,25(\mathrm{OH})_{2} \mathrm{D}$ also modulates the T cell response via APC (Figure 3 ).

Direct exposure of $B$ cells to $1,25(\mathrm{OH})_{2} \mathrm{D}$ has also been a topic of interest. Proliferation of PBMC and $B$ cells on different combinations of $B$ cell specific and aspecific stimuli is inhibited by $1,25(\mathrm{OH})_{2} \mathrm{D}$ (Chen et al., 2007; Lemire et al., 1984; Iho et al., 1986). However, $1,25(\mathrm{OH})_{2} \mathrm{D}$ exposition also induced apoptosis of proliferating $B$ cells (Chen et al., 2007). Furthermore, phenotypic changes were noticed (Chen et al., 2007; Heine et al., 2008; Chen et al., 1987) and differentiation to plasma cells was inhibited (Chen et al., 2007). The subsequent synthesis of IgM and IgG by PBMC and $B$ cells on different stimuli was inhibited (Chen et al., 1987; Chen et al 2007; Iho et al., 1986; Lemire et al., 1984). When isolated $\mathrm{CD}_{19^{+}} \mathrm{B}$ cells were stimulated by $\mathrm{B}$ cell receptor cross-linking, anti-CD40 and IL-4, 1,25(OH) $)_{2} \mathrm{D}$ induced the secretion of IL-10 (Heine et al., 2008). Interestingly, the cells cultured by this protocol excreted no IgG, and their proliferation was unaffected by $1,25(\mathrm{OH})_{2} \mathrm{D}$. Although $1,25(\mathrm{OH})_{2} \mathrm{D}$ has direct effects on the $B$ cells, several authors argued that indirect modulation of the $\mathrm{B}$ cell response might be more likely in physiological conditions. Much lower doses of $1,25(\mathrm{OH})_{2} \mathrm{D}$ were needed to inhibit PHA driven T cell proliferation compared to pokeweed mitogen driven B cell proliferation (Shiozawa et al., 1987). In addition, PBMC depletion of either monocytes/macrophages (Chen et al., 1987, Müller et al., 1991) or T cells (Müller et al., 1991), dramatically abrogated the reduction of IgG synthesis by $1,25(\mathrm{OH})_{2} \mathrm{D}$. Direct stimulation of antibody production by Epstein Bar Virus was also not affected by $1,25(\mathrm{OH})_{2} \mathrm{D}$ (Müller et al., 1991). Nevertheless, the $\mathrm{B}$ cell appears to be a potential direct target of $1,25(\mathrm{OH})_{2} \mathrm{D}$ when exposed to a number of stimuli. The role of $1,25(\mathrm{OH})_{2} \mathrm{D}$ in the induction of IL-10 producing regulatory B-cells in vivo adds an exciting new area to the field of vitamin $D$ and autoimmune diseases.

It can be concluded that, both directly and indirectly, $1,25(\mathrm{OH})_{2} \mathrm{D}$ skews the $\mathrm{CD}^{+} \mathrm{T}$ cell compartment to a less inflammatory response. In vitro assays showed 
that this skewing can be effectuated directly or via modulation of APC (Figure 3). The interaction between $C D 8^{+} T$ cells and vitamin $D$ is at present not fully understood and requires further attention. In T cell mediated auto-immune diseases, the inhibition of IFN- $\gamma$ producing Th1 and IL-17 producing Th17 cells in combination with promotion of Tregs, can be of benefit for relieving disease activity.

\section{Vitamin D and experimental autoimmune encephalomyelitis}

Experimental autoimmune encephalomyelitis (EAE) is a useful animal model for MS. Although still a matter of debate, Th1/ Th17 cells are considered to be the most important effector cells. Since Th1/Th17 response is inhibited by $1,25(\mathrm{OH})_{2} \mathrm{D}$ in vitro, a beneficial effect of $1,25(\mathrm{OH})_{2} \mathrm{D}$ on a Th1/Th17 mediated disease like EAE seems logical. Indeed, whole body ultraviolet radiation before immunisation, associated with a rise in vitamin $D_{3}$ photosynthesis, prevented the development of clinical signs of EAE (Hauser et al., 1984).

In several studies, oral or intraperitoneal administration of $1,25(\mathrm{OH})_{2} \mathrm{D}$ before EAE-induction with myelin proteins completely prevented the appearance of any symptoms (Cantorna et al., 1996; Lemire and Archer 1991). This was also established by a low calcium diet before immunisation, possibly by raising the plasma $1,25(\mathrm{OH})_{2} \mathrm{D}$ level physiologically (Cantorna et al., 1999). After immunization, but before the appearance of clinical symptoms, $1,25(\mathrm{OH})_{2} \mathrm{D}$ was still able to prevent disease (Muthian et al., 2006; van Etten et al., 2003). In the animals in which EAE was not prevented, the disease was milder and survival longer (Branisteanu et al., 1995; Branisteanu et al., 1997; Lemire and Archer 1991; Muthian et al., 2006; Nashold et al., 2001; van Etten et al., 2003). In animals with clinical active disease, $1,25(\mathrm{OH})_{2} \mathrm{D}$ halted disease progression and even reduced disability scores (Cantorna et al., 1996; Nashold et al., 2000; Nataf et al., 1996). The effects observed were dose-dependent (Lemire and Archer 1991; Lemire et al., 1994). Typically, one study reported that none of the treated animals relapsed despite cessation of therapy as early as 5 days post-immunisation (Lemire and Archer, 1991). In another study relapses occurred within 10 days after discontinuation of therapy (Cantorna et al., 1996). Whether these differences can be explained by differences in mouse strains, i.e. SJL/J mice versus B10.PL mice, or by distinct antigens, rat versus guinea pig spinal cord, remains to be determined. In Vitamin D Receptor (VDR)-knockout mice EAE also developed, but $1,25(\mathrm{OH})_{2} \mathrm{D}$ was not able to prevent the development of $E A E$, indicating that the VDR is necessary for the beneficial effect of $1,25(\mathrm{OH})_{2} \mathrm{D}$ (Meehan and DeLuca, 2002b). Exposure to vitamin $D_{3}$, a precursor of $1,25(O H)_{2} D_{3}$, significantly inhibited EAE only in female mice with intact ovaries (Spach and Hayes, 2005). This suggests a gender-related difference in vitamin $D_{3}$ metabolism which 
might, if the same in humans, contribute to the difference in MS prevalence between males and females.

As expected, in the animals where EAE symptoms were prevented or resolved, the extent and the intensity of histopathological inflammation of the CNS was respectively limited or reduced (Cantorna et al., 1998; Lemire and Archer 1991; Nashold et al., 2000). In semi-quantitative immunohistochemical analysis, a relative decline of OX-42 (monocytes, macrophages and microglia), OX-6 (MHC-class II) and NOSII (monocytes, macrophages, microglia and astrocytes) positive cells was observed in inflammatory CNS lesions of $1,25(\mathrm{OH})_{2}$ D-treated mice compared to vehicle-treated animals (Garcion et al., 1997; Garcion et al., 2003; Nataf et al., 1996). A decline of CD4+ cells ( $T$ lymphocytes, activated microglia and some macrophages) was also observed (Garcion et al., 2003; Nataf et al., 1996).

Not only the clinical and histopathological effects, but also the effect of $1,25(\mathrm{OH})_{2} \mathrm{D}$ on the immune response in EAE itself has been investigated. In the sera of $1,25(\mathrm{OH})_{2} \mathrm{D}$-treated animals, a decline in antibody production against Myelin Basic Protein (MBP) was observed (Branisteanu et al., 1995; Lemire and Archer 1991), displaying either a direct or indirect modulation of the $B$ cell response. Interestingly, treatment with $1,25(\mathrm{OH})_{2} \mathrm{D}$ ameliorated symptoms of EAE in CD8 knockout mice, (Meehan and DeLuca 2002a). This observation draws attention further away from $\mathrm{CD}^{+} \mathrm{T}$ cells towards $\mathrm{CD}^{+}{ }^{+} \mathrm{T}$ cells as main target of vitamin $\mathrm{D}^{\prime} \mathrm{s}$ action. However, conflicting evidence exists about $\mathrm{CD}^{+} \mathrm{T}$ cell cytokine response to $1,25(\mathrm{OH})_{2} \mathrm{D}$ treatment. Spleen cells from EAE-animals produced significantly less IFN- $\gamma$ after in vitro $1,25(\mathrm{OH})_{2} \mathrm{D}$ exposure (Muthian et al., 2006). However, in MBP-specific Th1 lymphocytes this effect was not observed (Nashold et al., 2001). In vivo, 1,25(OH) 2 did not affect IFN- $\gamma$ transcription in peripheral lymph nodes (Cantorna et al., 1998; Nashold et al., 2001). In contrast, in CNS samples both no significant change in and a complete absence of IFN- $\gamma$ transcription have been reported (Cantorna et al., 1998; Nashold et al., 2001). Transcription of TNF- $\alpha$, also a Th1 cytokine, was not influenced by $1,25(\mathrm{OH})_{2} \mathrm{D}$ (Nashold et al., 2001). In lymph nodes and CNS samples of clinically improved $1,25(\mathrm{OH})_{2}$ D-treated mice, both a significant increase as well as no significant change in IL-4 transcription were found (Cantorna et al., 1998; Nashold et al., 2001). However, $1,25(\mathrm{OH})_{2} \mathrm{D}$ had a less favourable effect on clinical EAE in IL-4 knockout mice (Cantorna et al., 2000). These conflicting observations with regard to cytokine profiles provide no additional insights in the effects of $1,25(\mathrm{OH})_{2} \mathrm{D}$ on the balance between Th1 and Th2 response in vivo in EAE.

An interesting observation was made in a MBP-specific TCR-transgenic mousestrain. In Rag-1 ${ }^{+/-}$mice $1,25(\mathrm{OH})_{2} \mathrm{D}$ was able to ameliorate disease, but in Rag-1knockout mice this effect was not observed (Nashold et al., 2001). This observation excludes APC's as the exclusive modulator of $1,25(\mathrm{OH})_{2} \mathrm{D}$ 's action on EAE. Another interesting observation was made in an IL-10 knockout mouse strain. In these mice, both vitamin $\mathrm{D}$ and $1,25(\mathrm{OH})_{2} \mathrm{D}$ failed to prevent symptoms of EAE (Spach et al., 
2006). This was also the case in IL-10R $\beta$-knockout mice. Therefore, the IL-10/IL-10R pathway is involved in the ameliorating effect of $1,25(\mathrm{OH})_{2} \mathrm{D}$ and vitamin $\mathrm{D}$. These observations support the view that an IL-10 producing Rag-1-dependent cell plays an important role. This might be the regulatory $\mathrm{T}$ cell. Indeed, dexamethason and $1,25(\mathrm{OH})_{2} \mathrm{D}$-cultured Treg-cells ameliorated or completely blocked EAE when transferred to mice (Barrat et al., 2002). A beneficial effect of Treg cells on EAE has previously been reported (Nicholson et al., 1997). A raised TGF- $\beta 1$ transcription was found after $1,25(\mathrm{OH})_{2} \mathrm{D}$ treatment in both peripheral lymph nodes and in CNS samples of EAE animals (Cantorna et al., 1998). However, this anti-inflammatory cytokine is not exclusively produced by Treg cells. Interestingly, increased plasma TGF$\beta 1$ was also observed after vitamin D supplementation in a human MS-population (Mahon et al., 2003). To assess whether the results of the experiments in the MBPspecific TCR transgenic mice could be attributable to an actual effect on the Treg cell, Foxp3 transcription, a marker of a certain subset of Treg cells, was quantified in the spinal cord samples of $1,25(\mathrm{OH})_{2} \mathrm{D}$ and placebo-treated animals 4 weeks postimmunization. No enhancement of expression was found (Spach et al., 2006). This indicates that no accumulation of Foxp3-expressing Treg cells occurred in the spinal cord samples, but does not rule out the priming and activation of Treg lymphocytes elsewhere, for instance in the lymphoid tissue. Another explanation is that the $1,25(\mathrm{OH})_{2} \mathrm{D}$-stimulated Treg lymphocytes responsible for the ameliorating effects of the hormone do not express Foxp3.

In summary, the in vivo modulation of the immune response in EAE by $1,25(\mathrm{OH})_{2} \mathrm{D}$ results in a change in Th1 and Th2 response, but study results are conflicting. Nevertheless, the role of APC's and Th1-Th2 shift is probably limited and Treg-cells appear to be important target cells for $1,25(\mathrm{OH})_{2} \mathrm{D}$ action (Damoiseaux, 2006). The modulation leads to an inhibition of the inflammatory immune response in the CNS and is accompanied by clinical and histopathological improvement of disease.

\section{Vitamin D and MS}

Strong evidence that directly supports the hypothesis that vitamin D is able to modulate disease in MS is lacking. However, a lot of clinical observations were made in MS-populations that support a role for vitamin D in MS. These include associations with serum 25(OH)D levels, the geographic distribution of MS-prevalence, the low bone mass density found in MS patients, the seasonal fluctuation of serum 25(OH)D levels, MS disease parameters and MS births, the clinical remission of disease during pregnancy and the associations of various genetic polymorphisms of the VDR with MS. 


\subsection{Serum $25(\mathrm{OH}) \mathrm{D}$ level}

Low circulating 25(OH)D levels in adolescence are associated with a high incidence of MS in a white American population; a 41\% decrease of incidence for every 50 $\mathrm{nmol} / \mathrm{L}$ increase in 25(OH)D has been calculated (Munger et al., 2006). Interestingly, increased outdoor activities in childhood and adolescence, hypothetically associated with raised 25(OH)D levels, are also associated with a decreased risk of developing MS in a Norwegian and Tasmanian population and a North-American twin population (Islam et al., 2007; Kampman et al., 2007; van der Mei et al., 2003).

After the first onset of symptoms of MS, circulating 25(OH)D levels dropped significantly in the American population (Munger et al., 2006). In a Scandinavian cohort of newly-diagnosed MS patients, summer serum 25(OH)D levels were significantly lower than in control subjects (Soliu-Hänninen et al., 2005). A mean serum 25(OH)D level lower than $50 \mathrm{nmol} / \mathrm{L}$ has been described in $48-71 \%$ of all patients in several MS-populations (Mahon et al., 2003; Nieves et al., 1994; Ozgocmen et al., 2005; Soliu-Hänninen et al 2007).

Several efforts have been made to correlate clinical outcome measures of MS disease severity with serum 25(OH)D levels. A significant correlation of plasma 25(OH)D with IgG index and gadolinium enhancing T1 or T2-weighted MRI lesions could not be found (Soliu-Hänninen et al., 2005; Soliu-Hänninen et al., 2007). In Tasmanian patients with a longer disease history, decreased serum 25(OH)D levels were strongly correlated with an increased EDSS-score (van der Mei et al., 2007). Questionnaires revealed reduced sun-exposure because of disability as being an important mechanism for this association. Lower 25(OH)D levels have also been reported during relapses in relapsing remitting MS patients (Soliu-Hänninen et al., 2005; Soliu-Hänninen et al., 2007).

Another clinical observation is the positive association between lighter skin types and lower disability scores in female patients with MS for longer than 10 years (Woolmore et al 2007). Although 25(OH)D levels were not measured in the latter study, a positive association between skin type in terms of melanin density and 25(OH)D levels has been described in MS patients (van der Mei et al., 2007).

\subsection{Geographical distribution}

MS has a typical geographical distribution: it has a low prevalence in equatorial regions and an increasing prevalence with increasing latitudes in both hemispheres. For example, in the northern regions of Europe and the USA an increased MS prevalence is shown in comparison with the southern regions (Kurtzke 2000). The opposite is true for Australia, where a decreased prevalence is seen in the southern coast in comparison with the sub-tropical northern coast (Hammond et al., 1988).

A significant inverse correlation between MS-prevalence and the average December daily solar radiation, the average annual hours of sunlight and the average annual UVR-level has been observed in several studies (Acheson et al., 1960; van 
der Mei et al., 2001). Therefore, the geographical differences in these parameters are considered to be a contributing factor to the typical distribution of MS. Not only latitude, but also altitude influences MS prevalence. The reported lower MS prevalence at high altitudes $(>1000 \mathrm{~m})$ compared with low altitudes $(<1000 \mathrm{~m})$ in Switzerland corresponded with the more optimal solar radiation at greater heights (Kurtzke 1967). Although a significant confounding effect of ethnicity and genetics has also been observed, migrating populations seem to acquire the MS risk of the area they move to (Hammond et al., 2000; Pugliatti et al., 2002). Limited sunlight exposure in MS patients is also shown by the lower incidence of actinic damage and nonmelanoma skin cancer in this cohort, both associated with high levels of sunexposure (Freedman et al., 2000; Goldacre et al., 2004; van der Mei et al., 2003). Whether MS is a consequence of or rather a reason for this is uncertain.

Photosynthesis of vitamin $D_{3}$ is positively correlated with solar radiation. The mechanism by which the sun influences the prevalence of multiple sclerosis might be the promotion of vitamin D synthesis.

\subsection{Seasonal variation}

The seasonal variation in serum 25(OH)D levels was first described in 1974 by Stamp and McLaughlin. Since then, worldwide studies have underlined this phenomenon and geographical variations were noticed. Oral intake of vitamin $D$ does not effect this fluctuation because it only contributes a small amount of the total 25(OH)D level (Maxwell 1994). In MS populations, fluctuations of 25(OH)D levels similar to those in healthy control-populations have been found (Soliu-Hänninen et al., 2007).

In relapsing remitting MS, a seasonal variation in the exacerbation rate was first described in the 1970's. This fluctuation differs per geographical location. The peak exacerbation rate was observed in the warmer months in Arizona, in the warmest and coldest months in Japan and in the winter and spring in Switzerland (Bamford et al., 1983; Ogawa et al., 2004; Wuthrich and Rieder 1970). A comparable fluctuation was also found in plasma IFN- $\gamma$ and TNF- $\alpha$ levels, hallmarks of Th1 lymphocyte activity (Balashov et al., 1998; Killestein et al., 2002). An inverse fluctuation of the Treg cytokine IL-10 was found (Stewart et al., 2007). Unfortunately, these observations were not directly related to plasma levels of $25(\mathrm{OH}) \mathrm{D}$. A seasonal variation has also been reported in the number of active lesions on MRI scan. In a small German study, more gadolinium enhancing lesions were found in spring and early summer (April) and less in autumn (October) (Auer et al., 2000). A strikingly similar inverse fluctuation was also found in the plasma 25(OH)D levels of a similar but healthy population in the same geographical location (Embry et al., 2000). In other larger studies in different geographical areas, these observations could not be reproduced with significant results (Killestein et al., 2002; Koziol and Feng, 2004; Rovaris et al., 2001). 


\subsection{Season of birth}

Another seasonal fluctuation is seen in the month of birth of MS patients. In Denmark, Sweden, Great Britain and Canada, many MS patients are born in May and relatively few in November (Sadovnick and Yee, 1994; Tremlett and Devonshire 2006; Willer et al., 2005). In a recent large Canadian study, this only differed significantly from the normal population in the relapsing remitting and not in the primary progressive population (Sadovnick et al., 2007). Other observations of the clinical consequences of season of birth are scarce. Being born in January has been reported to be marginally associated with a slower disease progression and in another small study summer babies had a later age of MS onset (Sotgiu et al., 2006; Tremlett and Devonshire 2006).

The reduced expression of several proteins associated with MS has been observed in the offspring of severely vitamin D depleted female rats (Almeras et al., 2007). This underlines the important role of vitamin D in pregnancy, but it remains uncertain whether the excess of MS patients born in winter can be attributable to maternal 25(OH)D levels. Other factors during pregnancy and early youth, such as virus infections, low birth weight and maternal folate deficiency, might interfere.

\subsection{Pregnancy}

In MS patients, clinical remission of the disease is often observed during pregnancy with a higher relapse rate post-partum (Korn-Lubetzki et al., 1984). Pregnancy has been reported to protect against the development of MS in a healthy population and against disease progression in MS patients (Runmarker and Andersen 1995). It is also known that during pregnancy, $1,25(\mathrm{OH})_{2} \mathrm{D}$ levels increase physiologically and peak during the third trimester with an abrupt decline post-partum (Verhaeghe and Bouillon 1992). It has been suggested that this rise in $1,25(\mathrm{OH})_{2} \mathrm{D}$ might be an explanation for the clinical remission of the disease (Schwartz 1993). Indeed, in pregnant MS patients a shift in cytokine production from a Th1 to a Th2/ Treg-profile with a shift towards a Th1 cytokine profile postpartum has been observed (Al-Shammri et al., 2004; Gilmore et al., 2004). This is compatible with the in vitro effects of $1,25(\mathrm{OH})_{2}$ D on T lymphocytes (Figure 3 ).

In $\mathrm{EAE}$, a mouse model of MS, a positive correlation between oestrogen production and immune suppressing activity of $1,25(\mathrm{OH})_{2} \mathrm{D}$ has been described (Spach and Hayes 2005). This might also illustrate, if the mechanism in humans is the same, an interaction between hormonal changes and the ameliorating effects of vitamin $D$ on disease. However, it is not yet clear whether clinical remission in MS patients can be contributed to a change in the level of $1,25(\mathrm{OH})_{2} \mathrm{D}$ or is largely confounded by numerous other physiological immune suppressing changes in the pregnant woman. 


\subsection{Bone Mineral Density}

MS patients are known to have a lower Bone Mineral Density (BMD) and to be more at risk for fractures after minor injury (Schwid et al., 1996). An increased fracture rate in the absence of major trauma has been reported (Cosman et al., 1998). This was historically considered to be explained by immobilisation and glucocorticoid use. Indeed, BMD in the femoral neck is significantly inversely correlated with disability and EDSS-score (Ozgocmen et al., 2005; Schwid et al., 1996). However, there is conflicting evidence regarding the direct effects of the intensity of glucocorticoid use on bone density in MS populations (Formica et al., 1997; Ozgocmen et al., 2005; Schwid et al., 1996). Besides these findings, the serum 25(OH)D-level is also significantly correlated with a low BMD (Nieves et al., 1994). Thus, vitamin D deficiency, together with immobilisation and glucocorticoid therapy, also contributes to low bone mass in MS patients.

\subsection{Vitamin D receptor gene polymorphisms}

A role for genetic factors in the development of MS is well known (Hauser and Oksenberg 2006). Genetic polymorphisms of several vitamin D related proteins have been investigated. Neither a difference in frequency and transmission of the vitamin D Binding Protein gene, nor of transmission of the genotype of CYP27B1 has been found (Niino et al., 2002; Steckley et al., 2000).

In the VDR-gene (VDRG) on chromosome 12q, numerous polymorphisms have been described (Uitterlinden et al., 2004). A significant association with MS was found for the VDRG polymorphisms Bsm-I in a Japanese, Apa I in a Japanese and Australian and Taq-I in an Australian population (Fukazawa et al., 1999; Niino et al., 2000; Tajouri et al., 2005). A trend for the polymorphism Fok-I has been described in an UK population (Partridge et al., 2004). These associations are not universal and geographical differences are noticeable. For example, no preferential transmission of Apa-I and Taq-1 from MS-affected parents to affected offspring was found in a Canadian study and the Taq-I polymorphism was not associated with MS in an UK population (Partridge et al., 2004; Steckley et al., 2000).

However, the associations point to an increased vulnerability of developing MS in individuals with these polymorphisms in certain populations. Nevertheless, only the Fok I polymorphism is located in an exon of the VDRG and is known to have a functional impact on the immune system (van Etten et al., 2007). The other polymorphisms are restriction length polymorphisms in an intron of the gene and their biological effects are uncertain (Uitterlinden et al., 2004). Linkage with a not yet revealed truly functional allele might be a mechanism of action. Further studies assessing vitamin $D$ and MS parameters or prospective trials with oral vitamin $D$ supplementation will have to define the clinical relevance of those polymorphisms in MS. 


\section{Vitamin D therapy in MS}

Potential effects of oral vitamin D intake on MS have been observed. In a recent Norwegian case control study a protective effect of regular fish consumption and cod liver oil was found (Kampman et al., 2007). The lower MS mortality and disability rates in the coastal regions compared to the inlands was earlier hypothesised to be attributable to a difference in dietary fish intake (Westlund 1970). In a large observational study in the United States, the use of supplemental vitamin D, mostly in the form of multi-vitamins, by healthy female nurses seemed to lower their risk on MS with 40\% (Munger et al., 2004).

In two prospective but very small patient series, supplementation of vitamin $D$ $[10 \mu \mathrm{g} / \mathrm{d}(400 \mathrm{IU} / \mathrm{d})$ and $125 \mu \mathrm{g} / \mathrm{d}(5000 \mathrm{IU} / \mathrm{d})]$ in combination with other nutriments seemed to have an effect on exacerbation rate and EDSS, but these studies were neither blinded, nor placebo controlled (Goldberg et al., 1986; Nordvik et al., 2000). In $39 \mathrm{MS}$ patients, 6-month supplementation of $25 \mu \mathrm{g} / \mathrm{d}(1.000 \mathrm{lU} / \mathrm{d})$ vitamin $\mathrm{D}_{3}$ led to an increase of serum 25(OH)D levels, a significant increase of the cytokine TGF- $\beta$ and a decline in IL-2 mRNA levels; but the correlation with clinical parameters was not investigated (Mahon et al., 2003). A recent safety study in 12 patients with supplementation of up to $7000 \mu \mathrm{g} /$ week [280.000 IU/week) vitamin $D_{3}$ for 28 weeks showed a decline in the number of gadolinium enhancing lesion on MRI (Kimball et al., 2007). Supplementation with vitamin D metabolites has been investigated, but also more in relation to safety and toxicity than to clinical effectiveness. In small series of 5 and 13 patients, supplementation with $1.5 \mu \mathrm{g} / \mathrm{d} 1 \alpha(\mathrm{OH}) \mathrm{D}$ for 6 months

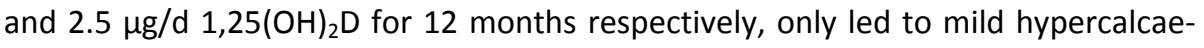
mia when compliant to dietary advice (Achiron et al., 2003; Wingerchuk et al., 2005).

Therefore little evidence of a beneficial effect of oral vitamin D supplementation on clinical disease in MS can be provided. Only a few small patient series have been conducted so far. This might be attributable to some concerns about the safety of vitamin D supplementation. The major side effect of $1,25(\mathrm{OH})_{2} \mathrm{D}$ supplementation seen in EAE is the physiological increase in plasma calcium, ultimately leading to a dose-dependent hypercalcaemia (Cantorna et al., 1996; Lemire and Archer 1991). This can lead to reduction of bone mineral density and potential lifethreatening complications such as renal and heart failure. In human populations, people with sarcoidosis or Mycobacterium infections and people treated with thiazide diuretics are believed to be sensitive to hypercalcaemia and hypervitaminosis D (Hathcock et al., 2007). Therefore, a cautious attitude towards vitamin D supplementation is often found among clinicians.

In human osteoporosis and bone metabolism research, numerous trials have been conducted with supplementation of vitamin $D$. In a recent extensive review, a no adverse effects limit (NOAEL) of $250 \mu \mathrm{g}$ (10.000 IU) has been proposed for sup- 
plementation of vitamin D to healthy adults (Hathcock et al., 2007). This daily intake leads to a plasma 25(OH)D level of $220 \mathrm{nmol} / \mathrm{L}$, whereas much higher levels would be needed to evoke a hypercalcaemia. Supplementation of up to $1000 \mu \mathrm{g} /$ day for 28 weeks in $12 \mathrm{MS}$ patients led to a mean serum 25(OH)D concentration of 386 $\mathrm{nmol} / \mathrm{L}$ without causing hypercalcaemia or hypercalciuria (Kimball et al., 2007). Therefore it seems relatively safe to treat vitamin $D$ deficient patients with substantial doses of vitamin $D$.

In EAE research, experiments have been conducted with hypocalcaemic analogues of $1,25(\mathrm{OH})_{2} \mathrm{D}$ with sustained immune regulating properties (Lemire et al., 1994; van Etten et al., 2003). More than 270 analogues of 1,25(OH) $2 \mathrm{D}$ have been developed by adding a benzene-ring to or changing side-chains of the molecule (Bouillon et al., 1995). To our knowledge, no human studies with hypocalcaemic analogues of vitamin D in MS patients have yet been published.

\section{Conclusion}

There is evidence to support the role of vitamin D as an immune modulating agent. An inhibitory effect on Th1 cell function and a promoting effect on Th2 and Treg cells have been described in vitro. In EAE, a beneficial effect of $1,25(\mathrm{OH})_{2} \mathrm{D}$ on the clinical and histological features of disease has also been described. The most important target cell in the action of $1,25(\mathrm{OH})_{2} \mathrm{D}$ on the immune response in EAE is probably the Treg lymphocyte.

Vitamin $D$ is an immune modulator, but if it can be considered as a disease modulator in MS remains uncertain. Various observations in MS populations show an association between various vitamin D parameters and MS and are suggestive of an immune and disease modulating effect of vitamin $D$, but cannot be considered as solid evidence. Nevertheless, these observations provide a good reason for further research in this direction. Before conclusions can be drawn about the potential of vitamin $\mathrm{D}$ as an immune modulator in MS, further studies investigating the immune modulating mechanism as well as double-blind placebo-controlled trials are necessary. 


\section{Association of vitamin D metabolite levels with relapse rate and disability in patients with multiple sclerosis}

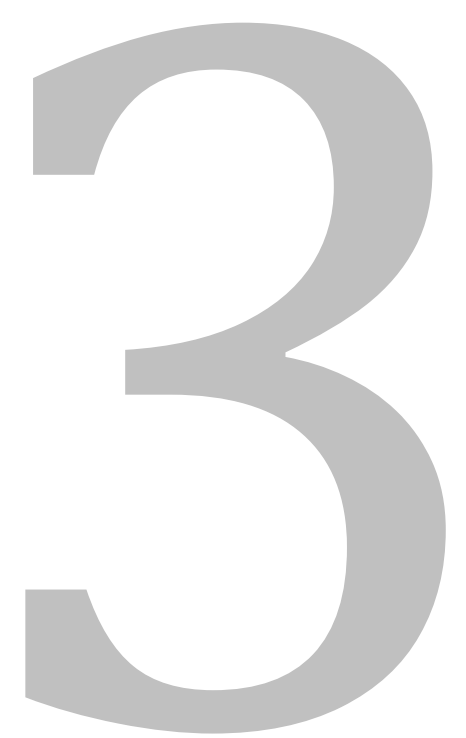

Published as: Joost Smolders, Paul Menheere, Alfons Kessels, Jan Damoiseaux, Raymond Hupperts. Association of vitamin $D$ metabolite levels with relapse rate and disability in multiple sclerosis. Multiple Sclerosis 2008;14:1220-1224. 


\section{Abstract}

Background: Multiple Sclerosis (MS) has been associated with low serum concentrations of 25-hydroxyvitamin D $(25(\mathrm{OH}) \mathrm{D})$. The purpose of this cross-sectional study was to investigate the association of the serum concentrations of $25(\mathrm{OH}) \mathrm{D}$ and 1,25 dihydroxyvitamin $\mathrm{D}\left(1,25(\mathrm{OH})_{2} \mathrm{D}\right)$, the biologically active metabolite of vitamin $\mathrm{D}$, with clinical MS severity as expressed by EDSS-score and relapse rate.

Patients and Methods: Serum samples from 267 MS patients were collected for measurement of serum $1,25(\mathrm{OH})_{2} \mathrm{D}$ and $25(\mathrm{OH}) \mathrm{D}$ concentrations. Clinical MS parameters at the date of serum sampling were determined.

Results: Both metabolite levels were significantly lower in the progressive MS phenotypes when compared to the relapsing remitting (RR)MS phenotype. In RRMS patients (disease course $\leq 5$ years), high $25(\mathrm{OH}) \mathrm{D}$ levels were associated with a high chance of remaining relapse-free. Low 25(OH)D levels were associated with high EDSS-scores. The serum level of $1,25(\mathrm{OH})_{2} \mathrm{D}$ was not directly associated with relapse rate or EDSS-score, and was dependent of age and 25(OH)D level.

Conclusion: Circulating $25(\mathrm{OH}) \mathrm{D}$ is associated with both relapse rate and disability in MS patients. These results are suggestive for a disease modulating effect of the serum concentrations of $25(\mathrm{OH}) \mathrm{D}$ on MS. The low circulating $1,25(\mathrm{OH})_{2} \mathrm{D}$ levels in progressive MS are due to older age and lower 25(OH)D levels. The potential consequences of vitamin D supplementation in MS will be discussed. 


\section{Introduction}

A combination of as yet poorly defined genetic and environmental factors is needed to develop Multiple Sclerosis (MS) (Compston and Coles 2005). Recent studies suggest that a poor vitamin $D$ status is an important environmental risk factor (Smolders et al., 2008a, chapter 2). Vitamin D is predominantly photosynthesised in the skin by sunlight. In the human circulation, it is mainly found as two metabolites: the principal circulating metabolite 25 -hydroxyvitamin $\mathrm{D}(25(\mathrm{OH}) \mathrm{D})$, and the biologically active metabolite 1,25-dihydroxyvitamin $\mathrm{D}\left(1,25(\mathrm{OH})_{2} \mathrm{D}\right)$. The circulating concentration $1,25(\mathrm{OH})_{2} \mathrm{D}$ is mainly the result of hydroxylation of $25(\mathrm{OH}) \mathrm{D}$ in the kidney (Jongen et al., 1984). In vitro, $1,25(\mathrm{OH})_{2} \mathrm{D}$ is a potent immune modulator, which inhibits pro-inflammatory and promotes anti-inflammatory cells and cytokines (Smolders et al., 2008a, chapter 2). In the murine model experimental autoimmune encephalomyelitis (EAE), supplementation of both vitamin D metabolites either prevents the disease or guides the disease into remission. Raising the circulating levels of $1,25(\mathrm{OH})_{2} \mathrm{D}$ by supplementing $1,25(\mathrm{OH})_{2} \mathrm{D}$ effectively prevented or ameliorated EAE (Cantorna et al., 1996; Lemire et al., 1991). Supplementation of vitamin D before EAE-induction caused a rise in the serum concentration of $25(\mathrm{OH}) \mathrm{D}$, but not of $1,25(\mathrm{OH})_{2} \mathrm{D}$ (Spach et al., 2005). In the animals in which remission was achieved, elevated levels of $1,25(\mathrm{OH})_{2} \mathrm{D}$ were found in the CNS, considered as locally hydroxylised $25(\mathrm{OH}) \mathrm{D}$ by for instance macrophages or dendritic cells.

Low circulating levels of 25(OH)D in adolescence correlate with a high risk of developing MS in humans (Munger et al., 2006). Lower 25(OH)D levels have been reported in MS compared with healthy control populations (van der Mei et al., 2007). In MS-populations, Expanded Disability Status Scale (EDSS) scores correlate negatively with circulating levels of 25(OH)D and these levels are lower during relapses than remission in relapsing remitting MS (Soliu-Hänninen 2005; SoliuHänninen 2008; van der Mei 2007). However, their causality is dubious: either disability by MS influences sun-exposure and thus 25(OH)D levels (van der Mei et al., 2007), or 25(OH)D influences MS disability, or maybe even both. Recent studies revealed an association between sun-exposure, disability and 25(OH)D levels, but supplementation of small amounts of vitamin $\mathrm{D}$ also changed the cytokines in the blood of MS patients to a anti-inflammatory profile (Mahon et al., 2003). An association of $25(\mathrm{OH}) \mathrm{D}$ levels with relapse rate, MRI-parameters or cerebrospinal fluid IgG-indices has not been found (Soliu-Hänninen 2005; Soliu-Hänninen 2008).

The role of circulating $1,25(\mathrm{OH})_{2} \mathrm{D}$ in MS is even less well defined. In an MS population, the serum concentration of $1,25(\mathrm{OH})_{2} \mathrm{D}$ correlated positively with serum 25(OH)D levels (Barnes et al., 2007). In vitro and in EAE-research, it seems that higher serum levels of $1,25(\mathrm{OH})_{2} \mathrm{D}$ alter the immune system, causing it to be less pro-inflammatory (Smolders et al., 2008a, chapter 2). We hypothesised that interference with serum $1,25(\mathrm{OH})_{2} \mathrm{D}$ could be an effector pathway by which vitamin $D$ 
modulates MS. No large studies have yet addressed the association of clinical MS severity with circulating $1,25(\mathrm{OH})_{2} \mathrm{D}$ levels. Two small pilot studies investigated supplementation of $1,25(\mathrm{OH})_{2} \mathrm{D}$ for 48 weeks in 15 patients and $1 \alpha(\mathrm{OH}) \mathrm{D}$ for 6 months in 5 MS patients (Achiron et al., 2003; Wingerchuk et al., 2005). However, these studies were primarily concerned with the safety of supplementation rather than the clinical outcome.

The main purpose of our study was to investigate if a low serum concentration of the vitamin $D$ metabolites $25(\mathrm{OH}) \mathrm{D}$ and $1,25(\mathrm{OH})_{2} \mathrm{D}$ is associated with severe clinical MS as expressed by a high EDSS-score or a high relapse rate. We assessed relapse rate in the total relapsing remitting (RR)MS cohort and in a subgroup with a short disease course ( $\leq 5$ years). In the latter group, the predominantly inflammatory rather than neurodegenerative disease process most closely resembles neuroinflammation as seen in the EAE model. Therefore, we hypothesised that a clinical manifestation of the anti-inflammatory effect of vitamin $D$, as observed both in vitro and in $\mathrm{EAE}$, might be most prominent in this group.

\section{Patients and Methods}

267 MS patients with clinically and MRI-confirmed MS (McDonald et al., 2005) and a disease duration of $\geq 0.5$ years since the first symptoms of the disease, were recruited from consecutive patients admitted to our University Hospital outpatient clinic in the period 2005-2007. They all lived in the southern area of the Netherlands (latitude $50^{\circ} \mathrm{N}-51^{\circ} \mathrm{N}$ ). The characteristics of this population are shown in Table 1.

Table 1 Population characteristics.

\begin{tabular}{llcc}
\hline & & N/ Mean & $\% /$ SD \\
\hline Sex & Male & 66 & $24.7 \%$ \\
& Female & 201 & $75.3 \%$ \\
MS phenotype & RRMS & 126 & $47.2 \%$ \\
& SPMS & 85 & $31.8 \%$ \\
& PPMS & 48 & $18.0 \%$ \\
Age (years) & Uncertain & 8 & $3.0 \%$ \\
Age at disease onset (years) & 47.0 & \pm 11.6 \\
Disease duration (years) & 34.1 & \pm 10.1 \\
EDSS-score (years) & 12.9 & \pm 9.4 \\
\hline
\end{tabular}


Serum samples were shielded from direct light after collection and stored at $-20^{\circ} \mathrm{C}$. Both the metabolite levels were measured by routine analysis in our clinical chemical laboratory. Forced by closure of the first manufacturer, the $25(\mathrm{OH}) \mathrm{D}$ assay switched in June 2006 from a chemiluminescence immunoassay (Nichols Institute Diagnostics, California, USA) to a radioimmunoassay (Immunodiagnostic Systems, Boldon, UK). Forty two samples were tested with both assays and showed a good correlation $\left(R^{2}=0.92\right)$ without significant differences $(P=0.495) .1,25(\mathrm{OH})_{2} D$ levels were determined with a commercially available radioimmunoassay kit (Immunodiagnostic Systems, Boldon, UK). In an international consensus meeting, a 25(OH)D concentration of $70-80 \mathrm{nmol} / \mathrm{L}$ has been argued to be adequate for a normal calcium metabolism (Dawson-Hughes et al., 2005). A recent paper concluded that 25(OH)D levels should exceed at least $70 \mathrm{nmol} / \mathrm{L}$ to prevent osteoporosis (Vieth 2005). Therefore, we considered 25(OH)D levels below $70 \mathrm{nmol} / \mathrm{L}$ as indicative for a suboptimal vitamin D status.

Clinical MS characteristics were retrieved from our patient database (iMed system). We collected EDSS-scores at serum sampling and counted the number of relapses in a 2 year period before serum sampling. The one year relapse rate was calculated from this count, also in patients with a disease course of $<2$ years $(\mathrm{N}=15)$. Furthermore, we determined other clinical variables as age, sex, MS phenotype (RRMS, secondary progressive (SPMS), primary progressive (PPMS), unknown), disease course since first symptom, and the occurrence of a relapse within \pm 6 weeks after blood collection.

SPSS software (SPSS Inc., version 12.0, Chicago, USA) was used for statistical analysis. Mean values were compared using T-tests, or in small sample sizes with the Mann-Whitney $U$ test. Mean values are provided with standard deviation (SD; \pm ), mean differences (MD) with standard error (SE; \pm ). Relationships were evaluated using regression analysis. The relationship of the vitamin D metabolites with EDSSscore was analysed by a linear regression model, the relationship with relapse (yes/no) and relapse rate (N/year) by respectively a logistic and a Poisson regression model. All potential confounders were included simultaneously in the models, in order to adjust the analysis. Both the crude and adjusted odds ratios (OR) or regression coefficients $(\beta)$ with corresponding $95 \%$ confidence intervals $(95 \% \mathrm{Cl})$ are provided. Potential confounders were: sex (male/ female), age (years), disease duration (years). A 2-sided P-value $<0.05$ was considered statistically significant. Since all stratifications were hypothesis-driven, no correction for multiple testing was applied. 


\section{Results}

\subsection{Vitamin $D$ metabolite levels}

The mean $25(\mathrm{OH}) \mathrm{D}$ and $1,25(\mathrm{OH})_{2} \mathrm{D}$ concentrations stratified for clinical MS phenotype are shown in Table 2. Compared with the RRMS group, the circulating levels of both metabolites were significantly lower in the progressive MS groups (respectively $\mathrm{P}<0.001$ and $\mathrm{P}=0.002$ ). In the RRMS group with a disease course of $\leq 5$ years, the $25(\mathrm{OH}) \mathrm{D}$ and $1,25(\mathrm{OH})_{2} \mathrm{D}$ values did not differ significantly from the total RRMS group (respectively $\mathrm{P}=0.191 ; \mathrm{P}=0.173$ ). The percentage of patients with a suboptimal vitamin D status was substantial even in the RRMS-cohort with a disease course of $\leq 5$ years (34.9\%), and exceeding $81.2 \%$ in the SP-cohort. There was no difference in $25(\mathrm{OH}) \mathrm{D}$ and $1,25(\mathrm{OH})_{2} \mathrm{D}$ levels between the sexes, and both metabolites did not display a clear significant seasonal fluctuation (data not shown).

Table 2 Vitamin D metabolite concentrations in the MS-cohort stratified by clinical phenotype.

\begin{tabular}{lccccc}
\hline & Total MS & $\begin{array}{c}\text { RRMS } \\
\text { Duration } \leq 5 \\
\text { yrs. }\end{array}$ & RRMS & SPMS & PPMS \\
& $(\mathrm{N}=267)$ & $(\mathrm{N}=43)$ & $(\mathrm{N}=126)$ & $(\mathrm{N}=85)$ & $(\mathrm{N}=48)$ \\
\hline $25(\mathrm{OH}) \mathrm{D}(\mathrm{nmol} / \mathrm{L}) *$ & $62.53( \pm 32.4)$ & $79.47( \pm 32.2)$ & $72.06( \pm 31.9)$ & $51.27( \pm 28.8)$ & $57.40( \pm 31.7)$ \\
$1,25(\mathrm{OH})_{2} \mathrm{D}(\mathrm{pmol} / \mathrm{l}) *$ & $107.65( \pm 43.2)$ & $127.88( \pm 43.4)$ & $116.92( \pm 45.4)$ & $99.48( \pm 41.8)$ & $100.79( \pm 36.5)$ \\
Suboptimal vitamin D & $170(63.7 \%)$ & $15(34.9 \%)$ & $61(48.8 \%)$ & $69(81.2 \%)$ & $33(68.8 \%)$ \\
status** & & & & & \\
\hline
\end{tabular}

RRMS: relapsing remitting MS; SPMS: secondary progressive MS; PPMS: primary progressive MS. *Mean $( \pm \mathrm{SD}) .{ }^{* *} \mathrm{~N}(\%)$ with serum $25(\mathrm{OH}) \mathrm{D}$ levels $<70 \mathrm{nmol} / \mathrm{L}$.

\subsection{Relapse rate}

In the whole RRMS cohort $(\mathrm{N}=126)$, the mean relapse rate was $0.69( \pm 1.02)$ / year. We analysed both the raw, and the in the regression model adjusted vitamin $\mathrm{D}$ data. There was no association of both the raw and adjusted vitamin D metabolite data with relapse rate (Table $\mathbf{3}$ ).

In the RRMS cohort with a disease course of $\leq 5$ years, the mean relapse rate was $1.17( \pm 1.09) /$ year and the mean EDSS-score 2.68 ( \pm 1.74$)$. There was no significant association of the vitamin D metabolites with relapse rate (Table 3 ). However, when the patients with and without relapses were compared, the relative risk of remaining relapse free prior to serum sampling increased by $51 \%$ for each 10 $\mathrm{nmol} / \mathrm{L}$ increase of $25(\mathrm{OH}) \mathrm{D}(\mathrm{P}=0.017)$. The association with the other metabolite, $1,25(\mathrm{OH})_{2} \mathrm{D}$, was not statistically significant $(P=0.201)$. The mean EDSS-score did not differ significantly between the groups with or without relapses (MD: 0.63 $( \pm 0.69) ; P=0.385)$. 
Table 3 The raw and adjusted regression coefficients and odds ratios of vitamin D metabolites and clinical parameters of disease severity.

\begin{tabular}{|c|c|c|c|c|c|c|c|c|}
\hline & \multicolumn{4}{|l|}{$25(\mathrm{OH}) \mathrm{D}$} & \multicolumn{4}{|c|}{$1,25(\mathrm{OH})_{2} \mathrm{D}$} \\
\hline & \multicolumn{2}{|l|}{ Crude } & \multicolumn{2}{|c|}{ Adjusted** } & \multicolumn{2}{|l|}{ Crude } & \multicolumn{2}{|c|}{ Adjusted** } \\
\hline & $\beta / O R$ & $(95 \% \mathrm{Cl})$ & $\beta / O R$ & $(95 \% \mathrm{Cl})$ & $\beta / O R$ & $(95 \% \mathrm{Cl})$ & $\beta / O R$ & $(95 \% \mathrm{Cl})$ \\
\hline \multicolumn{9}{|l|}{ All MS (N=267) } \\
\hline EDSS-score $(\beta)$ & $-0.023^{*}$ & $\begin{array}{c}(-0.031- \\
-0.015)\end{array}$ & $-0.014^{*}$ & $\begin{array}{c}(-0.022- \\
-0.006)\end{array}$ & -0.006 & $\begin{array}{c}(-0.013- \\
0.000)\end{array}$ & 0.000 & $\begin{array}{c}(-0.006- \\
0.006)\end{array}$ \\
\hline \multicolumn{9}{|l|}{ RRMS (N=126) } \\
\hline $\begin{array}{l}\text { Relapsefree } \\
\text { (OR) }\end{array}$ & 1.000 & $\begin{array}{c}(0.989- \\
1.012)\end{array}$ & 0.993 & $\begin{array}{c}(0.979- \\
1.007)\end{array}$ & 1.006 & $\begin{array}{c}(0.998- \\
1.014)\end{array}$ & 1.003 & $\begin{array}{c}(0.933- \\
1.013)\end{array}$ \\
\hline Relapse Rate $(\beta)$ & & & -0.005 & $\begin{array}{c}(-0.013- \\
0.003)\end{array}$ & & & 0.000 & $\begin{array}{c}(-0.005- \\
0.005)\end{array}$ \\
\hline \multicolumn{9}{|c|}{ RRMS; course $\leq 5$ yrs. $(N=43)$} \\
\hline $\begin{array}{l}\text { Relapsefree } \\
\text { (OR) }\end{array}$ & 0.975 & $\begin{array}{c}(0.949- \\
1.002)\end{array}$ & $0.949 *$ & $\begin{array}{c}(0.909- \\
0.991)\end{array}$ & 0.984 & $\begin{array}{c}(0.966- \\
1.003)\end{array}$ & 0.985 & $\begin{array}{c}(0.964- \\
1.007)\end{array}$ \\
\hline Relapse Rate $(\beta)$ & & & -0.007 & $\begin{array}{c}(-0.016- \\
0.003)\end{array}$ & & & 0.000 & $\begin{array}{c}(-0.008- \\
0.007)\end{array}$ \\
\hline \multicolumn{9}{|c|}{ RRMS; course $\leq 5$ yrs; EDSS $\leq 3.5(\mathrm{~N}=31)$} \\
\hline $\begin{array}{l}\text { Relapsefree } \\
\text { (OR). }\end{array}$ & $0.964 *$ & $\begin{array}{c}(0.932- \\
0.998)\end{array}$ & $0.963^{*}$ & $\begin{array}{c}(0.889- \\
0.998)\end{array}$ & $0.966^{*}$ & $\begin{array}{c}(0.936- \\
0.997)\end{array}$ & $0.964^{*}$ & $\begin{array}{c}(0.931- \\
0.999)\end{array}$ \\
\hline Relapse Rate $(\beta)$ & & & -0.009 & $\begin{array}{c}(-0.019- \\
0.001)\end{array}$ & & & -0.006 & $\begin{array}{c}(-0.014- \\
0.002)\end{array}$ \\
\hline
\end{tabular}

RRMS: relapsing remitting MS; EDSS: Expanded Disability Status Scale; $\beta$ : regression coefficient; OR: Odds Ratio. Dependent variables: EDSS-score (linear regression model), Relapse free (yes/no; logistic regression model), Relapse Rate (N/year; Poisson regression model). ${ }^{*} \mathrm{P}<0.050$. ${ }^{*}$ Predictive value of serum $25(\mathrm{OH}) \mathrm{D}$ and $1,25(\mathrm{OH})_{2} \mathrm{D}$ adjusted for age, sex, disease duration.

In this cohort, we conducted a subgroup-analysis of patients who were fully ambulatory at the time of serum sampling (EDSS-score $\leq 3.5$ ). This subgroup analysis was performed in order to assess the association in a presumably more homogenous cohort regarding sun-exposure. Both $25(\mathrm{OH}) \mathrm{D}$ and $1,25(\mathrm{OH})_{2} \mathrm{D}$ levels were lower in patients with 1 or more relapses compared to patients with no relapses prior to serum sampling (Figure 1). EDSS-scores did not differ significantly between the groups (MD: $0.60( \pm 0.48) ; P=0.226)$. Both high 25(OH)D $(P=0.043)$ and $1,25(\mathrm{OH})_{2} \mathrm{D}$ levels $(P=0.046)$ were associated with a high chance of remaining relapse free (Table 3$)$. The association of $25(\mathrm{OH}) \mathrm{D}$ level with relapse rate reached a significance level of $\mathrm{P}=0.087$. 


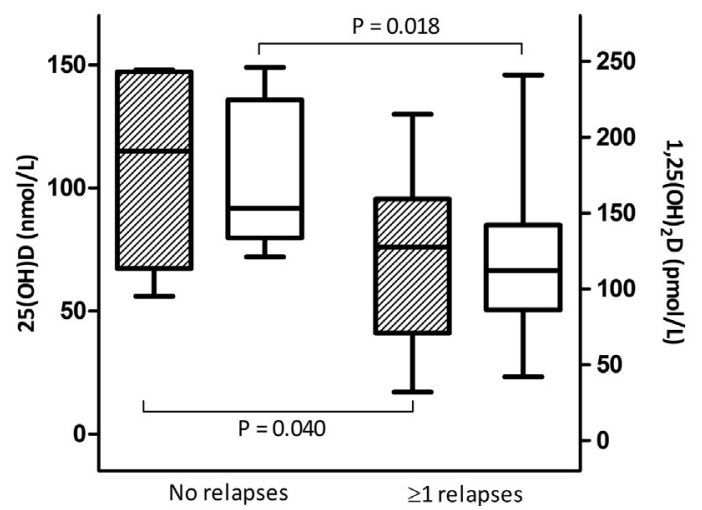

Figure 1 Serum vitamin D metabolite levels in fully ambulatory RRMS patients with and without relapses prior to serum sampling.

$(N=31$; disease duration $\leq 5$ years; EDSS score <3.5. Grey boxes: $25(\mathrm{OH}) \mathrm{D}$, White boxes: $1,25(\mathrm{OH})_{2} \mathrm{D}$. Test for significance: Mann-Whitney $\mathrm{U}$ test

\subsection{EDSS-score}

In the whole MS population, the raw 25(OH)D levels correlated negatively with EDSS-score (Table 3). There was no significant association between EDSS-score and raw $1,25(\mathrm{OH})_{2} \mathrm{D}$ levels $(\mathrm{P}=0.065)$. To address the elusive causality between disability and vitamin $\mathrm{D}$, both metabolites were tested as predictors as well as a dependents of EDSS-score in a multiple linear regression model. Only the adjusted 25(OH)D level was an independent predictor of EDSS-score (Table 3). When the vitamin D metabolites were considered as dependents of disability, only 25(OH)D was predicted by EDSS-score $(\beta=-3.155 ; 95 \% \mathrm{Cl}-4.936--1.374)$. The $1,25(\mathrm{OH})_{2} \mathrm{D}$ level was dependent upon 25(OH)D level $(\beta=0.550 ; 95 \% \mathrm{Cl} 0.395-0.705)$ and age $(\beta=-0.810$; $95 \% \mathrm{Cl}-1.310--0.310)$, but not upon EDSS-score.

\section{Discussion}

This is the first study to assess the serum levels of both $25(\mathrm{OH}) \mathrm{D}$ and $1,25(\mathrm{OH})_{2} \mathrm{D}$ in a large MS-population, including correlation of $1,25(\mathrm{OH})_{2} \mathrm{D}$ with clinical disease severity. We showed that low circulating levels of both $25(\mathrm{OH}) \mathrm{D}$ and $1,25(\mathrm{OH})_{2} \mathrm{D}$ are associated with the progressive MS phenotypes. Only low 25(OH)D levels are associated with an increase in clinical MS severity as measured by EDSS-score and the occurrence of relapses. Circulating $1,25(\mathrm{OH})_{2} \mathrm{D}$ is not independently associated with these clinical parameters, and is dependent of age and 25(OH)D level.

Although the association with relapse rate did not reach statistical significance, we did find significantly higher 25(OH)D levels in RRMS patients without relapses compared to patients with relapses, despite comparable EDSS-scores at serum sam- 
pling. This finding supports the observations of Souliu-Hänninen et al., who also investigated 2 year relapse rate before baseline 25(OH)D measurement (SoliuHänninen et al., 2008). They observed a trend towards lower 25(OH)D levels in patients with a high relapse rate. Their small sample-size $(N=26)$ probably explains this lack of significance, but also the inclusion of patients with a disease course of up to 15 years might contribute. We did only observe an association in patients with a disease course of $\leq 5$ years, and not in our total RRMS cohort. As we hypothesised, the specific inflammatory disease process at RRMS-onset might explain this phenomenon, but we can speculate about other explanations. The lower vitamin D metabolite levels in the secondary progressive group might be indicative of an association between low 25(OH)D levels and neurodegeneration, i.e. disease progression.

Our findings show that the serum concentration of $1,25(\mathrm{OH})_{2} \mathrm{D}$ does not play a key role in the interaction between vitamin $D$ and clinical MS severity. The lower $1,25(\mathrm{OH})_{2} \mathrm{D}$ levels that we found in the fully ambulatory patients with relapses and in the patients with high EDSS-scores are most likely attributable to the correlation between the vitamin $D$ metabolites (Barnes et al., 2007). The $1,25(\mathrm{OH})_{2} \mathrm{D}$ levels present in the serum, hydroxylized in the kidneys, are of vital significance for calcium metabolism, but are not likely to be involved in a disease modulating mechanism in MS. In the previously described EAE models, a beneficial reaction of disability on serum 1,25(OH) 2 D elevation has been observed (Cantorna et al., 1996; Lemire et al., 1991). However, this is most likely attributable to the use of supraphysiological levels of the hormone, leading to serious side-effects like hypercalcaemia. Apart from 25(OH)D, age is an important negative predictor of serum $1,25(\mathrm{OH})_{2} \mathrm{D}$. In progressive MS patients, impaired renal function with low glomerular filtration rates is often found (Calabresi et al., 2002). Chronic damage to the kidney could lead to a impaired $1 \alpha$-hydroxylation of $25(\mathrm{OH}) \mathrm{D}$ over the decades and thereby contribute to lower serum $1,25(\mathrm{OH})_{2} \mathrm{D}$ levels in older MS patients. Therefore, besides the MS modulating potential, vitamin $\mathrm{D}$ supplementation might certainly be very important in helping to maintain proper serum $1,25(\mathrm{OH})_{2} \mathrm{D}$ levels and a healthy calcium metabolism in this population, made vulnerable for loss of bone mineral density (Nieves et al., 1994).

The causality of the interaction between 25(OH)D levels and MS is dubious; the low 25(OH)D levels during relapses or in patients with high EDSS-scores can be interpreted in various ways. However, the association that we found between relapses and circulating 25(OH)D levels in RRMS patients with a disease course $\leq 5$ years, more strongly suggests a modulating effect of vitamin D on MS pathobiology. The mechanism underlying this modulation is still elusive, but some suggestions have been made in experimental research (Smolders et al., 2008a, chapter 2). The potential therapeutic consequences of vitamin $D$ also remain to be determined. There is more evidence appearing that supplementation of substantial doses of 
vitamin D in MS patients is an arguable and relatively safe option (Kimball et al., 2007). Therefore, we suggest that it is time for double-blind placebo-controlled trials to assess the role of vitamin D in MS treatment.

\section{Acknowledgements}

The authors would like to thank MS nurses Bertine Timmermans and Riny Wieers for their help with the collection of the vitamin D data. 


\section{Vitamin D status is positively correlated with regulatory $\mathrm{T}$ cell function in patients with relapsing remitting multiple sclerosis}

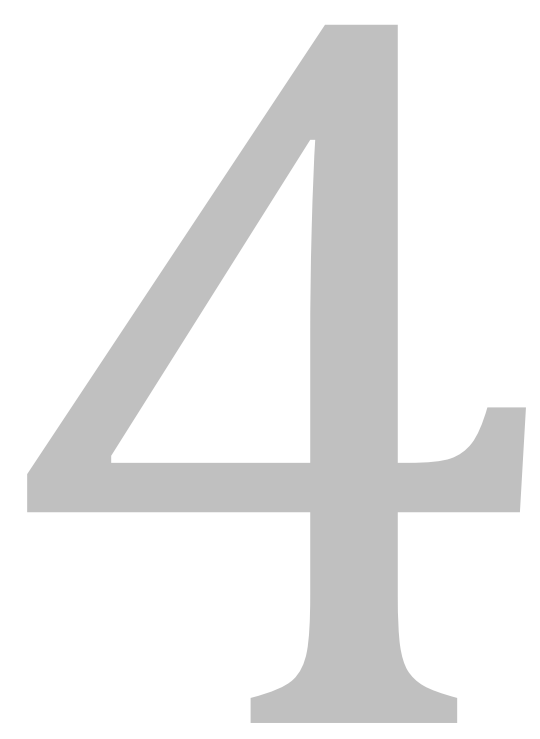

Published as: Joost Smolders, Mariëlle Thewissen, Evelyn Peelen, Paul Menheere, Jan Willem Cohen Tervaert, Jan Damoiseaux, Raymond Hupperts. Vitamin D status is positively correlated with regulatory $T$ cell function in patients with multiple sclerosis. Plos One 2009;4:e6635. 


\section{Abstract}

Background: In several autoimmune diseases, including multiple sclerosis (MS), a compromised regulatory T cell (Treg) function is believed to be critically involved in the disease process. In vitro, the biologically active metabolite of vitamin D has been shown to promote Treg development. A poor vitamin D status has been linked with MS incidence and MS disease activity. In the present study, we assess a potential in vivo correlation between vitamin $\mathrm{D}$ status and Treg function in relapsing remitting MS (RRMS) patients.

Methodology/ Principal Findings: Serum levels of 25-hydroxyvitamin D (25(OH)D) were measured in 29 RRMS patients. The number of circulating Tregs was assessed by flow-cytometry, and their functionality was tested in vitro in a CFSE-based proliferation suppression assay. Additionally, the intracellular cytokine profile of $\mathrm{T}$ helper cells was determined directly ex-vivo by flow-cytometry. Serum levels of $25(\mathrm{OH}) \mathrm{D}$ correlated positively with the ability of Tregs to suppress $T$ cell proliferation $(R=$ $0.590, P=0.002)$. No correlation between 25(OH)D levels and the number of Tregs was found. The IFN- $/$ /IL-4 ratio (Th1/Th2-balance) was more directed towards IL-4 in patients with favourable $25(\mathrm{OH}) \mathrm{D}$ levels $(\mathrm{R}=-0.435, \mathrm{P}=0.023)$.

Conclusions/Significance: These results show an association of high $25(\mathrm{OH}) \mathrm{D}$ levels with an improved Treg function, and with skewing of the Th1/Th2 balance towards Th2. These findings suggest that vitamin $D$ is an important promoter of $T$ cell regulation in vivo in MS patients. It is tempting to speculate that our results may not only hold for MS, but also for other autoimmune diseases. Future intervention studies will show whether modulation of vitamin D status results in modulation of the T cell response and subsequent amelioration of disease activity. 


\section{Introduction}

Multiple Sclerosis (MS) is a disabling, chronic inflammatory disease of the central nervous system (CNS). Although some patients experience progression of disability from the first symptoms onwards, the disease is at its onset mostly characterised by repetitive sub-acute deteriorations of symptoms with remissions afterwards, i.e. relapsing remitting MS (RRMS). After several years, sustained and progressive disability often occurs and the disease becomes secondary progressive (Compston and Coles, 2005).

Although the pathophysiological process in MS is not yet fully elucidated, T cell mediated inflammation within the CNS plays an important role. Auto-reactive T cells move through the blood brain barrier, and contribute to local inflammation of the CNS (Bar-Or 2008). Historically, these auto-reactive T cells were believed to comprise predominantly interferon gamma (IFN- $\gamma$ ) producing $T$ helper 1 (Th1) cells. More recently interleukin-17 (IL-17) producing Th17 cells have been argued to be important pathogenic T cells in MS (Kebir et al., 2007; Steinman 2007). In a healthy T cell compartment, regulatory $T$ cells (Treg) regulate the quantity and quality of the immune response, and prevent auto-reactive $T$ cell responses, and hereby autoimmune diseases (Sakaguchi et al., 2008). Although the number of Tregs is not decreased, their capability to suppress polyclonal or antigen-specific proliferation of $\mathrm{T}$ cells in vitro has been shown to be compromised in MS patients (Haas et al., 2005; Venken et al., 2006; Viglietta et al., 2004).

Experimental studies showed that the biologically active metabolite of vitamin $D, 1,25$-dihydroxyvitamin $\mathrm{D}\left(1,25(\mathrm{OH})_{2} \mathrm{D}\right)$, is able to skew the $\mathrm{T}$ cell compartment into a more anti-inflammatory and regulated state, with inhibition of Th1 and Th17 cells and promotion of Th2 and Treg cells (Correale et al., 2009; Smolders et al., 2008a, chapter 2). Interestingly, in the experimental autoimmune encephalomyelitis (EAE) animal model of MS, treatment with vitamin D prevented, and even cured, the disease (Cantorna et al., 1996). These findings suggest a potential role for vitamin D in MS, as has been investigated in several epidemiological studies. Near the equator, where vitamin D photosynthesis is optimal, MS incidence is low (Kurtzke 1967). Furthermore, increased sun exposition and a good vitamin D status in childhood and adolescence, reflected by the serum values of 25-dydroxyvitamin $D$ (25(OH)D) (Hollis 1996), have been associated with a decreased risk for developing MS (Islam et al., 2007; Kampman et al., 2007; Munger et al., 2006). An increased activity and disability of MS has also been associated with a poor vitamin D status (Kragt et al., 2009; Smolders et al., 2008b, chapter 3; van der Mei et al., 2007). Since vitamin $\mathrm{D}$ modulates the immune response in vitro and in animal models, it is highly interesting to assess whether this modulation can also be found in vivo in MS patients. This could be, beside regulation of the transcription of MS-associated alleles (Ramapolagan et al., 2009), an important driver of the associations between vitamin 
D status and MS. At present, however, no published studies assessed the potential relationship between serum levels of $25(\mathrm{OH}) \mathrm{D}$ and the T cell compartment in MS.

In the present study, we assess whether vitamin D status is correlated with the in vivo composition and function of the T cell compartment in MS patients. Since in RRMS patients with a short disease duration disease pathophysiology has been argued to be predominantly inflammatory (Compston and Coles 2005) and Treg function has been shown to be particularly compromised (Venken et al., 2006), we assess a potential anti-inflammatory and in particular Treg-promoting effect of vitamin $D$, as being related to vitamin $D$ status, in these patients.

\section{Materials and methods}

\subsection{Subjects}

We included in this study 29 Caucasian subjects, by approaching consecutive patients matching the inclusion criteria, who visited the outpatient clinic of our MS centre. All subjects had RRMS according to the revised McDonald criteria (Polman et al., 2005), with a disease duration of $<5$ years since the first to MS attributable symptoms. Both patients treated with interferon beta $1 \mathrm{a}$ or $1 \mathrm{~b}$, and patients untreated with immune modulation were included. Exclusion criteria were: no clinically definite phenotype, use of other immune modulation than interferon beta $1 \mathrm{a}$ or $1 b$, occurrence of a relapse $<5$ weeks before blood collection, recent start $(<1 / 2$ year) of vitamin $D$ supplementation. The characteristics of the patients are described in Table 1.

Table 1 Patients characteristics.

\begin{tabular}{lll}
\hline & Median / N (\%) & Range [min - max] \\
\hline Male / Female (N) & $10(34 \%) / 19(66 \%)$ & \\
Age (years) & 39.23 & {$[22.61-58.63]$} \\
Duration MS (years) & 3.48 & {$[0.69-4.89]$} \\
Relapse Rate (N/year) & 0.00 & {$[0.00-3.00]$} \\
Relapse free (years) & 1.04 & {$[0.10-3.91]$} \\
EDSS* score (points) & 2.0 & {$[0.00-6.00]$} \\
Interferon beta treated (N) & $25(86 \%)$ & \\
\hline
\end{tabular}

*Expanded disability status scale

\subsection{Ethical statement}

Written informed consent was acquired from all subjects participating in this study, according to the declaration of Helsinki. The study was reviewed and approved by both the regional ethical committee on human research 'Atrium MC, Orbis MC, 
Zuyd', and the institutional ethical committee 'Local Advisory Board on Scientific Research'.

\subsection{Vitamin D assays}

Blood withdrawal was performed in the period from September 2008 until February 2009. The cells for the cellular assays and the serum for vitamin D measurement were retrieved at the same time, and cellular assays were performed on the day of blood collection. The collected serum was immediately shielded from direct light and stored at $-20^{\circ} \mathrm{C}$. At the end of the study, all samples were analysed simultaneously. The serum values of $25(\mathrm{OH}) \mathrm{D}$ were measured with a commercially available radioimmuno assay (Immunodiagnostic Systems, Boldon, UK) (Smolders et al., 2008b, chapter 3).

\subsection{Cell culture reagents}

Cells were cultured in RPMI glutamax medium (Gibco Invitrogen, Breda, The Netherlands) supplemented with $10 \%$ Foetal Calf Serum (Greiner Bio-One, Alphen a/d Rijn, The Netherlands), 1\% non-essential amino acids (Gibco Invitrogen), 1\% sodium pyruvate (Gibco Invitrogen) and $2 \%$ penicillin-streptomycin (Gibco Invitrogen) in Ubottom 96-wells plates.

\subsection{Cell purification}

Cell isolation was performed as described before, with minor modifications (Venken et al., 2007). PBMC were isolated by Ficoll gradient centrifugation (Histopaque; Sigma Aldrich, Zwijndrecht, The Netherlands). $\mathrm{CD}^{+} \mathrm{T}$ cells were selectively isolated with RosetteSep (Stem Cell Technologies, Grenoble, France). Approximately 20-30 x $10^{6} \mathrm{CD}^{+} \mathrm{T}$ cells were incubated at $4^{\circ} \mathrm{C}$ for 30 minutes with anti-CD4-APC (BD Biosciences, Breda, The Netherlands), anti-CD25-PE (BD Biosciences) and anti-CD127-FITC (BD Biosciences). Human $\mathrm{CD} 4^{+} \mathrm{CD} 25^{+} \mathrm{CD} 127^{-}$Tregs (Liu et al., 2006; Seddiki et al., 2006) and $C D 4^{+} C D 25^{-}$responder $T$ cells (Tresps) were sorted on a FacsAria ${ }^{T M}$ (BD Biosciences) cell sorter (Figure 1A). The mean purity of the sorted populations was 97.51\% (SD 0.81) for the Tregs and 97.45\% (SD 1.65) for the Tresps. Accessory cells were obtained by irradiating autologous PBMC with 66.2 gray. 
A

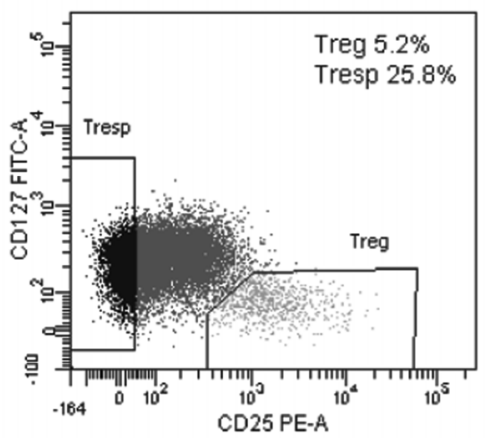

B

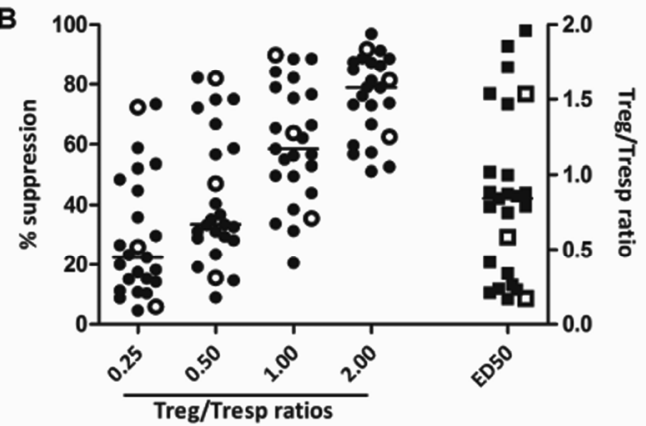

Figure 1 Results proliferation suppression assay.

(A) Representative dot-plot of the sorting protocol. $\mathrm{CD} 25^{+} \mathrm{CD} 127^{-}$cells within the $\mathrm{CD} 4^{+}$lymphogate were sorted as Tregs, CD25 cells were sorted as Tresps. (B) The percentages of suppression which were achieved for the respective Treg/Tresp ratios of the individual patients are shown. The Treg/Tresp ratio at which $50 \%$ inhibition of proliferation was achieved is defined as ED50 of suppression. The distribution of ED50 is shown in the rightmost column. The lines show the median values. The closed dots represent the Beta Interferon-treated patients, the open dots the untreated patients.

\subsection{Proliferation assay}

The CFSE-based proliferation suppression assay was adapted from Venken et al. (Venken et al., 2007). In short, the freshly isolated $C D 4^{+} \mathrm{CD} 25^{-}$Tresps were labelled with carboxy fluorescein diacetate succinimidyl ester (CFSE; Molecular Probes Invitrogen, Breda, The Netherlands). In a U-bottom 96-wells plate, $2 \times 10^{5}$ Tresps were stimulated with soluble anti-CD3 $(2.0 \mathrm{pg} / \mathrm{mL}$, WT32 IgG2a monoclonal antibody, kindly provided by dr. W Tax, Radboud University Nijmegen Medical Centre, Nijmegen, The Netherlands) in the presence of $2 \times 10^{5}$ irradiated accessory cells. Tresps were co-cultured for 5 days with varying amounts of Tregs (Treg/Tresp ratios $0 / 1,0.25 / 1,0.5 / 1,1 / 1$ or $2 / 1$ ). All conditions were performed in triplo in a final volume of $200 \mu \mathrm{L}$. After culture, the cells were stained with anti-CD4-APC and 7AAD (BD Biosciences), and the CFSE signal of cells in the $C D 4^{+} 7 A A D^{-}$lymphogate was

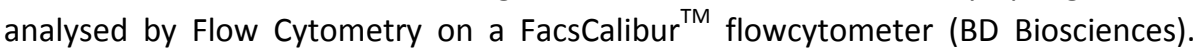
Data were analysed with CellQuest software (BD Biosciences). The amount of prolif- 
eration achieved in the $0 / 1$ ratio was set at $0 \%$ suppression. The mean relative amount of suppression in the other ratios was calculated. By linear interpolation, the Treg/Tresp ratio at which $50 \%$ suppression of proliferation was achieved (ED50) was calculated.

\subsection{T cell phenotyping}

Tregs were defined as $\mathrm{CD} 25^{+} \mathrm{FoxP}^{+} \mathrm{CD}^{+} \mathrm{T}$ cells (Fontenot et al., 2003; Hori et al., 2003) and as CD $25^{+} \mathrm{CD} 127^{-} \mathrm{CD}^{+} \mathrm{T}$ cells (Liu et al., 2006; Seddiki et al., 2006). For determining the number of Tregs, PBMC were stained with anti-CD3-PerCP (BD Biosciences), anti-CD4-APC, anti-CD4-FITC (BD Biosciences), anti-CD25-PE, antiCD127-FITC or anti-FoxP3-APC (E-Bioscience, San Diego, USA), and analysed on a FacsCalibur $^{\mathrm{TM}}$ flowcytometer. The absolute number of lymphocytes was determined with a haematological cell counter (Beckman Coulter, Woerden, The Netherlands).

$\mathrm{T}$ helper cell subsets were determined by assessing the intracellular cytokine pattern of $\mathrm{CD}^{+} \mathrm{CD} 8^{-}$lymphocytes, which are further referred to as $\mathrm{CD} 4^{+} \mathrm{T}$ cells, by flowcytometry (Ordonez et al., 2009). PBMC were stimulated for 5 hours with calcium ionomycine (Sigma Aldrich), phorbol 12-myristate 13-acetate (PMA; Sigma Aldrich) and monensin (BD Biosciences). Cells were stained intra-cellularly with antiIL-4-PE (BD Biosciences), anti-IFN- $\gamma$-FITC (BD Biosciences), anti-IL-17-PE (EBioscience) and anti-IL-10-PE (E-Bioscience), and extra-cellularly with anti-CD3PerCP and anti-CD8-APC.

\subsection{Statistics}

Statistical analysis was conducted with Statistical Package for Social Sciences version 15.0 software (SPSS inc., Chicago IL, USA) and figures were constructed with GraphPad Prism 5 software (GraphPad Software inc., La Jolla CA, USA). Of continuous variables, the median and corresponding range (min - max) are provided. When normally distributed (Shapiro-Wilk test $P>0.05$ ), a linear relationship between two continuous variables was tested with the Pearson correlation coefficient (Pearson R). Abnormally distributed variables were Log-transformed. In case of persistent abnormal distribution, the Spearman correlation coefficient (Spearman R) was determined. A P value $<0.05$ was considered statistically significant.

\section{Results}

\subsection{Serum 25(OH)D levels.}

We determined the serum levels of $25(\mathrm{OH}) \mathrm{D}$, the vitamin $\mathrm{D}$ metabolite which is accepted to reflect vitamin $D$ status best (Hollis et al., 1996). The median serum $25(\mathrm{OH}) \mathrm{D}$ level was $54 \mathrm{nmol} / \mathrm{L}$. 


\subsection{Suppressive capacity of Tregs correlates positively with 25(OH)D levels.}

To evaluate Treg suppressive capacity, we conducted an in vitro CFSE-based proliferation suppression assay (Figure 1B). Of 4 patients, not enough cells were retrieved to start the assay. In all other individual patients, Tregs suppressed proliferation of $T$ responder cells in a dose-dependent manner. There was no apparent difference in Treg suppression between Beta Interferon treated and untreated patients (Figure 1B). The median Treg/Tresp ratio at $50 \%$ suppression of proliferation (ED50) was $0.82(0.16-1.96)$. Serum 25(OH)D levels correlated negatively with ED50 (Spearman $R=-0.590, P=0.002$ ) (Figure $2 A$ ). This correlation was reflected by the positive correlation between vitamin $D$ status and the amount of suppression in the individual Treg/Tresp ratios (Figure 2B-E).

\subsection{Number of circulating Tregs does not correlate with 25(OH)D levels.}

Next, we evaluated the absolute and relative number of Tregs in the circulation (Figure 3). Regulatory cells within the $\mathrm{CD}^{+}{ }^{+}$cell compartment were defined as $\mathrm{CD} 25^{+} \mathrm{CD} 127^{-}$and $\mathrm{CD} 25^{+} \mathrm{FoxP}^{+}$cells. The median percentage of $\mathrm{CD}_{2} 5^{+} \mathrm{FoxP}^{+}{ }^{+} \mathrm{Tregs}$ in the $\mathrm{CD}^{+} \mathrm{T}$ cell compartment was $5.63 \%$ (2.67 - 15.81) (absolute number $9.61 \mathrm{x}$ $\left.10^{7} \mathrm{C} / \mathrm{L}(4.65-25.41)\right)$. The median percentage of $\mathrm{CD} 25^{+} \mathrm{CD} 127^{-}$Tregs was $6.56 \%$ $(2.93-12.32)$ (absolute $10.32 \times 10^{7} \mathrm{c} / \mathrm{L}(4.44-24.14)$ ). A strong positive correlation was observed between the numbers of $\mathrm{CD} 25^{+} \mathrm{CD} 27^{-}$and $\mathrm{CD} 25^{+} \mathrm{FoxP}^{+} \mathrm{CD} 4^{+}$Tregs $(\mathrm{R}$ $=0.826, \mathrm{P}<0.001)$. Serum levels of $25(\mathrm{OH}) \mathrm{D}$ were not correlated with the relative and absolute number of Tregs (Figure 4).

\subsection{The Th1/Th2 balance correlates negatively with 25(OH)D levels.}

$\mathrm{CD}^{+}{ }^{+} \mathrm{T}$ cells were classified as Th1, Th2 or Th17 by assessing their intracellular cytokine profile (IFN- $\gamma$, IL-4 and IL-17, resp.) (Figure 5A). We also assessed the percentage of $\mathrm{CD}^{+} \mathrm{T}$ cells producing the regulatory cytokine IL-10 (Correale et al., 2009). The median percentage of IFN- $\gamma^{+}$cells within the $\mathrm{CD}^{+}{ }^{+} \mathrm{T}$ cell compartment was $12.11 \%(2.60-26.18)$, of IL- $4^{+}$cells $2.07 \%(0.90-4.93)$, of IL- $17^{+}$cells $0.92 \%(0.31-$ $2.35)$, and of IL- $10^{+}$cells $0.83 \%(0.43-1.45)$. No significant correlations between serum 25(OH)D levels and the individual percentages of $\mathrm{T}$ helper cell subsets were found, although there was a trend towards a negative correlation with the percentage of IFN $-\gamma^{+} \mathrm{CD} 4^{+} \mathrm{T}$ cells (Pearson $\mathrm{R}=-0.336 \mathrm{P}=0.060$ ). The balance between Th1 and Th2 is used to indicate a more pro- or anti-inflammatory composition of the T cell compartment (Steinman 2007). This balance is described by the ratio of IFN- $\gamma^{+}$ and IL- $4^{+} \mathrm{CD} 4^{+} \mathrm{T}$ cells. The IFN- $\gamma / \mathrm{IL}-4$ ratio correlated negatively with serum $25(\mathrm{OH}) \mathrm{D}$ levels (Pearson $\mathrm{R}=-0.435 \mathrm{P}=0.023$ ) (Figure 5B). 


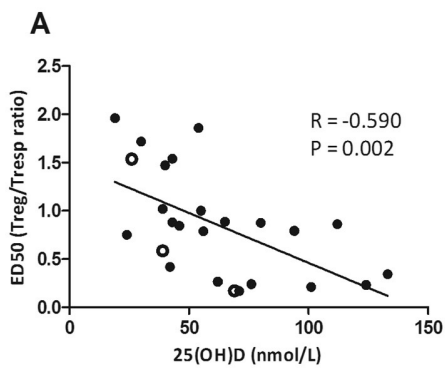

B Treg: Tresp 0.25:1

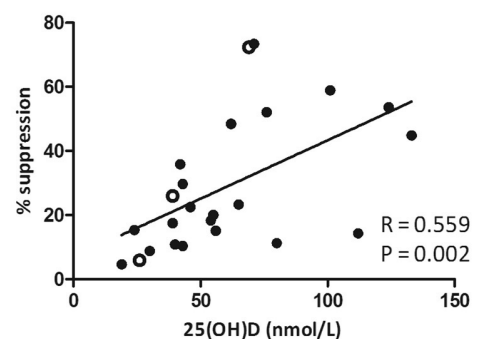

D Tresp:Tresp 1:1

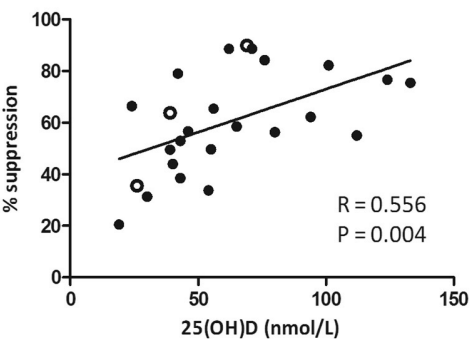

C Treg:Tresp 0.50:1

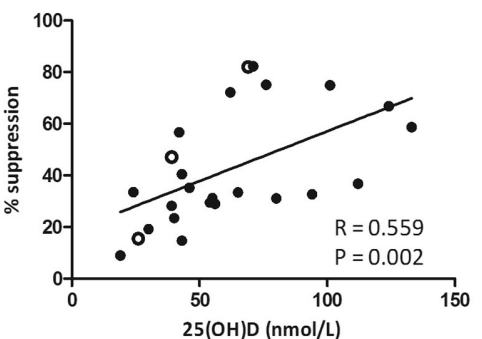

E Treg:Tresp 2:1

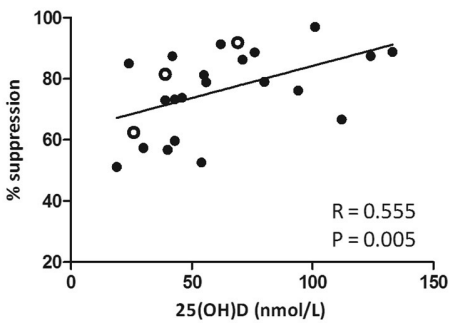

Figure 2 Correlation between Treg suppressive function and serum 25(OH)D levels.

(A) The correlation between ED50 and serum 25(OH)D levels. (B-E) Correlation between inhibition of suppression and 25(OH)D levels for the individual Treg/Tresp ratios. The Spearman correlation coefficient is shown. The regression line illustrates the direction of the association. The closed dots represent the Beta Interferon-treated patients, the open dots the untreated patients. 
A

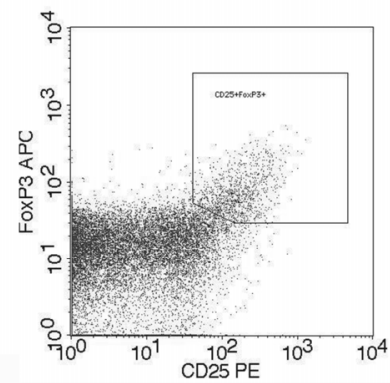

C

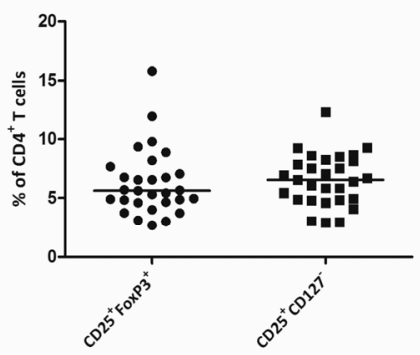

B

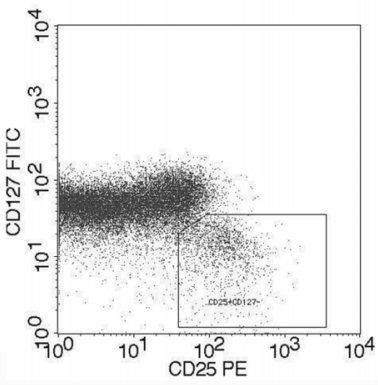

D

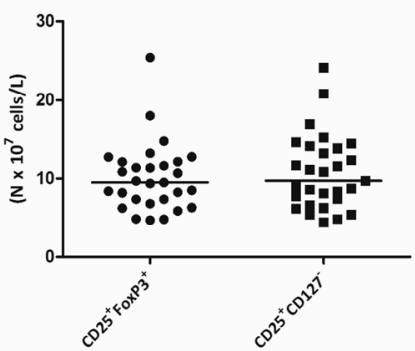

Figure 3 Relative and absolute number of circulating Tregs.

Within the $\mathrm{CD}^{+}{ }^{+} \mathrm{CD} 4^{+}$lymphogate, Tregs were defined as either being (A) $\mathrm{CD} 25^{+} \mathrm{FoxP}^{+}$or being (B) $\mathrm{CD} 25^{+} \mathrm{CD} 127$. (C) The percentages of Tregs within the $\mathrm{CD} 4^{+} \mathrm{T}$ cell compartment. (D) Absolute number of circulating Tregs. The lines indicate the median values.
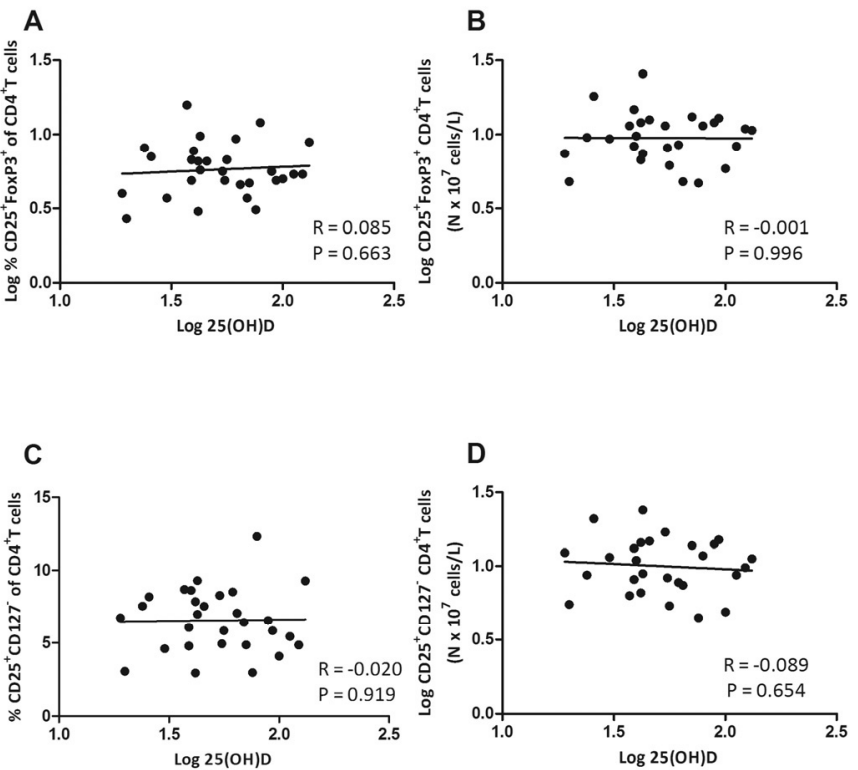

Figure 4 Correlation of the number of circulating Tregs with serum 25(OH)D levels.

(A-D) Correlation of relative and absolute number of Tregs with 25(OH)D levels. The Pearson correlation coefficient and corresponding regression line are shown. 

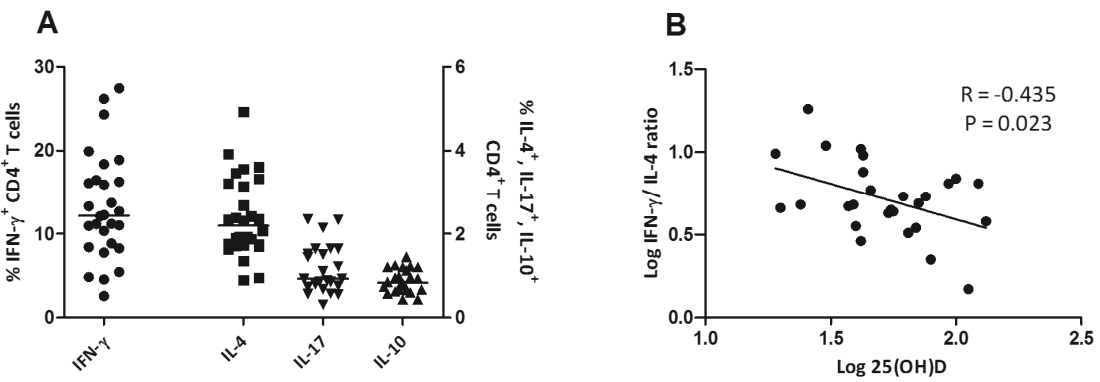

Figure 5 Correlation of Thelper cell subsets with serum 25(OH)D levels.

(A) The percentages of IFN- $\gamma^{+}, \mathrm{IL}-4^{+}, \mathrm{IL}-17^{+}$and $\mathrm{IL}-10^{+} \mathrm{CD} 4^{+} \mathrm{T}$ cells. The lines show the median values. (B) The correlation between IFN- $-\mathrm{IL}-4$ ratio and serum 25(OH)D levels. The Pearson correlation coefficient and corresponding regression line are shown.

\subsection{No association between MS disease activity and vitamin D status or T cell parameters.}

Neither vitamin D status, nor T cell parameters as Treg function or T cell phenotype did correlate with measures of MS disease activity as described in Table 1 (data not shown).

\section{Discussion}

Vitamin D status has been linked with MS either in large epidemiological studies or in experimental in vitro and animal studies. This is the first study to investigate the correlation between vitamin $\mathrm{D}$ status and the composition of the T cell compartment and in particular Treg function in vivo in MS patients. Our data shows that serum $25(\mathrm{OH}) \mathrm{D}$ levels correlate positively with the ability of $\mathrm{CD} 4^{+} \mathrm{CD} 25^{+} \mathrm{CD} 127^{-}$Tregs to suppress proliferation of Tresp cells. The absolute and relative Treg numbers in the circulation were not correlated with vitamin D status. Although we did not observe a significant association between $25(\mathrm{OH}) \mathrm{D}$ levels and the individual percentages of $\mathrm{CD}^{+}{ }^{+} \mathrm{T}$ helper cell subsets, the decreasing IFN- $\gamma / \mathrm{IL}-4$ ratio reflected a skewing of the Th1/Th2-balance towards a more Th2 phenotype in patients with higher serum $25(\mathrm{OH}) \mathrm{D}$ levels. Altogether, this data indicates that high serum 25(OH)D levels are associated with a less inflammatory and better regulated T cell compartment in MS.

In our data, we found no association between vitamin D status and disease severity and activity of MS. This is in contrast with earlier observations (Kragt et al., 2009; Smolders et al., 2008b; Chapter 3; van der Mei et al., 2007). However, since we measured patients in the period from September until February, the seasonal fluctuation of vitamin D status is likely to confound these associations (Kimlin et al., 2008). In contrast to the MS activity variables, this seems not critical for the correlation with the T cell tests: the data obtained reflects the status of the T cell com- 
partment at the moment of blood collection. Additionally, several studies have shown a seasonal fluctuation of immunological parameters in MS patients comparable to the fluctuation of serum 25(OH)D levels (Balashov et al., 1998; Stewart et al., 2007).

In a previous study, $\mathrm{CD} 4^{+} \mathrm{CD} 25^{\text {high }}$ Tregs of RRMS patients achieved only about $40 \%$ suppression in a 1:1 Treg/Tresp ratio as measured in a ${ }^{3} \mathrm{H}$-Thymidine assay (Viglietta et al., 2004). A later study confirmed a mean suppression of $40 \%$ in untreated RRMS patients, and of 50\% in Beta interferon users (Venken et al., 2006). Our RRMS patients reached in the $1: 1$ ratio a mean suppression of $60 \%(20-90)$. Beta Interferon treatment has been shown to promote Treg function (Venken et al., 2008). Therefore, the fact that most of our patients were treated with Beta Interferon might have contributed to this substantially more favourable suppression. Additionally, we included the $\alpha$-chain of the IL-7 receptor (CD127), which has been shown to be specifically absent on $\mathrm{CD} 4^{+} \mathrm{CD} 25^{+} \mathrm{FoxP}^{+}$Tregs, in our sorting protocol to define Tregs (Liu et al., 2006; Seddiki et al., 2006).Therefore, the sorted population of $\mathrm{CD} 4^{+} \mathrm{CD} 25^{+} \mathrm{CD} 127^{-}$Tregs may comprise a more pure Treg fraction, compared to $\mathrm{CD} 4^{+} \mathrm{CD} 25^{\text {high }}$ sorted T cells alone (Michel et al., 2008].

Our data shows that in RRMS patients with a short disease duration, in which Treg function has been shown to be particularly compromised (Venken et al., 2006), Treg suppressor function correlates positively with serum 25(OH)D levels. The relationship between Treg function and 25(OH)D levels is likely to contribute to the inter-individual variation of Treg suppressive function in MS cohorts in other studies (Haas et al., 2005; Venken et al., 2006; Viglietta et al., 2004). However, we could not find an association of serum vitamin $\mathrm{D}$ values with the number of $\mathrm{CD} 4^{+} \mathrm{CD} 25^{+} \mathrm{FoxP}^{+}$ or $\mathrm{CD}^{+} \mathrm{CD} 25^{+} \mathrm{CD} 127^{-}$Tregs in the circulation. This discrepancy between the impaired number and function of Tregs has been shown in other studies on Tregs in MS and other autoimmune diseases (Constantino et al., 2008). However, the underlying mechanism is not know. Interestingly, a recent publication showed a negative correlation between the percentage of FoxP3 ${ }^{+}$Tregs within the T cell compartment of MS patients and their vitamin D status (Royal III et al., 2009). However, the heterogeneous study population considering race and disease duration, and the use of linear regression models to analyse not-equally distributed parameters in a limited sample size, require careful interpretation of these results. The discrepancy with our data not showing a comparable correlation, might be attributable to these methodological differences.

Additionally, we found a negative correlation between serum 25(OH)D levels and the IFN- $\gamma / \mathrm{IL}-4$ ratio. This ratio is commonly used to describe the balance in the immune system between pro-inflammatory IFN- $\gamma^{+}$Th1 cells and anti-inflammatory IL-4 ${ }^{+}$Th2 cells (Steinman 2007). Our data suggests that, in patients with relatively high 25(OH)D-levels, the balance between Th1 and Th2 is more skewed in the direction of Th2. Interestingly, in vitro research also suggested that vitamin D skews the $T$ 
cell compartment from a Th1 towards a Th2 phenotype (Correale et al., 2009; Smolders et al., 2008a; Chapter 3). Therefore, high 25(OH)D D levels appear to be associated with a less-pro-inflammatory T-cell compartment in MS patients.

In conclusion, we have shown that serum 25(OH)D levels are associated with the suppressive function of Tregs and the composition of the T cell compartment in MS patients. These findings further support the hypothesis that vitamin $D$ is an important promoter of $\mathrm{T}$ cell regulation in MS. Since in RRMS patients the Treg compartment has been shown to be compromised, our findings provide additional arguments to maintain a healthy vitamin D status in these patients. Also other autoimmune diseases have been associated with both low vitamin D levels, and a reduced regulatory T cell function (Arnson et al., 2008; Constantino et al., 2008). Whether a poor vitamin $\mathrm{D}$ status correlates in healthy populations with a reduced Treg function and potentially a subsequently increased risk for developing autoimmune diseases, remains to be established. Altogether, it is tempting to speculate about the potential therapeutic effect of vitamin D supplementation in autoimmune diseases. Previously, it was demonstrated that therapy with Beta Interferon in MS results in a promotion of regulatory $T$ cell function (Venken et al., 2008) and a decrease of relapse rate (IFNB MS study group, 1995). Since we observed an additional effect of 25(OH)D levels in Beta Interferon users, this might provide a rationale for add-on therapy with vitamin D during Beta Interferon therapy in MS. Randomized clinical trials should assess an additional role of vitamin D treatment on the $T$ cell compartment and more importantly on disease activity of MS.

\section{Acknowledgements}

The authors would like to thank MS-nurses Tiny Kempkens, Judith Poeth and Ingrid Mevissen for their help with patient inclusion and blood collection, and Jozien Jaspers-Spits and Dennis Meesters for their skilled technical assistance with the laboratory procedures. 



\section{Regulatory T cell function correlates with serum 25-hydroxyvitamin $\mathrm{D}$, but not with 1,25-dihydroxyvitamin D, parathyroid hormone and calcium levels in patients with relapsing remitting multiple sclerosis.}

Published as: Joost Smolders, Paul Menheere, Mariëlle Thewissen, Evelyn Peelen, Jan Willem Cohen Tervaert, Raymond Hupperts, Jan Damoiseaux. Regulatory T cell function correlates with serum 25-hydorxyvitamin D, but not with 1,25-dihydroxyvitamin $D$, parathyroid hormone and calcium levels in patients with relapsing remitting multiple sclerosis. Journal of Steroid Biochemistry and Molecular Biology 2010;121:243-246. 


\section{Abstract}

Vitamin D has been proposed as a potential immune modulator in multiple sclerosis (MS), but was primarily identified for its effects on calcium homeostasis. It is uncertain whether these calcaemic functions of vitamin D are critically involved in its immune modulating potential. We earlier reported a correlation between serum 25hydroxyvitamin D $(25(\mathrm{OH}) \mathrm{D})$ levels and regulatory T cell (Treg) function. In the present study, the correlation of serum levels of 1,25-dihydroxyvitamin $D\left(1,25(\mathrm{OH})_{2} \mathrm{D}\right)$, intact parathyroid hormone (PTH), and total calcium with Treg number and functionality and the proportions of other T helper cell subsets was assessed in 29 relapsing remitting MS patients. In contrast to serum $25(\mathrm{OH}) \mathrm{D}$ levels, serum concentrations of neither $1,25(\mathrm{OH})_{2} \mathrm{D}$, nor PTH and total calcium correlated significantly with Treg function or Th1/Th2 ratio. None of the parameters correlated with the relative and absolute number of Tregs. Interestingly, the serum levels of $1,25(\mathrm{OH})_{2} \mathrm{D}$ correlated positively with the proportion of T helper type 17 (Th17) cells. These results suggest that the serum levels of $1,25(\mathrm{OH})_{2} \mathrm{D}, \mathrm{PTH}$, and total calcium are not critically involved in the correlation between vitamin $\mathrm{D}$ status and $\mathrm{T}$ cell regulation. 


\section{Introduction}

Multiple sclerosis (MS) is a debilitating disease affecting young people, in which an auto-reactive T helper cell type 1 (Th1) and Th17 response initiates focal inflammation in the central nervous system (Bar Or 2008). In experimental studies, vitamin D inhibits Th1 and Th17 cells, and promotes Th2 and regulatory T cells (Treg) (Correale et al., 2009; Smolders et al., 2008a, chapter 2). Recently, we showed that vitamin D status, as reflected by serum levels of 25 -hydroxyvitamin $D$, correlated positively with Treg functionality, and with a more towards Th2 directed Th1/Th2 balance in patients with relapsing remitting MS (RRMS) (Smolders et al., 2009d, chapter 4). Association studies showed that vitamin D status was poorer in subjects developing MS in later life (Munger et al., 2006), and correlated negatively with disease activity (Smolders et al., 2008b, chapter 3). Although 25(OH)D is the most abundant metabolite, the biologically active metabolite 1,25 -dihydroxyvitamin $\mathrm{D}\left(1,25(\mathrm{OH})_{2} \mathrm{D}\right)$ is also present in the circulation. The serum levels of $1,25(\mathrm{OH})_{2} \mathrm{D}$ are primarily derived from hydroxylation of 25(OH)D in the kidneys upon signals from calcium metabolism, e.g. calcium and parathyroid hormone (PTH) (Jongen et al., 1984). An increase in serum $1,25(\mathrm{OH})_{2} \mathrm{D}$ results in increasing serum calcium levels, by promoting calcium resorbtion in kidney and intestine, and osteoclast activation. It is uncertain whether these calcaemic effects of vitamin D are also critically involved in its interaction with the immune system.

The data on T cell characteristics and $25(\mathrm{OH}) \mathrm{D}$ values have been reported in detail before (Smolders et al., 2009d, chapter 4). In the present study, we assessed whether serum levels of $1,25(\mathrm{OH})_{2} \mathrm{D}, \mathrm{PTH}$, and total calcium, all related with the calcaemic function of vitamin $\mathrm{D}$, correlated with Treg function, the absolute and relative number of Tregs in the circulation, and with $\mathrm{T}$ helper cell subsets in patients with MS.

\section{Materials and methods}

A cohort of 29 Caucasian RRMS patients was included. The cohort comprised 19 females (66\%), the median age was 39 yrs. (23-59), the median disease duration 3.5 yrs (0.7-4.9), the median relapse rate $0 / y r(0-3)$, and the median expanded disability status scale (EDSS) score $2(0-6)$. Twenty-five (86\%) patients were treated with beta interferon, the remainder received no immune modulation. All patients signed informed consent, and the study was approved by the local medical ethics committee according to the declaration of Helsinki.

Peripheral blood was drawn in the period September 2008 - February 2009. Serum values of $25(\mathrm{OH}) \mathrm{D}$ and $1,25(\mathrm{OH})_{2} \mathrm{D}$ were determined with commercially available radioimmuno assays (Immunodiagnostic Systems, Boldon, UK). Serum total 
calcium levels were determined with the Immunolite $2000^{\mathrm{TM}}$ (Siemens Healthcare Diagnostics, Deerfield IL, USA), and intact PTH levels were determined with the Synchron LX ${ }^{\mathrm{TM}}$ (Beckman Coulter, Woerden, The Netherlands). Reference values of the clinical chemical laboratory are provided.

T cell variables were determined as described extensively before (Smolders et al., 2009d, chapter 4). In short, the proportions of CD4 ${ }^{+}$Tregs and Thelper cell subsets in the circulation were determined directly ex-vivo by flow-cytometry. Tregs were defined as $\mathrm{CD}^{+}{ }^{+} \mathrm{T}$ cells being either $\mathrm{CD} 25^{+} \mathrm{FoxP} 3^{+}$or $\mathrm{CD} 25^{+} \mathrm{CD} 127^{-}$, and $\mathrm{T}$ helper cells were defined by intracellular cytokine expression of $\mathrm{CD}^{+} \mathrm{T}$ cells on 5 hour stimulation with phorbol 12-myristate 13-acetate (PMA) and calcium ionomycine (Th1: Interferon- $\gamma$ (IFN- $\gamma$ ), Th2: IL-4, Th17: IL-17, and IL-10 producing cells). To calculate absolute cell numbers, lymphocytes were counted on a hematological cell counter (Beckman Coulter). The ability of Tregs to suppress proliferation of polyclonal activated responder T (Tresp) cells was assessed in a carboxyfluorescein succinimidyl ester (CFSE) based proliferation suppression assay. In brief, $\mathrm{CD}^{+} \mathrm{CD} 25^{+} \mathrm{CD} 127$ Tregs and $\mathrm{CD} 4^{+} \mathrm{CD} 25^{-}$Tresps were sorted on a FacsAria ${ }^{\mathrm{TM}}$ cell sorter (BD Biosciences, Breda, The Netherlands). After CFSE labeling, Tresps were activated with anti-CD3 monoclonal antibody and cultured with irradiated autologous feeders in the presence of varying amounts of Tregs (Treg/Tresp ratio is 0/1, 0.25/1, $0.50 / 1,1 / 1$, and 1/2). After 5 days, proliferation in each culture condition was evaluated by flow-cytometric analyses of the CFSE signal and expressed relative to proliferation in the Tresp monoculture. Suppression of proliferation was then calcu-

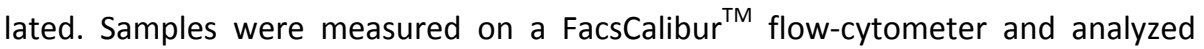
with CellQuest ${ }^{\mathrm{TM}}$ software (both BD Biosciences).

Statistical analysis was performed with SPSS version 15.0 (SPSS inc., Chicago IL, USA) and figures were constructed with GraphPad Prism 5 (GraphPad software inc., La Jolla CA, USA). Continuous variables are presented as median value with corresponding range (min-max). When normally distributed (Shapiro-Wilk test $P>0.05$ ), the Pearson correlation coefficient is provided to describe the relationship between two continuous variables. In case of an abnormal distribution, persistent after logarithmic transformation, the Spearman correlation coefficient is given. An uncorrected $\mathrm{P}$-value $<0.05$ was considered to be significant.

\section{Results}

\subsection{Serum levels of vitamin D metabolites, PTH and calcium}

The median $25(\mathrm{OH}) \mathrm{D}$ value was $54 \mathrm{nmol} / \mathrm{L}(19-133)$, the median $1,25(\mathrm{OH})_{2} \mathrm{D}$ value was $126 \mathrm{pmol} / \mathrm{L}(55-203)$. The two vitamin D metabolites correlated positively (Pearson $\mathrm{R}=0.631, \mathrm{P}<0.001)$. The median PTH-value was $2.32 \mathrm{pmol} / \mathrm{L}(1.28-9.36)$ (reference 1.3-6.8 pmol/L), the median total calcium value $2.36 \mathrm{mmol} / \mathrm{L}(2.14-2.48)$ 
(reference $2.10-2.55 \mathrm{mmol} / \mathrm{L}$ ). Serum levels of PTH correlated negatively with total calcium (Pearson $\mathrm{R}=-0.382, \mathrm{P}=0.041$ ) and 25(OH)D levels (Pearson $\mathrm{R}=-0.582, \mathrm{P}=$ 0.001). Total calcium levels correlated positively with $1,25(\mathrm{OH})_{2} \mathrm{D}$ levels (Pearson $\mathrm{R}=$ $0.385, \mathrm{P}=0.039)$.

\subsection{Correlation with Treg number and functionality.}

The median suppression of proliferation in the 1:1 Treg/Tresp ratio was $60 \%$ (2092). As described before, serum 25(OH)D values correlated positively with Treg suppressive function (Figure 1A). Serum 1,25(OH) ${ }_{2} \mathrm{D}, \mathrm{PTH}$ and calcium did not correlate significantly with Treg functionality (Figure 1 B-D). This was the same for all individual Treg/Tresp-ratio culture conditions. The percentage of $\mathrm{CD} 25^{+} \mathrm{CD} 127^{-}$Tregs within the $\mathrm{CD}^{+}{ }^{+}$cell compartment was $6.6 \%$ (2.9-12.3), of $\mathrm{CD}_{2} 5^{+}$FoxP3 ${ }^{+}$Tregs $^{5.6 \%}$ (2.7-15.8). The absolute and relative numbers of Tregs in the circulation did not correlate with any of the parameters studied (data not shown).

\subsection{Correlation with $T$ helper cell subset percentages.}

The median percentage of Th1 cells within the $\mathrm{CD}^{+} \mathrm{T}$ cell compartment was $12.1 \%$ (2.6-26.2), of Th2 2.1\% (0.9-4.9), of Th17 0.9\% (0.3-2.4), and of IL-10 producing cells $0.8 \%(0.4-1.5)$. As described earlier, serum 25(OH)D correlated negatively with the Th1/Th2-ratio (Figure 1E). The other calcium metabolism parameters did not correlate significantly with Th1/Th2 ratio (Figure $\mathbf{1 F - H ) . ~ T h e r e ~ w a s ~ a l s o ~ n o ~ c o r r e l a - ~}$ tion of any of the markers with the individual percentages of Th1, Th2 and IL-10 producing $\mathrm{CD}^{+} \mathrm{T}$ cells (data not shown). Interestingly, the proportion of Th17 cells correlated positively with serum $1,25(\mathrm{OH})_{2} \mathrm{D}$ levels, despite the absence of a correlation with $25(\mathrm{OH}) \mathrm{D}, \mathrm{PTH}$ or total calcium levels (Figure $1 \mathrm{l}-\mathrm{L}$ ). 

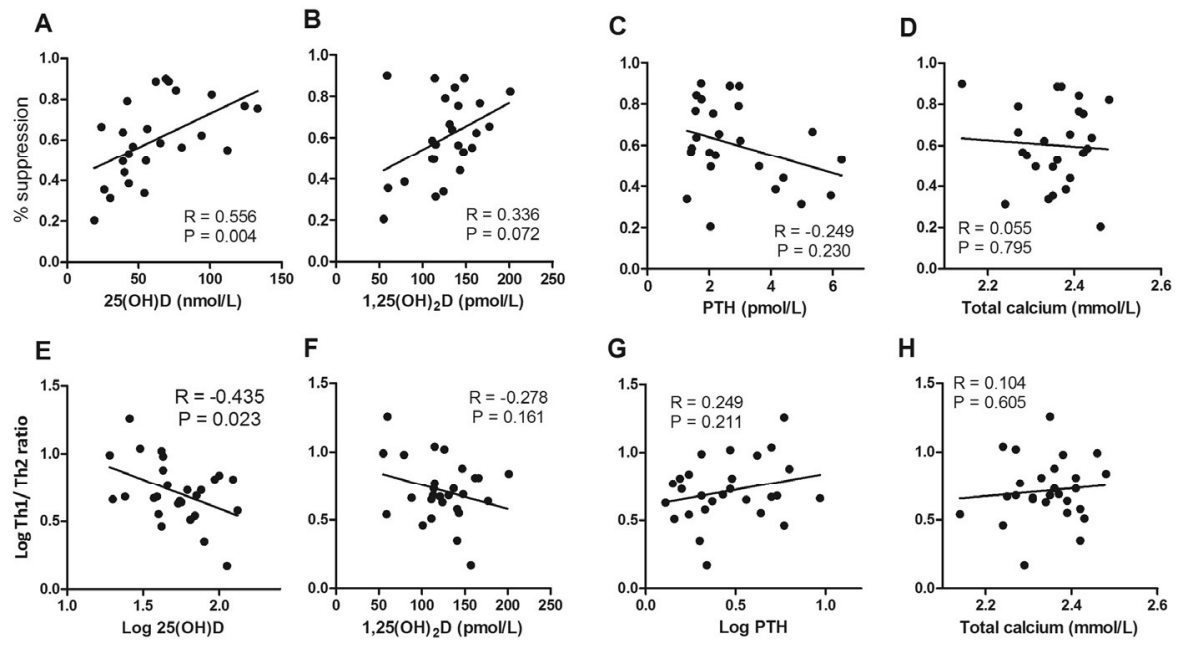

$\mathrm{H}$
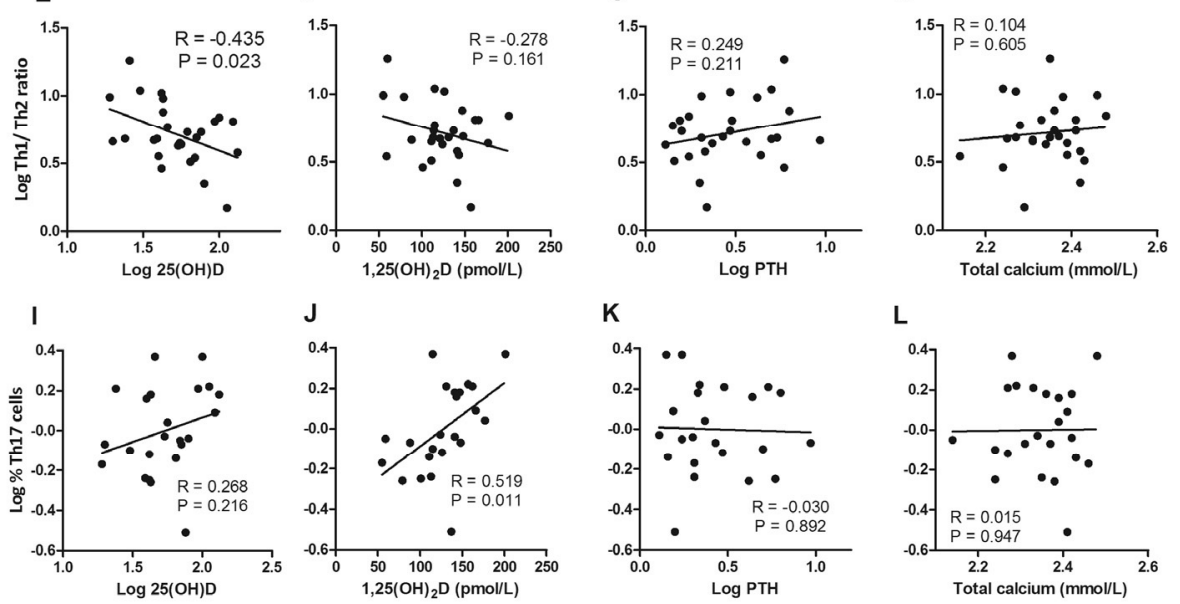

Figure 1 Correlation of the serum levels of $25(\mathrm{OH}) \mathrm{D}, 1,25(\mathrm{OH})_{2} \mathrm{D}, \mathrm{PTH}$, and total calcium with T cell characteristics.

T cell characteristics comprise: (A-D) the amount of suppression (\%) of $\mathrm{CD}^{+} \mathrm{CD} 25^{-}$responder $\mathrm{T}$ cell proliferation achieved by an equal amount of $\mathrm{CD} 4^{+} \mathrm{CD} 25^{+} \mathrm{CD} 127^{-}$regulatory $\mathrm{T}$ cells in a coculture, $(E-H)$ the ratio of the proportions of IFN $-\gamma^{+}$and IL- $4^{+} \mathrm{CD} 4^{+} \mathrm{T}$ cells (Th1/Th2 ratio) in a PBMC culture stimulated with PMA and calcium ionomycine, and (I-L) the proportion of IL-17 ${ }^{+}$ $\mathrm{CD}^{+} \mathrm{T}$ cells in a PBMC culture stimulated with PMA and calcium ionomycine. Dependent on the distribution of the variables, either the Spearman (A-D) or Pearson (E-L) correlation coefficient is provided. A regression line is inserted to illustrate correlation.

\section{Discussion}

In the present study, the relationship between several $\mathrm{T}$ cell characteristics and serum $1,25(\mathrm{OH})_{2}$ D, PTH and total calcium was studied in a cohort of RRMS patients. In contrast to the earlier reported positive correlation of serum 25(OH)D levels with Treg function and negative correlation with Th1/Th2 ratio, the serum values of $1,25(\mathrm{OH})_{2} \mathrm{D}, \mathrm{PTH}$, and total calcium did not correlate significantly with these $\mathrm{T}$ cell parameters. Serum $1,25(\mathrm{OH})_{2} \mathrm{D}$ did correlate positively with the proportion of Th17 cells.

The role of calcium metabolism in the interaction between vitamin $D$ and $M S$ is at present unclear. In experimental autoimmune encephalomyelitis (EAE), an ani- 
mal-model of MS, dietary calcium intake and the subsequent elevation of serum calcium concentration were critical factors in the clinical and immunological effects of $1,25(\mathrm{OH})_{2} \mathrm{D}$ therapy (Cantorna et al., 1999). Calcitonin, a protein released during hypercalcaemia, enhanced the clinical effectiveness of $1,25(\mathrm{OH})_{2} \mathrm{D}$ in EAE (Becklund et al., 2009a), but was not mandatory (Becklund et al., 2009b). This proposed importance of calcium in EAE, led to the notice that calcium might also be a critical factor in the relationship between vitamin D and MS. In a longitudinal study, SoliuHänninen et al., found that MS patients had lower serum total calcium and higher intact PTH levels during spring and winter compared to healthy controls, despite similar 25(OH)D levels (Soliu-Hänninen et al., 2008). Additionally, intact PTH and $25(\mathrm{OH}) \mathrm{D}$ levels were, respectively, higher and lower during relapse when compared to remission.

Contrastingly, our data suggest that serum calcium, PTH, and $1,25(\mathrm{OH})_{2} \mathrm{D}$ are not critically involved in the interaction between vitamin $D$ status and $T$ cell regulation in MS patients. The trend towards correlation of $1,25(\mathrm{OH})_{2} \mathrm{D}$ with Treg suppressive function is likely to be secondary to the strong relationship between $25(\mathrm{OH}) \mathrm{D}$ and $1,25(\mathrm{OH})_{2} \mathrm{D}$. Likewise, the apparent negative correlation between disability and $1,25(\mathrm{OH})_{2} \mathrm{D}$ levels in MS patients that we earlier reported, appeared to be dependent on the correlation of EDSS with serum 25(OH)D in a multiple regression analysis (Smolders et al., 2008b, chapter 3). A patient control study also suggested that the contribution of serum $1,25(\mathrm{OH})_{2} \mathrm{D}$ levels to the risk for developing $\mathrm{MS}$ is limited (Kragt et al., 2009). Several authors proposed a model for interaction between vitamin $D$ status and the immune system, in which activated immune cells, including macrophages and $\mathrm{CD}^{+}{ }^{+} \mathrm{T}$ cells, form high levels of $1,25(\mathrm{OH})_{2} \mathrm{D}$ out of $25(\mathrm{OH}) \mathrm{D}$ at sites of immune activation (Correale et al., 2009). These local levels of $1,25(\mathrm{OH})_{2} \mathrm{D}$ inhibit auto-reactive $\mathrm{T}$ cell activation, promote $\mathrm{T}$ cell regulation, and might subsequently result in a reduced disease activity of MS and a lower risk for developing MS. A recent case report described 3 cases of vitamin D dependent rickets type 1 in combination with MS within one family (Torkildsen et al., 2008). Additionally to a deficiency of serum $1,25(\mathrm{OH})_{2} \mathrm{D}$ levels in these patients, the defect in the 25(OH)D$1 \alpha$-hydroxylase gene also abolishes $1,25(\mathrm{OH})_{2} \mathrm{D}$ formation by activated immune cells. Although speculative, our data suggest the latter mechanism to be most important in the reported association. Royal III et al., reported that the ratio between $1,25(\mathrm{OH})_{2} \mathrm{D}$ and $25(\mathrm{OH}) \mathrm{D}$ correlated with the proportion of Tregs in the CD4 ${ }^{+} \mathrm{T}$ cell compartment (Royal $3^{\text {rd }}$ et al., 2009). We could not reproduce these results in our patient cohort.

The positive correlation of $1,25(\mathrm{OH})_{2} \mathrm{D}$ with the percentage of Th17 cells seems contradictory. Th17 cells have been proposed to be the most important pathogenic cells in MS (Bar Or 2008). Therefore, a positive correlation of serum $1,25(\mathrm{OH})_{2} \mathrm{D}$ levels and these cells suggests a negative effect of vitamin D on MS, which has, however, not been observed in clinical studies (Kragt et al., 2009; Smolders et al., 
2008b, chapter 3). Additionally, the exact significance of IL-17 producing T cells for autoimmune diseases, in the context of $\mathrm{CD}^{+}{ }^{+} \mathrm{T}$ cell plasticity and IL-17 producing Tregs, is at present uncertain (Zhou et al., 2009). Alternatively, several autoimmune disease, including MS, have been associated with a loss of bone mineral density (BMD) (Nieves et al., 1994). Th17 cells have been proposed to promote osteoclast function via IL-17 production, and to establish hereby loss of BMD (Nakashima et al., 2009). Therefore, elevated $1,25(\mathrm{OH})_{2} \mathrm{D}$ values against a background of uncorrelated 25(OH)D levels might also be a result rather than a cause of an increased population of IL-17 producing Th17 cells.

Our study has several limitations. We assessed only a limited amount of markers of calcium metabolism in our cohort. Serum total rather than ionized calcium levels were measured. However, the cohort comprised no severely ill, cachectic or obese patients. Therefore, it is not likely that correction for serum albumin would dramatically affect our results. Lastly, the cohort is, although homogeneous, fairly small.

In conclusion, we found that the earlier reported correlations of Treg function and Th1/Th2 balance with serum 25(OH)D levels, were not accompanied by correlations of these $T$ cell parameters with the serum values of $1,25(\mathrm{OH})_{2} \mathrm{D}, \mathrm{PTH}$, and calcium. These results support the hypothesis that serum $25(\mathrm{OH}) \mathrm{D}$ is important for peripheral T cell regulation in MS in a direct manner, and not via modulating calcium metabolism. At present, intervention studies supplied calcium together with vitamin D. From our study, we conclude that it is questionable whether an elevation of serum calcium levels is critical for the effects of vitamin D on immune regulation and subsequent disease activity of MS. However, to preserve bone mineral density, a sufficient dietary intake of calcium in patients treated with high doses of vitamin D is required. Additionally, our data provide rationale to supplement MS patients with vitamin $\mathrm{D}$, rather than $1,25(\mathrm{OH})_{2} \mathrm{D}$. 


\section{Safety and T cell modulating effects of high dose vitamin $\mathrm{D}_{3}$ supplementation in relapsing remitting multiple sclerosis}

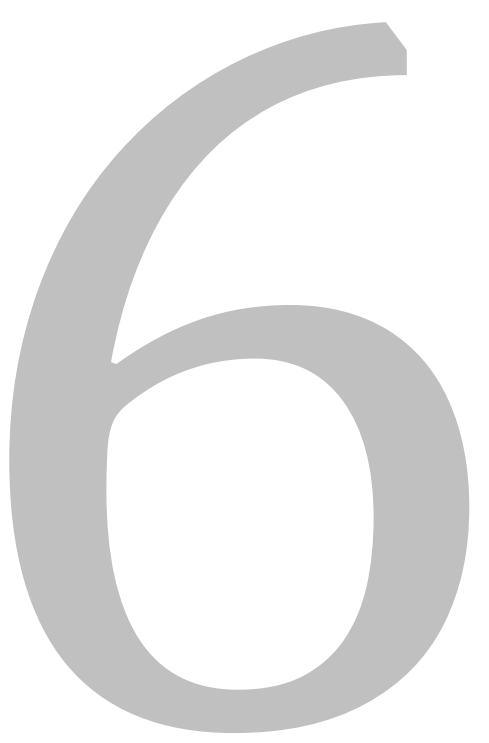

Published as: Joost Smolders, Evelyn Peelen, Mariëlle Thewissen, Jan Willem Cohen Tervaert, Paul Menheere, Raymond Hupperts, Jan Damoiseaux. Safety and T cell modulating effects of high dose vitamin $D_{3}$ supplementation in multiple sclerosis. PLoS One 2010;5:e15235. 


\section{Abstract}

Background: A poor vitamin D status has been associated with a high disease activity of multiple sclerosis (MS). Recently, we described associations between vitamin $D$ status and peripheral T cell characteristics in relapsing remitting MS (RRMS) patients. In the present study, we studied the effects of high dose vitamin $D_{3}$ supplementation on safety and $T$ cell related outcome measures.

Methodology/ Principal Findings: Fifteen RRMS patients were supplemented with 20 $000 \mathrm{IU} / \mathrm{d}$ vitamin $\mathrm{D}_{3}$ for 12 weeks. Vitamin $\mathrm{D}$ and calcium metabolism were carefully monitored, and T cell characteristics were studied by flowcytometry. All patients finished the protocol without side-effects, hypercalcaemia, or hypercalciuria. The median vitamin $D$ status increased from $50 \mathrm{nmol} / \mathrm{L}(31-175)$ at week 0 to 380 $\mathrm{nmol} / \mathrm{L}(151-535)$ at week $12(\mathrm{P}<0.001)$. During the study, 1 patient experienced an exacerbation of MS and was censored from the T cell analysis. The proportions of (naïve and memory) $\mathrm{CD}^{+}$Tregs remained unaffected. Treg suppressive function improved not significanty. An increased proportion of IL-10 ${ }^{+} \mathrm{CD} 4^{+} \mathrm{T}$ cells was found after supplementation. Additionally, a decrease of the ratio between IFN- $\gamma^{+}$and IL$4^{+} \mathrm{CD}^{+} \mathrm{T}$ cells was observed.

Conclusion/ Significance: Twelve week supplementation of high dose vitamin $D_{3}$ in RRMS patients was well tolerated and did not induce decompensation of calcium metabolism. The skewing towards an anti-inflammatory cytokine profile supports the evidence on vitamin D as an immune-modulator, and may be used as outcome measure for upcoming randomized placebo-controlled trials.

Registration: This study was registered at www.clinicaltrials.gov as NCT00940719. 


\section{Introduction}

Multiple Sclerosis (MS) is an inflammatory disease of the central nervous system, probably of autoimmune origin. It is presumed to arise from a combination of genetic and environmental factors (Compston and Coles, 2008). One of the environmental factors which gained much attention during the last decades, is vitamin D. A poor exposure to either vitamin D or sunlight, its most important inducer, has been associated with a high risk of developing MS (Ascherio et al., 2010). The underlying mechanism has not been unravelled yet, but a central role for the actions of vitamin D on immune regulation has been proposed (Hayes et al., 1997; Smolders et al., 2008a, chapter 2). The biologically active metabolite of vitamin $D, 1,25-$ dihydroxyvitamin $\mathrm{D}\left(1,25(\mathrm{OH})_{2} \mathrm{D}\right)$, has potent immune modulating properties, both in vitro and in the experimental animal model of MS, Experimental Autoimmune Encephalomyelitis (EAE) (Correale et al., 2009; Cantorna et al., 1996). In vitro, exposure to $1,25(\mathrm{OH})_{2} \mathrm{D}$ inhibits $\mathrm{CD}^{+} \mathrm{T}$ cell proliferation and pro-inflammatory cytokine production (IFN- $\gamma$ and IL-17), and promotes anti-inflammatory cytokine production (IL-4 and IL-10) and acquisition of regulatory T cell (Treg) phenotype (Smolders et al., 2008a, chapter 2).

Not only incidence, but also disease activity of MS has been associated with vitamin D status. Disability of MS is inversely correlated with vitamin D status [Smolders et al., 2008b, chapter 3; van der Mei et al., 2007], but the causality of this association is uncertain (Ascherio and Munger, 2008). Additionally, a poor vitamin D status has been associated with an increased risk on relapses (Simpson et al., 2010; Smolders et al., 2008b, chapter 3; Soliu-Hänninen et al., 2005). A recent study revealed an increased proportion of relapse free relapsing remitting MS (RRMS) patients in a cohort supplemented with $14000 \mathrm{IU}$ vitamin $\mathrm{D}_{3} / \mathrm{d}$ for 52 weeks (Burton et al., 2010). The immune modulating properties of vitamin $D$ have been proposed to underlie these associations. Supplementation of $1000 \mathrm{IU}$ vitamin $D_{3} / d$ for 6 months induced elevated circulating TGF- $\beta$ levels in MS patients (Mahon et al., 2003). We studied the correlation of vitamin $D$ status with $T$ cell regulatory status in a crosssectional design (Smolders et al., 2009d, chapter 4). Although no correlations with the circulating numbers of $\mathrm{CD}^{+}{ }^{+}$Treg were found, vitamin D status correlated positively with the suppressive capacity of Treg. Additionally, the ratio between proinflammatory IFN $-\gamma^{+}$and anti-inflammatory IL- $4^{+} \mathrm{CD} 4^{+} \mathrm{T}$ cells was higher in RRMS patients with a poor vitamin D status. These associations were independent from the effects of vitamin D on calcium homeostasis (Smolders et al., 2010, chapter 5).

These clinical observations and experimental data on vitamin D and MS warrant the development of well designed clinical trials to assess the disease and immune modulating effects of vitamin D in MS. The aim of the present pilot study was to explore the safety and the in vivo effects on the peripheral T cell compartment of high dose vitamin $\mathrm{D}_{3}$ supplementation in MS. 


\section{Materials and methods}

\subsection{Subjects}

Between October - December 2009, 15 RRMS patients were enrolled (Polman et al., 2005 ). Inclusion criteria were age $>18$ years, disease duration $<6$ years, use of Beta Interferon (IFN- $\beta$ ) $1 a$ or $1 b$, and being relapse free $\geq 6$ weeks prior to enrolment. Exclusion criteria were current use of drugs associated with an increased susceptibility to hypercalcaemia, treatment with immune modulating/ suppressive drugs other than IFN- $\beta \leq 6$ weeks prior to enrolment, pregnancy, hypercalcaemia, serum creatinine $>100 \mu \mathrm{mol} / \mathrm{L}$, and a history of primary hyperparathyroidism, hypercalcaemia, renal dysfunction, cardiac disease, malignancy, or granulomatous disease. Holidays to sunny locations and the use of solariums were not allowed. Continuation of multivitamins containing vitamin $D \leq 600 \mathrm{IU} \mu \mathrm{g} /$ day was allowed. Written informed consent was obtained from each subject. The regional ethical committee 'Atrium-Orbis-Zuyd' and the institutional ' Local Advisory Board on Scientific Research' approved this study. This study is registered at www.clinicaltrials.gov as NCT00940719.

\subsection{Vitamin $D_{3}$ supplementation}

To achieve serum 25-hydroxyvitamin D (25(OH)D) levels comparable to the study by Burton et al. within 12 weeks (Burton et al., 2010), participants were supplemented with $20000 \mathrm{IU}$ vitamin $D_{3} / d$. An oil-based vitamin $D_{3}$ solution in a concentration of $20000 \mathrm{IU} / \mathrm{mL}$ was obtained (Vigantol Oil; Merck Serono, Darmstad, Germany) and patients were instructed to ingest $1 \mathrm{~mL}$ each morning (Maalouf et al., 2008). No dose-escalation was incorporated, no dietary restrictions were imposed, and no additional calcium supplementation was provided. Vitamin $D_{3}$ solution was provided twice for 6 weeks. At the end of week 6 and 12, residual volume of the vitamin $D_{3}$ solution was assessed. Additionally, patients registered their vitamin $D_{3}$ intake daily on a calendar. As a safety follow-up, additional visits were performed at week 16 and 24.

\subsection{Biochemical analysis}

At each study visit, calcium, albumin, and 25(OH)D were measured. Additionally, we periodically measured parathyroid hormone (PTH), creatinine, urea, electrolytes and liver function enzymes [alanine transaminase (ALT), aspartate transaminase (AST), and alkaline phosphatase (ALP)]. A urine sample was obtained the morning of the study visits to determine the ratio between the molar concentrations of calcium and creatinine. We measured PTH on the Immunolite 2500analyzer (Siemens Healthcare Diagnostics, Deerfield, IL, USA). Other serum and urine biochemical analytes were measured on the Beckman DXC880i analyzer (Beckman Coulter, Woerden, The Netherlands). A radioimmunoassay kit (Immunodiagnostic Systems, 
Boldon, UK) was used to measure serum $25(\mathrm{OH}) \mathrm{D}$ and $1,25(\mathrm{OH})_{2} \mathrm{D}$ concentrations. Toxicity of vitamin $D_{3}$ manifests as hypercalcemia (serum total calcium $\geq 2.6$ $\mathrm{mmol} / \mathrm{L}$ ) or hypercalciuria (urinary calcium to creatinine ratio $>1.0 \mathrm{mmol} / \mathrm{L} \mathrm{x}$ $\left.(\mathrm{mmol} / \mathrm{L})^{-1}\right)$ (Kimball et al., 2007).

\subsection{Cell isolation and purification}

Cell isolation was performed as described before (Smolders et al., 2009d, chapter 4). PBMC were isolated by Ficoll gradient centrifugation (Histopaque; Sigma Aldrich, Zwijndrecht, The Netherlands). $\mathrm{CD}^{+} \mathrm{T}$ cells were isolated by negative selection with RosetteSep (Stem Cell Technologies, Grenoble, France). $\mathrm{CD} 4^{+} \mathrm{T}$ cells were incubated at $4^{\circ} \mathrm{C}$ for 30 minutes with anti-CD4-APC (Biolegend, Uithoorn, The Netherlands, \#300514), anti-CD25-PE (BD Biosciences, Breda, The Netherlands, \#555432) and anti-CD127-FITC (E-Bioscience, Hatfield, UK, \#11-1278). Human CD4 ${ }^{+}$CD $25^{+}$CD $127^{-}$ Treg (Liu et al., 2006), and $\mathrm{CD}^{+} \mathrm{CD} 25^{-}$responder T cells (Tresp) were sorted on a FacsAria (BD Biosciences) cell sorter. After the sort, the median proportion $\mathrm{CD}^{+} \mathrm{CD} 25^{+} \mathrm{CD} 127^{-}$cells of all events was $98.9 \%(97.6-99.5)$ in the Treg tube, and the median proportion $\mathrm{CD} 4^{+} \mathrm{CD} 25^{-}$cells was $99.1 \%(91.0-99.6)$ in the Tresp tube. Accessory cells were obtained by irradiating autologous PBMC with 66.2 gray.

\subsection{Proliferation suppression assay}

The CFSE-based proliferation suppression assay was performed as described before (Smolders et al., 2009d, chapter 4). In short, the freshly isolated Tresp were labelled with CFSE (Molecular Probes Invitrogen, Breda, The Netherlands). In a U-bottom 96wells plate, $2 * 10^{4}$ Tresps were stimulated with soluble anti-CD3 $(2.0 \mathrm{pg} / \mathrm{mL}$, WT32 IgG2a monoclonal antibody, kindly provided by dr. W Tax, Radboud University Nijmegen Medical Centre, Nijmegen, The Netherlands) in the presence of $1 * 10^{5}$ irradiated accessory cells. Tresp were co-cultured for 5 days with varying amounts of Treg (Treg/Tresp ratios $0 / 1,0.25 / 1,0.5 / 1,1 / 1$ or $2 / 1$ ). All conditions were performed in triplo in a final volume of $200 \mu \mathrm{L}$. Control conditions were incorporated to validate the assay, including monocultures of un-stimulated Tresp, and of stimulated accessory cells, Treg, and surpluses of Tresp. After culture, cells were stained with anti-CD4-APC and 7AAD (BD Biosciences, \#559925), and the CFSE signal of cells in the $C D 4^{+} 7 A A D^{-}$lymphogate was analysed by flow cytometry on a FACS Canto II flowcytometer (BD Biosciences). Data were analysed with FACS Diva software version 6.1.2. (BD Biosciences). The amount of proliferation achieved in the $0 / 1$ ratio was set at $0 \%$ suppression. The median relative amount of suppression in the Treg/ Tresp co-cultures was calculated. By linear interpolation, the inhibitor ratio (Treg/Tresp) ratio at which $40 \%$ suppression of proliferation was achieved (IR40) was calculated. 


\subsection{T cell phenotyping and cytokine analysis}

Treg were defined as $\mathrm{CD} 25^{+} \mathrm{FoxP}^{+} \mathrm{CD} 4^{+} \mathrm{T}$ cells (Fontenot et al., 2003) and as $\mathrm{CD} 25^{+} \mathrm{CD} 127^{-} \mathrm{CD}^{+} \mathrm{T}$ cells (Liu et al., 2006). Furthermore, CD45RA expression was used to stratify $\mathrm{CD} 25^{+} \mathrm{CD} 127^{-} \mathrm{CD}^{+} \mathrm{T}$ cells for memory (CD45RA) and naïve (CD45RA ${ }^{+}$) Treg (Seddiki et al., 2006). For phenotyping, PBMC were stained with different combinations of anti-CD3-horizon 450 (BD biosciences, \#560365), antiCD3- PerCP (BD biosciences, \#27355), anti-CD4-APC, anti-CD4-PerCP (Biolegend, \#300528), anti-CD25-PECy7 (BD Biosciences, \#54679), anti-CD45RA-PE (BD Biosciences, \#07804), anti-CD127-FITC or anti-FoxP3-PE (E-Bioscience, \#12-4776), and analysed on a FACS Canto II flowcytometer. The absolute number of lymphocytes was determined with a haematological cell counter (Beckman Coulter).

The cytokine profile of $\mathrm{CD}^{+} \mathrm{T}$ cells was determined by assessing the intracellular cytokine pattern of $\mathrm{CD}^{+} \mathrm{CD} 8^{-}$lymphocytes, which are further referred to as $\mathrm{CD} 4^{+}$ T cells, by flowcytometry (Smolders et al., 2009d, chapter 4). PBMC were stimulated for 5 hours with calcium ionomycine (Sigma Aldrich), PMA (Sigma Aldrich) and cytokine excretion was blocked with monensin (BD Biosciences). CD69 expression was included to assess the activation status of the cells. Cells were stained intracellularly with anti-IL-4-PE (Biolegend, \#500704), anti-IFN- $\gamma$-FITC (BD Biosciences, \#340449), anti-IL-17A-PerCP-CY5.5 (Biolegend, \#512314), anti-IL-10-APC (Biolegend, \#501410) and anti-CD69-PE-CY7 (Biolegend, \#310912), and extracellularly with anti-CD3horizon 450 and anti-CD8-APC-H7 (BD Biosciences, \#641400). Samples were analysed on a FACS Canto II flowcytometer.

\subsection{Statistical analysis}

Statistical analysis was conducted with SPSS version 15.0 software (SPSS inc., Chicago IL, USA) and figures were constructed with GraphPad Prism 5 software (GraphPad Software inc., La Jolla CA, USA). The median and corresponding range (min max) are provided for continuous variables. Differences between two related samples (week 0 and 12) were assessed with the Wilcoxon signed-ranks test, the Man Whitney $U$ test was used for unpaired testing. Paired testing was applied unless indicated otherwise. A p-value $<0.05$ was considered statistically significant.

\section{Results}

\subsection{Adverse events and patient compliance}

The characteristics of the 15 participants are shown in Table 1. All patients completed the 12 week supplementation protocol without side effects other than increased flatulence $(N=1)$. Patients reported some beneficial changes, including decreased fatigue $(N=8)$, decreased headache $(N=2)$, decrease in eczematous eruptions $(\mathrm{N}=1)$. During the 12 weeks of supplementation, 1 patient developed a 
relapse of MS, at week 7 of the protocol, which was confirmed by the treating neurologist. This patient was treated with pulsed prednisolone therapy. During the follow-up period, 1 additional patient suffered from an MS relapse (week 19), resulting in a mean annualized relapse rate of 0.27 (SD 0.70) over 24 weeks in this cohort, compared to 0.80 (SD 0.77) in the year prior to this study (Mann Whitney $U$ test $P=0.014)$. No further (serious) adverse events were registered. The median total number of missed days of vitamin $D_{3}$ intake was $0 / 84$ days $(0-5)$, according to the patient's diaries. Measurement of residue in the returned vitamin $D$ bottles revealed a median difference of $-0.2 / 42 \mathrm{~mL}(-8.0-8.0)$ at week 6 , and of $+0.4 / 42$ $\mathrm{mL}(-7.5-5.0)$ at week 12.

Table 1 Patient characteristics.

\begin{tabular}{lll}
\hline & Median/ Category & Min-Max range/ N (\%) \\
\hline Sex & Female & $\mathrm{N}=8(53 \%)$ \\
& Male & $\mathrm{N}=7(47 \%)$ \\
Age & 35.15 year & $25.47-49.36$ \\
MS duration since first symptoms & 3.47 year & $0.63-5.58$ \\
Time since last relapse & 0.96 year & $0.21-3.35$ \\
Number of relapses last 12 months & 1.0 & $0.0-3.0$ \\
EDSS-score* & 2.0 & $0.5-4.0$ \\
IFN- $\beta$ type & Avonex & $\mathrm{N}=3(20 \%)$ \\
& Betaferon & $\mathrm{N}=3(20 \%)$ \\
& Rebif & $\mathrm{N}=9(60 \%)$ \\
Race & Caucasian & $\mathrm{N}=14(93 \%)$ \\
& Hispanic & $\mathrm{N}=1(7 \%)$ \\
\hline
\end{tabular}

*Expanded Disability Status Scale (Kurtzke 1983)

\subsection{Biochemical assessment}

Serum levels of 25(OH)D increased gradually during the study in all patients (Figure 1A). The median level was $50 \mathrm{nmol} / \mathrm{L}(31-175)$ at week 0 , and the serum level 25(OH)D of 2 patients exceeded $100 \mathrm{nmol} / \mathrm{L}$ (109 and $175 \mathrm{nmol} / \mathrm{L}$, respectively). Remarkably, the patient with the highest serum 25(OH)D level used no vitamin supplements. At week 12, the median 25(OH)D levels was $380 \mathrm{nmol} / \mathrm{L}(151-535)$ (P $<0.001)$. Additionally, a rise in serum $1,25(\mathrm{OH})_{2} \mathrm{D}$ levels was observed, which stabilized after 4 weeks (Figure 1B). After 6 weeks of supplementation, a decrease in serum PTH was observed (Table 2). Serum uncorrected and albumin corrected calcium levels were not significantly elevated, and remained below $2.6 \mathrm{mmol} / \mathrm{L}$ in all subjects (Figure 1C). Additionally, no hypercalciuria (urinary calcium to creatinine ratio > 1.0) was observed (Figure 1D). Liver enzyme tests remained unaffected. However, serum creatinine levels gradually increased during vitamin $D_{3}$ supplementation, but remained stable during the follow-up visits (Table 2 ). 


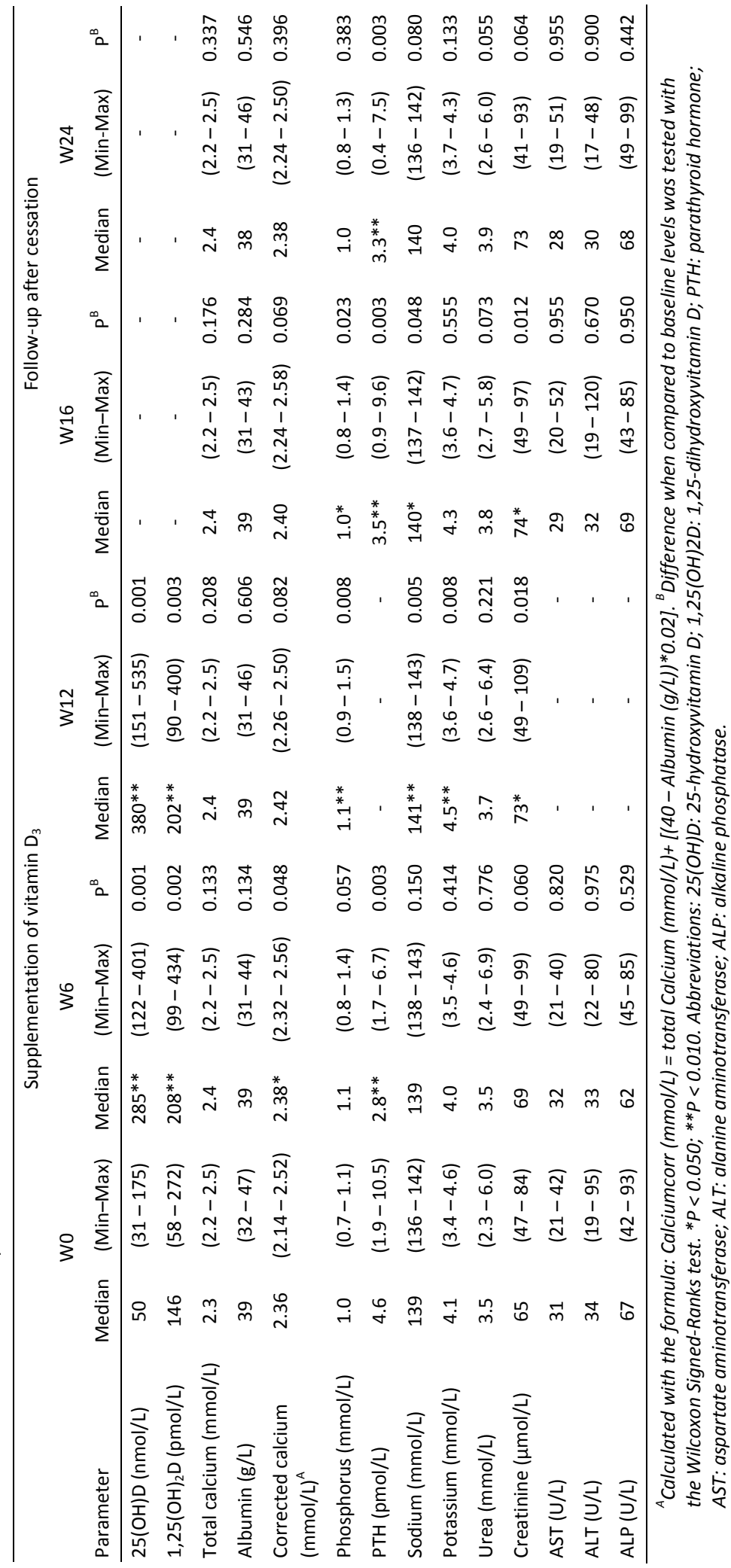


A

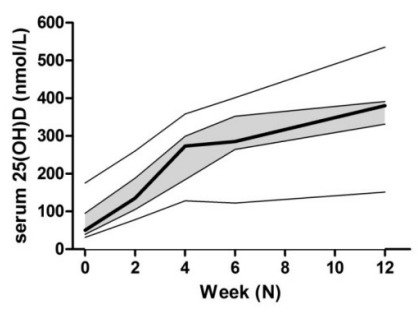

C

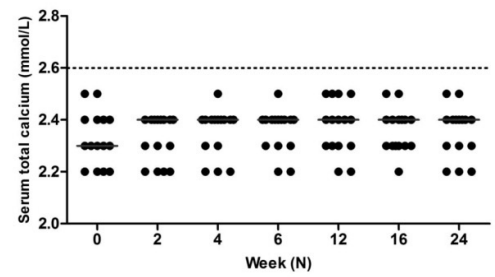

B

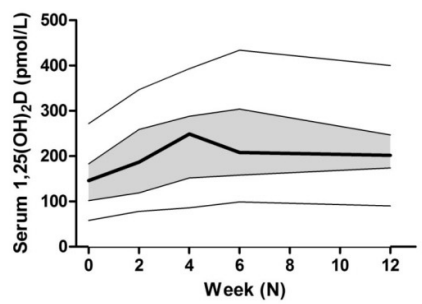

D

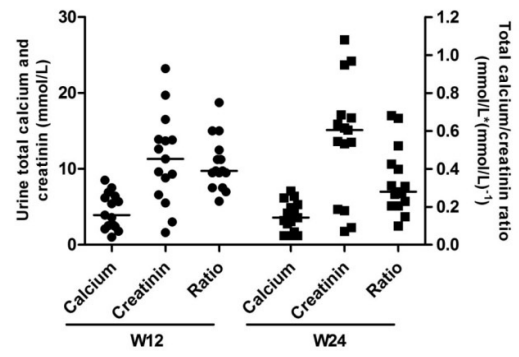

Figure 1 Vitamin $D$ and calcium metabolism during vitamin $D_{3}$ supplementation.

A-B) The serum levels of $25(\mathrm{OH}) \mathrm{D}(\mathrm{A})$ and $1,25(\mathrm{OH})_{2} \mathrm{D}(\mathrm{B})$ are shown for the study visits at week $0,2,4,6$, and 12 . The thick line indicates the median level, the grey zone the interquartile range. The thin lines show the minimum and maximum values. C) Total serum calcium levels at all study visits (week $0,2,4,6,12,16$, and 24). Hypercalcaemia is designated as a serum total calcium level $\geq 2.6 \mathrm{mmol} / \mathrm{L}$. The grey lines indicate the median values. D) Urine levels of total calcium and creatinine levels and their ratio at week 12 and 24 . Hypercalciuria is designated as a urine total calcium $/$ creatinine ratio $>1.0 \mathrm{mmol} / \mathrm{L}^{*}(\mathrm{mmol} / \mathrm{L})^{-1}$. The lines indicate the median values.

\subsection{Regulatory $T$ cell numbers are not affected by vitamin $D$ supplementation}

The difference in composition and function of the $T$ cell compartment between week 0 and week 12 was assessed in the 14 patients that remained relapse-free during the first 12 weeks. No difference was observed in the absolute amount of $\mathrm{T}$ cells in the circulation $\left[1.37 \times 10^{6}(0.91-2.39)\right.$ vs. $1.32 \times 10^{6}(0.90-2.24)$ cells $/ \mathrm{mL}$; $P$ $=0.761)$. PBMC were stained directly ex vivo to determine the proportions of circulating $\mathrm{CD}^{+}$Treg cells (Figure 2A). Week 0 and week 12 proportions of $\mathrm{CD} 25^{+}{ }^{+}$oxP3 ${ }^{+}$ and $\mathrm{CD} 25^{+} \mathrm{CD} 127^{-} \mathrm{CD} 4^{+}$Treg did not differ significantly (Figure 2B-C). Proportions of these two Treg phenotypes correlated well (Pearson $\mathrm{R}=0.891, \mathrm{P}<0.001 ; \mathrm{ICC}=$ $0.872, \mathrm{P}<0.001)$, and $74.03 \%(52.09-89.75)$ of $\mathrm{CD} 25^{+} \mathrm{CD} 127^{-}$Treg was FoxP3 ${ }^{+}$. The expression of CD45RA was used to stratify Treg for CD45RA ${ }^{+}$naïve and CD45RA memory Treg (Figure 2A). There was no difference in the circulating proportions of both naïve and memory Treg between week 0 and week 12 (Figure 2D). 

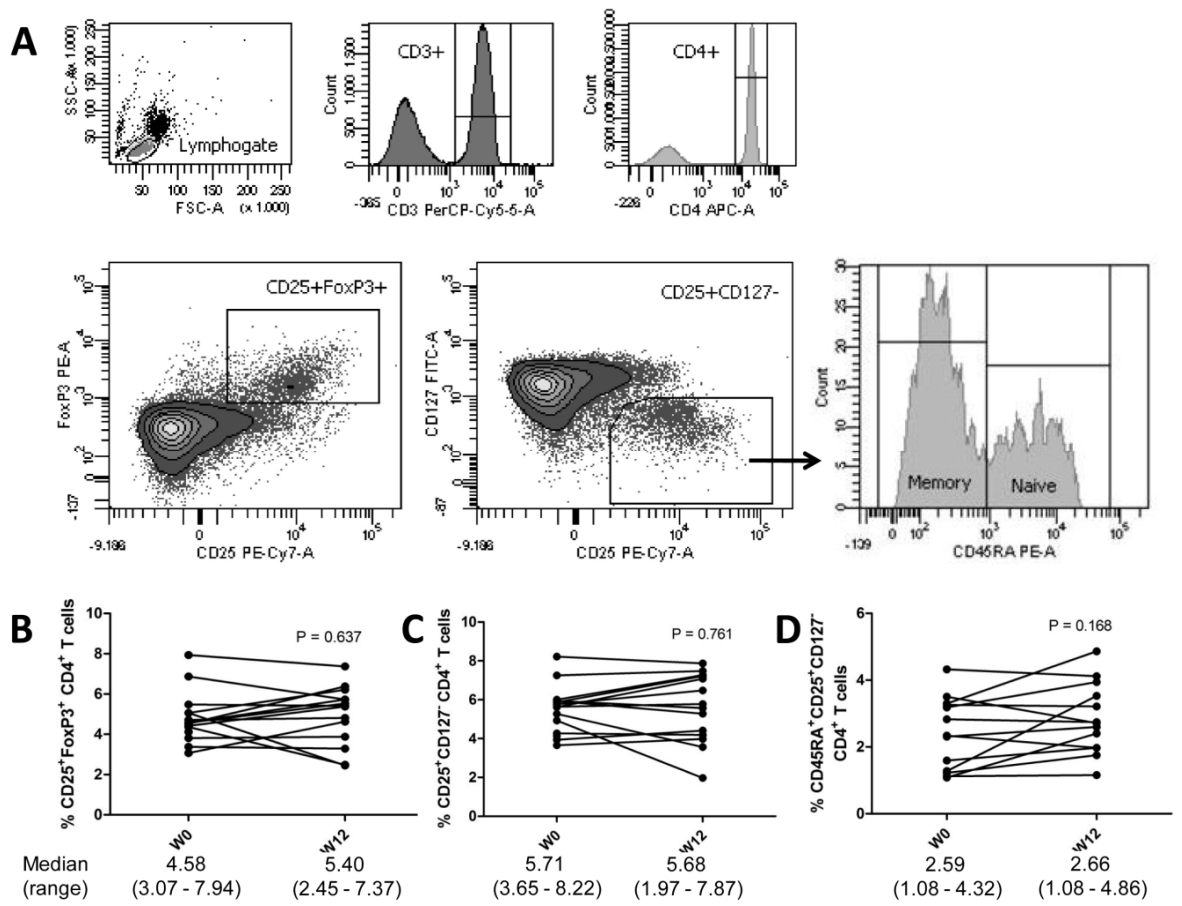

Figure 2 Phenotypic analysis of circulating regulatory T cells (Treg).

A) Isolated PBMC were analyzed directly ex-vivo by flow cytometry. In the lymphogate, $\mathrm{CD}^{+} \mathrm{CD}^{+}$cells were assessed for the proportions of $\mathrm{CD}_{2} 5^{+}$FoxP $3^{+}$and $\mathrm{CD} 25^{+} \mathrm{CD} 127^{-}$Treg cells. Expression of CD45RA was analyzed to phenotype naïve (CD45RA ${ }^{+}$) and memory (CD45RA) Treg. B-D) The proportions of circulating $\mathrm{CD} 25^{+} \mathrm{FoxP}^{+}$(B) and $\mathrm{CD} 25^{+} \mathrm{CD} 127^{-}$(C)Treg, and of naive Treg (D) before and after vitamin $D_{3}$ supplementation (week 0 and 12 ). Significance was assessed with the Wilcoxon signed ranks comparison test.

\subsection{No significant improvement of regulatory $T$ cell suppressive function}

The suppressive capacity of Treg was assessed ex-vivo in a proliferation suppression assay. Of 1 patient, Tresp cells were anergic to anti-CD3 stimulation at week 0 . Of the remaining 13 patients, a proliferation suppression assay was acquired at week 0 and week 12. No difference was observed in the amount of Tresp cell proliferation in the culture system [82.8\% (53.9 - 93.3) vs. 83.4\% (64.0-96.3); $P=0.848]$. At both time points, an increasing suppression of Tresp proliferation was seen with increasing Treg/Tresp ratio (Figure 3). At week 0 , the median IR40 was at a Treg/Tresp ratio of $0.79(0.37-1.31)$. At week 12 , the median IR40 was at $0.48(0.29$ - 1.27) (Mann Whitney $U$ test $P=0.090$ ). However, there was no statistically signifycant improvement of Treg suppressive function $(P=0.143)$. Baseline $25(\mathrm{OH}) \mathrm{D}$ levels did not differ significantly between improving and non-improving subjects (49 nmol/L (39-109) vs. $74 \mathrm{nmol} / \mathrm{L}(48-104)$, respectively; $\mathrm{P}=0.260)$. However, nonimproving subjects tended to have better suppression at week 0 when compared to 
improving subjects (IR40 $0.51(0.37-0.99)$ vs. $0.86(0.49-1.31)$, respectively; $\mathrm{P}=$ 0.076).

A
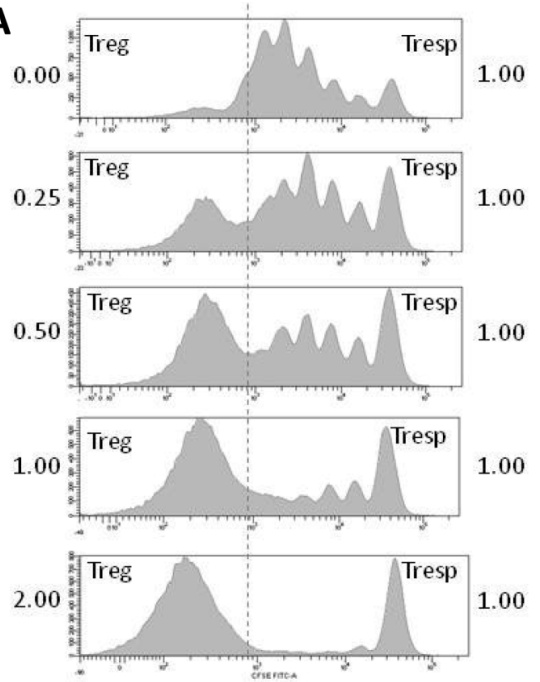

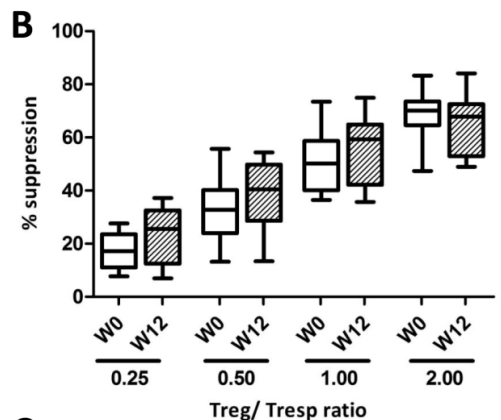

C

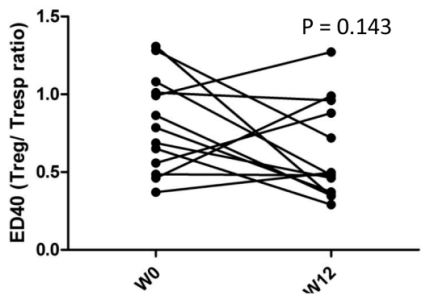

Figure 3 Regulatory T cell suppressive function.

A) A representative example of the CFSE signal in the CD4 ${ }^{+} 7 A A D^{-}$lymphogate. The upper panel $(0.00)$ shows proliferation of Tresp cells without Treg. Co-culture with an increasing proportion of Treg results in an inhibition of Tresp cell proliferation (downward panels, ratio 0.25:1, 0.5:1, 1:1 and 2:1, respectively). An increasing proportion of CFSE Treg can be observed, and a subsequent decrease of proliferating CFSE ${ }^{+}$Tresp cells. Between the Treg/Tresp ratio 0.25 and 2.0, all patients achieved at both time points (week 0 and 12) $40 \%$ suppression of proliferation (IR40). B) The box and whisker plots show the suppression at each Treg/ Tresp ratio before (week 0, open boxes) and after supplementation (week 12, dashed boxes). The boxes show the interquartile range, the whiskers the minimum and maximum value. C) IR40 before and after vitamin $D_{3}$ supplementation (week 0 and 12).

\section{5 $\mathrm{CD}^{+} \mathrm{T}$ cell cytokine profile shifts from pro- to anti-inflammatory}

The cytokine profile of the $\mathrm{CD}^{+} \mathrm{T}$ cells was assessed with an intracellular FACSstaining (Figure 4A). Cytokines of interest were IFN- $\gamma$ (Th1 cytokine), IL-17 (Th17 cytokine), IL-4 (Th2 cytokine) and IL-10 (regulatory cytokine). The efficacy of stimulation, as evaluated by the expression level of the activation marker CD69, was comparable between week 0 and 12 (median MFI = 91030 (45 $880-169$ 520) and 88580 (56 $550-123710$ ), respectively). When week 0 and 12 were compared, no difference was observed in the proportions of $\mathrm{CD}^{+} \mathrm{T}$ cells positive for IFN- $\gamma[7.82 \%$ $(3.45-12.74)$ vs. $6.51 \%(1.07-14.66)]$, IL-17 [0.90\% (0.50 - 2.09) vs. $0.85 \%(0.16-$ $2.19)]$, or IL-4 $(2.04 \%(0.80-3.62)$ vs. $2.37 \%(0.88-4.21)]$. However, the proportion of IL- $10^{+} \mathrm{CD}^{+} \mathrm{T}$ cells was significantly increased $[0.36 \%(0.20-0.95)$ vs. $0.69 \%(0.13$ -1.14 ); $P=0.021$ ] (Figure 4B). When the Th1/ Th2 balance was assessed, we found 
that the IFN- $\gamma^{+} / \mathrm{IL}-4^{+}$balance was decreased after supplementation [3.68 (1.86 10.76 ) vs. 2.98 (0.71-5.55); $P=0.035$ ] (Figure $4 C$ ).
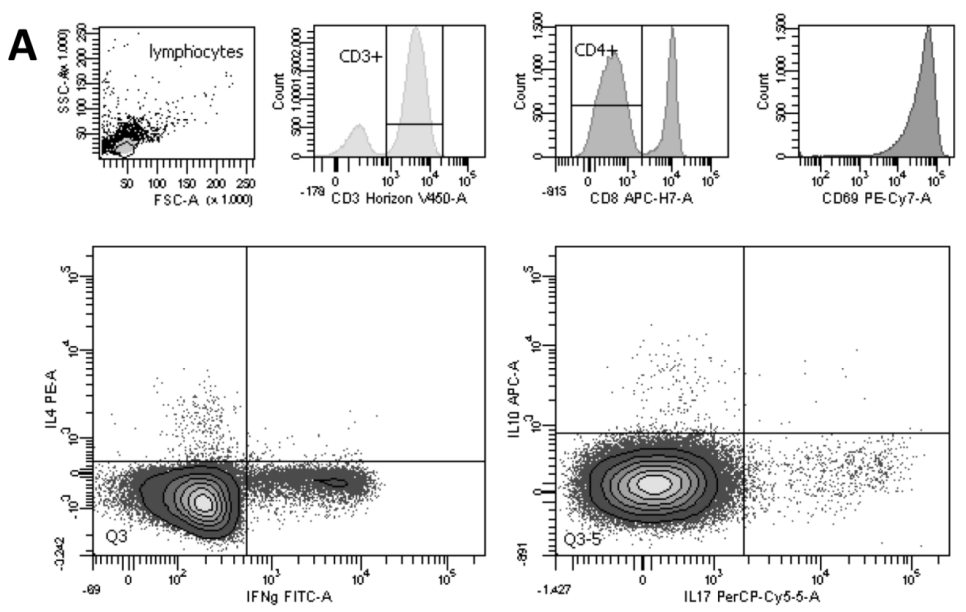

B

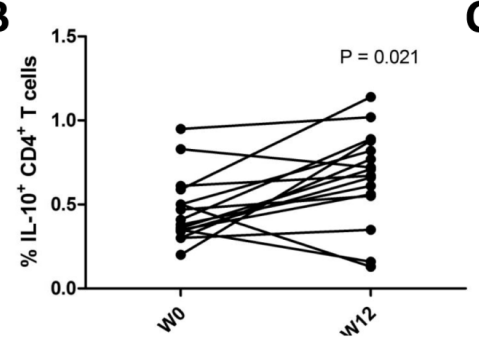

$\mathrm{C}$

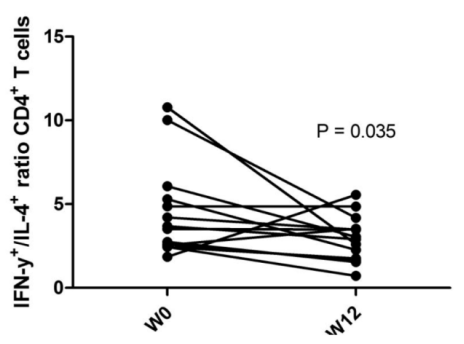

Figure 4 Thelper cell cytokine profiles.

A) One million PBMC were stimulated for 5 hours with PMA and calcium ionomycin in the presence of monensin, and subsequently stained for flow cytometric analysis. In the lymphogate, $\mathrm{CD} 3^{+} \mathrm{CD} 8$ cells were assessed for the proportions of IFN- $\gamma^{+}, \mathrm{IL}-4^{+}, \mathrm{IL}-17^{+}$and IL-10 $10^{+}$ cells. CD69 was included to evaluate activation. B) The proportions of $\mathrm{IL}-10^{+} \mathrm{CD}^{+} \mathrm{T}$ cells before and after supplementation. C) The ratio between Th1 (IFN- $\left.\gamma^{+}\right)$and Th2 $\left(\right.$IL- $\left.-4^{+}\right)$cells before and after supplementation. Significance was assessed with the Wilcoxon signed ranks comparison test.

\section{Discussion}

In this study, the effects of high dose vitamin $D_{3}$ supplementation on safety and $T$ cell parameters in patients with RRMS were assessed. We observed that supplementation of $20000 \mathrm{IU} / \mathrm{d}$ vitamin $\mathrm{D}_{3}$ for 12 weeks was without negative side-effects and without decompensation of calcium metabolism (i.e. hypercalcaemia and hypercalciuria). The number of Treg remained unaffected, as well as the numbers of Treg memory and naïve subtypes. Results regarding Treg suppressive capacity were inconclusive. A shift was observed in the cytokine profiles of $\mathrm{CD} 4^{+} \mathrm{T}$ cells, with a 
relative decline in pro-inflammatory $\left(\right.$ IFN- $\left.\gamma^{+}\right)$and a relative increase in antiinflammatory (IL-4 $4^{+}$and IL-10 $\left.{ }^{+}\right) \mathrm{CD}^{+} \mathrm{T}$ cells. These results further add to the notion that vitamin $\mathrm{D}$ is a physiological immune modulator in vivo. Monitoring the cytokine profile of CD4+ T cells could be a valuable tool to assess the immunological efficacy of vitamin $D_{3}$ in randomized controlled clinical trials on vitamin $D$ supplementation in patients with MS.

This study confirmed that supplementation of high doses vitamin $D_{3}$ does not induce a decompensation of calcium metabolism in patients with MS (Burton et al., 2008; Kimball et al., 2007). Without a dose-escalation supplementation scheme, we did not detect hypercalcaemia or hypercalciuria. The slight non-significant increase in serum calcium and phosphorus most likely reflects a correction of vitamin D insufficiency in this cohort. A gradual increase in serum creatinine levels was observed during vitamin $D_{3}$ supplementation, which however remained below $110 \mu \mathrm{mol} / \mathrm{L}$ in all patients. The dramatic complication of a hypercalcaemia associated decrease of glomerular filtration rate (GFR) is unlikely, since neither hypercalcaemia nor hypercalciuria was detected. Earlier dose-escalation trials supplementing up to 280000 IU/w for 28 weeks and up to 40000 IU for 52 weeks did not report either significant elevations of serum creatinine levels, or calcifications in the kidneys (Burton et al., 2008; Kimball et al., 2007). Interestingly, however, earlier reports described a rise in serum creatinine which was not accompanied by a decreased GFR in patients treated with $1,25(\mathrm{OH})_{2} \mathrm{D}$ or $1 \alpha(\mathrm{OH}) \mathrm{D}$ (Andreev et al., 1992). Physiologically, 25(OH)D is filtrated in complex with vitamin $\mathrm{D}$ binding protein (DBP) by the glomeruli and reabsorbed by proximal tubular epithelial cells (Doorenbos et al., 2009). Interestingly, creatinine is being secreted in the proximal renal tubuli as well. We postulate that a massive increase of $25(\mathrm{OH}) \mathrm{D}-\mathrm{DBP}$ complex reabsorbtion competes with tubular creatinine excretion and hereby increases serum creatinine levels. Although we believe that the increased serum creatinine levels do not reflect a decreased GFR, future studies on massive dose vitamin $D$ supplementation should be cautious towards patients with an impaired kidney function. On the whole, biochemical data show the absence of vitamin $D_{3}$ toxicity in participants of this study.

We found no effect of vitamin D supplementation on the number of Treg in the circulation. In MS, the function rather than the number of Treg has been reported to be impaired (Venken et al., 2006; Viglietta et al., 2004), and to relate with serum 25(OH)D levels (Smolders et al., 2009d, chapter 4). Additionally, other immune modulating therapies also have been shown to improve Treg function rather than Treg numbers (Haas et al., 2009; Korporal et al., 2008). An expansion of naïve Treg has been described in Glatiramer Acetate treatment (Haas et al., 2009), and a decrease of memory Treg cells in IFN- $\beta$ treatment (Korporal et al., 2008). Therefore, we also assessed these Treg subsets, but found no effect of vitamin $D_{3}$ supplementation on the proportions of naïve and memory Treg. 
Previously, we observed a correlation of Treg suppressive capacity with serum 25(OH)D levels (Smolders et al., 2009d, chapter 4). Although Treg suppressive function was improved in a proportion of patients after 12 weeks of vitamin $D_{3}$ supplementation, this improvement was not statistically significant. The size of the cohort assessed is most likely too small to detect a difference in this complex assay. Alternatively, one could speculate from our previous work that only in the patients with the poorest vitamin D statuses, an improved suppression can be expected (Smolders et al., 2009d, chapter 4). Although vitamin D statuses at week 0 were lower in the 9 improving patients when compared to the 4 non-improving patients, the difference was not significant. Additionally, Treg suppressive function is not impaired in all RRMS patients, especially when treated with IFN- $\beta$ (Haas et al., 2009; Korporal et al., 2008; Michel et al., 2008; Venken et al., 2006). Therefore, it can be speculated that an adequate Treg function cannot be improved further on vitamin $D_{3}$ supplementation. Indeed, the patients of whom Treg suppressive function improved tended to have a poorer suppression at week 0 . Altogether, the data collected in this study regarding Treg suppressive function remain inconclusive.

A significant effect on the composition of the $T$ helper cell compartment was detected. The ratio of IFN- $\gamma^{+} / \mathrm{IL}-4^{+} \mathrm{CD} 4^{+} \mathrm{T}$ cells represents the balance between proinflammatory Th1 and anti-inflammatory Th2 cells, and is regarded an important variable in autoimmune diseases (Abbas et al., 1996). During supplementation, this ratio changed towards a less pro-inflammatory profile. This is in accordance with previous cross-sectional findings (Smolders et al., 2009d, chapter 4). Interestingly, we detected also more IL-10 ${ }^{+} \mathrm{CD}^{+} \mathrm{T}$ cells after supplementation. The source of IL10 ${ }^{+}$cells in the $\mathrm{CD}^{+} \mathrm{T}$ cell compartment may be the T regulatory cell type $1(\operatorname{Tr} 1)$ (Moore et al., 2001). Alternatively, IL-10 has also been proposed to be a typical Th2 cytokine. However, we measured no double producers of IL-10 and the (other) typical Th2 cytokine IL-4 (data not shown). Therefore, we speculate that the rise in IL$10^{+} \mathrm{CD}^{+} \mathrm{T}$ cells might reflect expansion of inducible regulatory $\operatorname{Tr} 1$ cells. The finding of a decreased ratio between pro- and anti-inflammatory $\mathrm{CD}^{+}{ }^{+} \mathrm{T}$ cells conforms to observations in experimental studies (Correale et al., 2009) and further supports the assessment of vitamin $D_{3}$ as a natural immune modulator in MS (Hayes et al., 1997).

Although the present study did not comprise a placebo-group, it delivered valuable new information. We earlier performed a cross-sectional study, in which serum 25(OH)D levels correlated with peripheral T cell homeostasis (Smolders et al., 2009d, chapter 4). However, the cross-sectional design did not allow statements on causality, since physical exercise and UV exposure per se could be the real underlying mediators (Becklund et al., 2010). Our current study revealed 25(OH)D as a good causal candidate. Ultimately, however, placebo controlled studies should demonstrate whether vitamin $D_{3}$ is an immune modulator in vivo. Regarding these upcoming trials, it is also of interest that we included patients treated with immune modulating drugs (IFN- $\beta$ ). Interestingly, therapy with $1,25(\mathrm{OH})_{2} \mathrm{D}$ showed synergistic ef- 
fects with IFN- $\beta$ in an EAE model of MS (van Etten et al., 2007). Upcoming clinical trials will most likely assess add-on effects of vitamin $D_{3}$ on current immune modulating drugs. The present study suggests that an add-on immune modulating effect of vitamin $D_{3}$ on top of IFN- $\beta$ is a feasible outcome measure.

In conclusion, we showed in a cohort of RRMS patients that supplementation of high doses vitamin $D_{3}$ did not result in a decompensated calcium metabolism. Additionally, vitamin $\mathrm{D}_{3}$ appeared to skew the $\mathrm{CD} 4^{+} \mathrm{T}$ cell compartment to a more pronounced anti-inflammatory state. Herewith, we confirmed that the peripheral CD4 ${ }^{+}$ T cell compartment is a potentially important outcome measure in upcoming randomized controlled clinical trials. Ultimately, these trials should demonstrate whether vitamin $D_{3}$ is an immune and disease modulating compound in MS.

\section{Acknowledgements}

The authors thank MS nurses Tiny Kempkens, Judith Poeth, and Ingrid Mevissen (all Orbis Medical Center, Sittard, The Netherlands) for their help with patient inclusion and follow-up, clinical chemists dr. Mario Vogt and dr. Joop ten Kate (both Orbis Medical Center), and hospital pharmacist dr. Rob Janknegt (Orbis Medical Center) for their collaboration, and technicians Jozien Jaspers-Spits, Henk van Rie and Mark Willems (all Maastricht University Medical Center, Maastricht, The Netherlands) for their skilled technical assistance with the immunological assays. 



\section{Fok-I vitamin D receptor gene polymorphism (rs10735810) and vitamin D metabolism in multiple sclerosis}

Published as: Joost Smolders, Jan Damoiseaux, Paul Menheere, Jan Willem Cohen Tervaert, Raymond Hupperts. Fok-I vitamin $D$ receptor gene polymorphism (rs10735810) and vitamin D metabolism in multiple sclerosis. Journal of Neuroimmunology 2009;207:117-121. 


\section{Abstract}

Multiple sclerosis (MS) has been associated with low serum levels of 25-hydroxyvitamin D (25(OH)D). Several genetic polymorphisms of the vitamin D receptor gene (VDRG), of whom Fok-I (rs10735810) has functional consequences for receptor protein structure, have been studied in relation to MS with variable results. The purpose of our study was to assess an association of the Fok-I VDRG polymorphism with MS, and to further unravel the interaction of this polymorphism with vitamin $D$ metabolism. Therefore, we genotyped $212 \mathrm{MS}$ patients and 289 healthy controls for the Fok-I polymorphism and determined levels of the vitamin D metabolites $25(\mathrm{OH}) \mathrm{D}$ and $1,25(\mathrm{OH})_{2} \mathrm{D}$. No association of the Fok-I VDRG polymorphism with MS was found. The F-allele was associated with lower winter and summer serum 25(OH)D levels in our MS patients, and with lower 25(OH)D levels in healthy controls. Remarkably, the F-allele corresponded with higher $1,25(\mathrm{OH})_{2} \mathrm{D}$ levels in MS patients. In all groups, carriers of the F-allele had higher $1,25(\mathrm{OH})_{2} \mathrm{D} / 25(\mathrm{OH}) \mathrm{D}$-ratios compared to their f-allele counterparts. In conclusion, we demonstrated the functional consequences of the Fok-I VDRG polymorphism for vitamin D metabolism. This should be taken into account in association and ultimately intervention studies on vitamin D and MS. 


\section{Introduction}

Limited vitamin $D$ exposure is considered to be an environmental risk factor for developing multiple sclerosis (MS) (Smolders et al., 2008a, chapter 2). Twenty-fivehydroxyvitamin $D(25(O H) D)$ is the principal vitamin $D$ metabolite in serum, and is widely used to determine the vitamin D status of an individual (Hollis 1996). Low serum levels of 25(OH)D in adolescence are associated with an increased risk of developing MS in a white American population (Munger et al., 2006). Limited sunlight exposure, the principal source of vitamin D synthesis, is associated with a high risk for MS in American, Tasmanian and Norwegian populations (Islam et al., 2007; Kampman et al., 2007; van der Mei et al., 2003). One of the genetic factors contributing to this risk, might be the genetic constitution of the vitamin D receptor (VDR), the receptor for the biologically active metabolite of vitamin $D, 1,25-$ dihydroxyvitamin $\mathrm{D}\left(1,25(\mathrm{OH})_{2} \mathrm{D}\right)$.

The vitamin D receptor gene (VDRG) is located on chromosome 12q 12-14. Various single nucleotide polymorphisms (SNP's) in the VDRG have been described. The most frequently studied in MS are usually referred to by the names of the digestion enzymes used for genotyping. The polymorphisms Apa-I (rs7975232), Bsm-I (rs1544410) and Taq-I (rs731236) are located in an intron near the $3^{\prime}$ end, and the polymorphism Fok-I (rs10735810) in an exon near the 5' end of the VDRG. The Fok-I polymorphism leads to a 3 amino-acids longer VDR protein by directly introducing a start codon. A functional impact of this polymorphism on the immune response has been demonstrated (Colin et al., 2000; van Etten et al., 2007). The biological consequences of the other polymorphisms are less certain.

Several studies have addressed the association of these VDRG polymorphisms with MS, with variable results (Fukazawa et al., 1999; Niino et al., 2000; Partridge et al., 2004; Steckley et al., 2000; Tajouri et al., 2005; Yeo et al., 2004). Since the studies in which an association was reported were performed in a subtropical area with much sunlight (Tajouri et al., 2005), and an area where the diet contains large amounts of fat fish (Fukazawa et al., 1999; Niino et al., 2000), these populations were presumably exposed to relatively large environmental supplies of vitamin D. We hypothesized that an association of a VDRG polymorphism with MS might only be penetrant in a population with an adequate vitamin $D$ exposition. We determined the VDRG polymorphism and 25(OH)D levels in patients and controls, in order to assess a possible association with selective inclusion of patients with an adequate vitamin $D$ status. However, upon validation of this approach, there appeared a direct interaction of the polymorphism with vitamin $D$ metabolism.

This study had several purposes. First of all, a possible association of the Fok-I VDRG polymorphism with MS was assessed in our population. Secondly, we investigated an association of the Fok-I polymorphism with $25(\mathrm{OH}) \mathrm{D}$ levels in a large population. In order to further evaluate the consequences of the polymorphism for vita- 
min D metabolism, we also assessed an association of the Fok-I VDRG polymorphism with serum levels of the biologically active metabolite of vitamin $D$, $1,25(\mathrm{OH})_{2} \mathrm{D}$. To limit the effect of seasonal fluctuation of vitamin D photosynthesis, these associations were assessed both in summer and in winter period.

\section{Subjects and Methods}

\subsection{Population}

Two-hundred and twelve patients with clinically and MRI-confirmed MS (McDonald et al., 2001) and 289 healthy community controls were included in this study, after informed consent was acquired. The characteristics these two cohorts are shown in Table 1. Patients and controls all lived in the southern part of the Netherlands (latitude $50^{\circ} \mathrm{N}-51^{\circ} \mathrm{N}$ ). This project was approved by the local medical ethics committee.

Table 1 Population characteristics of the MS and control population.

\begin{tabular}{llcccc}
\hline & & \multicolumn{2}{c}{$\begin{array}{c}\text { Patients } \\
(n=212)\end{array}$} & \multicolumn{2}{c}{ Healthy Controls } \\
& & N/Mean & $\% / S D$ & N/Mean & $\% / S D$ \\
\hline Sex & M & 62 & $29.2 \%$ & 138 & $50.2 \%$ \\
MS phenotype & RRMS & 150 & $70.8 \%$ & 137 & $49.8 \%$ \\
& SPMS & 97 & $45.8 \%$ & & \\
& PPMS & 72 & $34.0 \%$ & & \\
& Unknown & 38 & $17.9 \%$ & & \\
Age (years) & 5 & $2.4 \%$ & & \\
MS duration (years) & & 46.7 & \pm 11.9 & & \\
EDSS-score & 12.7 & 4.24 & \pm 9.92 & & \\
\hline
\end{tabular}

Values are presented either as absolute number with corresponding percentage (\%), or as mean value with corresponding standard deviation ( \pm ). EDSS: Expanded Disability Status Scale; RRMS: relapsing remitting MS; SPMS: secondary progressive MS; PPMS: primary progressive MS.

\subsection{Clinical and biochemical parameters.}

Blood samples of our MS patients were collected in summer (from May to October) and winter (from November to April). Plasma samples were available only of a limited amount of healthy controls $(\mathrm{N}=133)$ and the exact dates of blood collection were not known. The serum 25(OH)D and 1,25(OH) $)_{2} \mathrm{D}$ levels were determined as previously described (Smolders et al., 2008b, chapter 3). We described the relationship between these metabolites as ratios $\left(1000 \times 1,25(\mathrm{OH})_{2} \mathrm{D} / 25(\mathrm{OH}) \mathrm{D}\right)$. Parameters such as sex, age, clinical MS-phenotype $(\mathrm{RR}=$ relapsing remitting, $\mathrm{SP}=$ secondary progressive, $\mathrm{PP}=$ primary progressive, unknown), disease course and Expanded 
Disability Status Scale (EDSS)-score at the time of serum sampling were collected from our patient-database.

\subsection{Genotyping}

DNA was extracted from peripheral blood leukocytes with a High Pure PCR Preparation Kit (Roche, Woerden, The Netherlands) following the manufacturer's instructions, and stored at $-20^{\circ} \mathrm{C}$. The Fok-I polymorphism was determined by a previously described method (Tajouri et al., 2005). In brief, the regions were amplified by a polymerase chain reaction with normal unlabeled nucleotides. The amplicon was digested with the Fok-I restriction enzyme (Roche, Woerden, The Netherlands) and electrophoresed on a gelstar-stained $2 \%$ agarose gel. The presence of a restriction site was represented by the lowercase (' $f$ ', nucleotide A), and its absence by the uppercase ('F', nucleotide G) allele.

\subsection{Statistics}

Genotype and allele frequencies were calculated from the analysed genotypes. SPSS-software (version 12.0, SPSS Inc., California, USA) was used for analysis. Deviation from Hardy-Weinberg equilibrium (HWE; $P<0.05$ ) was tested with the $\chi^{2}$ test. The relationship between VDR genotype or allele frequency and MS was tested in a logistic regression model, adjusted for age (years) and sex (male/ female) by introducing them simultaneously in the model. Results are presented as odds ratios (OR) with $95 \%$ confidence intervals $(95 \% \mathrm{Cl})$. The relationship between Fok-I VDR genotype and vitamin D metabolite levels was tested in a linear regression model. Unequally distributed metabolite values (Lilliefors corrected Kolmogorov-Smirmov test $P<0.05)$ were log-transformed. We adjusted this relationship for confounders, by introducing them simultaneously in the model. Confounders of the relationship between 25(OH)D and Fok-I VDR genotype were age, sex and EDSS-score (Smolders et al., 2008b, chapter 3). The relationship between $1,25(\mathrm{OH})_{2} \mathrm{D}$ and Fok-I VDR genotype was adjusted for age, sex and vitamin D status (25(OH)D-levels) (Smolders et al., 2008b, chapter 3). Results are presented as regression coefficients (C) with $95 \%$ $\mathrm{Cl}$. Variation in the $1,25(\mathrm{OH})_{2} \mathrm{D} / 25(\mathrm{OH}) \mathrm{D}$-ratios was assessed with an analysis of variance (ANOVA). A two-sided $\mathrm{P}$-value $<0.050$ was considered significant.

\section{Results}

\subsection{No association of Fok-I VDR genotype with MS}

The genotype and allele-frequencies of the Fok-I VDRG polymorphism in the whole MS and control populations are described in Table 2. Both cohorts were in HardyWeinberg equilibrium. There was no difference in the distribution of genotypes or alleles between patients and controls. 
Table 2 Distribution of the Fok-I vitamin D receptor gene polymorphism in MS patients and in healthy controls.

\begin{tabular}{|c|c|c|c|c|c|c|}
\hline & \multicolumn{2}{|c|}{$\begin{array}{l}\text { Patients } \\
(n=212)\end{array}$} & \multicolumn{2}{|c|}{$\begin{array}{l}\text { Healthy controls } \\
\qquad(n=289)\end{array}$} & \multirow[b]{2}{*}{ OR } & \multirow[b]{2}{*}{$(95 \% \mathrm{Cl})$} \\
\hline & $\mathrm{N}$ & $\%$ & $\mathrm{~N}$ & $\%$ & & \\
\hline$F / F$ & 79 & $37.3 \%$ & 113 & $39.1 \%$ & 1.015 & $(0.649-1.588)$ \\
\hline$F / f$ & 103 & $48.6 \%$ & 134 & $46.4 \%$ & 1.002 & $(0.647-1.553)$ \\
\hline$f / f$ & 30 & $24.1 \%$ & 42 & $14.5 \%$ & 0.966 & $(0.516-1.811)$ \\
\hline $\mathrm{F}$ & 261 & $61.6 \%$ & 360 & $62.3 \%$ & 1.027 & $(0.552-1.406)$ \\
\hline \multirow[t]{3}{*}{$f$} & 163 & $38.4 \%$ & 218 & $37.7 \%$ & 0.974 & $(0.711-1.336)$ \\
\hline & HWE & & HWE & & & \\
\hline & $P=0.77$ & & $P=0.90$ & & & \\
\hline
\end{tabular}

HWE: Hardy-Weinberg equilibrium; OR: age- and sex adjusted odds-ratios with corresponding $95 \%$ confidence intervals

Next, we intended to identify a possible association between the Fok-I VDRG polymorphism and MS by selective inclusion of patients with an adequate vitamin $D$ status. However, since a possible association between 25(OH)D levels and the Fok-I VDRG polymorphism could be a confounder, we further explored the association of the polymorphism with the two vitamin D metabolites.

\subsection{Association of Fok-I VDR genotype with 25(OH)D levels in MS patients.}

In the MS cohort, carriers of two F-alleles had both lower summer and winter serum 25(OH)D levels than carriers of two f-alleles (Figure 1). The Fok-I genotype was a significant predictor of summer $25(\mathrm{OH}) \mathrm{D}$ level $(\mathrm{C}=7.109,95 \% \mathrm{Cl} 0.935-13.283, \mathrm{P}=$ $0.024)$. The association with log-transformed winter 25(OH)D level did not reach significance $(\mathrm{C}=0.038,95 \% \mathrm{Cl}-0.006-0.081, \mathrm{P}=0.088)$. Since $25(\mathrm{OH}) \mathrm{D}$ status is associated with the level of disability in MS patients, we adjusted our analysis for EDSS-score, and found that both summer $(\mathrm{C}=8.338,95 \% \mathrm{Cl} 2.547-14.129, \mathrm{P}=$ 0.005 ) and log-transformed winter 25(OH)D levels $(C=0.043,95 \% \mathrm{Cl} 0.001-0.085$, $\mathrm{P}=0.043$ ) were significantly associated with Fok-I VDR genotype.

\subsection{Association of Fok-I VDR genotype with 25(OH)D levels in healthy controls.}

In the healthy controls, carriers of an F-allele had also lower 25(OH)D levels (Figure 1), and the Fok-I VDR genotype was found to be a significant predictor of 25(OH)D levels ( $C=6.388,95 \% \mathrm{Cl} 0.841-11.936, \mathrm{P}=0.024)$.

\subsection{Association of Fok-I VDR genotype with $1,25(\mathrm{OH})_{2}$ D levels in MS patients.}

In contrast to the $25(\mathrm{OH}) \mathrm{D}$ levels, we observed slightly higher serum $1,25(\mathrm{OH})_{2} \mathrm{D}$ levels in carriers of two F-alleles compared to carriers of two f-alleles (Figure 1). This is surprising, since we found a positive correlation between the two metabolites 
(summer: $\mathrm{R}=0.367, \mathrm{P}<0.001$ and winter: $\mathrm{R}=0.354, \mathrm{P}<0.001$ ). The $1,25(\mathrm{OH})_{2} \mathrm{D} /$ $25(\mathrm{OH}) \mathrm{D}$-ratios show that carriers of an $\mathrm{F}$ allele have relatively higher $1,25(\mathrm{OH})_{2} \mathrm{D}$ levels related to $25(\mathrm{OH}) \mathrm{D}$ levels in winter $(\mathrm{P}=0.034)$, and a trend towards this association in summer $(P=0.079)$.
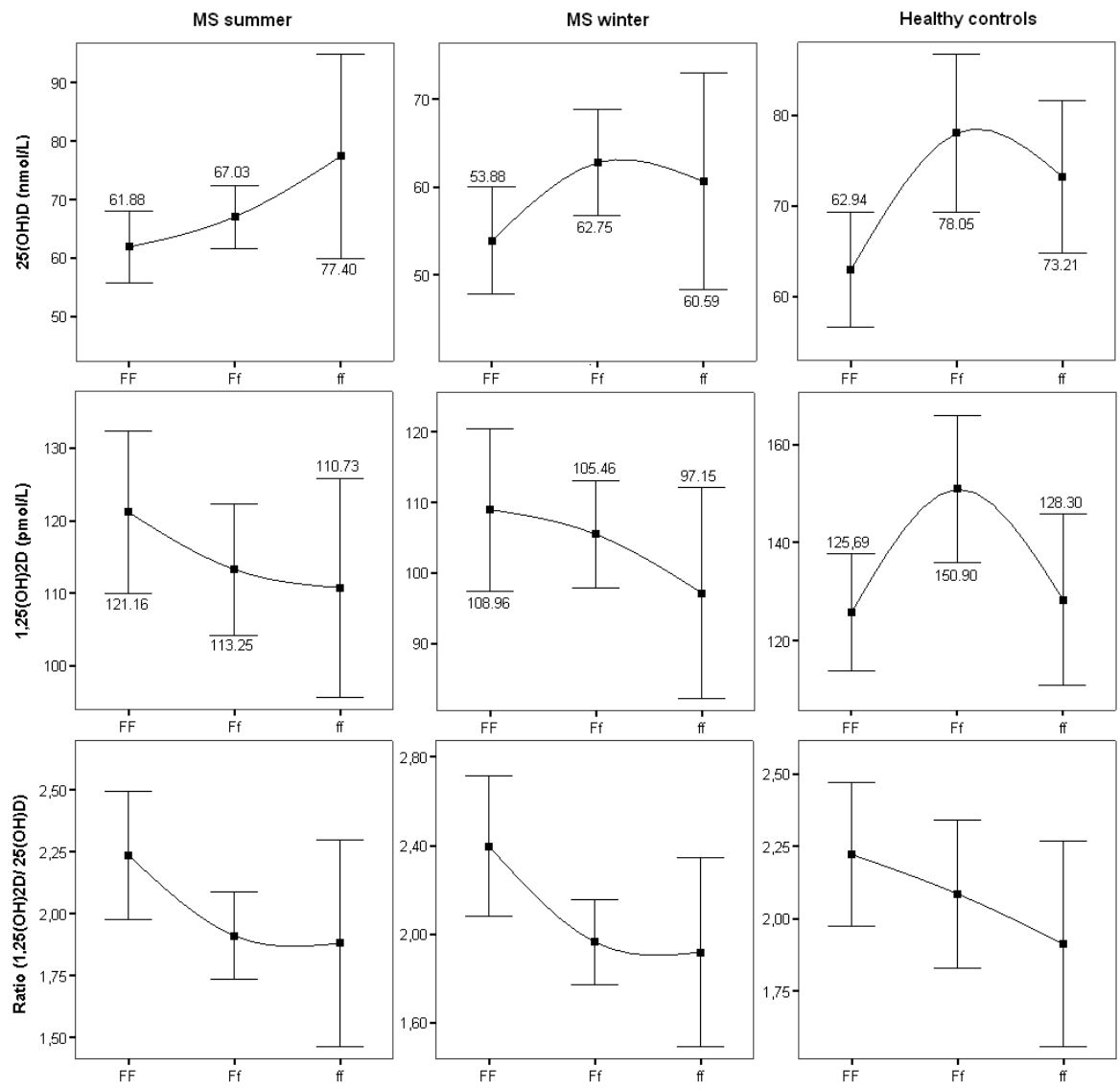

Figure 1 Serum levels of $25(\mathrm{OH}) \mathrm{D}$ and $1,25(\mathrm{OH})_{2} \mathrm{D}$ and the $1,25(\mathrm{OH})_{2} \mathrm{D} / 25(\mathrm{OH}) \mathrm{D}$-ratio of the MS population in summer and winter, and of the healthy control population, stratified for Fok-I VDR genotype.

The dots show the mean value with corresponding $95 \% \mathrm{Cl}$. A line was inserted to illustrate the direction of the association.

When analysed uncorrected for possible confounders, both log-transformed summer and winter $1,25(\mathrm{OH})_{2} \mathrm{D}$ levels were not predicted by Fok-I VDR genotype (data not shown). In the adjusted regression model, Fok-I VDR genotype predicted logtransformed summer $1,25(\mathrm{OH})_{2} \mathrm{D}$ levels $(\mathrm{C}=-0.032,95 \% \mathrm{Cl}-0.062--0.001, \mathrm{P}=$ $0.045)$, and showed a trend towards prediction of log-transformed winter $1,25(\mathrm{OH})_{2} \mathrm{D}$ levels $(\mathrm{C}=-0.032,95 \% \mathrm{Cl}=-0.066-0.003, \mathrm{P}=0.073)$. 
3.5 Association of Fok-I VDR genotype with $1,25(\mathrm{OH})_{2} \mathrm{D}$ levels in healthy controls. In the healthy control cohort, there was descriptively no clear association of plasma $1,25(\mathrm{OH})_{2} \mathrm{D}$ levels with the $\mathrm{F}$ or f-allele to be observed (Figure 1). Like in the MS cohort, $1,25(\mathrm{OH})_{2} \mathrm{D}$ and $25(\mathrm{OH}) \mathrm{D}$ levels correlated positively $(\mathrm{R}=0.424, \mathrm{P}<0.001)$. Interestingly, the $1,25(\mathrm{OH})_{2} \mathrm{D} / 25(\mathrm{OH}) \mathrm{D}$-ratio did also show an association of the $\mathrm{F}$ allele with relatively higher $1,25(\mathrm{OH})_{2} \mathrm{D}$ levels compared to $25(\mathrm{OH}) \mathrm{D}$ status $(\mathrm{P}=$ 0.024). However, the Fok-I VDRG polymorphism failed to predict log-transformed plasma $1,25(\mathrm{OH})_{2} \mathrm{D}$ levels in the adjusted regression model.

\section{Discussion}

This is the first study to asses serum levels of $25(\mathrm{OH}) \mathrm{D}$ and $1,25(\mathrm{OH})_{2} \mathrm{D}$, and the FokI VDRG polymorphism in two unrelated large cohorts of MS patients and healthy controls. Firstly, we did not find an association of the Fok-I VDRG polymorphism with MS in our population. Secondly, we observed an association of the F allele with low 25(OH)D levels in patients and controls. Thirdly, we extended these findings in our MS cohort by showing a reverse association of the $\mathrm{F}$ allele with high summer $1,25(\mathrm{OH})_{2} \mathrm{D}$ levels, and a trend towards association with high winter values. Lastly, in both MS patients and healthy control carriers of an F-allele, 1,25(OH) $)_{2} \mathrm{D} / 25(\mathrm{OH}) \mathrm{D}$ ratios were higher compared to their f-allele counterparts. These results show that the Fok-I VDRG polymorphism has important consequences for vitamin D metabolism in both MS and healthy control populations.

It is challenging to interpret our results. The association of the Fok-I VDRG polymorphism with 25(OH)D levels was earlier described by Orton et al., in an MS twin cohort (Orton et al., 2008). Since the serum level of this metabolite has been associated with the incidence of MS and several other autoimmune diseases, interference of the Fok-I VDRG polymorphism with its serum levels makes the polymorphism potentially relevant. Additionally, the association that we observed of the Fok-I polymorphism with $1,25(\mathrm{OH})_{2} \mathrm{D}$ levels and $1,25(\mathrm{OH})_{2} \mathrm{D} / 25(\mathrm{OH}) \mathrm{D}$-ratios might provide more insight in the drivers of the association initially described by Orton et al., The serum level of $1,25(\mathrm{OH})_{2} \mathrm{D}$ is mainly the result of a balance between $1 \alpha$ hydroxylation of 25(OH)D in the kidneys (Jongen et al., 1984), and deactivation of $1,25(\mathrm{OH})_{2} \mathrm{D}$ by 24 -hydroxylation in its target tissues (reviewed in Dusso et al., 2005). These processes are strictly regulated by serum calcium, phosphate and parathyroid hormone (PTH) levels. However, several papers also suggest a substantial role for self-regulation, i.e. negative feedback mechanisms, in vitamin $\mathrm{D}$ metabolism. Treatment of cell cultures with $1,25(\mathrm{OH})_{2} \mathrm{D}$ has been shown to reduce the amount of 25(OH)D-1 $\alpha$-hydroxylase mRNA (reviewed in Dusso et al., 2005). Takeyama et al., showed a critical role of the VDR in this process, using a VDR knockout mouse model (Takeyama et al., 1997). The absence of the VDR gene revealed dramatically higher 
serum $1,25(\mathrm{OH})_{2}$ D levels, but $25(\mathrm{OH}) \mathrm{D}$ levels were not significantly affected. Transcription analysis revealed inhibition of CYP27B1 by $1,25(\mathrm{OH})_{2} \mathrm{D}$ only in mice expressing the VDR. Interestingly, the vitamin D inactivating enzyme CYP24A1 $\left(1,25(\mathrm{OH})_{2} \mathrm{D}\right.$-24-hydroxylase) was also only up-regulated by $1,25(\mathrm{OH})_{2} \mathrm{D}$ in mice expressing the VDR. Furthermore, increasing levels of $1,25(\mathrm{OH})_{2} \mathrm{D}$ also limit the formation of its precursor 25(OH)D out of vitamin D. In an in vivo animal model, rat hepatic CYP27A1 (vitamin D-25-hydroxylase) expression was inhibited by systemic $1,25(\mathrm{OH})_{2} \mathrm{D}$ treatment (Theodoropoulos et al., 2003b), and in vitro treatment of human fetal intestine tissue with $1,25(\mathrm{OH})_{2} \mathrm{D}$ was also associated with a decreased CYP27A1 expression (Theodoropoulos et al., 2003a). Altogether, these studies suggest a negative feedback loop in vitamin $D$ metabolism which is activated upon VDR ligation, and limits the synthesis of both $1,25(\mathrm{OH})_{2} \mathrm{D}$ and its precursor $25(\mathrm{OH}) \mathrm{D}$. The results of our study suggest that the balance between $25(\mathrm{OH}) \mathrm{D}$ and $1,25(\mathrm{OH})_{2} \mathrm{D}$ synthesis at serum level is affected by the Fok-I VDRG polymorphism. When reflected to our model of vitamin D metabolism, the reverse association of the Fok-I VDRG polymorphism with the two metabolites suggest that it primarily interferes with the serum levels of $1,25(\mathrm{OH})_{2} \mathrm{D}$, leading to secondary changes of $25(\mathrm{OH}) \mathrm{D}$ levels. Whether this interference is mediated by CYP27B1, CYP24A1, calcium, phosphate or PTH-levels remains to be determined. Although somewhat speculative, the two polymorphisms of CYP27B1, which have been related to 25(OH)D levels, are also most likely to primarily affect $1,25(\mathrm{OH})_{2} \mathrm{D}$ levels (Orton et al., 2008). Further experimental studies on polymorphisms of the VDR and the CYP-enzymes in vitamin D metabolism should provide more insight.

Although the Fok-I VDRG polymorphism affects 25(OH)D levels, and 25(OH)D levels have been associated with the risk on developing MS (Munger et al., 2006), the anticipated association of the polymorphism with MS was not observed. Although others did describe a trend towards an association of the f-allele with a decreased risk for MS (Partridge et al., 2004) and an association of the f-allele with a decreased severity of MS (Mamutse et al., 2008), immunological in vitro studies (Colin et al., 2000; van Etten et al., 2007) and association studies (Orton et al., 2008; Tajouri et al., 2005) show conflicting results. As we hypothesised, vitamin D status is likely to be a confounding factor in these studies and our study. We initially intended to take this factor into account in our study by selective inclusion of MS patients with an optimal vitamin D status in our analysis. However, since the polymorphism appeared to interact intensively with vitamin $D$ metabolism in both patients and healthy controls, this approach was no longer valid. Interestingly, a recent study in type 1 diabetes mellitus (T1DM) research, another disease which has been associated with $25(\mathrm{OH}) \mathrm{D}$ levels, also suggests the interference of vitamin D exposition in association studies on the VDRG. Ponsonby et al., showed in a recent metaregression analysis that the odds ratios for the association of the Fok-I VDRG poly- 
morphism with T1DM increased with increasing regional winter UVR radiation levels (Ponsonby et al., 2008).

This study has provided some new data and hypothesis on the consequences of the Fok-I VDRG polymorphism for vitamin D metabolism and for MS. In future intervention studies on vitamin $D$ in MS, the polymorphism is likely to influence the response of vitamin D metabolism on exposure to large amounts of vitamin D. Further clinical and experimental studies on vitamin D metabolites and MS should take the Fok-I VDRG polymorphism into account, and further clarify the role of vitamin D, its metabolites and its receptor in MS.

\section{Acknowledgements}

No sources of funding were used to assist in the preparation of this manuscript. The authors have no conflicts of interest that are directly relevant to the content of this manuscript. We thank dr. Mariëlle Thewissen and Evelyn Peelen for the useful discussions, Bertine Timmermans and Riny Wieërs for their help with collecting the vitamin D data, and Ruud Theunissen for his skilled technical assistance. 


\section{Design of a randomized, controlled clinical trial on add-on therapy with vitamin $\mathrm{D}_{3}$ in Interferon Beta-treated patients with relapsing remitting multiple sclerosis}

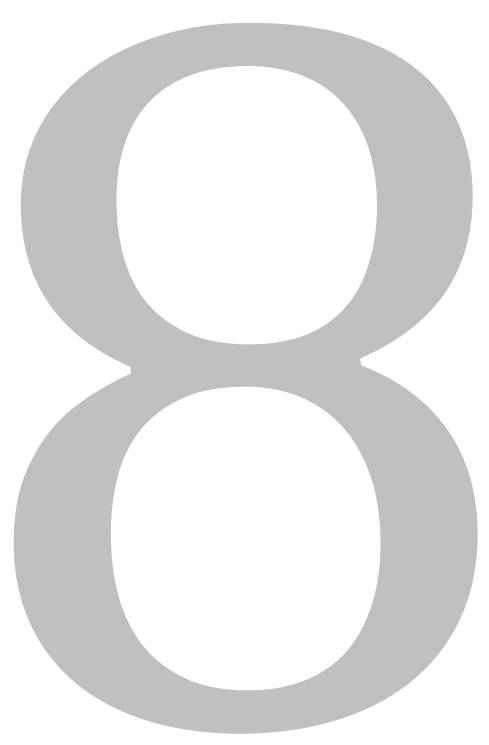

Submitted as: Joost Smolders, Raymond Hupperts, Frederik Barkhof, Luigi Grimaldi, Trygve Holmøy, Joep Killestein, Peter Rieckmann, Myriam Schluep, Reinhold Vieth, UIrike Hostalek, Lizette Ghazi-Visser, Manolo Beelke, on behalf of the SOLAR study group. Efficacy of Vitamin $D_{3}$ as Add-on Therapy in Patients with Relapsing-Remitting Multiple Sclerosis Receiving Subcutaneous Interferon Beta-1a: A Phase II, Multicentre, Doubleblind, Randomized, Placebo-Controlled Trial. 


\section{Abstract}

Recent studies have demonstrated the immunomodulatory properties of vitamin $D$, and vitamin D deficiency may be a risk factor for the development of MS. The risk of developing MS has, in fact, been associated with rising latitudes, past exposure to sun and serum vitamin D level. Serum 25-hydroxyvitamin D [25(OH)D] levels have also been associated with relapses and disability progression. The identification of risk factors, such as vitamin D deficiency, in MS may provide an opportunity to improve current treatment strategies, through combination therapy with established MS treatments. Accordingly, vitamin D may play a role in MS therapy. Small clinical studies of vitamin D supplementation in patients with MS have reported positive immunomodulatory effects, reduced relapse rates and a reduction in the number of gadolinium-enhancing lesions. However, large randomized clinical trials of vitamin D supplementation in patients with MS are lacking.

SOLAR (Supplementation of Vigantol oil versus placebo as add-on in patients with relapsing-remitting multiple sclerosis receiving rebif treatment) is a 96-week, three-arm, multicentre, double-blind, randomized, placebo-controlled, Phase II trial (NCT01285401). SOLAR will evaluate the efficacy of vitamin $\mathrm{D}_{3}$ as add-on therapy to subcutaneous interferon beta-1a in patients with RRMS. Recruitment began in February 2011 and is aimed to take place over 1 calendar year due to the potential influence of seasonal differences in 25(OH)D D levels. 


\section{Introduction}

Multiple sclerosis (MS) is a chronic, inflammatory and degenerative disease of the central nervous system, believed to be triggered by environmental factors in patients with complex genetic-risk profiles (Compston and Coles, 2008). Current disease-modifying drugs can reduce relapses and may delay disability progression in patients with relapsing-remitting MS (RRMS) (IFNB Multiple Sclerosis Study Group, 1993; Jacobs et al., 1996; Johnson et al., 1995; PRISMS Study Group, 1998), the most common disease course at onset (Weinshenker et al., 1989).

Vitamin D deficiency is a putative risk factor for MS (Ascherio et al., 2010; Smolders et al., 2008a, chapter 2). Identifying such risk factors as potential targets of therapy may provide an opportunity to improve current MS treatment strategies. The risk of developing MS has been correlated to rising latitudes, past exposure to sun and serum 25-hydroxyvitamin D [25(OH)D] level (Pierrot-Deseilligny, 2009). Levels of vitamin $D$ are determined by dietary intake, sun exposure and genetic make-up (Orton et al., 2008). Vitamin $D_{3}$ (cholecalciferol), the naturally occurring form of vitamin $D$, is predominantly found in two metabolite forms in the circulation: the prehormone, 25-hydroxyvitamin D; and the thousand-times less abundant, biologically active metabolite, 1,25-dihydroxyvitamin $\mathrm{D}\left[1,25(\mathrm{OH})_{2} \mathrm{D}\right]$. Circulating concentrations of $1,25(\mathrm{OH})_{2} \mathrm{D}$ are mainly the result of a 25 -hydroxylation step in the kidney, which is regulated according to the needs of calcium homeostasis (Jongen et al., 1984). This activation step into $1,25(\mathrm{OH})_{2} \mathrm{D}$ can also occur within other tissues, including immune-modulating cells, where the activation is not affected by calcium homeostasis; in this case $1,25(\mathrm{OH})_{2} \mathrm{D}$ is not thought to enter the circulation, but rather its role is to moderate immune function by autocrine and paracrine mechanisms, suggesting that vitamin D may have a role in human physiology beyond skeletal and calcium homeostasis (Adams and Hewison, 2008).

In several studies, a potential causal association between serum 25(OH)D concentrations and MS disease activity has been observed. A high chance of remaining relapse-free has been associated with higher serum 25(OH)D levels (Smolders et al., 2008 , chapter 3 ), with each $10 \mathrm{nmol} / \mathrm{L}$ increase in $25(\mathrm{OH}) \mathrm{D}$ resulting in a reduction in the risk of relapse of up to $12 \%$ (Simpson et al., 2010). In addition, in paediatriconset MS and clinically isolated syndrome, every $10 \mathrm{ng} / \mathrm{mL}$ increase in adjusted $25(\mathrm{OH}) \mathrm{D}$ level was associated with a $34 \%$ decrease in the rate of subsequent relapses (Mowry et al., 2010), (equating to an approximate 14\% decrease in the rate of subsequent relapses per $10 \mathrm{nmol} / \mathrm{L}$ increase). Furthermore, serum 25(OH)D and $1,25(\mathrm{OH})_{2} \mathrm{D}$ levels have been reported to be lower during MS relapses than during remission (Correale et al., 2009; Soliu-Hänninen et al., 2005). An inverse relation between Expanded Disability Status Scale (EDSS) progression and vitamin D levels has also been reported (Smolders et al., 2008, chapter 3). 
Functional interaction of vitamin D with the main MS-linked HLA-DRB1*1501 allele (Ramagopalan et al., 2009), or selective immune system regulation (Hayes et al., 1997) are possible mechanisms underlying the modulating effect of vitamin D on MS pathobiology. The biologically active metabolite of vitamin $\mathrm{D}$ has been shown to induce suppression of IL-2, IL-1 and lymphocyte proliferation (Tsoukas et al., 1984; Tsoukas et al., 1989). High levels of serum 25(OH)D have been associated with an improved regulatory $\mathrm{T}$ cell function and with skewing of the Th1/Th2 balance towards a Th2 type response, suggesting that vitamin D may be an important regulator of peripheral T cell function in MS (Smolders et al., 2009, chapter 4). A reduced proliferative response of $\mathrm{CD}^{+} \mathrm{T}$ cells to myelin peptides was observed in patients who received high-dose vitamin D supplementation (up to 40000 IU daily), when compared with that in patients without supplementation and when compared with that prior to treatment (Burton et al., 2010). Strong immunomodulatory properties of molecules derived from vitamin $D_{3}$ have also been demonstrated in murine experimental autoimmune encephalomyelitis (EAE), a model of MS. TX527, an analogue of $1,25(\mathrm{OH})_{2} \mathrm{D}_{3}$, can attenuate $\mathrm{EAE}$ and results in significant disease protection in combination with interferon (IFN)-beta, superior to the effects of the individual treatments (van Etten et al., 2007).

Small preliminary studies of vitamin $D_{3}$ supplementation, with or without calcium, have reported positive immunomodulatory effects (Burton et al., 2010), reduced relapse rates (Goldberg et al., 1986) and a reduction in the number of gadolinium (Gd)-enhancing lesions (Kimball et al., 2007) in patients with MS. Furthermore, vitamin D supplementation in patients with MS raised serum transforming growth factor beta-1 levels (Mahon et al., 2003), which may indicate a neuroprotective effect.

In a recent pilot study, patients with RRMS receiving IFN-beta were supplemented with high-dose (20 000 IU daily) vitamin $D_{3}$, the same compound that will be used in the SOLAR study, for 12 weeks (Smolders et al., 2010, chapter 6). A shift towards an anti-inflammatory cytokine profile, with an increased proportion of IL$10^{+} \mathrm{CD}^{+} \mathrm{T}$ cells and a decrease in the ratio between IFN $-\gamma^{+}$and IL- $4^{+} \mathrm{CD} 4^{+} \mathrm{T}$ cells was observed, thus suggesting that combining IFN-beta with vitamin $D_{3}$, to further modulate the immune system of patients with MS may be beneficial.

Although there is no direct evidence demonstrating the clinical benefit of combining vitamin $D_{3}$ with IFN-beta therapy in MS, the majority of patients in studies examining vitamin D in MS were also receiving IFN-beta. To date, these studies have been limited to assessing the association between the risk of relapse and vitamin $D$ level (Smolders et al., 2008b, chapter 3; Simpson et al., 2010; Mowry et al., 2010), and the safety of high dose vitamin D (Burton et al., 2010; Kimball et al., 2007; Smolders et al., 2010b, chapter 6) in MS. The recent pilot study of high-dose vitamin $D_{3}$ treatment (Smolders et al., 2010, chapter 6), and the potential synergism for IFNbeta and vitamin D in a mouse model of MS (van Etten et al., 2007), suggest that a 
double-blind placebo-controlled trial is necessary to determine the potential add-on effects of vitamin $D_{3}$ to IFN-beta treatment.

The SOLAR (Supplementation of VigantOL ${ }^{\circledR}$ oil versus placebo as Add-on in patients with relapsing-remitting multiple sclerosis receiving Rebif ${ }^{\oplus}$ treatment) study is designed to assess the efficacy of vitamin $D_{3}$ as add-on therapy to subcutaneous (sc) IFN beta-1a in patients with RRMS (www.clinicaltrials.gov NCT01285401).

\section{Methods}

\subsection{SOLAR trial design, objectives and rationale}

SOLAR is a 96-week, three-arm, multicentre, double-blind, randomized, placebocontrolled, Phase II trial (Figure 1). The primary objective of the SOLAR study is to assess the efficacy of vitamin $D_{3}$ (cholecalciferol, Vigantol oil, Merck KGaA, Darmstadt, Germany) versus placebo as add-on therapy in patients with RRMS receiving sc IFN beta-1a (Rebif , Merck Serono S.A. - Geneva) 44 $\mu \mathrm{g}$ three times weekly (tiw).

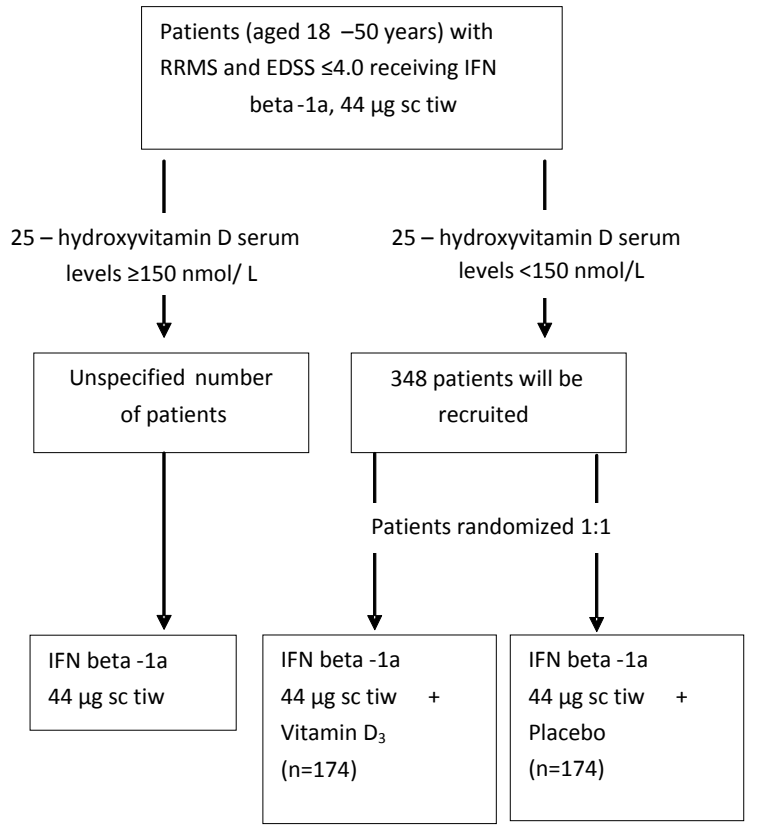

Figure 1 Patient recruitment and randomization.

EDSS, Expanded Disability Status Scale; IFN, interferon; sc, subcutaneous; RRMS, relapsingremitting multiple sclerosis; tiw, three times weekly.

The secondary objectives are to: assess changes in clinical and magnetic resonance imaging (MRI) parameters; investigate the safety profile of study treatment 
over 96 weeks; and explore pharmacogenetics, gene expression and circulating biomarkers, and potential correlations with vitamin $\mathrm{D}_{3}$ treatment outcomes.

A total of 348 patients with RRMS and with serum 25(OH)D levels $<150 \mathrm{nmol} / \mathrm{L}$ will be randomized $(1: 1)$ to receive vitamin $D_{3}$ or placebo as add-on therapy to IFN beta-1a, $44 \mu \mathrm{g}$ sc tiw. Patients randomized to vitamin $D_{3}$ will receive 7000 IU (175 $\mu \mathrm{g})$ daily for 4 weeks. If treatment with vitamin $D$ is tolerated (as described below), patients will receive 14000 IU $(350 \mu \mathrm{g})$ daily for a further 92 weeks; otherwise, patients will continue to receive $7000 \mathrm{IU}$ daily. In case of further intolerance, vita$\min D_{3}$ supplementation will be withdrawn; patients will be encouraged to maintain the assessment schedule until the end of the treatment period during which vitamin $D_{3}$ withdrawal occurred. The stability of the vitamin $D_{3}$ compound is guaranteed for the entire shelf life of the product. An unspecified number of patients (estimated to be 10) with supraphysiological serum $25(\mathrm{OH}) \mathrm{D}$ levels $\geq 150 \mathrm{nmol} / \mathrm{L}$ will receive IFN beta-1a, $44 \mu \mathrm{g}$ sc tiw, only. For all patients, if treatment with IFN beta-1a, $44 \mu \mathrm{g} \mathrm{sc}$ tiw, is not well tolerated patients will receive IFN beta-1a, $22 \mu \mathrm{g} \mathrm{sc}$ tiw, based on the physician's decision.

Vitamin $D_{3}$ will be administered as an oral solution $(500 \mu \mathrm{g} / \mathrm{mL})$ each morning during breakfast, as the absorption of a fat-soluble vitamin benefits from the contemporaneous intake of fat (e.g. dropping the daily dose on a piece of buttered bread). sc IFN beta-1a will be administered before going to bed. The exception to this schedule will be during visits to the trial site where vitamin $D_{3}$, or placebo, will be administered only after the collection of blood samples.

Serum calcium ( $<2.6 \mathrm{mmol} / \mathrm{L}$ ) levels, as well as the urinary ratio of calcium to creatinine $(<1.0)$ will be determined before the start of treatment, week 4, week 12 and every 12 weeks thereafter. If the urinary ratio of calcium to creatinine is elevated, this measurement will be repeated as soon as possible to confirm the result before any action is taken, as urine calcium levels are highly variable. If any parameter is above the mentioned upper limit of normal for patients receiving $14000 \mathrm{IU}$ daily, the dose of vitamin $D_{3}$ may be decreased by $50 \%$ (i.e. from 14000 IU daily to 7000 IU daily) or omitted for 1 month with a re-administration of $50 \%$ of the dose thereafter. All patients will continue to receive their dose of IFN beta-1a for the duration of the study.

\subsection{Rationale for vitamin $D_{3}$ dosing in combination with IFN-beta}

To be able to differentiate treatment effects between the vitamin $D_{3}$ and placebotreated arms, patients will be supplemented with high doses of vitamin $D_{3}$, as a lower dose of vitamin $D_{3}$ within a controlled trial setting may not reveal potential benefits (Burton et al., 2010). In addition, evidence for high dose vitamin $D_{3}$ effectiveness in the context of an immunomodulatory treatment is supported by results from two recent studies: where patients with RRMS, receiving IFN-beta, were supplemented with 20000 IU daily vitamin $D_{3}$ (Smolders et al., 2010, chapter 6); and 
where patients with MS received escalating vitamin D doses up to 40000 IU daily over 28 weeks, followed by 10000 IU daily over 12 weeks, and further downtitrated to 0 IU daily (Burton et al., 2010).

Studies investigating $25(\mathrm{OH}) \mathrm{D}$ levels have suggested that a concentration exceeding $100 \mathrm{nmol} / \mathrm{L}$ is optimal in healthy individuals (Hollis et al., 2007), and may reduce the risk of MS (Munger et al., 2009). In addition, studies assessing vitamin D adequacy in fracture prevention and preservation of bone mineral density suggest that concentrations of 25(OH)D should exceed $75 \mathrm{nmol} / \mathrm{L}$ (Vieth et al., 2006). Moreover several cohort studies among patients with MS have shown that patients with RRMS are environmentally exposed to physiological 25(OH)D levels up to 150 nmol/L (Smolders et al., 2008b, chapter 3; Simpson et al., 2010; Mowry et al., 2010).

A study designed to test the tolerability of specific $25(\mathrm{OH}) \mathrm{D}$ concentrations, reported a reduction in the number of $\mathrm{Gd}$-enhancing lesions in patients with $\mathrm{MS}$ receiving $1200 \mathrm{mg}$ elemental $\mathrm{Ca} /$ day alongside increasing doses of vitamin $\mathrm{D}_{3}$, from 28 000 to 280000 IU weekly (Kimball et al., 2007). Furthermore, evidence of immunomodulatory effects was observed in patients with MS treated with high-dose oral vitamin D, which resulted in a mean serum 25(OH)D peak of $413 \mathrm{nmol} / \mathrm{L}$ (Burton et al., 2010). Therefore, we selected a dose of 7000 IU daily for 4 weeks, followed by 14000 IU daily for a further 92 weeks.

\subsection{Dose safety and potential side effects}

Baseline serum 25(OH)D levels of $150 \mathrm{nmol} / \mathrm{L}$ in patients treated with $14000 \mathrm{IU}$ vitamin $D_{3}$ per day, corresponding to $350 \mu \mathrm{g}$, is expected to increase the $25(\mathrm{OH}) \mathrm{D}$ serum level by $245 \mathrm{nmol} / \mathrm{L}$, based on a $0.70 \mathrm{nmol}$ increase for each additional $1 \mu \mathrm{g}$ vitamin $D_{3}$ input (Heaney et al., 2003). Therefore, we expect the resulting serum $25(\mathrm{OH}) \mathrm{D}$ level of $395 \mathrm{nmol} / \mathrm{L}$ in patients receiving vitamin $\mathrm{D}_{3}$ to be below the critical threshold of $500 \mathrm{nmol} / \mathrm{L}$ that may lead to hypercalcaemia (Heaney et al., 2008). In a previous study, the serum 25(OH)D levels of patients with MS receiving high doses of vitamin $D_{3}$ (increasing doses of vitamin $D_{3}$ from 28000 to 280000 IU weekly, for 28 weeks) was initially $78 \mathrm{nmol} / \mathrm{L}$, rising to $386 \mathrm{nmol} / \mathrm{L}$ after treatment, meaning that patients reached twice the top of the physiologic range without eliciting hypercalcaemia or hypercalciuria (Kimball et al., 2007). No significant adverse advents (AEs) were observed in patients with MS treated with high doses of vitamin $D_{3}$ (up to 40000 IU daily over 28 weeks, followed by 10000 IU daily for 12 weeks, and further down-titrated to $0 \mathrm{IU}$ daily), leading to the conclusion that approximately 10 000 IU daily was a safe regimen (Burton et al., 2010). Vitamin $D_{3}$ was well tolerated and resulted in desirable vitamin $\mathrm{D}_{3}$ levels in a study investigating long- (1 year) and short-term (8 weeks) safety in healthy adolescents at doses of 14000 IU weekly, equivalent to 2000 IU daily (Maalouf et al., 2008). In addition, 15 patients with RRMS receiving IFN-beta were recently supplemented with 20000 IU daily of vita$\min D_{3}$ for 12 weeks without a dose-escalation scheme. The resulting median serum 
25(OH)D level of $348 \mathrm{nmol} / \mathrm{L}$ did not induce AEs such as hypercalcaemia or hypercalciuria (Smolders et al., 2010, chapter 6).

\subsection{Rationale for the three-arm study design}

There is currently no consensus on the optimal physiological range of vitamin $D_{3}$ in the general population, nor a recognised threshold below which individuals should be considered as vitamin $D_{3}$-deficient. Therefore, to avoid potential low vitamin $D_{3}$ level selection bias, a serum 25(OH)D level of $<150 \mathrm{nmol} / \mathrm{L}$ has been defined as a cut-off value. In addition to stratifying randomized patients by serum 25(OH)D levels at baseline, patients will also be stratified (in order of importance) by body mass index (due to the fat-soluble nature of vitamin $D_{3}$ ), gender and number of relapses in the past 2 years, in order to assess the impact of these variables on clinical outcomes and to assure equal distribution among the treatment arms. Avoiding potential vitamin $D_{3}$ level selection bias and stratifying patients by variables is considered to be the most ethically acceptable study design, considering the potential benefits of vitamin $D_{3}$ supplementation in patients with RRMS. In addition, this approach will allow the potential synergistic mode of action (MoA) of IFN-beta with vitamin $D_{3}$ in MS to be explored, with respect to IFN-beta with placebo.

Samples from patients in the third arm, with supraphysiological serum $25(\mathrm{OH}) \mathrm{D}$ levels ( $\geq 150 \mathrm{nmol} / \mathrm{L}$ ), will be used in exploratory analyses. Pharmacogenetic analyses will investigate whether common genetic polymorphisms distinguish these patients from those with serum 25(OH)D levels $<150 \mathrm{nmol} / \mathrm{L}$. In addition, it will also be of interest to determine whether these patients have a more benign course of disease than those with serum $25(\mathrm{OH}) \mathrm{D}$ levels $<150 \mathrm{nmol} / \mathrm{L}$, suggesting natural protection.

\subsection{Patient criteria}

Patients who meet the following criteria will be eligible for the study: aged 18-50 years; have a diagnosis of RRMS (McDonald 2005 criteria; Polman et al., 2005); have a brain and/or spinal MRI with findings typical of MS; have a first clinical event occurring within 5 years prior to screening; have had at least one clinical event, or one or more Gd-enhancing or new T2 MRI lesions within the 12 months prior to screening; have an EDSS score $\leq 4.0$ at screening; are either currently and for the first time receiving Sc IFN beta-1a tiw for a minimum of 90 days and for not longer than 12 months prior to the baseline visit. All patients must be willing and able to comply with the protocol for the duration of the trial and provide written informed consent. The main exclusion criteria are: pregnancy or lactation; any disease other than MS that could better explain signs and symptoms; complete transverse myelitis or bilateral optic neuritis; a relapse within 30 days prior to study day 1 (SD1); use of corticosteroids or adrenocorticotrophic hormone within 30 days prior to SD1; abnormalities of vitamin D-related hormonal system other than due to low dietary 
intake or decreased sun exposure; urine calcium/creatinine $(\mathrm{mmol} / \mathrm{mmol})$ ratio $>1.0$ or hypercalcaemia (11 mg/100 cc [5.5 mEq/l]); inadequate liver function (defined by alanine aminotransferase [ALT] $>3$ times upper limit of normal [ULN]; aspartate aminotransferase $>3$ times ULN; alkaline phosphatase $>2.5$ times ULN; or bilirubin $>1.5$ times ULN, if associated with any elevation of ALT or alkaline phosphatase); concomitant medications that influence vitamin D metabolism other than corticosteroids (e.g., phenytoin, barbiturates, thiazide diuretics and cardiac glycosides); currently taking $>400 \mathrm{IU}(>10 \mu \mathrm{g})$ of vitamin D supplement daily; or conditions with increased susceptibility to hypercalcaemia (e.g., known arrhythmia or heart disease, treatment with digitalis or hydrochlorothiazide, nephrolithiasis).

\subsection{Randomization}

Patients with serum 25(OH)D levels $<150 \mathrm{nmol} / \mathrm{L}$ will be randomized 1:1 at SD1, by means of an interactive voice-response system, to vitamin $D_{3}$ or placebo, and will be double-blinded for all assessments. Patients with serum 25(OH)D levels $\geq 150$ $\mathrm{nmol} / \mathrm{L}$ will be automatically assigned to the sc IFN beta-1a treatment group and undergo all trial assessments without receiving either vitamin $D_{3}$ or placebo.

\subsection{Primary endpoints}

The primary endpoint will be a composite endpoint of MRI and clinical variables. The primary MRI endpoint will be the mean number of combined unique active (CUA) lesions at week 48. The primary clinical endpoint will be the proportion of relapse-free patients at week 96 , chosen as previous studies have demonstrated correlations between vitamin D supplementation and relapse-free status (Burton et al., 2010; Smolders et al., 2008b, chapter 3; Simpson et al., 2010; Mowry et al., 2010). The composite endpoint will be assessed in a hierarchical manner, with the primary MRI endpoint measured at week 48 and the primary clinical endpoint measured at week 96.

\subsection{Secondary endpoints}

Secondary clinical endpoints will include relapses and chronic disease (i.e. disability) progression. Relapse-related endpoints will be measured by the: proportion of relapse-free patients at week 48; time to first documented relapse; annualized relapse rate at weeks 48 and 96; total number of reported relapses at all time points; and requirement for glucocorticoid treatment during the trial. Secondary disabilityrelated endpoints will be measured by the: proportion of patients free from confirmed EDSS progression at weeks 48 and 96; time to 24 weeks' sustained disability progression on EDSS; and proportion of patients with 24 weeks' sustained disability progression on EDSS at weeks 48 and 96.

The secondary MRI endpoints (Table 1 ) will assess the anti-inflammatory effect (lesion activity, disease activity and burden of disease) and a potential neuroprotec- 
tive effect (development of black holes and brain atrophy) of Vitamin D supplementation. Additional secondary efficacy endpoints will measure the proportion of patients free from disease activity and the change in cognitive function from baseline at weeks 48 and 96, measured by the Symbol Digit Modalities Test (SDMT).

\subsection{Safety and immunogenicity endpoints}

Safety endpoints will be evaluated up to week 96 and will include safety data from all completed trial visits, including: the occurrence of AEs, serious AEs and laboratory abnormalities; adherence to treatment; change from baseline in bone mass density at week 96 (test optional); reasons for trial termination; serum calcium level; urine calcium/creatinine ratios; serum $25(\mathrm{OH}) \mathrm{D}_{3}$; and serum $1,25(\mathrm{OH})_{2} \mathrm{D}_{3}$ levels. Immunogenicity endpoints will include the proportion of patients, measured from baseline, who are positive for binding antibodies (BAbs) and neutralizing antibodies (NAbs) to IFN beta.

\subsection{Assessments}

Patients will undergo 12 visits during the trial period (Figure 2). MRI assessments will be performed at SD1 and weeks 48 and 96 . Neurological function will be assessed at screening, SD1 and every 12 weeks thereafter. Cognitive function (SDMT) will be assessed at SD1 and weeks 24, 48, 72 and 96. Relapses will be evaluated at SD1, week 4, week 12 and every 12 weeks thereafter up to week 96. BAbs and NAbs to IFN beta-1a will be measured at SD1, week 12 and every 12 weeks thereafter up to week 96. Serum 25(OH)D levels will be measured at screening, SD1 and weeks 48 and 96. Gene expression profiling will be performed at SD1 and weeks 24, 48, 72 and 96, and pharmacogenetic biomarkers investigated in samples taken at SD1.

\subsection{Biomarkers and pharmacogenetics}

Circulating biomarkers, gene expression, and pharmacogenetic analyses will be performed on blood and plasma samples to identify potential surrogate biomarkers. Biomarker analysis will investigate potential correlations between vitamin $\mathrm{D}_{3}$ add-on therapy and clinical- and MRI-based outcomes. In addition, biomarker analysis will explore the pharmacological response to treatment and the mechanism of action of vitamin $\mathrm{D}_{3}$. Clinical and MRI outcomes will be evaluated in relation to single nucleotide polymorphisms of the vitamin D binding protein, vitamin D receptor, CYP27B1, CYP24A1, CYP2R1, and in MS-related CD25, CD127 and HLA-DRB1*1501. Circulating protein and gene expression profiling will be measured at relapse. It is also important to note that different or additional biomarkers may be analysed to reflect the latest advances in biomarker research. 
Table 1 Additional MRI-based secondary endpoints.

\begin{tabular}{ll}
\hline Scanning sequence & Endpoint \\
\hline T1 (Gd-enhancing) & Mean number of new T1 Gd-enhancing lesions per patient per scan at weeks \\
& 48 and 96 \\
& Cumulative number of T1 Gd-enhancing lesions over weeks 48 and 96 \\
& Proportion of patients free from T1 Gd-enhancing lesions at weeks 48 and 96 \\
T1 (Gd-enhancing) and T2 & Cumulative number of CUA lesions at weeks 48 and 96 \\
& Mean number of CUA lesions per patient per scan at week 96 \\
T2 & Mean change from baseline in the total volume of T2 lesions at weeks 48 and \\
& 96 (T2 BOD; mm ${ }^{3}$ ) \\
T1 non-enhancing & Proportion of patients free from new T1 hypointense lesions (black holes) at \\
& weeks 48 and 96 \\
& Percentage of new T1 hypointense lesions (black holes) at weeks 48 and 96 \\
& within the subgroup of new or enlarging non-enhancing T2 lesions \\
& Mean change from baseline in total volume of T1 hypointense lesions at week \\
& 48 and week 96 (mm ${ }^{3}$ ) \\
& Percent brain volume change at weeks 48 and 96 from baseline, and at week \\
& 96 from week 48 \\
& Proportion of T1 Gd-enhancing lesions at SD1 that transform into black holes \\
& at weeks 48 and 96
\end{tabular}

$B O D$, burden of disease; CUA, combined unique active; Gd, gadolinium, MRI, magnetic resonance imaging; SD1, study day 1

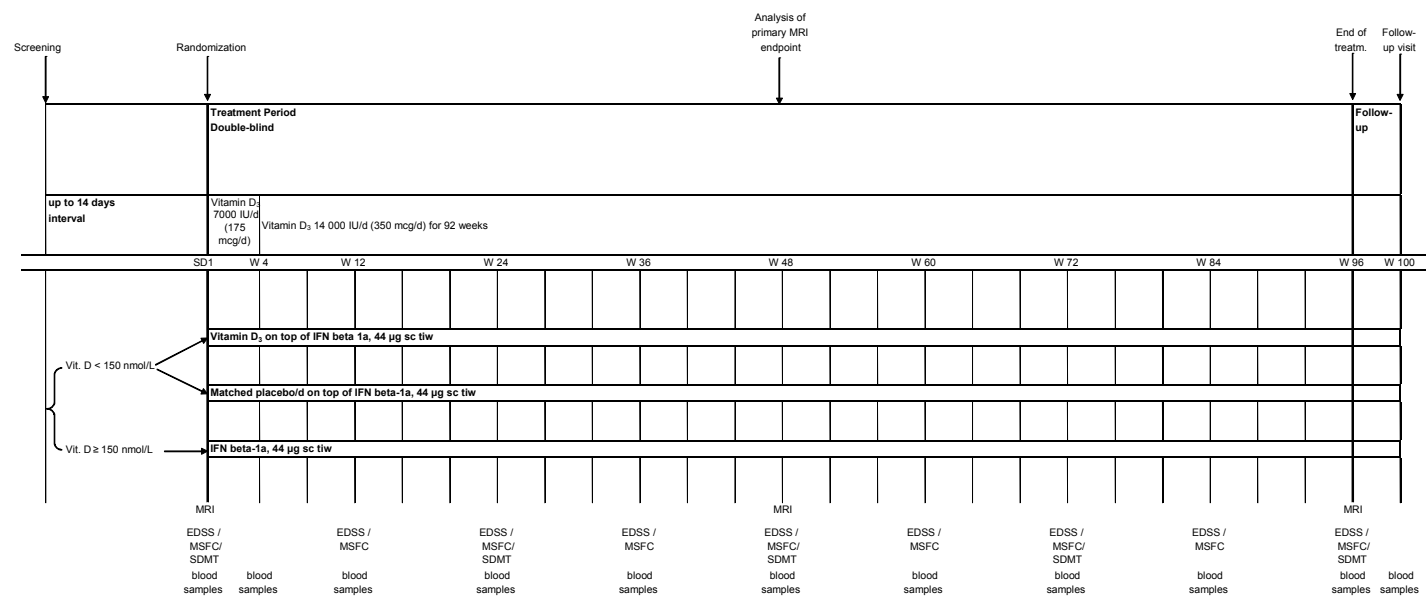

Figure 2 Study design.

EDSS, Expanded Disability Status Scale; MRI, magnetic resonance imaging; MSFC, multiple sclerosis functional composite; Sc, subcutaneous; SD1, study day 1; SDMT, single digit modalities test; tiw, three times weekly 


\subsection{Sample size and statistical analysis}

The study is $80 \%$ powered to detect an increase from $53 \%$ to $69 \%$ in the proportion of relapse-free patients at week 96 . The study is also powered to detect futility based upon the mean number of CUA lesions at week 48 at the interim analysis. Assuming that the mean number of CUA lesions follows an approximate negative binomial distribution, with a mean (SD) for treatment group 1 (patients receiving vitamin $D_{3}$ and IFN beta-1a, $44 \mu \mathrm{g}$ sc tiw) of 1.03 (1.61) and treatment group 2 (patients receiving placebo and IFN beta-1a, $44 \mu \mathrm{g}$ sc tiw) of 0.48 (1.11), then 200 patients (100 per arm) provides $80 \%$ power to detect this increase in the mean number of CUA lesions over treatment group 3 (IFN beta-1a, $44 \mu \mathrm{g}$ sc tiw only) with $p<0.05$. The study is designed to detect at least an $18 \%$ mean decrease from baseline in the mean number of CUA lesions at week 48.

The planned sample size of 348 patients with $25(\mathrm{OH}) \mathrm{D}$ serum levels $<150 \mathrm{nmol} /$ $L$ in the two randomized arms is based upon the primary clinical endpoint.

\subsection{Patient recruitment}

The SOLAR study will be conducted in Europe, involving approximately 60 sites across Belgium, Denmark, Estonia, Finland, Germany, Hungary, Latvia, Lithuania, Norway, Switzerland, the Netherlands and Italy. Recruitment of patients from northern and southern Europe will allow for an investigation of the effects of latitude (sun exposure) on treatment outcomes. Recruitment is aimed to take place over 1 calendar year due to the potential influence of seasonal differences in vitamin D levels. Recruitment began in half of the countries in February/March and will begin in April/May in the other half, which should result in a close to linear recruitment curve, with an accrual rate estimate of 0.5 patient's per-month per-site. The site initiation sequence is performed only in relation to the approval of the study documents by the site IRB/EC and contract finalization, and is not dictated by any other factors (e.g. latitude of the site).

\subsection{Sub-studies}

The SOLAR(IUM) trial will be a parallel, immunological sub-study in the Netherlands. The trial will assess whether, in patients supplemented with vitamin $D_{3}$ for 1 year, the CD4+ T cell compartment displays a more pronounced anti-inflammatory state when compared with placebo-supplemented patients. The primary endpoint will be the difference in distribution of cytokine profile of peripheral CD4+ T lymphocytes by flow cytometry at week 48 between the two randomized treatment groups.

A second sub-study in Switzerland will aim to investigate the effect of vitamin D treatment on antigen-specific T cells in patients with MS. The secondary objective will be to assess the immunomodulatory effect of SC IFN beta-1a with or without vitamin $D_{3}$ supplementation compared with no immunomodulatory treatment, using the two randomized treatment groups. For this analysis, a fourth group of 
patients will be enrolled: patients with RRMS without any treatment for the past 3 months, matched with the randomized patients in terms of EDSS score, age and sex.

\section{Conclusions}

Although the mechanisms underlying the modulating effect of vitamin D on MS pathobiology are not currently fully understood, current literature suggests that vitamin $D$ is a likely environmental factor contributing to the risk of developing of MS. In addition, initial studies indicate that the dose of vitamin $D_{3}$ we plan to use in this study may be clinically beneficial to patients with MS, without inducing adverse events. SOLAR will be the first large, placebo-controlled international study to assess vitamin $D_{3}$ as add-on therapy to Sc IFN beta-1a in patients with RRMS, using clinical and MRI outcomes. The study will also consider confounding factors, serum 25(OH)D levels reached, sunlight exposure and latitude. Further, analyses of specific genetic sequences already described will be performed to evaluate correlations between specific genetic preconditions and treatment response, In addition, the SOLAR study will provide important information that will assist with the design of future trials of vitamin D supplementation in MS treatment, by identifying how different populations of patients with MS respond to vitamin $D_{3}$.

\section{Acknowledgements}

This study is supported by Merck Serono S.A. - Geneva, Switzerland (an affiliate of Merck KGaA, Darmstadt, Germany). The authors thank John Wiltshire, PhD, of Caudex Medical, Oxford, UK (supported by Merck Serono S.A. - Geneva, Switzerland, an affiliate of Merck KGaA, Darmstadt, Germany) for assistance with the preparation of this manuscript. 



\section{General discussion}

Adapted from: Joost Smolders. Vitamin $D$ and multiple sclerosis: correlation, causality and controversy. Autoimmune Diseases 2011; document ID 629538:1-3. 



\section{Baseline}

The vitamin D and multiple sclerosis (MS) story in Maastricht started with a review of the literature, as is described in chapter 2. In this review, two questions were addressed: i) is vitamin D a modulator of MS disease activity? ii) which biological processes may underlie this modulation?

Regarding the first question, evidence was limited. Only association studies and small pilot studies had been reported. These studies addressed the association of vitamin D status with both the risk on developing MS and disease activity of MS. People who developed MS in later life were exposed to lower amounts of sunlight and other correlates of vitamin D exposure in childhood and adolescence. Within MS cohorts, patients with either a relapse or high EDSS-score displayed the poorest vitamin D statuses. Although these reports could only be regarded as circumstantial evidence, they were abundant and showed a consistent picture: an increase in vitamin D exposure may reduce both the risk on developing MS, and disease activity of MS. These observations provided an excellent reason to perform further studies on vitamin D in MS. Additionally, literature revealed that not only vitamin D status, but also genetic polymorphisms of the VDR had been associated with risk on developing MS. This led to a more complicated model of the relationship between vitamin D and MS (Figure 1).

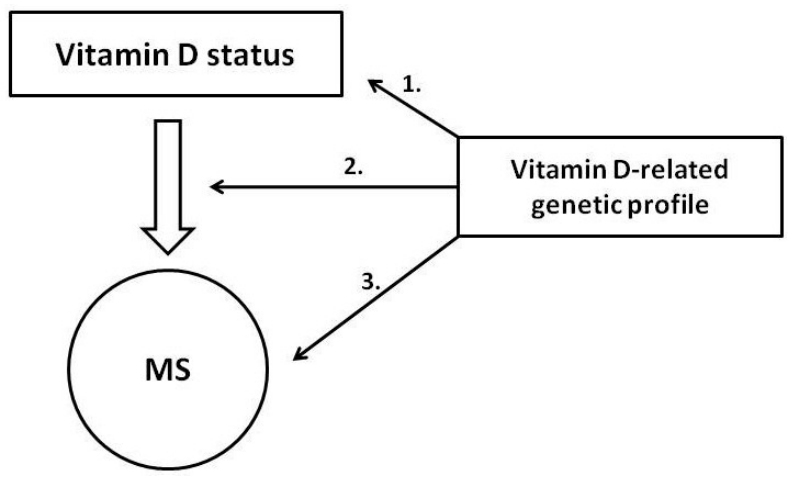

Figure 1 Potential interaction between vitamin D exposure, vitamin D receptor gene polymorphisms, and the risk on developing MS.

Vitamin D related genetic variation can affect the risk on MS via 3 potential mechanisms: 1.) via modulation of vitamin $D$ status, 2.) via modulation of the quantity/ quality of the biological response to vitamin $D, 3$.) via a direct effect of the risk of $M S$, in which the vitamin $D$ exposure is not important.

Much more experimental evidence had been published, showing that vitamin $D$ is actively involved in the regulation of the adaptive immune response in vitro and in animal models of MS (discussed in chapter 2 ). This led to our hypothesis, that a lack of sufficient vitamin $\mathrm{D}$ exposure may result in a decompensation of the regulatory 
role of vitamin $D$ in the adaptive immune response. The subsequent disturbance of peripheral T cell homeostasis may lead to an increased risk for either developing or experiencing a more active disease course of MS. However, the translation of experimental data to epidemiological observations could be poorly made. Although low serum levels of 25(OH)D were found in MS, supplementation of EAE rodents with vitamin $D$ was not as effective as $1,25(\mathrm{OH})_{2} \mathrm{D}$. Furthermore, the effects appeared to be restricted to female animals (Spach et al., 2005). Evidence in vivo in MS patients on any relationship between T cell homeostasis and serum 25(OH)D levels was lacking. Therefore, it remained therefore to be seen whether vitamin $D$ could be regarded as a peripheral immune modulator in MS.

In this thesis, we describe the work that we did on vitamin D and MS, in order to further elucidate whether vitamin D can be used as an immune modulator in MS. In the upcoming paragraphs, we will discuss the assessment of an association between vitamin D status disease activity of MS in our patient population, the assessment of vitamin $D$ as a peripheral immune modulator in MS, the study on effects of a vitamin $D$ receptor gene polymorphism, and the implications of these findings for the trial design of a large international trial on vitamin $D_{3}$ supplementation in MS. This chapter will end with the conclusions of this thesis, and with ideas for future research as well as for the possible application of vitamin D in clinical practice.

\section{MS disease activity and vitamin D status}

In chapter 3, we describe an association study between disease activity/ severity of MS and vitamin D status. We assessed the serum concentrations of two vitamin D metabolites: $25(\mathrm{OH}) \mathrm{D}$, the biologically inactive yet most stable and most abundant vitamin $\mathrm{D}$ metabolite, and $1,25(\mathrm{OH})_{2} \mathrm{D}$, the biologically active metabolite with a short half-life. As outcome measures for disease activity/ severity, we assessed relapse activity (annualized relapse rate, relapse-free in the 2 years prior to sampling $(\mathrm{Y} / \mathrm{N})$ ) and EDSS-score. We found that $25(\mathrm{OH}) \mathrm{D}$ status was negatively correlated with EDSS-score, and that patients who were relapse-free prior to serum sampling, displayed a better vitamin D status. Serum $1,25(\mathrm{OH})_{2} \mathrm{D}$ levels were not correlated with EDSS-score, and were dependent on serum 25(OH)D levels and age.

Measuring disability of MS is a complicated issue. As a measure for disability we used the EDSS-score (Kurtzke 1983). Although in use for over 25 years, this scale certainly has its limitations. The lower ranks of the scale are dependent on findings in neurological examination, the higher ranks on limitation of mobility. The nonlinearity of the scale makes the use of this scale in regression analysis questionable (Twork et al., 2010). Novel clinimetric scales have been developed, including the Multiple Sclerosis Functional Composite (MSFC) (Cutter et al., 1999). This scale has been argued to have less limitations (Polman and Rudick, 2010), but longstanding 
experience with it is in many centers lacking. Therefore, in our study, we have chosen to use the EDSS-score, knowing its limitations.

Causality cannot be derived from association studies. The association between EDSS-score and vitamin D status is a good example in this perspective. EDSS-score correlates negatively with sun exposure, and sun-exposure predicts vitamin $D$ status (van der Mei et al., 2007). Alternatively, Burton et al. showed recently in a small phase I/II study that supplementation of high doses of vitamin $D_{3}$ increased the proportion of MS patients with a stable EDSS-score over 2 years (Burton et al., 2010). In our study, we reproduced the earlier reported association between EDSSscore and vitamin D status (Nieves et al., 2001, van der Mei et al., 2007). Although no argument for an effect of vitamin D on MS pathophysiology, it shows that especially patients with a higher EDSS-score are at risk for having a poor vitamin D status. Therefore, these patients are logical candidates for assessment of their vitamin $D$ status in clinical routine and eventual vitamin $D$ supplementation to maintain a healthy calcium metabolism (Dawson-Hughes et al., 2005). Other parameters are more suitable for observational and therapeutic studies in MS, than a single EDSSscore. Disability progression due to MS is believed to reflect severity of disease pathophysiology in the CNS, i.e. neuroinflammation (Poonawalla et al., 2010) and maybe most importantly neurodegeneration (Minneboo et al., 2009). Loss of neurons over time is a predominant feature (Ferguson et al., 1997) not only in progressive MS (Furby et al., 2010), but also at disease onset (Filippi et al., 2003). Intervention in this pathophysiological process would be a highly relevant finding. Therefore, not disability at a certain time point per se, but rather disability progression of MS is a more suitable outcome measure (Leray et al., 2010). Of the cohort described in chapter 3, first 5 year follow-up data on EDSS progression and vitamin D status will become available soon. This dataset will allow us to assess a contribution of vitamin $\mathrm{D}$ status to MS progression in a prospective longitudinal design. Additionally, the relationship of vitamin D status with other symptoms of MS can be assessed prospectively. Cognitive complaints, depression and fatigue are for instance also frequently observed in MS (Bol et al., 2009). Recently, we found that vitamin D status correlated with the presence of depressive symptoms in MS (Knippenberg et al., 2010). These and other parameters may also be assessed in future studies on vita$\min \mathrm{D}$ in $\mathrm{MS}$

The second parameter of MS disease activity which we took into account in chapter 3, was relapse rate of MS. Ideally, the study should have been performed prospectively, but only data on relapse-activity up to 2 years prior to serum sampling were available. With the assumption that the variance in vitamin D status found between the studied subjects would reflect the variance of vitamin D status as it was during the 2 years prior to serum sampling, we included these data in our analysis. The contribution of vitamin $\mathrm{D}$ status to relapse rate was assessed in a Poisson regression model (Wang et al., 2009), the contribution to the odds on remaining 
relapse-free in a logistic regression model. In the whole RRMS cohort, vitamin D status did not contribute significantly to either the odds on remaining relapse free, or relapse rate.

Based on our literature review, we hypothesized vitamin $D$ to be a modulator of predominantly $\mathrm{CD}^{+} \mathrm{T}$ cell responses. When assessing an association between vitamin D status and MS, we intended to focus on the patients in which the CD4 ${ }^{+} \mathrm{T}$ celldriven inflammatory response is the most predominant feature of MS pathophysiology. These have been argued to be RRMS patients with a short disease duration (Compston and Coles, 2005). Interestingly, in these patients, peripheral T cell homeostasis has been reported to be markedly disturbed (Venken et al., 2007). To define this group of patients, we looked to the lower quartile of our RRMS cohort, regarding disease duration since the onset of first symptoms. This resulted in the cut-off value of 5 years, which could be argued to be an entirely artificial value. However, several studies have argued relapse activity and progression of disability in the first 5 years after MS onset to predict long term outcome (Degenhardt et al., 2009). On the other hand, in a long term follow-up study, only in the first 2 years after MS onset, relapse rate predicted the time to objective EDSS endpoints (Scalfari et al., 2010). Despite the questionability of this cut-off duration, the resulting cohort will have at least a more homogeneous MS pathophysiology with a larger contribution of T cell mediated inflammation, when compared to the entire RRMS cohort.

In this particular group, we found that relapse-free patients displayed higher serum 25(OH)D levels when compared to patients who relapsed within 2 years prior to serum sampling. Although multiple alternative explanations exist for this association, it was one of the first indications in the field that vitamin D might indeed influence risk on relapses of MS. Later studies with prospective designs reproduced this association, and took it as their main outcome measure (Simpson et al., 2010; Mowry et al., 2010). Additionally, a small phase I/II study provided an indication that supplementation of high doses vitamin $D_{3}$ might increase the odds on remaining relapse-free (Burton et al., 2010). Altogether, our observation provided directions for other studies on vitamin D and MS, also in our own research line. Firstly, it provided us a defined cohort in which the assessment of an association between vitamin D status and peripheral T cell homeostasis appeared to be most relevant. Secondly, it provided us with a part of the combined primary outcome measure for the large clinical trial, and some restrictions of the patients to be included (vide infra).

Lastly, we touched in chapter 3 on the issue of serum $1,25(\mathrm{OH})_{2} \mathrm{D}$ versus $25(\mathrm{OH}) \mathrm{D}$ as relevant for disease modulation in MS. Although all experts agree on the idea that the serum 25(OH)D level is the most useful indicator a subjects' vitamin D status, the biologically active metabolite is also in 1000-fold lower concentrations present in the circulation. Only vitamin D dependent rickets type I and type II, and evaluation of hypercalcaemia have been proposed as diagnostic indications for measurement of serum 1,25(OH) $)_{2}$, (Hollis et al., 1996). In hyper- or hypoparathy- 
roidism and chronic kidney failure, serum $1,25(\mathrm{OH})_{2} \mathrm{D}$ is rather a confirmatory test. In healthy individuals, these levels are tightly regulated by the serum calcium and parathyroid levels. However, we and others also found positive correlation between serum 25(OH)D and 1,25(OH) ${ }_{2}$ D levels in the serum (Barnes et al., 2005; Smolders et al., 2009a, chapter 6). Therefore, an impairment of serum 25(OH)D levels contributes to a relative impairment of serum $1,25(\mathrm{OH})_{2} \mathrm{D}$ levels. This has been hypothesized to be of interest for patients with MS. In experimental studies, most frequently $1,25(\mathrm{OH})_{2} \mathrm{D}$ is used to assess the effects of vitamin $\mathrm{D}$ (reviewed in chapter 2). In animal studies, $1,25(\mathrm{OH})_{2} \mathrm{D}$ treatment prevented and cured symptoms of EAE to a larger extent then vitamin D (Cantorna et al 1996, Spach et al., 2000). Subsequently, small safety studies investigated the safety of $1,25(\mathrm{OH})_{2} \mathrm{D}$ and $1 \alpha(\mathrm{OH}) \mathrm{D}$ supplementation to patients with MS (Achiron et al., 2003; Wingerchuk et al., 2005). In chapter 3, we assessed whether serum levels of $1,25(\mathrm{OH})_{2} \mathrm{D}$ contributed to EDSSscore and relapse rate of MS. In short, there was no contribution of serum $1,25(\mathrm{OH})_{2} \mathrm{D}$ levels to either relapse rate or EDSS-score in our cohort. Although the raw dataset showed a difference in serum $1,25(\mathrm{OH})_{2} \mathrm{D}$ between relapse-free and relapsing patients, this was not retained in the regression model after adjustment for confounders. Our results contributed to the idea that not the serum levels of $1,25(\mathrm{OH})_{2} \mathrm{D}$, but rather the serum $25(\mathrm{OH}) \mathrm{D}$ concentrations are important in MS. It needs to be said that epidemiological evidence also supports this hypothesis. No epidemiological studies reported an increased risk of MS in patients with kidney diseases and low serum levels of $1,25(\mathrm{OH})_{2} \mathrm{D}$. There has been one report on an increased risk for MS in patients with vitamin $\mathrm{D}$ dependent rickets, in which normal serum levels of $25(\mathrm{OH}) \mathrm{D}$ in the absence of $1,25(\mathrm{OH})_{2} \mathrm{D}$ are found (Torkildsen et al., 2008; Ramagopalan et al., 2010). However, it is uncertain whether the serum levels of $1,25(\mathrm{OH})_{2} \mathrm{D}$, or rather the inability of (immune) cells to activate $25(\mathrm{OH}) \mathrm{D}$ locally is responsible for this association. In chapter $\mathbf{5}$, we further elaborate on this issue.

\section{Peripheral T cell homeostasis and vitamin D status}

In chapters 4-6, the interaction between vitamin D and the T cell compartment of MS patients is explored in vivo. Since vitamin $D$ is a potent promoter of $T$ cell homeostasis in vitro (Smolders et al., 2008a, chapter 2), we hypothesized this effect to be the main driver of its associations with MS. In RRMS patients, predominantly those with a short disease duration, peripheral $\mathrm{T}$ cell homeostasis has been described to be disturbed (Viglietta et al., 2004, Haas et al., 2005, Venken et al., 2006). Additionally, MS modulating drugs have been reported to restore this homeostasis (Korporal et al., 2008, Haas et al., 2009). Therefore, a shortage in vitamin D status may result in a more disturbed peripheral $T$ cell homeostasis, and a more active disease course of MS. In the studies described in chapters 4-6, we included patients 
resembling the cohort in which we found associations between vitamin D status and relapse activity in chapter 3 . We first took a cross-sectional approach in chapter $\mathbf{4}$, and assessed whether there was a correlation of vitamin $D$ status with composition and function of the $\mathrm{CD} 4^{+} \mathrm{T}$ cell compartment. We included hallmarks of peripheral $\mathrm{T}$ cell homeostasis, as have been assessed before as outcome measures in MS, including number of Treg, Treg suppressive capacity, and peripheral $\mathrm{CD}^{+} \mathrm{T}$ cell cytokine profiles.

The Treg has become a hot item in autoimmune disease research over the past decade (Damoiseaux 2006). Originally, these cells were characterized as CD25 $5^{\text {high }}$ $\mathrm{CD}^{+}{ }^{\mathrm{T}}$ cells (Sakaguchi et al., 2008). Since CD25 (IL-2R $\alpha$-chain) is also an activationmarker on $\mathrm{CD}^{+} \mathrm{T}$ cells, phenotyping can be problematic. Identification of the transcription-factor Forkhead Box P3 (FoxP3) as a marker of Treg made phenotyping easier (Fontenot et al., 2003; Hori et al., 2003), and the lack of CD127 (IL-7Ra-chain) expression further improved identification of Treg (Liu et al., 2006; Seddiki et al., 2006). A fascinating observation is that polymorphisms in both the IL-7 and IL-2 receptor genes surfaced in a genome wide association study as risk alleles for developing MS (International MS Genetics Consortium, 2007). However, literature is still controversial whether the $\mathrm{CD} 25^{+}$FoxP3 ${ }^{+} \mathrm{CD} 127^{-} \mathrm{CD} 4^{+} \mathrm{T}$ cell should been seen as 'true' Treg, or whether $\mathrm{CD}_{2} 5^{+} \mathrm{FoxP}^{+}$and $\mathrm{CD} 25^{+} \mathrm{CD} 127^{-}$cells should be seen as two distinct phenotypes with Treg properties. Although a strong correlation between the two Treg phenotypes is observed $(R=0.826-0.891)$ in our studies, only approximately $75 \%$ of $\mathrm{CD} 25^{+} \mathrm{CD} 127^{-}$Treg is FoxP3 ${ }^{+}$(chapter 4 and 6 ). The number of Treg has generally been reported not to differ between healthy controls and patients with MS, regardless of their phenotype (Viglietta et al., 2004, Haas et al., 2005, Venken et al., 2006). Beside the number of Treg, the functionality of Treg can be quantified as their ability to suppress proliferation and cytokine production of non-Treg $\mathrm{CD}^{+}{ }^{+} \mathrm{T}$ cells (Tresp) in a proliferation-suppression assay (Venken et al., 2007). In MS, the suppressive capacity of $C D 4^{+} C D 25^{\text {high }}$ Treg has been reported to be impaired (Viglietta et al., 2004, Haas et al., 2005, Venken et al., 2006), but another study reported only an impairment of $\mathrm{CD}^{2} 5^{+} \mathrm{CD} 127^{-}$Treg suppressive function during relapses of MS (Michel et al., 2008).

Traditionally, the ratio of Th1 (IFN- $\left.\gamma^{+}\right)$and Th2 (IL- $\left.4^{+}\right)$cells gained much attention in autoimmune research. In this model, the balance between pro- and antiinflammatory $\mathrm{T}$ cells were the main drivers of autoimmune diseases (Abbas et al., 1996). However, the introduction of Treg and Th17 (IL-17 ${ }^{+}$) cells in auto-immunology complicated this picture (Steinman 2007). Nevertheless, the Th1/Th2 balance is still widely regarded as informative about the inflammatory state of the peripheral $\mathrm{T}$ cell compartment, and the role of Th17 cells in MS is still not consolidated. Additionally, $\mathrm{CD}^{+} \mathrm{T}$ cells can secrete the regulatory cytokine IL-10 These cells have been argued to reflect the proportion of T regulatory cell type $1(\operatorname{Tr} 1)$ in the circulation (Moore et al., 2001), but IL-10 production by Th2 cells and Treg has also been described. One 
limitation which needs to be taken into account, is that characterization of immune cells in the circulation, does not need to reflect the state of immune cells in other compartments. Immune cells can be present in 4 relevant compartments in MS: the secondary lymphoid organs, the peripheral blood, the cerebrospinal fluid (CSF), and within the CNS. The correlation between findings in these compartments is uncertain, and the immune status within in the CSF has been argued to be more informative for MS than within the peripheral blood (Stüve et al., 2006). Nevertheless, T cell characteristics in the circulation do correlate with disease status of MS. More IL- $17^{+}$ and IFN $-\gamma^{+} \mathrm{CD}^{+} \mathrm{T}$ cells were found in MS patients when compared to healthy controls, and in relapsing versus stable MS patients after stimulation with PMA and calcium ionomycin (Edwards et al., 2010). One can conclude that the peripheral T cell compartment allows characterization of a more pronounced pro- or antiinflammatory state of T cells in the periphery, but that the relevance of these parameters for the disease process of MS is only partly consolidated.

In a cohort of 29 patients, we found that the number of Treg did not correlate with vitamin $D$ status, but that their functionality was worse in patients with a poor vitamin D status. In this assay it is, however, uncertain whether Treg are less capable to suppress $\mathrm{CD} 4+\mathrm{CD} 25$ - $\mathrm{T}$ cell proliferation, or $\mathrm{CD} 4^{+} \mathrm{CD} 25^{-}$Tresp are more resistant to suppression by Treg. It is remarkable that all patients with the worst Treg suppressive capacity displayed a vitamin D status lower than $50 \mathrm{nmol} / \mathrm{L}$, which is widely accepted as the lower limit to prevent a decompensation of calcium metabolism (Dawson-Hughes et al., 2005). This made us wonder whether it was not the vitamin $D$ status per se, but rather the decompensation of calcium metabolism which was important in peripheral T cell homeostasis. Interestingly, elevation of serum calcium levels has been shown to be mandatory in the therapeutic effect of $1,25(\mathrm{OH})_{2} \mathrm{D}$ in EAE (Cantorna et al., 1999). We determined serum concentrations of $1,25(\mathrm{OH})_{2} \mathrm{D}$, parathyroid hormone, and total calcium, and found no correlation of Treg suppressive capacity with these parameters (described in chapter 5). Although more correlates of calcaemic functions of vitamin D can be proposed, our data suggest that the interaction between vitamin $D$ and Treg suppressive capacity is not exclusively dependent on calcium homeostasis. Additionally to the Treg assay, we assessed the cytokine profile of $\mathrm{CD}^{+} \mathrm{T}$ cells in these 29 patients. We found that not the proportions of IFN- $\gamma^{+}, \mathrm{IL}-4^{+}, \mathrm{IL}-17^{+}$and IL- $10^{+}$cells, but rather the Th1/Th2 (IFN$\mathrm{V}^{+} / \mathrm{IL}-4^{+}$) ratio correlated negatively with vitamin $\mathrm{D}$ status. It has been argued that not the absolute proportions, but rather the ratios of pro- and anti-inflammatory cells are of interest in autoimmune diseases (Abbas et al., 1996). Alternatively, however, mainly the proportion of IFN $-\nu^{+} \mathrm{CD} 4+\mathrm{T}$ cells is decreased, suggesting that the decreased Th1/Th2 balance is mainly the result of a decreased proportion of Th1 cells. Additionally, we also showed for the Th1/Th2 ratio, that a correlation with correlates of vitamin D's calcaemic functions was absent (described in chapter 5 ). Altogether, the data presented in chapter $\mathbf{4}$ and $\mathbf{5}$ suggest that a proportion of MS 
patients with a poor vitamin D status displays a less well regulated T cell compartment.

As stated above, causality cannot be derived from association studies. Sunshine per se has been shown to prevent experimental models of MS independently of vitamin D (Becklund et al., 2010), and a correlation of vitamin D status with immune regulation may be nothing more than an epiphenomena of this effect. Additionally, physical exercise has been shown to affect peripheral Treg measurements (Wilson et al., 2009), and to correlate with an increased level of sun-exposure (Kampman et al., 2008). In summary, only intervention studies can cast more light on the causality of the association between vitamin D status and peripheral $T$ cell homeostasis in MS. Therefore, we wanted to assess whether the T cell parameters studied in chapter 5 and 6 could provide useful outcome measure for intervention studies. We designed a pilot-study, in which we assessed both the safety and the effects on peripheral $\mathrm{CD}^{+} \mathrm{T}$ cell homeostasis of high-dose vitamin $\mathrm{D}_{3}$ supplementation in MS (described in chapter 6).

\section{Peripheral $\mathrm{T}$ cell homeostasis and vitamin $\mathrm{D}$ supplementation}

In our pilot, we included 15 RRMS patients matching the inclusion criteria of chapter 4 and 5. Vitamin $D_{3}$ was supplemented in a dose of $20.000 \mathrm{lU} / \mathrm{d}(500 \mu \mathrm{g} / \mathrm{d})$. The aim of this dose was to reach in a timeframe of 12 weeks circulating 25(OH)D concentrations, comparable to those reached in the study of Burton et al., since in this study clinical effects of vitamin $D_{3}$ supplementation were suggested. The mean 25(OH)D level reached in our study $357 \mathrm{nmol} / \mathrm{L}$, compared to the mean of $413 \mathrm{nmol} / \mathrm{L}$ which was reached by Burton et al., (Burton et al., 2010). The timeframe of 12 weeks was chosen for practical reasons: we wanted to control the level of vitamin $D$ and sunlight that our subjects were exposed to. In Figure 2, the amount of vitamin D effective UV-radiation in Sittard, where our MS center is located, is shown. The first patient started with vitamin D supplementation at October 2009, and the last patient's blood was drawn for the last T cell analysis at March 2010. Within this timeframe, the amount of vitamin D synthesized in the skin was negligible, and sunshine per-se was also not likely to severely confound our results.

The first goal of the pilot, was to explore the safety of vitamin $D_{3}$ supplementation. The main side effect of a hypervitaminosis $D$ is a decompensation of calcium metabolism (Kimball et al., 2007; Hathcock et al., 2007). A hypervitaminosis D could induce a hypercalcaemia, which could result in severe complications as heart failure and renal failure (Peacock 2010). However, cases of hypercalcaemia after vitamin D supplementation have only been described in subjects with additional diseases, as malignancies and granulomatous diseases (Hathcock et al., 2007). Additionally, MS patient series showed that supplementation of high doses of vitamin $D_{3}$ did not 
result in a decompensation of calcium metabolism (Kimball et al., 2007; Burton et al., 2010). Although these data provide confidence to supplement patients with high doses of vitamin $D_{3}$, carefulness is warranted. For instance, an unrecognized tuberculosis could induce a hypercalcaemia shortly after the start of supplementation, leading to complications in patients suffering from arrhythmias or renal dysfunction. Therefore, a careful inclusion of patients, and an intensive follow-up is recommended, certainly the first few months of intervention studies. Regarding the longterm safety of high dose vitamin $D_{3}$ supplementation, large datasets are lacking. Therefore, several concerns remain. One concern is the effect of a rise of total circulating calcium levels on the rate of cardiovascular events. Higher serum calcium levels have been associated with an increased carotid artery plaque thickness (Rubin et al., 2007), and an increased risk of cardiovascular events in retrospective (Jorde et al., 1999; Foley et al., 2008) and prospective (Lind et al., 1997; Tonelli et al., 2005) cohort studies in healthy populations. However, intervention studies on calcium supplementation did not reported marked enhancement of the risk on cardiovascular events (Wang et al., 2010). Additionally, it is uncertain whether the relatively marginal or even absent increase in total serum calcium levels as observed in our study and other studies on massive dose vitamin $D_{3}$ supplementation (Kimball et al., 2007; Burton et al., 2010) can be compared to the effects found between extremes in large populations. Studies on long-term vitamin $D_{3}$ with or without calcium supplementation should provide data on this matter. Another concern has been raised by a recent publication. In several (elderly) populations, supplementation of vitamin $D_{3}$ with/ without calcium reduced the risk on falls and fractures (Bischoff-Ferrari 2005; Bischoff-Ferrari 2009). Additionally, bone mass density correlated positively with vitamin D status (Bischoff-Ferrari 2004). However, in elderly women ( $\mathrm{N}=2256)$, once yearly supplementation of $500.000 \mathrm{IU}(12.500 \mu \mathrm{g})$ of vitamin $D_{3}$ resulted in an increased fall risk (15\%), and an increased fracture risk (26\%), when compared to placebo (Sanders et al., 2010). However, It is uncertain whether this increased risk is the result of the high doses, the lack of calcium supplementation, or the once-yearly administration. Post-hoc analysis revealed the latter mechanism to be plausible. Altogether, long-term safety of high-dose vitamin $D_{3}$ supplementation is not fully consolidated and should be included as outcomemeasure in upcoming trials on vitamin $\mathrm{D}_{3}$ supplementation in MS. Our study showed that in the short run, supplementation of vitamin $D_{3}$ does not evoke a decompensation of calcium metabolism, and is safe in a selected patient population. 


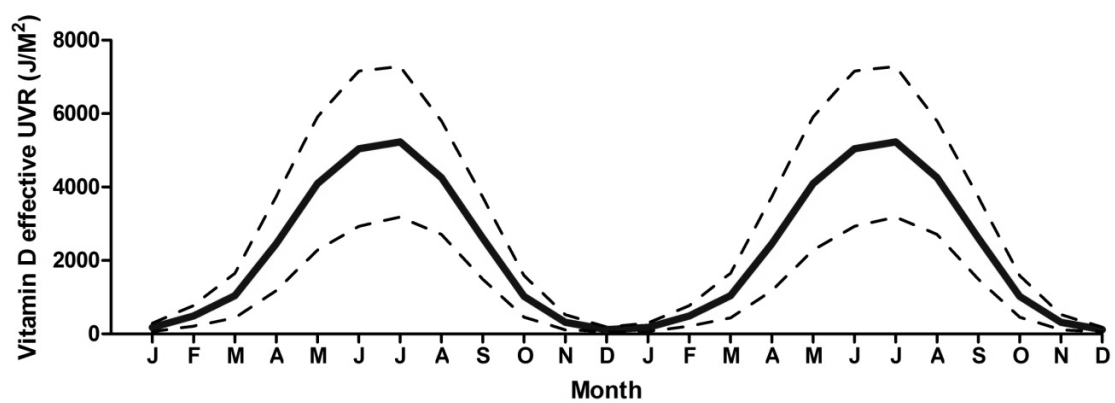

Figure 2 The mean amount of vitamin $\mathrm{D}$ effective ultraviolet radiation $\left(\mathrm{J} / \mathrm{M}^{2}\right)$ adjusted for clouds and ozone in Sittard between January $1^{\text {st }} 1979$ and $31^{\text {st }} 1990$, stratified for months. Between October and March, vitamin D effective UV radiation is almost absent (Courtesy of Ola Engelsen, Norwegian Institute for Air Research, The Polar Environmental Centre, Norway).

The second goal of the intervention study, was to assess whether we could measure a difference in peripheral $\mathrm{CD}^{+}{ }^{+} \mathrm{T}$ cell characteristics before and after supplementation. As discussed into detail in chapter 6, we did not find any effect on Treg numbers in the circulation, no significant improvement of Treg function in the circulation, but a shift of $\mathrm{CD}^{+} \mathrm{T}$ cell cytokine profile after stimulation of PBMC directly exvivo. A limitation of our dataset is that we did not assess the suppressive effect of Treg on cytokine production in the proliferation suppression assays. Besides the true absence of an effect in this pilot, Treg suppressive capacity may be a too complex and difficult outcome measure to monitor an immune modulating effect of vitamin $D$ supplementation in upcoming trials. The discrepancy between chapter 4 and chapter 6 is difficult to explain. A provoking hypothesis is that the $\operatorname{CD} 25^{+} \mathrm{CD} 127^{-}$ or $\mathrm{CD}_{25} 5^{+} \mathrm{FoxP}^{+}$Treg may not be the most important cell in the immune modulation by vitamin $\mathrm{D}_{3}$. The increased proportion of circulating IL-10 ${ }^{+} \mathrm{CD} 4^{+} \mathrm{T}$ cells could represent an expansion of the Tr1 compartment. An increased proportion of these cells in the periphery could also drive the increased Treg suppressive capacity and decreased Th1/Th2 ratio in patients with an adequate vitamin $D$ status as described in chapter 4 and 5. DC are potent targets of $1,25(\mathrm{OH})_{2} \mathrm{D}$ in vitro, and have been argued to be of vital interest for the actions of vitamin $D_{3}$ on the adaptive immune response. Tolerogenic $1,25(\mathrm{OH})_{2} \mathrm{D}$-treated DC induce a skewing from Th1 to Th2 cells, and have been shown to promote $\mathrm{IL}-10^{+} \mathrm{CD} 4^{+} \mathrm{T}$ cell development. In chapter 4 , however, we assessed the proportion of circulating IL- $10^{+} \mathrm{CD} 4^{+} \mathrm{T}$ cells, and found no correlation with vitamin $\mathrm{D}$ status. However, this may be attributable to a technically inferior analysis due to the unpaired design and the older generation flowcytometer. It will be a challenge for future studies to capture the interaction between vitamin $D$ and $\operatorname{Tr} 1$ (function) in patients with MS. Alternatively, in the cohort described in chapter 4, 6/29 patients displayed an especially poor suppression. In the participants of the pilot study, a similar pronounced poor suppression was not observed. 
Therefore, the discrepancy may be a sampling effect. Additionally, in several patients control studies, a substantial proportion of MS patients shows a Treg suppressive capacity comparable to healthy controls (Viglietta et al., 2004; Venken et al., 2006). It is uncertain whether vitamin D supplementation can be expected to improve Treg suppressive capacity when it is already within the physiological range at baseline. A trial design which could take this limitation into account, is selection of patients with a poor Treg function at baseline, and allocation towards either vitamin $D_{3}$ or placebo supplementation afterwards. Alternatively, since we found more frequently a poor Treg suppressive capacity in patients with a poor vitamin $D$ status (chapter 4 ), inclusion of patients with a poor vitamin D status (<50 nmol/L) would also result in a study cohort which is enriched in patients with a poor Treg function. In chapter 4, it also appears that a certain proportion of patients displays a normal Treg function, despite a poor vitamin D status. This observation suggests that certain factors may make an individual more susceptible to immunological complications of a poor vitamin D status. This might be genetic background. Both immune- and vitamin D-related genes have been argued to affect the interaction between vitamin D and the immune response in MS (Colin et al., 2000; Ramagopalan et al., 2009; van Etten et al., 2007), and the response of an individual on vitamin D supplementation (Orton et al., 2008). When developing definitive studies on the effects of vitamin $D$ supplementation on the peripheral immune system, these variables should be taken into account. Additionally, the choice of immunological assays to assess the effects of vitamin D should also be carefully made. Based on our results, a focus on T cell cytokine-profile directly ex-vivo could be a logical choice. Others have chosen T cell proliferation on specific stimulation by CNS proteins (Burton et al., 2010). The most important limitation of this system is that only a subset of patients responds to these stimuli (Banwell et al., 2008). Although the stimulation observed is specific, the effect of the intervention is not necessarily so. An increase in regulatory/ anti-inflammatory cells in the culture system may also affect the response. Studies like the one presented in chapter 6 provide more data for a rational choice in this perspective.

Although the numbers are small and the study is unblinded and uncontrolled, the results show at least that the peripheral immune modulating potential of vita$\min D_{3}$ is a plausible underlying mechanism of the associations between vitamin $D$ status and MS disease activity in the investigated population of patients. Furthermore, it provided directions to design an immunological substudy to the large randomized placebo controlled trial (chapter 8). 


\section{Genes and vitamin D}

In chapter 7, we discussed the effect of a genetic polymorphism of the vitamin D receptor (VDR) on serum 25(OH)D levels in patients with MS. Apparently, the polymorphism Fok-I (RS10735810) interfered with the regulation of vitamin D metabolism. However, the risk for developing MS was unaffected.

When seasonal variation of serum $25(\mathrm{OH}) \mathrm{D}$ was eliminated by measuring all subjects in the same month, $77 \%$ of the variation of serum $25(\mathrm{OH}) \mathrm{D}$ has been estimated to be attributable to a variation in genetic factors in a population of MS patients and healthy controls (Orton et al., 2008). As candidate genes for these genetic factors, genes involved in vitamin $D$ metabolism have been frequently investigated with various results. The most well established predictors of vitamin D status, are two genetic polymorphisms within the vitamin D binding protein gene, i.e. RS4588 and RS7041 (Engelman et al., 2008; Sinotte et al., 2009). Additionally, polymorphisms of the CYP27B1 gene have been associated with serum 25(OH)D levels, albeit with variable results (Orton et al., 2008; Engelman et al., 2008). Concerning the effects of single nucleotide polymorphisms (SNP's) within the VDR gene, the results are even less clear (Table 1). When analyzing exclusively genetic contributions to vitamin $D$ status, all other contributors to vitamin $D$ status should most preferably be eliminated. The level of exposure to environmental sources of vitamin $D$ is probably the important one. The seasonal fluctuation of serum 25(OH)D-levels can be dealt with by limitation of the timeframe of inclusion, or by introducing month of serum sampling in regression models. However, even when seasonal fluctuation is eliminated, $23 \%$ of the variation in serum $25(\mathrm{OH}) \mathrm{D}$ levels has been estimated to be caused by other factors than genes (Orton et al., 2008). Variation in diet and sunbehavior is not taken into account. The most appropriate way to address the issue of exposure is to sample serum in a short time-frame and additionally to quantify vitamin $D$ exposure with questionnaires regarding diet and sun-behavior (Van der Mei et al., 2007), or with a sun-exposure meter (Simpson et al., 2010). Even when the extent of sun-exposure is standardized, the efficiency of sunlight to induce synthesis vitamin D differs between geographic locations (Figure 3), making populations in different geographical areas hard to compare (Wang et al., 2010). Additionally, the distribution of vitamin D related SNP's is likely to be affected in different populations by natural selection (Jablonski and Chaplin, 2010), since an allele associated with increased 25(OH)D levels may be more essential for survival to someone living near the polar circle, than for someone living near the equator. Lastly, clear differences can be observed in the vitamin D metabolism of Caucasians when compared to African Americans (Harris 2006). Beside these factors, there are also other contributors to vitamin D status, including body mass index (BMI), skin melanin density, age, and drug use. All these factors introduce noise in the analysis of a relationship between vitamin $\mathrm{D}$ status and genetic polymorphisms, and the different 
ways by which studies cope with these confounders, may also contribute critically to their different results (Table 1).

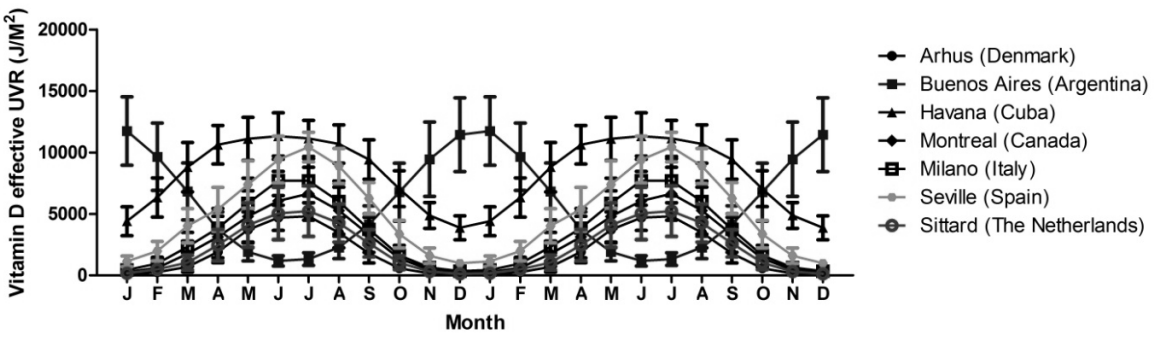

Figure 3 The mean amount of vitamin $\mathrm{D}$ effective ultraviolet radiation $\left(\mathrm{J} / \mathrm{M}^{2}\right)$ adjusted for clouds and ozone in several countries between January $1^{\text {st }} 1979$ and $31^{\text {st }} 1990$, stratified for months.

(Courtesy of Ola Engelsen, Norwegian Institute for Air Research, The Polar Environmental Centre, Norway)

Table 1 Vitamin D receptor gene polymorphisms and serum 25(OH)D levels

\begin{tabular}{lcclll}
\hline Study & $\begin{array}{c}\# \\
\text { Subjects }\end{array}$ & $\begin{array}{c}\# \\
\text { SNPs }\end{array}$ & $\begin{array}{l}\text { Associated with } \\
\text { 25(OH)D }\end{array}$ & \multicolumn{2}{l}{$\begin{array}{l}\text { Adjustments in model Inclusion } \\
\text { timeframe }\end{array}$} \\
\hline d' Alesio et al., 2005 & 185 & 3 & Hap. RS4516035 \& & Age, month, BMI, & None \\
& & & RS7139166 & PTH, calcium intake. & \\
Wjst et al., 2006 & 872 & 12 & None & Age, month & None \\
Engelman et al., 2008 & 229 & 14 & RS10783219 & Age, Sex & None \\
Orton et al., 2008 & 198 & 30 & RS10735810 & None & Mar-Apr \\
$\begin{array}{l}\text { Smolders et al., } \\
\text { 2009a }\end{array}$ & $212 / 289$ & 1 & RS10735810 & Age, Sex, Disability & May-Oct/ Nov-Apr \\
Smolders et al., & $212 / 289$ & 2 & None & Age, Sex, Disability & May-Oct/ Nov-Apr \\
2009b & & & & &
\end{tabular}

In our dataset, we reduced the effect of season of serum sampling by including individuals during either summer or winter period. Additionally, we took sun exposure into account by introducing EDSS-score in the analysis. Van der Mei et al., showed that EDSS-score correlates negatively with the level of sun-exposure (Van der Mei et al., 2007). In our population, vitamin D status correlated negatively with EDSS-score (Smolders et al., 2008b, chapter 3). The reproducibility of the predictive effect of the polymorphism on serum 25(OH)D levels in MS patients in summer and winter, and in healthy controls, supports its relevance, as well as the reproduction in a Canadian cohort of MS patients and healthy controls (Orton et al., 2008). Therefore, we can conclude that the Fok-I VDR polymorphism affects at least serum 25(OH)D levels, and therefore the interaction as is indicated by arrow 1 in Figure 1.

Subsequently, an effect of genetic polymorphisms on the circulating 25(OH)D levels would also be expected to affect the risk on developing MS. Poor serum 25(OH)D levels have been associated with an increased risk for developing MS 
(Munger et al., 2006). However, vitamin D related genes seldom surface in genome wide screens (International MS Genetics Consortium, 2007), and only one large study convincingly showed an association of CYP27B1 SNP's with the risk on developing MS in a Swedish population (Sundqvist et al., 2010). A conceivable explanation is, that genetic background is only one of many factors which affect serum $25(\mathrm{OH}) \mathrm{D}$ levels. An effect of a polymorphism on vitamin D status (vide supra) should be very strong to overrule all these other factors. Additionally, other genetic and environmental risk factors might also interfere. The genotype of HLA-DR alleles has also been reported to interact with vitamin D status (Ramagopalan et al., 2009). Therefore, it is not too surprising that we do not find an association of the Fok-I VDR gene polymorphism with MS in our population. The uncorrected difference in mean serum 25(OH)D level was only $10-16 \mathrm{nmol} / \mathrm{L}$ between homozygous carriers of the major and minor allele, and $13-17 \mathrm{nmol} / \mathrm{L}$ when corrected for age, sex, and disability. Considering the wide range of serum 25(OH)D levels found in our studies, this contribution is quite modest. Another mechanism could be, that a polymorphism affects the functionality of the VDR (arrow 2 in Figure 1). A genetic defect within the CYP27B1 gene, which causes vitamin D dependent rickets type 1 , has been found in several relatives with familial MS (Torkildsen et al., 2008; Ramagopalan et al., 2010). In addition, common genetic variants of the CYP27B1 gene have also been associated with the odds on MS (Sundqvist et al., 2010). In vitamin D dependent rickets type 2 (VDDR-2), the VDR pathway in the cell is disturbed. Interestingly, $1,25(\mathrm{OH})_{2} \mathrm{D}$ reduces IFN-y production in PBMC from healthy donors, but not in PBMC from VDDR-2 patients (Reichel et al., 1987). Additionally, treatment with $1,25(\mathrm{OH})_{2} \mathrm{D}$ induces no up-regulation of CYP24A1 in fibroblasts of VDDR-2 patients (Gamblin et al., 1985). An association of VDDR-2 with MS has not been described, but an association of genetic variants of the VDR with MS is conceivable. The Fok-I polymorphism leads to a longer isoform of the VDR, which has been argued to be less transcriptionally active (reviewed in Smolders et al., 2009c). However, consistent effects of the Fok-I VDR polymorphism on immune response to $1,25(\mathrm{OH})_{2} \mathrm{D}$ have not been described (Colin et al., 2000; van Etten et al., 2007).

\section{The clinical trial in preparation}

Some researchers and clinicians have been skeptical about the need for designing clinical trials on vitamin $D_{3}$ supplementation in $M S$, since the therapeutic efficacy might not match the efficacy of newly appearing MS drugs. To determine the theoretical efficacy of vitamin D supplementation, association studies can be used. In the assumption that trials will supplement moderate- to high-doses of vitamin $D_{3}$, it is reasonable to assume that an elevation of serum $25(\mathrm{OH}) \mathrm{D}$ levels of at least 50 $\mathrm{nmol} / \mathrm{L}$ will be achieved in each participant supplemented with vitamin $D_{3}$ (Burton 
et al., 2010, Kimball et al., 2007, chapter 6). An estimation of effect-size based on our own retrospective data is extremely inaccurate. These data would suggest a massive effect, with an $51 \%$ increase in the odds on remaining relapse-free for every $10 \mathrm{nmol} / \mathrm{L}$ increase of vitamin D (Smolders et al., 2008b, chapter 3). The prospective Tasmanian study calculated a 9-12\% increase in the proportion of relapsefree patients for each $10 \mathrm{nmol} / \mathrm{L}$ increase (Simpson et al., 2010). Interestingly, a prospective trial on vitamin D status and relapse-risk in children with MS also calculated a $13 \%$ increase in relapse-free proportion of patients for each $10 \mathrm{nmol} / \mathrm{L}$ increase of vitamin D status (Mowry et al., 2010). When assuming a linear relationship, this would mean at least a $45-60 \%$ increase in the relapse-free proportion of patients between both treatment-arms in the trial. However, it remains to be seen whether treatment effects will really be this large. Observational studies acquired their estimations of effect-size mostly by extensive modeling and making several assumptions. It must be realized that any estimation of effect size is surrounded by large confidence intervals. Vitamin D status itself is dependent on sun-exposure and outdoor physical activity. There is some evidence available that both these factors contribute individually to disease activity of MS (Becklund et al., 2010). Additionally, the inverse linearity of the relationship between vitamin $D$ status and the hazard on relapses in the supra-physiological range of serum $25(\mathrm{OH}) \mathrm{D}$ levels is uncertain. For the design of the trial, we performed a power-analysis from a worse-case scenario. The RNF study showed a relapse-free proportion of $52.8 \%$ after 2-year treatment with RebifC (Giovannoni et al., 2009). Interestingly, data from our own patient population displayed approximately the same proportion of $53.3 \%$. Therefore, we expect in the placebo arm, at the end of the study, $53 \%$ of all participants to remain relapse-free. The minimal increase that we want to be able to measure is to $69 \%$ relapse-free, which means a percentual increase of $30 \%$. It should be noted that this increase is only half of the increase predicted by association studies assuming an elevation of serum 25(OH)D of $50 \mathrm{nmol} / \mathrm{L}$.

What are the most obvious challenges faced when designing a trial on vitamin $D_{3}$ supplementation in MS? The first challenge is, that treatment and placebo arms do not compare either the presence or absence of the intervention (i.e. vitamin D), but rather exposure to vitamin $D$ in the physiological vs. the super-physiological range. This problem can be approached in two ways: either only patients with a poor vitamin $D$ status should be included, or patients should be supplemented with sufficiently high doses of vitamin $D_{3}$ to induce a larger difference between the two arms. Both approaches have their downsides. Including selectively patients with low serum 25(OH)D levels, leaves patients in the placebo group exposed to a poor vitamin D status and a sub-optimal calcium homeostasis for a long period of time (Dawson-Hughes et al., 2005). Alternatively, the safety of long-term high-dose vitamin $D_{3}$ supplementation is not yet fully consolidated (Hathcock et al., 2007; Kimball et al., 2007), and epidemiological evidence on the relationship between these supra- 
physiological 25(OH)D levels and disease activity of MS is at present lacking. A potential U-shaped relationship cannot be excluded, yet our own data and the data of Burton et al. do not point in that direction (Burton et al., 2010; chapter 6). In the upcoming SOLAR study, we choose the latter approach, since a beneficial effect of high-doses vitamin $D_{3}$ on MS activity has been suggested (Burton et al., 2010). Safety aspects will be carefully monitored, and an independent data safety monitoring board has been installed. The second challenge is the incorporation of genetic background in a trial. As described in chapter 7, several vitamin D related genes are likely to interact with the effects of vitamin D supplementation (Orton et al., 2007). Additionally, interaction of vitamin D status with the genotype of the MHC class II receptor has been proposed (Ramagopalan et al., 2009). Studies should be designed in such a way, that influences of these genes on treatment outcomes can be analyzed. In the SOLAR study, DNA will be sampled for this purpose. The last challenge is the careful choice of outcome measures. Primarily, the SOLAR study will focus on classical MS outcome measures, as relapse activity, EDSS progression, and MRI activity. Other symptoms frequently found in MS patients are cognitive deterioration, fatigue, and depression (Bol et al., 2010). For instance, the presence of depressive symptoms in MS patients has also been associated with a poor vitamin D status (Knippenberg et al., 2010). Including also these parameters could provide a complete overview of the impact of vitamin D supplementation of the disease process of MS.

With our research as presented in chapters 4-6, we made the interaction between vitamin $D$ status and peripheral T cell homeostasis a likely driver of a therapeutic effect of vitamin D. The SOLAR study provides the opportunity to test this hypothesis in a blinded, placebo-controlled design. The patients which will be included, match the patients which we included in the studies described in chapters 4-6. However, it should be kept in mind that an immune modulating effect of vitamin $D$ in the periphery might not be the only mechanism of action of vitamin $D$. Vitamin D is present in the circulation, but also in CNS of MS patients (Holmøy et al., 2009). The role that vitamin D plays in this inflammatory environment, is at present still unexplored. An up-regulation of the VDR and CYP27B1 in rodents with EAE when compared to control animals has been reported (Spach et al., 2005). Whether vitamin D also plays a role in local immune homeostasis in the CNS of MS patients is uncertain. If so, experimental evidence would provide more reason to also assess the effects of vitamin $D$ status on disability progression in patients with multiple sclerosis. 


\section{Conclusions}

This thesis is not the end of a story, but reports rather first investigations of a new research line. We started with a review of the existing literature on vitamin $D$ and $\mathrm{MS}$, and are now performing a large international multi-center randomized placebocontrolled clinical trial on vitamin $\mathrm{D}_{3}$ supplementation in MS. At present, the evidence from our work is not conclusive, but provided rather tools for further research.

From the research presented in this thesis, we can draw the following conclusions:

Vitamin $D$ is in vitro an important regulatory molecule within the adaptive immune response, but whether vitamin $\mathrm{D}$ is an immune and disease modulator in vivo in MS is uncertain (chapter 2).

In the MS population in South Limburg (The Netherlands), a poor vitamin D status is associated with a high level of disability, and with an increased relapse activity (chapter 3).

It is plausible that vitamin D act as a peripheral immune modulator in MS patients, and that low $25(\mathrm{OH}) \mathrm{D}$ levels result in a loss of regulation of peripheral $\mathrm{CD}^{+} \mathrm{T}$ cell homeostasis (chapters 4-6).

Patients with MS should be supplemented with vitamin $D$ in trials, and not with $1,25(\mathrm{OH})_{2} \mathrm{D}$ (chapters 3 and $\mathbf{5}$ ).

Supplementation of high doses vitamin $D_{3}$ without a dose-escalation scheme for 12 weeks does not induce a decompensated calcium metabolism (chapter 6).

Genetic polymorphisms of vitamin D related genes contribute to $25(\mathrm{OH}) \mathrm{D}$ concentrations in the circulation of patients with MS and of healthy subjects (chapter 7).

There is a large clinical trial underway, which addresses several key questions in the field of vitamin D and MS research (chapter 8).

\section{Future directions and concluding remarks}

In the end, the research presented in this thesis generated more questions than answers. This provides many entries for further studies.

T cells are the most important effector cells in MS (Bar-Or 2009). The correlation between vitamin $\mathrm{D}$ status and peripheral $\mathrm{T}$ cell homeostasis is not necessarily a direct effect of 25(OH)D on the T cell (Correale et al. 2009), but might be the result of an immunological chain of events. Many candidate targets can be proposed. Firstly, monocytes and dendritic cells are potent targets of $1,25(\mathrm{OH})_{2} \mathrm{D}$ in vitro, and $1,25(\mathrm{OH})_{2} \mathrm{D}$-treated dendritic cells skew the $\mathrm{T}$ cell compartment to a less proinflammatory state (chapter 2). Additionally, experimental research suggested that for a therapeutic effect of $1,25(\mathrm{OH})_{2} \mathrm{D}$ in EAE, a RAG-dependent (Nashold et al., 2001), IL-10 producing cell (Spach et al., 2006) is mandatory. Although we focused 
on T cells, the regulatory B cell is also a theoretical option (Heine et al., 2008). Interestingly, more studies are currently focusing on regulatory B cells in MS. Further characterization of the interaction between vitamin $D$ and the adaptive immune response in vivo could lead to a more specifically directed therapeutic intervention in MS.

The interaction between vitamin $D$ and the adaptive immune response is likely not specific. Since we included no control groups in chapters 4-6 of this thesis, we cannot validate this claim with our own data. However, an increased incidence of other autoimmune diseases has also been associated with correlates of a poor vitamin D exposure, including diabetes type 1 (Hypponen et al., 2001), rheumatoid arthritis (Cutolo et al., 2006), systemic lupus erythematodes (Müller et al., 1995), and vasculitis (Gatenby et al., 2009). Since a disturbed T cell homeostasis has also been argued to play a role in these diseases, observational and intervention studies on vitamin $\mathrm{D}$ (supplementation) and disease activity are warranted. Another therapeutic strategy with vitamin $D$ has been proposed in diabetes mellitus type 1 . Vaccination of epitope-loaded DC after tolerogenisation with $1,25(\mathrm{OH})_{2} \mathrm{D}$ has been proposed as a treatment option in transplant and autoimmune disease patients (Unger et al., 2009). This approach differs in essence from supplementation of vitamin D, since it aims to force the adaptive immune response in a tolerant state, rather than optimizing a biological homeostatic mechanism. In MS, the vaccination strategy may prove difficult, since the exact epitope against which the autoimmune response is directed, is not known.

The relationship between vitamin D status and several disease activity measures of MS has been assessed. The association between relapse activity of MS and vitamin D status is the most well consolidated (Mowry et al., 2010; Simpson et al., 2010; Smolders et al., 2008b, chapter 3). An association between EDSS-score and vitamin D status is known for the longest time (Smolders et al., 2008b, chapter 3; van der Mei et al., 2007), yet prospective studies on disability progression in MS are lacking. Additionally, we described a correlation between depressive symptoms of MS and vitamin D status (Knippenberg et al., 2010), which also requires consolidation. In a prospective follow-up of the (extended) cohort as described in chapter $\mathbf{3}$, several of these issues will be addressed. With clinical trials ahead, it is important to consolidate outcome measures of interest.

Vitamin D research is important. Supplementation can be safe, without sideeffects, and cheap. Although the efficacy in MS patients is difficult to estimate, a small additive effect to current or future disease modulating drugs in MS is worthwhile. Especially, since drug treatment costs for MS patients would be elevated by a negligible fraction, and the safety profile appears at present favorable. Not only a role in MS, but also in many other (autoimmune) disease has been proposed for vitamin $D$. In these days of rising healthcare costs, a potential benefit of a cheap 
intervention which could be applied on a public scale in the prevention and treatment of invalidating diseases is extremely important to investigate.

To conclude, the most relevant question for MS patients is at present whether they should be supplemented with vitamin $D_{3}$. Although we cannot relate our data to healthy control data, we showed in chapters 3-6 that about $50 \%$ of MS patients displays a vitamin D status $<50 \mathrm{nmol} / \mathrm{L}$. There is a considerable amount of agreement among experts that these levels are too poor to maintain a healthy calcium metabolism (Dawson-Hughes et al., 2005).Therefore, patients should be encouraged to supplement themselves with moderate amounts of vitamin $D_{3}$. Although cross-sectional studies show promising results, it should be made clear to patients that a therapeutic effect of vitamin D on the disease course of MS is at present uncertain. Therefore, supplementation of (high) doses of vitamin $D_{3}$ for the sake of modulating the disease course of MS, is at present premature. How does this idea relate to government policy? In 2008, the national Dutch Health Counsel advised the minister of public health on supplementation of vitamin $D_{3}$ to the Dutch public (Weggemans et al. 2009). In their much criticized report (Muskiet et al., 2010), advises for supplementation were mostly based on large national cohort studies . Supplementation of $20 \mu \mathrm{g} / \mathrm{d}$ was advised to institutionalized elderly with or without osteoporosis and to subjects older than 50 (females) or 70 (males) which have a dark skin-type or are not frequently exposed to sunlight, and to veiled females older than 50 years. The studies on which these advises are partly based (the Longitudinal Aging Study Amsterdam and the Hoorn study) show that $47-51 \%$ of ambulatory elderly has a vitamin D status $<50 \mathrm{nmol} / \mathrm{L}$. From the perspective of the Dutch Health Council committee, patients with MS (regardless age) who are not much exposed to sunlight, should also be recommended supplementation of $20 \mu \mathrm{g} / \mathrm{d}$ vitamin $D_{3}$. This may also account for other chronic diseased cohorts. Hopefully, in the next report of the Dutch Health Council regarding vitamin D, this significant and vulnerable part of Dutch society will not be forgotten. 

References
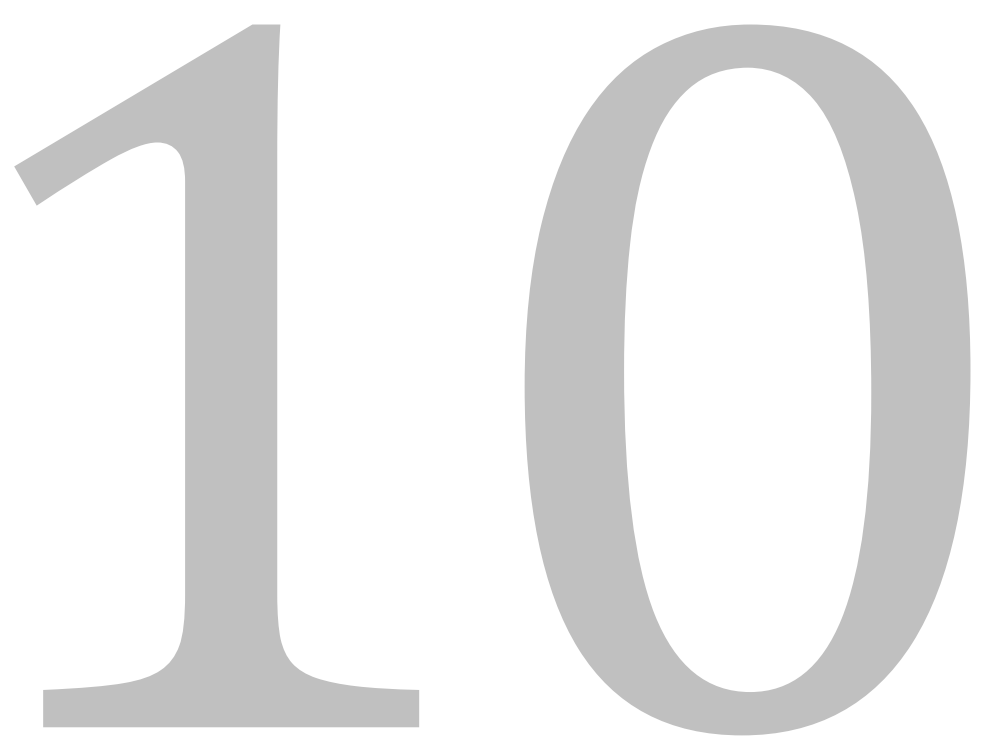
1. Abbas AK, Murphy KM, Sher A. Functional diversity of helper T lymphocytes. Nature 1996;383:78793.

2. Acheson ED, Bachrach CA, Wright FM. Some comments on the relationship of the distribution of multiple sclerosis to latitude, solar radiation, and other variables. Acta Psychiatr Scand Suppl 1960;35:132-147.

3. Achiron A, Barak Y, Miron S, Izhak Y, Faibel M, Edelstein S. Alfacalcidol treatment in multiple sclerosis. Clin Neuropharmacol 2003;26:53.

4. Adams JS, Hewison M. Unexpected actions of vitamin D: new perspectives on the regulation of innate and adaptive immunity. Nat Clin Pract Endocrinol Metab 2008;4:80-90.

5. Almeras L, Eyles D, Benech P, Laffite D, Villard C, Patatian A, Boucraut J, Mackay-Sim A, McGrath J, Feron $F$. Developmental vitamin $D$ deficiency alters brain protein expression in the adult rat: implications for neuropsychiatric disorders. Proteomics 2007;7:769-780.

6. Al-Shammri S, Rawoot P, Azizieh F, AbuQoora A, Hanna M, Saminathan TR, Raghupathy R. Th1/Th2 cytokine patterns and clinical profiles during and after pregnancy in women with multiple sclerosis. J Neurol Sci 2004;222:21-27.

7. Andreev $\mathrm{E}$, Koopman M, Arisz L. A rise in plasma creatinine that is not a sign of renal faillure: which drugs can be responsible? J Int Med 1992;246:247-252.

8. Arnson $\mathrm{Y}$, Amital H, Shoenfeld Y. Vitamin D and autoimmunity: new aetiological and therapeutic considerations. Ann Rheum Dis 2007;66:1137-1142.

9. Ascherio A, Munger KL, Lenette ET, Spiegelman D, Hernán MA, Olek MJ, Hankinson SE, Hunter DJ. Epstein-Bar virus antibodies and risk of multiple sclerosis: a prospective study. JAMA 2001;286:3083-3088.

10. Ascherio A, Munger KL, Simon C. Vitamin D and multiple sclerosis. Lancet Neurol 2010;9:599-612

11. Auer DP, Schumann EM, Kumpfel T, Gossl C, Trenkwalder C. Seasonal fluctuations of gadoliniumenhancing magnetic resonance imaging lesions in multiple sclerosis. Ann Neurol 2000;47:276-277.

12. Balashov KE, Olek MJ, Smith DR, Khoury SJ, Weiner HL. Seasonal variation of interferon-gamma production in progressive multiple sclerosis. Ann Neurol 1998;44:824-828.

13. Bamford CR, Sibley WA, Thies C. Seasonal variation of multiple sclerosis exacerbations in Arizona. Neurology 1983;33:697-701.

14. Banwell B, Bar-Or A, Cheung R, Kennedy J, Krupp LB, Becker DJ, Dosch HM; Wadsworth Pediatric Multiple Sclerosis Study Group. Abnormal T-cell reactivities in childhood inflammatory demyelinating disease and type 1 diabetes. Ann Neurol. 2008;63:98-111.

15. Barnes MS, Bonham MP, Robson PJ, Strain JJ, Lowe-Strong AS, Eaton-Evans J, et al., Assessment of 25-hydroxyvitamin $D$ and 1,25-dihydroxyvitamin D3 concentrations in male and female multiple sclerosis patients and control volunteers. Mult Scler 2007;13:670-672.

16. Bar-Or A. The immunology of multiple sclerosis. Semin Neurol 2008;28:29-45.

17. Barrat FJ, Cua DJ, Boonstra A, Richards DF, Crain C, Savelkoul HF, de Waal-Malefyt R, Coffman RL, Hawrylowicz CM, O'Garra A. In vitro generation of interleukin 10-producing regulatory CD4(+) T cells is induced by immunosuppressive drugs and inhibited by T helper type 1 (Th1)- and Th2inducing cytokines. J Exp Med 2002;195:603-616.

18. Bates CJ, Carter GD, Mishra GD, O'Shea D, Jones J, Prentice A. In a population study, can parathyroid hormone aid the definition of adequate vitamin $D$ status? A study of people aged 65 years and over from the British National Diet and Nutrition Survey. Osteoporos Int 2003;14:152-159.

19. Becklund BR, Hansen jr. DW, Deluca HF. Enhancement of 1,25-dihydroxyvitamin D3-mediated suppression of experimental autoimmune encephalomyelitis by calcitonin. Proc Natl Acad Sci USA 2009a;106:5276-5281.

20. Becklund BR, James BJ, Gagel RF, DeLuca HF. The calcitonin/calcitonin gene related peptide-alpha gene is not required for 1alpha,25-dihydroxyvitamin D3-mediated suppression of experimental autoimmune encephalomyelitis. Ach Biochem Biophys 2009b;488:105-108. 
21. Becklund BR, Severson KS, Vang SV, DeLuca HF. UV radiation suppresses experimental autoimmune encephalomyelitis independent of vitamin D production. Proc Natl Acad Sci U S A 2010;107:641823.

22. Bhalla AK, Amento EP, Krane SM. Differential effects of 1,25-dihydroxyvitamin D3 on human lymphocytes and monocyte/macrophages: inhibition of interleukin-2 and augmentation of interleukin1 production. Cell Immunol 1986;98:311-322.

23. Bischoff-Ferrari HA, Dietrich T, Orav EJ, Dawson-Hughes B. Positive association between 25-hydroxy vitamin $D$ levels and bone mineral density: a population-based study of younger and older adults. The Am J Med 2004; 116:634-639.

24. Bischoff-Ferrari HA, Willett WC, Wong, JB, Giovannucci E, Dietrich T, Dawson-Hughes B. Fracture Prevention With Vitamin D Supplementation, A Meta-analysis of Randomized Controlled Trials. JAMA 2005;293:2257-2264.

25. Bischoff-Ferrari HA, Dawson-Hughes B, Orav JE, Stuck AE, Theiler R, Wong JB, Egli A, Kiel DP, Henschkowski J. Fall prevention with supplemental and active forms of vitamin D: a meta-analysis of randomized controlled trials. BMJ 2009; 339:b3692.

26. Bol Y, Duits AA, Hupperts RM, Vlaeyen JW, Verhey FR. The psychology of fatigue in patients with multiple sclerosis: a review. J Psychosom Res 2009;66:3-11.

27. Boonstra A, Barrat FJ, Crain C, Heath VL, Savelkoul HF, O'Garra A. 1alpha,25-Dihydroxyvitamin d3 has a direct effect on naive CD4(+) T cells to enhance the development of Th2 cells. J Immunol 2001;167:4974-4980.

28. Bouillon R, Okamura WH, Norman AW. Structure-function relationships in the vitamin D endocrine system. Endocr Rev 1995;16:200-257.

29. Bouillon R. Vitamin D: from photosynthesis, metabolism and action to clinical applications. In: DeGroot L, Jameson J (Eds.). Endocrinology (Saunders, Philadelphia) 2005;5:1435-1463.

30. Branisteanu DD, Waer M, Sobis H, Marcelis S, Vandeputte M, Bouillon R. Prevention of murine experimental allergic encephalomyelitis: cooperative effects of cyclosporine and 1 alpha, 25(OH)2D3. J Neuroimmunol 1995;61:151-160.

31. Branisteanu DD, Mathieu C, Bouillon R. Synergism between sirolimus and 1,25-dihydroxyvitamin D3 in vitro and in vivo. J Neuroimmunol 1997;79:138-147.

32. Burton JM, Kimball S, Vieth R, Bar-Or A, Dosch HM, Cheung R, Gagne D, D'Sousa C, Ursell M, O'Connor P. A phase I/II dose-escalation trial of vitamin D3 and calcium in multiple sclerosis. Neurology 2010;74:1852-9.

33. Calabresi PA, Austin H, Racke MK, Goodman A, Choyke P, Maloni H, et al., Impaired renal function in progressive multiple sclerosis. Neurology 2002;59:1799-1801.

34. Cantorna MT, Hayes CE, DeLuca HF. 1,25-Dihydroxyvitamin D3 reversibly blocks the progression of relapsing encephalomyelitis, a model of multiple sclerosis. Proc Natl Acad Sci U S A 1996;93:78617864.

35. Cantorna MT, Woodward WD, Hayes CE, DeLuca HF. 1,25-dihydroxyvitamin D3 is a positive regulator for the two anti-encephalitogenic cytokines TGF-beta 1 and IL-4. J Immunol 1998;160:53145319.

36. Cantorna MT, Humpal-Winter J, DeLuca HF. Dietary calcium is a major factor in 1,25dihydroxycholecalciferol suppression of experimental autoimmune encephalomyelitis in mice. J Nutr 1999;129:1966-1971.

37. Cantorna MT, Humpal-Winter J, DeLuca HF. In vivo upregulation of interleukin-4 is one mechanism underlying the immunoregulatory effects of 1,25-dihydroxyvitamin $\mathrm{D}(3)$. Arch Biochem Biophys 2000;377:135-138.

38. Carlberg C, Quack M, Herdick M, Bury Y, Polly P, Toell A. Central role of VDR conformations for understanding selective actions of vitamin $D(3)$ analogues. Steroids 2001;66:213-221.

39. Cauley JA, Parimi N, Ensrud KE, Bauer DC, Cawthon PM, Cummings SR, Hoffman ER, Shikany JM, Barrett-Connor E, Orwoll E. Serum 25 HydroxyVitamin D and the Risk of Hip and Non-spine Fractures in Older Men. J Bone Min Res 2010;25:545-553. 
40. Chen KS, DeLuca HF. Cloning of the human 1 alpha,25-dihydroxyvitamin D-3 24-hydroxylase gene promoter and identification of two vitamin D-responsive elements. Biochim Biophys Acta 1995;1263:1-9.

41. Chen S, Sims GP, Chen XX, Gu YY, Chen S, Lipsky PE. Modulatory effects of 1,25-dihydroxyvitamin D3 on human B cell differentiation. J Immunol 2007;179:1634-1647.

42. Chen WC, Vayuvegula B, Gupta S. 1,25-Dihydroxyvitamin D3-mediated inhibition of human B cell differentiation. Clin Exp Immunol 1987;69:639-646.

43. Cippitelli M, Fionda C, Di Bona D, Di Rosa F, Lupo A, Piccoli M, Frati L, Santoni A. Negative regulation of CD95 ligand gene expression by vitamin D3 in T lymphocytes. J Immunol 2002;168:1154-1166.

44. Colin EM, Weel AE, Uitterlinden AG, Buurman CJ, Birkenhager JC, Pols HA, van Leeuwen JP. Consequences of vitamin $D$ receptor gene polymorphisms for growth inhibition of cultured human peripheral blood mononuclear cells by 1, 25-dihydroxyvitamin D3. Clin Endocrinol (Oxf)2000; 52:211216.

45. Compston A, Coles A. Multiple Sclerosis. Lancet 2002;359:1221-1231.

46. Compston A, Coles A. Multiple Sclerosis. Lancet 2008;372:1502-17.

47. Constantino C, Baecher-Allan C, Hafler D. Human regulatory T cells and autoimmunity. Eur J Immunol 2008;38:921-924.

48. Correale J, Ysrraelit MC, Gaitán MI. Immunomodulatory effects of vitamin D in multiple sclerosis. Brain 2009;132:1146-60.

49. Cosman F, Nieves J, Komar L, Ferrer G, Herbert J, Formica C, Shen V, Lindsay R. Fracture history and bone loss in patients with MS. Neurology 1998;51:1161-1165.

50. Cutolo M, Otsa K, Laas K, Yprus M, Lehtme R, Secchi ME, Sulli A, Paolino S, Seriolo B. Circannual vitamin $d$ serum levels and disease activity in rheumatoid arthritis: Northern versus Southern Europe. Clin Exp Rheumatol 2006; 24: 702-704.

51. Cutter GR, Baier ML, Rudick RA, Cookfair DL, Fischer JS, Petkau J, Syndulko K, Weinshenker BG, Antel JP, Confavreux C, Ellison GW, Lublin F, Miller AE, Rao SM, Reingold S, Thompson A, Willoughby E. Development of a multiple sclerosis functional composite as a clinical trial outcome measure. Brain 1999;122:871-882.

52. D’Ambrosio D, Cippitelli M, Cocciolo MG, Mazzeo D, Di Lucia P, Lang R, Sinigaglia F, PaninaBordignon P. Inhibition of IL-12 production by 1,25-dihydroxyvitamin D3. Involvement of NF-kappaB downregulation in transcriptional repression of the p40 gene. J Clin Invest 1998;101:252-262.

53. Damoiseaux J. Regulatory T cells: back to the future. Neth J Med 2006;64:4-9.

54. Davies PS, Bates CJ, Cole TJ, Prentice A, Clarke PC. Vitamin D: seasonal and regional differences in preschool children in Great Britain. Eur J Clin Nutr 1999;53:195-198.

55. Dawson-Hughes B, Heaney RP, Holick MF, Lips P, Meunier PJ, Vieth R. Estimates of optimal vitamin D status. Osteoporos Int 2005;16:713-716.

56. de Andres, C., Aristimuno, C., de Las Heras, V., Martinez-Gines, M.L., Bartolome, M., Arroyo, R., et al.,(2007). Interferon beta-1a therapy enhances CD4+ regulatory T-cell function: an ex vivo and in vitro longitudinal study in relapsing-remitting multiple sclerosis. J. Neuroimmunol. 182, 204-211.

57. Decallonne B, van Etten E, Overbergh L, Valckx D, Bouillon R, Mathieu C. 1Alpha,25dihydroxyvitamin D3 restores thymocyte apoptosis sensitivity in non-obese diabetic (NOD) mice through dendritic cells. J Autoimmun 2005;24:281-289.

58. Degenhardt A, Ramagopalan SV, Scalfari A, Ebers GC. Clinical prognostic factors in multiple sclerosis: a natural history review. Nat Rev Neurol 2009;5:672-582.

59. Deluca HF, Cantorna MT. Vitamin D: its role and uses in immunology. FASEB J 2001;15:2579-85.

60. Dong X, Bachman LA, Kumar R, Griffin MD. Generation of antigen-specific, interleukin-10-producing T-cells using dendritic cell stimulation and steroid hormone conditioning. Transpl Immunol 2003;11:323-333.

61. Dong X, Lutz W, Schroeder TM, Bachman LA, Westendorf JJ, Kumar R, Griffin MD. Regulation of relB in dendritic cells by means of modulated association of vitamin $D$ receptor and histone deacetylase 3 with the promoter. Proc Natl Acad Sci U S A 2006;102:16007-16012. 
62. Doorenbos CRC, van den Born J, Navis G, de Borst MH. Possible renoprotection by vitamin D in chronic renal disease: beyond mineral metabolism. Nat Rev Nephrol 2009;5:691-700.

63. Dusso AS, Brown AJ, Slatopolsky E. Vitamin D. Am J Physiol Renal Physiol 2005;289:F8-28.

64. Edwards $\amalg$, Robins RA, Constantinescu CS. Th17/Th1 phenotype in demyelinating disease. Cytokine 2010;50:19-23.

65. Embry AF, Snowdon LR, Vieth R. Vitamin D and seasonal fluctuations of gadolinium-enhancing magnetic resonance imaging lesions in multiple sclerosis. Ann Neurol 2000;48:271-272.

66. Engelman $C D$, Fingerlin $T E$, Langefeld $C D$, et al. Genetic and environmental determinants of 25hydroxyvitamin D and 1,25-dihydroxyvitamin D levels in Hispanic and African Americans. J Clin Endocrinol Metab2008;93:3381-3388.

67. Ferguson B, Matyszak MK, Esiri MM, Perry VH. Axonal damage in acute multiple sclerosis lesions. Brain. 1997;120:393-399.

68. Filippi M, Bozzali M, Rovaris M, Gonen O, Kesavadas C, Ghezzi A, Martinelli V, Grossman RI, Scotti G, Comi G, Falini A. Evidence for widespread axonal damage at the earliest clinical stage of multiple sclerosis. Brain 2003;126:433-437.

69. Foley RN, Collins AJ, Ishani A, Kalra PA. Calcium-phosphate levels and cardiovascular disease in community-dwelling adults: the Atherosclerosis Risk in Communities (ARIC) Study. Am Heart J 2008;156:556-563.

70. Fontenot J, Gavin M, Rudensky A. FoxP3 programs the development and function of $\mathrm{CD} 4^{+} \mathrm{CD} 25^{+}$ regulatory T cells. Nat Immunol 2003;4:330-336.

71. Formica CA, Cosman F, Nieves J, Herbert J, Lindsay R. Reduced bone mass and fat-free mass in women with multiple sclerosis: effects of ambulatory status and glucocorticoid Use. Calcif Tissue Int 1997;61:129-133.

72. Freedman DM, Dosemeci M, Alavanja MC. Mortality from multiple sclerosis and exposure to residential and occupational solar radiation: a case-control study based on death certificates. Occup Environ Med 2000;57:418-421.

73. Frischer JM, Bramow S, Dal-Bianco A, Lucchinetti CF, Rauschka $H$, Schmidbauer $M$, Laursen $H$, Sorensen PS, Lassmann $\mathrm{H}$. The relation between inflammation and neurodegeneration in multiple sclerosis brains. Brain 2009;132:1175-1189.

74. Fritsche J, Mondal K, Ehrnsperger A, Andreesen R, Kreutz M. Regulation of 25-hydroxyvitamin D3-1 alpha-hydroxylase and production of 1 alpha,25-dihydroxyvitamin D3 by human dendritic cells. Blood 2003;102:3314-3316.

75. Fukazawa T, Yabe I, Kikuchi S, Sasaki H, Hamada T, Miyasaka K, Tashiro K. Association of vitamin D receptor gene polymorphism with multiple sclerosis in Japanese. J Neurol Sci 1999;166:47-52.

76. Furby J, Hayton T, Altmann D, Brenner R, Chataway J, Smith KJ, Miller DH, Kapoor R. A longitudinal study of MRI-detected atrophy in secondary progressive multiple sclerosis. J Neurol 2010;257:1508-1516.

77. Gamblin GT, Liberman UA, Eil C, Downs RW Jr, DeGrange DA, Marx SJ. Vitamin D-dependent rickets type II. Defective induction of 25-hydroxyvitamin D3-24-hydroxylase by 1,25-dihydroxyvitamin D3 in cultured skin fibroblasts. J Clin Invest 1985;75:954-960.

78. Garcion E, Nataf S, Berod A, Darcy F, Brachet P. 1,25-Dihydroxyvitamin D3 inhibits the expression of inducible nitric oxide synthase in rat central nervous system during experimental allergic encephalomyelitis. Brain Res Mol Brain Res 1997;45:255-267.

79. Garcion E, Wion-Barbot N, Montero-Menei CN, Berger F, Wion D. New clues about vitamin D functions in the nervous system. Trends Endocrinol Metab 2002;13:100-105.

80. Garcion E, Sindji L, Nataf S, Brachet P, Darcy F, Montero-Menei CN. Treatment of experimental autoimmune encephalomyelitis in rat by 1,25-dihydroxyvitamin D3 leads to early effects within the central nervous system. Acta Neuropathol (Berl) 2003;105:438-448.

81. Gatenby PA, Lucas RM, Engelsen O, Ponsonby AL, Clements M. Antineutrophil cytoplasmic antibody-associated vasculitides: could geographic patterns be explained by ambient ultraviolet radiation? Arthritis Rheum 2009;61:1417-1424. 
82. Gauzzi MC, Purificato C, Donato K, Jin Y, Wang L, Daniel KC, Maghazachi AA, Belardelli F, Adorini L, Gessani S. Suppressive effect of 1alpha,25-dihydroxyvitamin D3 on type I IFN-mediated monocyte differentiation into dendritic cells: impairment of functional activities and chemotaxis. J Immunol 2005;174:270-276.

83. Gilmore W, Arias M, Stroud N, Stek A, McCarthy KA, Correale J. Preliminary studies of cytokine secretion patterns associated with pregnancy in MS patients. J Neurol Sci 2004;224:69-76.

84. Giovannoni G, Barbarash O, Casset-Semanaz F, King J, Metz L, Pardo G, Simsarian J, Sørensen PS, Stubinski B; Rebif New Formulation Study Group. Safety and immunogenicity of a new formulation of interferon beta-1a (Rebif New Formulation) in a Phase IIlb study in patients with relapsing multiple sclerosis: 96-week results. Mult Scler. 2009;15:219-228.

85. Goldacre MJ, Seagroatt V, Yeates D, Acheson ED. Skin cancer in people with multiple sclerosis: a record linkage study. J Epidemiol Community Health 2004;58:142-144.

86. Goldberg P, Fleming MC, Picard EH. Multiple sclerosis: decreased relapse rate through dietary supplementation with calcium, magnesium and vitamin D. Med Hypotheses 1986;21:193-200.

87. Gombart AF, Borregaard N, Koeffler HP. Human cathelicidin antimicrobial peptide (CAMP) gene is a direct target of the vitamin $D$ receptor and is strongly up-regulated in myeloid cells by 1,25 dihydroxyvitamin D3. FASEB J 2005;19:1067-1077.

88. Gottfried E, Rehli M, Hahn J, Holler E, Andreesen R, Kreutz M. Monocyte-derived cells express CYP27A1 and convert vitamin D3 into its active metabolite. Biochem Biophys Res Commun 2006;349:209-13.

89. Goverman, J. Autoimmune T cell responses in the central nervous system. Nat Rev Immunol 2009;9: 393-407.

90. Griffin MD, Lutz WH, Phan VA, Bachman LA, McKean DJ, Kumar R. Potent inhibition of dendritic cell differentiation and maturation by vitamin D analogs. Biochem Biophys Res Commun 2000;270:701708.

91. Griffin MD, Lutz W, Phan VA, Bachman LA, McKean DJ, Kumar R. Dendritic cell modulation by 1alpha,25 dihydroxyvitamin D3 and its analogs: a vitamin D receptor-dependent pathway that promotes a persistent state of immaturity in vitro and in vivo. Proc Natl Acad Sci U S A 2001;98:68006805.

92. Haas J, Hug A, Viehöver A, et al., Reduced suppressive effect of $C D 4^{+} C D 25^{\text {high }}$ regulatory $T$ cells on the $\mathrm{T}$ cell immune response against myelin oligodendrocyte glycoprotein in patients with multiple sclerosis. Eur J Immunol 2005;35:3343-3352.

93. Haas J, Korporal M, Balint B, Fritzsching B, Schwarz A, Wildemann B. Glatiramer acetate improves regulatory T-cell function by expansion of naive $\mathrm{CD} 4^{+} \mathrm{CD} 25^{+} \mathrm{FOXP3}{ }^{+} \mathrm{CD} 31^{+} \mathrm{T}$-cells in patients with multiple sclerosis. J Neuroimmunol 2009;216:113-7.

94. Hammond SR, McLeod JG, Millingen KS, Stewart-Wynne EG, English D, Holland JT, McCall MG. The epidemiology of multiple sclerosis in three Australian cities: Perth, Newcastle and Hobart. Brain 1988;111:1-25.

95. Hammond SR, English DR, McLeod JG. The age-range of risk of developing multiple sclerosis: evidence from a migrant population in Australia. Brain 2000;123:968-974.

96. Handel AE, Williamson AJ, Disanto G, Handunetthi L, Giovannoni G, Ramagopalan SV. An updated meta-analysis of risk of multiple sclerosis following infectious mononucleosis. PLoS One 2010;5:e12496.

97. Handunnetthi L, Ramagopalan SV, Ebers GC. Multiple sclerosis, vitamin D, and HLA-DRB1*15. Neurology 2010;74:1905-10.

98. Harris SS. Vitamin D and African Americans. J Nutr 2006 Apr;136:1126-1129

99. Hathcock JN, Shao A, Vieth R, Heaney R. Risk assessment for vitamin D. Am J Clin Nutr 2007;85:618.

100. Hauser SL, Oksenberg JR. The neurobiology of multiple sclerosis: genes, inflammation, and neurodegeneration. Neuron 2006;52:61-76. 
101. Hauser SL, Weiner HL, Che M, Shapiro ME, Gilles F, Letvin NL. Prevention of experimental allergic encephalomyelitis (EAE) in the $\mathrm{SJ} / \mathrm{J}$ mouse by whole body ultraviolet irradiation. J Immunol 1984;132:1276-1281.

102. Heaney RP, Davies KM, Chen TC, Holick MF, Barger-Lux MJ. Human serum 25-hydroxycholecalciferol response to extended oral dosing with cholecalciferol. Am J Clin Nutr 2003;77:204-10.

103. Heaney RP. Vitamin D: criteria for safety and efficacy. Nutr Rev 2008;66:S178-S181.

104. Heine G, Niesner U, Chang HD, Steinmeyer A, Zügel U, Zuberbier T, Radbruch A, Worm M. 1,25dihydroxyvitamin D(3) promotes IL-10 production in human B cells. Eur J Immunol 2008;38:22102218.

105. Hollis BW. Assessment of vitamin D nutritional and hormonal status: what to measure and how to do it. Calcif Tissue Int 1996;58:4-5.

106. Hollis BW, Wagner CL, Drezner MK, Binkley NC. Circulating Vitamin $D_{3}$ and 25-hydroxyvitamin D in Humans: An Important Tool to Define Adequate Nutritional Vitamin D Status. J Steroid Biochem Mol Biol 2007;103:631-634.

107. Holmøy T, Moen SM, Gundersen TA, Holick MF, Fainardi E, Castellazzi M, Casetta I. 25hydroxyvitamin $D$ in cerebrospinal fluid during relapse and remission of multiple sclerosis; Mult Scler 2009;15:1280-1285.

108. Hori S, Nomura T, Sakaguchi S. Control of regulatory T cell development by transcription factor FoxP3. Science 2003;299:1057-1061.

109. Hyppönen, E, Läärä $E$, Reunanen A, Järvelin MR, Virtanen SM. Intake of vitamin D and risk of type 1 diabetes: a birth-cohort study. Lancet 2001;358:1500-1503.

110. IFNB Multiple Sclerosis Study Group. Interferon beta- $1 b$ is effective in relapsing-remitting multiple sclerosis. I Clinical results of a multicenter, randomized, double-blind, placebo-controlled trial. Neurology 1993;43:655-61.

111. IFNB Multiple Sclerosis Study Group. Interferon Beta $1 \mathrm{~b}$ in the treatment of multiple sclerosis: final outcome of the randomised controlled trial. Neurology 1995;45:1277-1285.

112. Iho S, Takahashi T, Kura F, Sugiyama H, Hoshino T. The effect of 1,25-dihydroxyvitamin D3 on in vitro immunoglobulin production in human B cells. J Immunol 1986;136:4427-4431.

113. International Multiple Sclerosis Genetics Consortium, Hafler DA, Compston A, Sawcer S, Lander ES, Daly MJ, De Jager PL, de Bakker PI, Gabriel SB, Mirel DB, Ivinson AJ, Pericak-Vance MA, Gregory SG, Rioux JD, McCauley JL, Haines JL, Barcellos LF, Cree B, Oksenberg JR, Hauser SL. Risk alleles for multiple sclerosis identified by a genomewide study. N Engl J Med 2007;357:851-862.

114. Islam T, Gauderman WJ, Cozen W, Mack TM. Childhood sun exposure influences risk of multiple sclerosis in monozygotic twins. Neurology 2007;69:381-388.

115. Jablonski NG, Chaplin G. Colloquium paper: human skin pigmentation as an adaptation to UV radiation. Proc Natl Acad Sci U S A. 2010;107(Suppl 2):8962-8968.

116. Jacobs LD, Cookfair DL, Rudick RA, Herndon RM, Richert JR, Salazar AM, et al. Intramuscular interferon beta-1a for disease progression in relapsing multiple sclerosis. Ann Neurol 1996;39:285-94.

117. Johnson KP, Brooks BR, Cohen JA, Ford CC, Goldstein J, Lisak RP, et al. Copolymer 1 reduces relapse rate and improves disability in relapsing- remitting multiple sclerosis: results of a phase III multicenter, double-blind placebo-controlled trial. Neurology 1995;45:1268-76.

118. Jongen MJ, van der Vijgh WJ, Lips P, Netelenbos JC. Measurement of vitamin D metabolites in anephric subjects. Nephron 1984;36:230-234.

119. Jorde R, Sundsfjord J, Fitzgerald P, Bønaa KH. Serum calcium and cardiovascular risk factors and diseases: the Troms $\varnothing$ study. Hypertension 1999;34:484-490.

120. Kampman MT, Wilsgaard T, Mellgren SI. Outdoor activities and diet in childhood and adolescence relate to MS risk above the Arctic Circle. J Neurol 2007;254:471-477.

121. Kappos L, Freedman MS, Polman CH, Edan G, Hartung HP, Miller DH, Montalban X, Barkhof F, Radü EW, Metzig C, Bauer L, Lanius V, Sandbrink R, Pohl C. Long-term effect of early treatment with interferon beta-1b after a first clinical event suggestive of multiple sclerosis: 5-year active treatment extension of the phase 3 BENEFIT trial. Lancet Neurol 2009;8:987-997. 
122. Kebir H, Kreymborg K, Ifergan I, Dodelet-Devillers A. Cayrol C, Bernard M, Guiliani F, Arbour N, Becher B, Prat A. Human Th17 lymphocytes promote blood-brain barrier disruption and central nervous system inflammation. Nat Med 2007;13:1173-1175.

123. Knippenberg S, Bol Y, Damoiseaux J, Hupperts R, Smolders J. Vitamin d status in patients with MS correlates negatively with depression, but not with fatigue. Acta Neurol Scand 2010 In press.

124. Killestein J, Rep MH, Meilof JF, Ader HJ, Uitdehaag BM, Barkhof F, van Lier RA, Polman CH. Seasonal variation in immune measurements and MRI markers of disease activity in MS. Neurology 2002;58:1077-1080.

125. Kimball SM, Ursell MR, O'Connor P, Vieth R. Safety of vitamin D3 in adults with multiple sclerosis. Am J Clin Nutr 2007;86:645-651.

126. Kimlin M. Geographic location and vitamin D synthesis. Mol Aspects Med 2008;29:453-461.

127. Korn-Lubetzki I, Kahana E, Cooper G, Abramsky O. Activity of multiple sclerosis during pregnancy and puerperium. Ann Neurol 1984;16:229-231

128. Korporal M, Haas J, Balint B, Fritzsching B, Schwarz A, Moeller S, Fritz B, Suri-Payer E, Wildemann B. Interferon beta-induced restoration of regulatory $\mathrm{T}$-cell function in multiple sclerosis is prompted by an increase in newly generated naive regulatory T cells. Arch Neurol 2008;65:1434-9.

129. Koziol JA, Feng AC. Seasonal variations in exacerbations and MRI parameters in relapsing-remitting multiple sclerosis. Neuroepidemiology 2004;23:217-223.

130. Kragt JJ, van Amerongen BM, Killestein J, Dijkstra CD, Uitdehaag BM, Polman CH, Lips P. Higher levels of 25-hydroxyvitamin $D$ are associated with a lower incidence of multiple sclerosis only in women. Mult Scler 2009;15:9-15.

131. Kurtzke JF. On the fine structure of the distribution of multiple sclerosis. Acta Neurol Scand 1967;43:257-282.

132. Kurtzke JF. Rating neurologic impairment in multiple sclerosis: an expanded disability status scale (EDSS). Neurology 1983;33:14-52.

133. Kurtzke JF. Epidemiology of multiple sclerosis. Does this really point toward an etiology? Lectio Doctoralis. Neurol Sci 2000;21:383-403.

134. Lefebvre d'Hellencourt C, Montero-Menei CN, Bernard R, Couez D. Vitamin D3 inhibits proinflammatory cytokines and nitric oxide production by the EOC13 microglial cell line. J Neurosci Res 2003;71:575-582.

135. Lemire JM, Adams JS, Sakai R, Jordan SC. 1 alpha,25-dihydroxyvitamin D3 suppresses proliferation and immunoglobulin production by normal human peripheral blood mononuclear cells. J Clin Invest 1984;74:657-661.

136. Lemire JM, Archer DC. 1,25-dihydroxyvitamin D3 prevents the in vivo induction of murine experimental autoimmune encephalomyelitis. J Clin Invest 1991;87:1103-1107.

137. Lemire JM, Archer DC, Reddy GS. 1,25-Dihydroxy-24-OXO-16ene-vitamin D3, a renal metabolite of the vitamin D analog 1,25-dihydroxy-16ene-vitamin D3, exerts immunosuppressive activity equal to its parent without causing hypercalcemia in vivo. Endocrinology 1994;135:2818-2821. .

138. Leray E, Yeouang J, Le Page E, Coustans M, Laplaud D, Oger J, Edan G. Evidence for a two-stage disability progression in multiple sclerosis. Brain 2010;133:1900-1913.

139. Levin LI, Munger KL, O’Reilly EJ, Falk KI, Ascherio A. Primary infection with Epstein-Barr Virus and risk of multiple sclerosis. Ann Neurol 2010;67:824-830.

140. Lind L, Skarfors E, Berglund L, Lithell H, Ljunghall S. Serum calcium: a new, independent, prospective risk factor for myocardial infarction in middle-aged men followed for 18 years. J Clin Epidemiol 1997;50:967-973.

141. Liu W, Putnam AL, Xu-Yu Z, Szot GL, Lee MR, Zhu S, Gottlieb PA, Kapranov P, Gingeras TR, Fazekas de St Groth B, Clayberger C, Soper DM, Ziegler SF, Bluestone JA. CD127 expression inversely correlates with FoxP3 and suppressive function of human CD4+ Treg cells. J Exp Med 2006;203:1701-11.

142. Maalouf J, Nabulsi L, Vieth R, Kimball S, El-Rassi R, Mahfoud Z, El-HajjFuleihan G. Short- and longterm safety of weekly high-dose vitamin $D_{3}$ supplementation in school children. J Clin Endocrinol Metab 2008;93:2693-701. 
143. Mahon BD, Gordon SA, Cruz J, Cosman F, Cantorna MT. Cytokine profile in patients with multiple sclerosis following vitamin D supplementation. J Neuroimmunol 2003;134:128-32.

144. Mamutse G, Woolmore J, Pye E, Partridge J, Boggild M, Young C, Fryer A, Hoban PR, Rukin N, Alldersea J, Strange RC, Hawkins CP. Vitamin D receptor gene polymorphism is associated with reduced disability in multiple sclerosis. Mult Scler 2008;14:1280-1283.

145. Mawer EB, Lumb GA, Stanbury SW. Long Biological Half-life of Vitamin $D_{3}$ and its Polar Metabolites in Human Serum. Nature 1969;222:482-483.

146. Maxwell JD. Seasonal variation in vitamin D. Proc Nutr Soc 1994;53:533-543.

147. McDonald WI, Compston A, Edan G, Goodkin D, Hartung HP, Lublin FD, McFarland HF, Paty DW, Polman CH, Reingold SC, Sandberg-Wollheim M, Sibley W, Thompson A, van den Noort S, Weinshenker BY, Wolinsky JS. Recommended diagnostic criteria for multiple sclerosis: guidelines from the International Panel on the diagnosis of multiple sclerosis. Ann Neurol 2001;50:121-127.

148. McGrath, J.J., Feron, F.P., Burne, T.H., Mackay-Sim, A., Eyles, D.W., 2004. Vitamin D3-implications for brain development. J Steroid Biochem Mol Biol 89-90, 557-560.

149. Meehan MA, Kerman RH, Lemire JM. 1,25-Dihydroxyvitamin D3 enhances the generation of nonspecific suppressor cells while inhibiting the induction of cytotoxic cells in a human MLR. Cell Immunol 1992;140:400-409.

150. Meehan TF, DeLuca HF. CD8(+) T cells are not necessary for 1 alpha,25-dihydroxyvitamin $D(3)$ to suppress experimental autoimmune encephalomyelitis in mice. Proc Natl Acad Sci U S A 2002a;99:5557-5560.

151. Meehan TF, DeLuca HF. The vitamin D receptor is necessary for 1alpha,25-dihydroxyvitamin $D(3)$ to suppress experimental autoimmune encephalomyelitis in mice. Arch Biochem Biophys 2002b;408:200-204.

152. Michel L, Berthelot L, Pettré S, Wiertlewski S, Lefrère F, Braudeau C, Brouard S, Soulillou JP, Laplaud D. Patients with relapsing-remitting multiple sclerosis have normal Treg function when cells expressing IL-7 receptor alpha-chain are excluded from the analysis. J Clin Invest 2008;118:34113419.

153. Miller DH, Khan OA, Sheremata WA, Blumhardt LD, Rice GP, Libonati MA. A controlled trial of natalizumab for relapsing multiple sclerosis. N Engl J Med 2003;348:15-23.

154. Minneboo A, Uitdehaag BM, Jongen $P$, Vrenken $H$, Knol D, van Walderveen MA, Polman $\mathrm{CH}$, Castelijns JA, Barkhof F. Association between MRI parameters and the MS severity scale: a 12 year follow-up study. Mult Scler. 2009;15:632-637.

155. Moore KW, de Waal Malefyt R, Coffman RL, O'Garra A. Interleukin-10 and the interleukin-10 receptor. Annu Rev Immunol 2001;19:683-765.

156. Mowry EM, Krupp LB, Milazzo M, Chabas D, Strober JB, Belman AL, McDonald JC, Oksenberg JR, Bacchetti $P$, Waubant $E$. Vitamin $D$ status is associated with relapse rate in pediatric-onset multiple sclerosis. Ann Neurol 2010;67:618-624.

157. Muller K, Diamant M, Bendtzen K. Inhibition of production and function of interleukin-6 by $1,25-$ dihydroxyvitamin D3. Immunol Lett 1991;28:115-120.

158. Muller K, Bendtzen K. Inhibition of human T lymphocyte proliferation and cytokine production by human 1,25-dihydroxyvitamin $\mathrm{D}_{3}$. Differential effects on CD45-RA' and CD45-RO' cells. Autoimmunity 1992a;14:37-43.

159. Muller K, Haahr PM, Diamant M, Rieneck K, Kharazmi A, Bendtzen K. 1,25-Dihydroxyvitamin D3 inhibits cytokine production by human blood monocytes at the post-transcriptional level. Cytokine 1992b;4:506-512.

160. Muller K, Odum N, Bendtzen K. 1,25-dihydroxyvitamin D3 selectively reduces interleukin-2 levels and proliferation of human T cell lines in vitro. Immunol Lett 1993;35:177-182.

161. Müller K, Kriegbaum NJ, Baslund B, Sørensen OH, Thymann M, Bentzen K. Vitamin D3 metabolism in patients with rheumatic diseases: low serum levels of 25-hydroxyvitamin D3 in patients with systemic lupus erythematosus. Clin. Rheumatol. 1995;14:397-400. 
162. Munger KL, Zhang SM, O'Reilly E, Hernan MA, Olek MJ, Willett WC, Ascherio A. Vitamin D intake and incidence of multiple sclerosis. Neurology 2004;62:60-65.

163. Munger KL, Levin LI, Hollis BW, Howard NS, Ascherio A. Serum 25-hydroxyvitamin D levels and risk of multiple sclerosis. JAMA 2006;296:2832-2838.

164. Muskiet FA, van der Veer E, Schuitemaker GE, Wielders JP. Response to: Towards an adequate intake of vitamin D. An advisory report of the Health Council of the Netherlands. Eur J Clin Nutr. 2010;64:655.

165. Muthian G, Raikwar HP, Rajasingh J, Bright JJ. 1,25 Dihydroxyvitamin-D3 modulates JAK-STAT pathway in IL-12/IFNgamma axis leading to Th1 response in experimental allergic encephalomyelitis. J Neurosci Res 2006;83:1299-1309.

166. Nakashima T, Takayanagi H. Osteoimmunology: crosstalk between the immune and bone systems. J Clin Immunol 2009;29:555-567.

167. Nashold FE, Miller DJ, Hayes CE. 1,25-dihydroxyvitamin D3 treatment decreases macrophage accumulation in the CNS of mice with experimental autoimmune encephalomyelitis. J Neuroimmunol 2000;103:171-179.

168. Nashold FE, Hoag KA, Goverman J, Hayes CE. Rag-1-dependent cells are necessary for 1,25dihydroxyvitamin $\mathrm{D}(3)$ prevention of experimental autoimmune encephalomyelitis. J Neuroimmunol 2001;119:16-29.

169. Nataf S, Garcion E, Darcy F, Chabannes D, Muller JY, Brachet P. 1,25 Dihydroxyvitamin D3 exerts regional effects in the central nervous system during experimental allergic encephalomyelitis. J Neuropathol Exp Neurol 1996;55:904-914.

170. Neuhaus, O., Wiendl, H., Kieseier, B.C., Archelos, J.J., Hemmer, B., Stuve, O., et al., (2005). Multiple sclerosis: Mitoxantrone promotes differential effects on immunocompetent cells in vitro. J. Neuroimmunol. 168, 128-137

171. Neveu I, Naveilhan P, Jehan F, Baudet C, Wion D, De Luca HF, Brachet P. 1,25-dihydroxyvitamin D3 regulates the synthesis of nerve growth factor in primary cultures of glial cells. Brain Res Mol Brain Res 1994;24:70-76.

172. Nicholson LB, Murtaza A, Hafler BP, Sette A, Kuchroo VK. A T cell receptor antagonist peptide induces $T$ cells that mediate bystander suppression and prevent autoimmune encephalomyelitis induced with multiple myelin antigens. Proc Natl Acad Sci U S A 1997;94:9279-9284.

173. Nieves J, Cosman F, Herbert J, Shen V, Lindsay R. High prevalence of vitamin D deficiency and reduced bone mass in multiple sclerosis. Neurology 1994;44:1687-1692.

174. Niino M, Fukazawa T, Yabe I, Kikuchi S, Sasaki H, Tashiro K. Vitamin D receptor gene polymorphism in multiple sclerosis and the association with HLA class II alleles. J Neurol Sci 2000;177:65-71.

175. Niino M, Kikuchi S, Fukazawa T, Yabe I, Tashiro K. No association of vitamin D-binding protein gene polymorphisms in Japanese patients with MS. J Neuroimmunol 2002;127:177-179.

176. Nordvik I, Myhr KM, Nyland H, Bjerve KS. Effect of dietary advice and n-3 supplementation in newly diagnosed MS patients. Acta Neurol Scand 2000;102:143-149.

177. Ogawa G, Mochizuki H, Kanzaki M, Kaida K, Motoyoshi K, Kamakura K. Seasonal variation of multiple sclerosis exacerbations in Japan. Neurol Sci 2004;24:417-419.

178. Ohta M, Okabe T, Ozawa K, Urabe A, Takaku F. 1 alpha,25-Dihydroxyvitamin D3 (calcitriol) stimulates proliferation of human circulating monocytes in vitro. FEBS Lett 1985;185:9-13.

179. Omdahl JL, Morris HA, May BK. Hydroxylase enzymes of the vitamin D pathway: expression, function, and regulation. Annu Rev Nutr 2002;22:139-166.

180. Ordonez L, Bernard I, L'faqihi-Olive F, et al., CD45RC isoform expression identifies functionally distinct $T$ cell subsets differentially distributed between healthy individuals and AAV patients. PLoS One 2009;4:e5287.

181. Orton SM, Herrera BM, Yee IM, Valdar W, Ramagopalan SV, Sadovnick AD, Eber GC; Canadian Collaborative Study Group. Sex ratio of multiple sclerosis in Canada: a longitudinal study. Lancet Neurol 2006;5:932-936. 
182. Orton SM, Morris AP, Herrera BM, Ramagopalan SV, Lincoln MR, Chao MJ, Vieth R, Sadovnick AD, Ebers GC. Evidence for genetic regulation of vitamin D status in twins with multiple sclerosis. Am J Clin Nutr 2008;88:441-447.

183. Overbergh L, Decallonne B, Valckx D, Verstuyf A, Depovere J, Laureys J, Rutgeerts O, Saint-Arnaud R, Bouillon R, Mathieu C. Identification and immune regulation of 25-hydroxyvitamin D-1-alphahydroxylase in murine macrophages. Clin Exp Immunol 2000;120:139-146.

184. Ozgocmen S, Bulut S, Ilhan N, Gulkesen A, Ardicoglu O, Ozkan Y. Vitamin D deficiency and reduced bone mineral density in multiple sclerosis: effect of ambulatory status and functional capacity. J Bone Miner Metab 2005;23:309-313.

185. Partridge JM, Weatherby SJ, Woolmore JA, Highland DJ, Fryer AA, Mann CL, Boggild MD, Ollier WE, Strange RC, Hawkins CP. Susceptibility and outcome in MS: associations with polymorphisms in pigmentation-related genes. Neurology 2004;62:2323-2325.

186. Peacock M. Calcium metabolism in health and disease. Clin J Am Soc Nephrol 2010;5:s23-s30.

187. Penna G, Adorini L. 1 Alpha,25-dihydroxyvitamin D3 inhibits differentiation, maturation, activation, and survival of dendritic cells leading to impaired alloreactive $\mathrm{T}$ cell activation. J Immunol 2000;164:2405-2411.

188. Penna G, Amuchastegui S, Giarratana N, Daniel KC, Vulcano M, Sozzani S, Adorini L. 1,25Dihydroxyvitamin D3 selectively modulates tolerogenic properties in myeloid but not plasmacytoid dendritic cells. J Immunol 2007;178:145-53.

189. Pichler J, Gerstmayr M, Szépfalusi Z, Urbanek R, Peterlik M, Willheim M. 1 alpha,25(OH)2D3 inhibits not only Th1 but also Th2 differentiation in human cord blood T cells. Pediatr Res 2002;52:12-18.

190. Piemonti L, Monti P, Sironi M, Fraticelli P, Leone BE, Dal Cin E, Allavena P, Di Carlo V. Vitamin D3 affects differentiation, maturation, and function of human monocyte-derived dendritic cells. J Immunol 2000;164:4443-4451.

191. Pierrot-Deseilligny C. Clinical implications of a possible role of vitamin D in multiple sclerosis. J Neurol 2009;256:1468-79.

192. Pintado CO, Carracedo J, Rodriguez M, Perez-Calderon R, Ramirez R. 1 alpha, 25-dihydroxyvitamin D3 (calcitriol) induces apoptosis in stimulated T cells through an IL-2 dependent mechanism. Cytokine 1996;8:342-345.

193. Polman C, Reingold S, Edan G, Filippi M, Hartung HP, Kappos L, Lublin FD, Metz LM, McFarland HF, O'Connor PW, Sandberg-Wollheim M, Thompson AJ, Weinshenker BG, Wolinsky JG. Diagnostic criteria for multiple sclerosis: 2005 revisions to the "McDonald Criteria". Ann Neurol 2005;58:840-6.

194. Polman $\mathrm{CH}$, Rudick RA. The multiple sclerosis functional composite. 2010;74:s8-s15.

195. Ponsonby AL, Pezic A, Ellis J, Morley R, Cameron F, Carlin J, Dwyer T. Variation in Associations between Allelic Variants of the Vitamin D Receptor Gene and Onset of Type 1 Diabetes Mellitus by Ambient Winter Ultraviolet Radiation Levels: A Meta-Regression Analysis. Am J Epidemiol 2008;168:358-365.

196. Poonawalla AH, Datta S, Juneja V, Nelson F, Wolinsky JS, Cutter G, Narayana PA. Composite MRI scores improve correlation with EDSS in multiple sclerosis. Mult Scler 2010;16:1117-1125.

197. Poser CM, Paty DW, Scheinberg LC, et al., New diagnostic criteria for multiple sclerosis: guidelines for research protocols. Ann Neurol 1983;13:227-231.

198. PRISMS Study Group. Randomised double-blind placebo-controlled study of interferon beta-1a in relapsing/remitting multiple sclerosis. Lancet 1998;352:1498-504.

199. Pritchard, JB., ed., The Ancient Near East - Volume 1: An Anthology of Texts and Pictures, Princeton, New Jersey: Princeton University Press, 1958, pp. 227-230.

200. Provvedini DM, Tsoukas CD, Deftos LJ, Manolagas SC. 1,25-dihydroxyvitamin D3 receptors in human leukocytes. Science 1983;221:1181-1183.

201. Pugliatti M, Sotgiu S, Rosati G. The worldwide prevalence of multiple sclerosis. Clin Neurol Neurosurg 2002;104:182-191. 
202. Ramagopalan S, Maugeri N, Handunnetthi L, Lincoln MR, Orton SM, Dyment DA, DeLuca GC, Herrera BM, Chao MJ, Sadovnick AD, Ebers GC, Knight JC. Expression of the multiple sclerosisassociated MHC class II allele HLA-DRB1*1501 is regulated by vitamin D. PLoS Genet 2009;5:e1000369.

203. Ramagopalan SV, Hanwell HE, Giovannoni G, Knappskog PM, Nyland HI, Myhr KM, Ebers GC, Torkildsen O. Vitamin D-dependent rickets, HLA-DRB1, and the risk of multiple sclerosis. Arch Neurol $2010 ; 67: 1034-1035$.

204. Reichel H, Koeffler HP, Tobler A, Norman AW. 1 alpha,25-Dihydroxyvitamin D3 inhibits gammainterferon synthesis by normal human peripheral blood lymphocytes. Proc Natl Acad Sci U S A 1987;84:3385-3389.

205. Rigby WF, Stacy T, Fanger MW. Inhibition of T lymphocyte mitogenesis by 1,25-dihydroxyvitamin D3 (calcitriol). J Clin Invest 1984;74:1451-1455.

206. Rigby WF, Waugh M, Graziano RF. Regulation of human monocyte HLA-DR and CD4 antigen expression, and antigen presentation by 1,25-dihydroxyvitamin D3. Blood 1990;76:189-197.

207. Rovaris M, Comi G, Sormani MP, Wolinsky JS, Ladkani D, Filippi M. Effects of seasons on magnetic resonance imaging--measured disease activity in patients with multiple sclerosis. Ann Neurol 2001;49:415-416.

208. Royal III W, Mia Y, Li H, Naunton K. Peripheral blood regulatory T cell measurements correlate with serum vitamin D levels in patients with multiple sclerosis. J Neuroimmunol 2009;213:135-141.

209. Rubin MR, Rundek T, McMahon DJ, Lee HS, Sacco RL, Silverberg SJ. Carotid artery plaque thickness is associated with increased serum calcium levels: the Northern Manhattan study. Atherosclerosis 2007; 194:426-432.

210. Runmarker B, Andersen O. Pregnancy is associated with a lower risk of onset and a better prognosis in multiple sclerosis. Brain 1995;118:253-261.

211. Sadovnick AD, Yee IM. Season of birth in multiple sclerosis. Acta Neurol Scand 1994;89:190-191.

212. Sadovnick AD, Duquette $P$, Herrera B, Yee IM, Ebers GC. A timing-of-birth effect on multiple sclerosis clinical phenotype. Neurology 2007;69:60-62.

213. Sakaguchi S, Yamaguchi T, Nomura T, Ono M. Regulatory T cells and immune tolerance. Cell 2008;133:775-787.

214. Sanders AM, Stuart AL, Williamson EJ, Simpson JA, Kotowicz MA, Young D, Nicholson GC. Annual high-dose oral vitamin $D$ and falls and fractures in older women. JAMA 2010;303:1815-1822.

215. Scalfari A, Neuhaus A, Degenhardt A, Rice GP, Muraro PA, Daumer M, Ebers GC. The natural history of multiple sclerosis, a geographically based study 10: relapses and long-term disability. Brain 2010;133:1914-1929.

216. Schrempf, W., Ziemssen, T. (2007). Glatiramer acetate: mechanisms of action in multiple sclerosis. Autoimmun. Rev. 6, 469-475

217. Schumacher FA, Beeve GW, Kibler RF, et al., Problems of experimental trials of therapy in multiple sclerosis. Ann N Y Acad Sci 1965;122:552-568.

218. Schwartz GG. Hypothesis: calcitriol mediates pregnancy's protective effect on multiple sclerosis. Arch Neurol 1993;50:455.

219. Schwid SR, Goodman AD, Puzas JE, McDermott MP, Mattson DH. Sporadic corticosteroid pulses and osteoporosis in multiple sclerosis. Arch Neurol 1996;53:753-757.

220. Seddiki N, Santner-Nanan B, Martinson J, et al., Expression of interleukin (IL)-2 and IL-7 receptors discriminates between human regulatory and activated T cells. J Exp Med 2006a;203:1693-1700.

221. Seddiki N, Santner-Nanan B, Tangye SG, Alexander SI, Solomon M, Lee S, Nanan R, Fazekas de St Groth B. Persistence of naive CD45RA ${ }^{+}$regulatory T cells in adult life. Blood 2006b;107:2830-8.

222. Shiozawa S, Shiozawa K, Tanaka Y, Fujita T. 1 alpha,25-Dihydroxyvitamin D3 inhibits proliferative response of T- and B-lymphocytes in a serum-free culture. Int J Immunopharmacol 1987;9:719-723.

223. Sigmundsdottir H, Pan J, Debes GF, Alt C, Habtezion A, Soler D, Butcher EC. DCs metabolize sunlightinduced vitamin D3 to 'program' T cell attraction to the epidermal chemokine CCL27. Nat Immunol 2007;8:285-293. 
224. Simon KC, van der Mei IA, Munger KL, Ponsonby A, Dickinson J, Dwyer T, Sundström $P$, Ascherio A. Combined effects of smoking, anti-EBNA antibodies, and HLA-DRB1*1501 on multiple sclerosis risk. Neurology 2010;74:1365-1371.

225. Simpson S, Taylor B, Blizzard L, Ponsonby AL, Pittas F, Tremlett H, Dwyer T, Gies P, van der Mei I. Higher 25-hydroxyvitamin D is associated with lower relapse risk in MS. Ann Neurol 2010;68:193203.

226. Sinotte M, Diorio C, Berube S, Pollak M, Brisson J. Genetic polymorphisms of the vitamin D binding protein and plasma concentrations of 25-hydroxyvitamin D in premenopausal women. Am J Clin Nutr 2009;89:634-640.

227. Smith JE, Goodman DS. The turnover and transport of vitamin D and of a polar metabolite with the properties of 25-hydroxycholecalciferol in human plasma. J Clin Invest 1971;50:2159-2167

228. Smolders J, Damoiseaux J, Menheere P, Hupperts R. Vitamin D as an immune modulator in multiple sclerosis, a review. J Neuroimmunol 2008a;194:7-17 (chapter 2).

229. Smolders J, Menheere P, Kessels A, Damoiseaux J, Hupperts R. Association of vitamin D metabolite levels with relapse rate and disability in multiple sclerosis. Mult Scler 2008b;14:1220-1224 (chapter 3).

230. Smolders J, Damoiseaux J, Menheere P, Cohen Tervaert JW, Hupperts R. Fok-I vitamin D receptor gene polymorphism (rs10735810) and vitamin D metabolism in multiple sclerosis. J Neuroimmunol 2009a;207(1-2):117-121 (chapter 6).

231. Smolders J, Damoiseaux J, Menheere P, Cohen Tervaert JW, Hupperts R. Association study on two vitamin $D$ receptor polymorphisms and vitamin D metabolites in multiple sclerosis. Ann N Y Acad Sci 2009b;1173(1):515-520.

232. Smolders J, Peelen E, Thewissen M, Menheere P, Cohen Tervaert JW, Hupperts R, Damoiseaux J. The relevance of vitamin $D$ receptor gene polymorphisms for vitamin $D$ research in multiple sclerosis. Autoimmun Rev 2009c;8(7): 621-626.

233. Smolders J, Thewissen M, Peelen E, Menheere P, Cohen Tervaert JW, Damoiseaux J, Hupperts R. Vitamin $D$ status is positively correlated with regulatory $T$ cell function in patients with multiple sclerosis. PLoS One 2009d;4:e6635 (chapter 4).

234. Smolders J, Menheere P, Thewissen M, Peelen E, Cohen Tervaert JW, Hupperts R, Damoiseaux J. Regulatory $T$ cell function correlates with serum 25-hydroxyvitamin $D$, but not with 1,25dihydroxyvitamin $D$, parathyroid hormone and calcium levels in patients with relapsing remitting multiple sclerosis. J Steroid Biochem Mol Biol 2010;121:243-246 (chapter 5).

235. Soilu-Hanninen M, Airas L, Mononen I, Heikkila A, Viljanen M, Hanninen A. 25-Hydroxyvitamin D levels in serum at the onset of multiple sclerosis. Mult Scler 2005;11:266-271.

236. Soilu-Hanninen M, Laaksonen M, Laitinen I, Eralinna JP, Lilius EM, Mononen I. A longitudinal study of serum 25-hydroxyvitamin D and intact PTH levels indicate the importance of vitamin D and calcium homeostasis regulation in multiple sclerosis. J Neurol Neurosurg Psychiatry 2008;79:152-157.

237. Sotgiu S, Pugliatti M, Sotgiu MA, Fois ML, Arru G, Sanna A, Rosati G. Seasonal fluctuation of multiple sclerosis births in Sardinia. J Neurol 2009;253:38-44.

238. Spach KM, Hayes CE. Vitamin D3 confers protection from autoimmune encephalomyelitis only in female mice. J Immunol 2005;175:4119-4126.

239. Spach KM, Nashold FE, Dittel BN, Hayes CE. IL-10 signaling is essential for 1,25-dihydroxyvitamin D3mediated inhibition of experimental autoimmune encephalomyelitis. J Immunol 2006;177:60306037.

240. Steckley JL, Dyment DA, Sadovnick AD, Risch N, Hayes C, Ebers GC. Genetic analysis of vitamin D related genes in Canadian multiple sclerosis patients. Canadian Collaborative Study Group. Neurology 2000;54:729-732.

241. Steinman L. A brief history of Th17, the first major revision of the Th1/Th2 hypothesis of T cellmediated tissue damage. Nat Med 2007;13:139-145. 
242. Stewart JW, Alekel DL, Ritland LM, Van Loan M, Gertz E, Genschel U. Serum 25-hydroxyvitamin D is related to indicators of overall physical fitness in healthy postmenopausal women. Menopause 2009;16:1093-1101.

243. Stewart N, Taylor B, Ponsonby AL, Pittas F, van der Mei I, Woods G, Walters H. The effect of season on cytokine expression in multiple sclerosis and healthy subjects. J Neuroimmunol 2007;188:181186.

244. Stüve O, Marra CM, Jerome KR, et al. Immune surveillance in multiple sclerosis patients treated with Nataluzimab. Ann Neurol 2006;59:743-747.

245. Sundqvist E, Bäärnhielm M, Alfredsson L, Hillert J, Olsson T, Kockum I. Confirmation of association between multiple sclerosis and CYP27B1. Eur J Hum Genet 2010 in press.

246. Széles L, Keresztes G, Töröcsik D, Balajthy Z, Krenács L, Póliska S, Steinmeyer A, Zuegel U, Pruenster $M$, Rot A, Nagy L. 1,25-Dihydroxyvitamin $D_{3}$ Is an Autonomous Regulator of the Transcriptional Changes Leading to a Tolerogenic Dendritic Cell Phenotype. J Immunol 2009;182:2074-2083.

247. Tajouri L, Ovcaric M, Curtain R, Johnson MP, Griffiths LR, Csurhes P, Pender MP, Lea RA. Variation in the vitamin $D$ receptor gene is associated with multiple sclerosis in an Australian population. J Neurogenet 2005;19:25-38.

248. Tang B, Eslick G, Nowson C, Smith C, Bensoussan A. Use of calcium or calcium in combination with vitamin $D$ supplementation to prevent fractures and bone loss in people aged 50 years and older: a meta-analysis. Lancet 2007;370:657-666.

249. Takeyama K, Kitanaka S, Sato T, Kobori M, Yanagisawa J, Kato S. 25-Hydroxyvitamin D3 1alphahydroxylase and vitamin D synthesis. Science 1997;277:1827-1830.

250. Theodoropoulos C, Demers C, Delvin E, Menard D, Gascon-Barre M. Calcitriol regulates the expression of the genes encoding the three key vitamin D3 hydroxylases and the drug-metabolizing enzyme CYP3A4 in the human fetal intestine. Clin Endocrinol (Oxf) 2003a;58:489-499.

251. Theodoropoulos C, Demers C, Petit JL, Gascon-Barre M. High sensitivity of rat hepatic vitamin D325 hydroxylase CYP27A to 1,25-dihydroxyvitamin D3 administration. Am J Physiol Endocrinol Metab 2003b;284:E138-147.

252. Thien R, Baier K, Pietschmann P, Peterlik M, Willheim $M$. Interactions of 1 alpha,25dihydroxyvitamin D3 with IL-12 and IL-4 on cytokine expression of human T lymphocytes. J Allergy Clin Immunol 2005;116:683-689.

253. Tobler A, Gasson J, Reichel H, Norman AW, Koeffler HP. Granulocyte-macrophage colonystimulating factor. Sensitive and receptor-mediated regulation by 1,25 -dihydroxyvitamin D3 in normal human peripheral blood lymphocytes. J Clin Invest 1987;79:1700-1705.

254. Tonelli M, Sacks F, Pfeffer M, Gao Z, Curhan G; Cholesterol And Recurrent Events Trial Investigators. Relation between serum phosphate level and cardiovascular event rate in people with coronary disease. Circulation 2005;112:2627-2633.

255. Torkildsen O, Knappskog PM, Nyland HI, Myhr KM. Vitamin D-dependent rickets as a possible risk factor for multiple sclerosis. Arch Neurol 2008;65:809-811.

256. Towers TL, Freedman LP. Granulocyte-macrophage colony-stimulating factor gene transcription is directly repressed by the vitamin D3 receptor. Implications for allosteric influences on nuclear receptor structure and function by a DNA element. J Biol Chem 1998;273:10338-10348.

257. Tremlett HL, Devonshire VA. Does the season or month of birth influence disease progression in multiple sclerosis? Neuroepidemiology 2006;26:195-198.

258. Tsoukas CD, Provvedini DM, Manolagas SC. 1,25-dihydroxyvitamin D3: a novel immunoregulatory hormone. Science 1984;224:1438-40.

259. Tsoukas CD, Watry D, Escobar SS, Provvedini DM, Dinarello CA, Hustmyer FG, et al. Inhibition of interleukin-1 production by 1,25-dihydroxyvitamin D3. J Clin Endocrinol Metab 1989;69:127-33.

260. Twork S, Wiesmeth S, Spindler M, Wirtz M, Schipper S, Pöhlau D, Klewer J, Kugler J. Disability status and quality of life in multiple sclerosis: non-linearity of the expanded disability status scale (EDSS). Health and quality of life outcomes. 2010;8:55. 
261. Uitterlinden AG, Fang $Y$, van Meurs JB, van Leeuwen $H$, Pols HA. Vitamin D receptor gene polymorphisms in relation to Vitamin D related disease states. J Steroid Biochem Mol Biol 2004;89-90:187193.

262. Unger WW, Laban S, Kleijwegt FS, van der Silk AR, Roep BO. Induction of Treg by monocyte-derived DC modulated by vitamin D3 or dexamethasone: differential role of PD-L1. Eur J Immunol 2009;39:3147-3159.

263. van der Mei IA, Ponsonby AL, Dwyer T, Blizzard L, Simmons R, Taylor BV, Butzkueven H, Kilpatrick T. Past exposure to sun, skin phenotype, and risk of multiple sclerosis: case-control study. BMJ 2003;327:316.

264. van der Mei IA, Ponsonby AL, Dwyer T, Blizzard L, Taylor BV, Kilpatrick T, Butzkueven H, McMichael AJ. Vitamin D levels in people with multiple sclerosis and community controls in Tasmania, Australia. J Neurol 2007;254:581-590.

265. van Etten E, Branisteanu DD, Overbergh L, Bouillon R, Verstuyf A, Mathieu C. Combination of a 1,25dihydroxyvitamin D3 analog and a bisphosphonate prevents experimental autoimmune encephalomyelitis and preserves bone. Bone 2003;32:397-404.

266. van Etten E, Gysemans C, Branisteanu DD, Verstuyf A, Bouillon R, Overbergh L, Mathieu C. Novel insights in the immune function of the vitamin $D$ system: synergism with interferon-beta. J Steroid Biochem Mol Biol 2007a;103:546-51.

267. van Etten E, Verlinden L, Giulietti A, Ramos-Lopez E, Branisteanu DD, Ferreira GB, Overbergh L, Verstuyf A, Bouillon R, Roep BO, Badenhoop K, Mathieu C. The vitamin D receptor gene Fokl polymorphism: functional impact on the immune system. Eur J Immunol 2007b;37:395-405.

268. van Halteren AG, Tysma OM, van Etten E, Mathieu C, Roep BO. 1alpha,25-dihydroxyvitamin D3 or analogue treated dendritic cells modulate human autoreactive T cells via the selective induction of apoptosis. J Autoimmun 2004;23:233-239.

269. van Halteren AG, van Etten E, de Jong EC, Bouillon R, Roep BO, Mathieu C. Redirection of human autoreactive T-cells Upon interaction with dendritic cells modulated by TX527, an analog of 1,25 dihydroxyvitamin D(3). Diabetes 2002;51:2119-2125.

270. Veldman CM, Cantorna MT, DeLuca HF. Expression of 1,25-dihydroxyvitamin D(3) receptor in the immune system. Arch Biochem Biophys 2000;374:334-338.

271. Venken K, Hellings N, Hensen K, Rummens JL, Medaer R, D’hooghe MB, Dubois B, Raus J, Stinissen $P$. Secondary progressive in contrast to relapsing-remitting multiple sclerosis patients show a normal CD $4^{+} \mathrm{CD} 25^{+}$regulatory T-cell function and FOXP3 expression. J Neurosci Res 2006;83:1432-46.

272. Venken $\mathrm{K}$, Thewissen $\mathrm{M}$, Hellings $\mathrm{N}$, et al., A CFSE based assay for measuring $\mathrm{CD} 4{ }^{+} \mathrm{CD} 25^{+}$regulatory $\mathrm{T}$ cell mediated suppression of auto-antigen specific and polyclonal $\mathrm{T}$ cell responses. J Immunol Methods 2007;322:1-11.

273. Venken $\mathrm{K}$, Hellings $\mathrm{N}$, Thewissen $\mathrm{M}$, et al., Compromised $\mathrm{CD} 4^{+} \mathrm{CD} 25^{\text {high }}$ regulatory T-cell function in patients with relapsing-remitting multiple sclerosis is correlated with a reduced frequency of FoxP3positive cells and reduced FoxP3-expression at the single-cell level. Immunology 2008;123:79-89.

274. Venken K, Hellings N, Liblau R, Stinissen P. Disturbed regulatory T cell homeostasis in multiple sclerosis. Trends Mol Med 2010;16:58-68

275. Verhaeghe J, Bouillon R. Calciotropic hormones during reproduction. J Steroid Biochem Mol Biol 1992;41:469-477.

276. Vieth R. Vitamin D supplementation, 25-hydroxyvitamin D concentrations, and safety. Am J Clin Nutr 1999;69:842-856.

277. Vieth R. The role of vitamin D in the prevention of osteoporosis. Ann Med 2005;37:278-285.

278. Vieth R. What is the optimal vitamin D status for health? Prog Biophys Mol Biol 2006;92:26-32.

279. Viglietta V, Baecher-Allan C, Weiner H, Hafler D. Loss of functional suppression by $\mathrm{CD} 4^{+} \mathrm{CD} 25^{+}$regulatory T cells in patients with multiple sclerosis. J Exp Med 2004;199:971-979.

280. Von Essen M, Kongsbak M, Schjerling P, Olgaard K, Ødum N, Geisler C. Vitamin D controls T cell receptor signaling and activation of human T cells. Nat Immunol 2010;11:344-349. 
281. Wang TJ, Zhang F, Richards JB, Kestenbaum B, van Meurs JB, Berry D, Kiel DP, Streeten EA, Ohlsson C, Koller DL, Peltonen L, Cooper JD, O’Reilly PF, Houston DK, Glazer NL, Vandenput L, Peacock M, Shi J, Rivadeneira F, McCarthy MI, Anneli P, de Boer IH, Mangino M, Kato B, Smyth DJ, Booth SL, Jacques PF, Burke GL, Goodarzi M, Cheung CL, Wolf M, Rice K, Goltzman D, Hidiroglou N, Ladouceur M, Wareham NJ, Hocking LJ, Hart D, Arden NK, Cooper C, Malik S, Fraser WD, Hartikainen AL, Zhai G, Macdonald HM, Forouhi NG, Loos RJ, Reid DM, Hakim A, Dennison E, Liu Y, Power C, Stevens HE, Jaana L, Vasan RS, Soranzo N, Bojunga J, Psaty BM, Lorentzon M, Foroud T, Harris TB, Hofman A, Jansson JO, Cauley JA, Uitterlinden AG, Gibson Q, Järvelin MR, Karasik D, Siscovick DS, Econs MJ, Kritchevsky SB, Florez JC, Todd JA, Dupuis J, Hyppönen E, Spector TD. Common genetic determinants of vitamin D insufficiency: a genome-wide association study. Lancet. 2010;376:18018-8.

282. Wang TK, Bolland MJ, Pelt NC, Horne AM, Mason BH, Ames RW, Grey AB, Ruygrok PN, Gamble GD, Reid IR. Relationships between vascular calcification, calcium metabolism, bone density and fractures J Bone Miner Res 2010 in press.

283. Wang YC, Meyerson L, Tang YQ, Qian N. Statistical methods for the analysis of relapse data in MS clinical trials. J Neurol Sci 2009;285:206-211.

284. Weggemans RM, Schaafsma G, Kromhout D. Towards an adequate intake of vitamin D. An advisory report of the Heatlh Council of the Netherlands. Eur J Clin Nutr. 2009;63:1455-1457.

285. Weinshenker BG, Bass B, Rice GP, Noseworthy J, Carriere W, Baskerville J, Ebers GC. The natural history of multiple sclerosis: a geographically based study. 1. Clinical course and disability. Brain 1989;112:133-46.

286. Westlund K. Distribution and mortality time trend of multiple sclerosis and some other diseases in Norway. Acta Neurol Scand 1970;46:455-483.

287. Willer CJ, Dyment DA, Sadovnick AD, Rothwell PM, Murray TJ, Ebers GC. Timing of birth and risk of multiple sclerosis: population based study. BMJ 2005;330:120.

288. Wilson LD, Zaldivar FP, Schwindt CD, Wang-Rodriguez J, Cooper DM. Circulating T-regulatory cells, exercise and the elite adolescent swimmer. Pediatr Exerc Sci. 2009;21:305-317.

289. Wingerchuk DM, Lesaux J, Rice GP, Kremenchutzky M, Ebers GC. A pilot study of oral calcitriol (1,25dihydroxyvitamin D3) for relapsing-remitting multiple sclerosis. J Neurol Neurosurg Psychiatry 2005;76:1294-1296.

290. Woolmore JA, Stone M, Pye EM, Partridge JM, Boggild M, Young C, Jones PW, Fryer AA, Hawkins CP, Strange RC. Studies of associations between disability in multiple sclerosis, skin type, gender and ultraviolet radiation. Mult Scler 2007;13:369-375.

291. Wuthrich R, Rieder HP. The seasonal incidence of multiple sclerosis in Switzerland. Eur Neurol 1970;3:257-264.

292. Xu H, Soruri A, Gieseler RK, Peters JH. 1,25-Dihydroxyvitamin D3 exerts opposing effects to IL-4 on MHC class-II antigen expression, accessory activity, and phagocytosis of human monocytes. Scand J Immunol 1993;38:535-540.

293. Yeo TW, Maranian M, Singlehurst S, Gray J, Compston A, Sawcer S. Four single nucleotide polymorphisms from the vitamin D receptor gene in UK multiple sclerosis. J Neurol 2004;251:753-754.

294. Zarrabeitia MT, Riancho JA, Amado JA, Olmos JM, Gonzalez-Macias J. Effect of calcitriol on the secretion of prostaglandin E2, interleukin 1, and tumor necrosis factor alpha by human monocytes. Bone 1992;13:185-189.

295. Zehnder D, Bland R, Williams MC, McNinch RW, Howie AJ, Stewart PM, Hewison M. Extrarenal expression of 25-hydroxyvitamin d(3)-1 alpha-hydroxylase. J Clin Endocrinol Metab 2001;86:888894.

296. Zhou L, Chong MMW, Littman DR. Plasticity of CD4+ T cell lineage differentiation. Immunity 2009;30:646-655. 
Summary
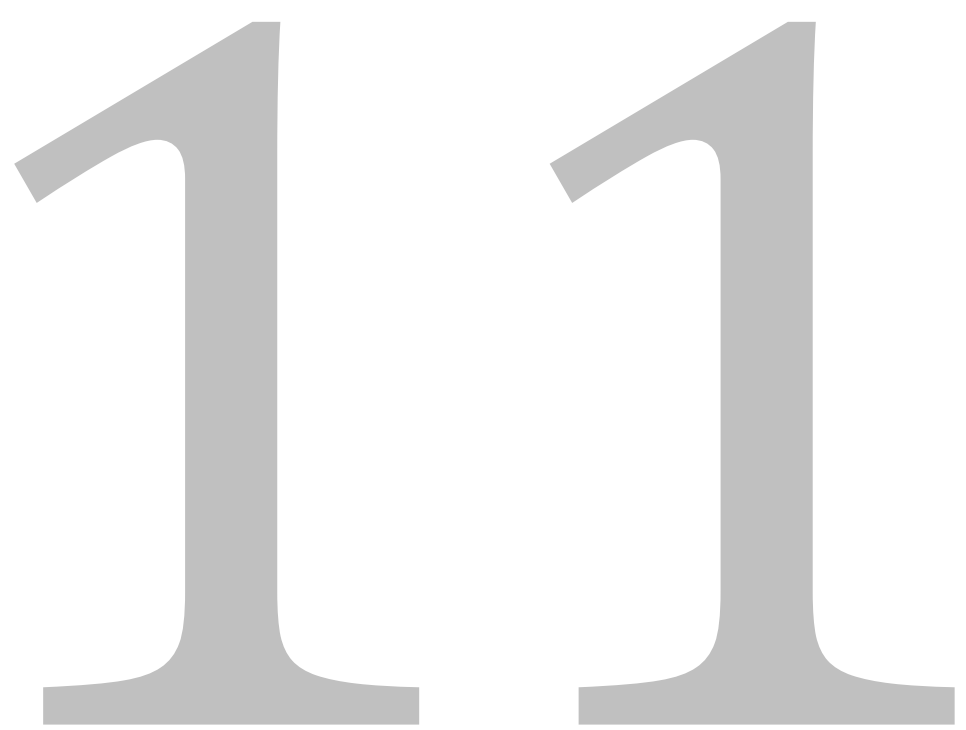

Multiple sclerosis (MS) is a severe inflammatory disease of the central nervous system. In patients with MS, the immune system attacks and damages the surrounding isolation sheet of neurons, the myelin. This results in a dysfunction of these neurons, and subsequently the patient will experience loss of body function. The reason for this attack of the immune system is not clear.

In the inflammatory reaction of $\mathrm{MS}, \mathrm{CD}^{+}{ }^{+} \mathrm{T}$ cells play an important role. These cells are central players in the adaptive immune response. When specialized antigen presenting cells encounter a pathogen (for instance a bacteria), they present this to $\mathrm{CD}^{+}{ }^{+} \mathrm{T}$ cells. If a $\mathrm{CD} 4^{+} \mathrm{T}$ cell recognizes this pathogen, it reacts by starting to proliferate and to produce inflammatory mediators (cytokines). These cytokines mediate clearance of the pathogen by other cells. It is important that T cells only start an inflammatory response upon presentation of an intruder from outside the body, and not upon presentation of self-antigens. To ensure this, T cells are carefully selected for being not auto-reactive during their development, and, additionally, specialized regulatory $T$ cells (Treg) control the remaining peripheral autoimmune $T$ cell response when needed. Current opinion is that, in patients with MS, these regulatory mechanisms fail, and that $T$ cells start an inflammatory response against selfantigens (autoimmune disease). The auto-antigen which causes this response, is at present unknown. In patients with MS, a relatively disturbed T cell compartment is frequently found, with less functional Treg and $\mathrm{CD}^{+} \mathrm{T}$ cells which produce more pro-inflammatory cytokines.

Vitamin $D$ is acquired both from dietary intake and from exposure of the skin to sunlight. It is predominantly known as an important molecule in calcium homeostasis. Several studies show an association between a limited exposure to vitamin D, and an increased level of disability of MS. This could indicate that vitamin D acts as an inhibitor on the disease process and disease activity of MS. With the vitamin D project of which this thesis is the start, we want to investigate i) if disease activity of MS can be inhibited by supplementation of vitamin D, and ii) which biological mechanisms mediate this effect.

In chapter 2, we describe a literature study. We review the evidence for a disease modulating effect of vitamin D in MS, and the role of vitamin D in the immune response. Experimental studies in animals and plastic dishes ('in vitro') show that vitamin D plays an essential role in the adaptive immune response as a strong promoter of $\mathrm{T}$ cell homeostasis. $\mathrm{T}$ cell proliferation and pro-inflammatory cytokine production are inhibited, and the production of anti-inflammatory cytokines and the development of Treg are promoted. In animal models of MS, vitamin D prevents and inhibits symptoms of disease. Interestingly, vitamin D status, or correlates of vitamin D status, correlate negatively with the risk on developing MS. An increased disease activity of MS has also been associated with an impaired vitamin D status. However, besides a few safety studies, large intervention-studies with vitamin D are 
lacking. We conclude that vitamin $\mathrm{D}$ is an immune modulator, but it is uncertain whether it can also be considered as an immune and disease modulator in MS.

In chapter 3, we investigated in a cross-sectional study among 267 patients from our MS population an association between vitamin D status and disease activity of MS. We showed that poor vitamin D statuses are especially found in patients with a high level of disability and in older patients. Additionally, we showed that RRMS patients with a short disease duration ( $<5$ years) who remained relapse-free prior to serum sampling displayed a better vitamin $D$ status when compared to patients with relapses prior to serum sampling. The latter observation suggests that a good vitamin D status might lower the hazard for relapses in this cohort.

Because a disturbed peripheral $\mathrm{CD}^{+} \mathrm{T}$ cell homeostasis is especially found in RRMS patients with a short disease duration, and vitamin $D$ is an important promoter of T cell homeostasis in vitro, we assessed in this cohort cross-sectionally if a correlation between vitamin $D$ status and both function and composition of the peripheral $\mathrm{CD}^{+} \mathrm{T}$ cell compartment was present (described in chapter 4). In 29 RRMS patients, not the number of Treg in the circulation, but rather the function of Treg was negatively correlated with vitamin D status. This means that Treg were less capable of controlling $\mathrm{T}$ cell proliferation in patients with a poor vitamin $\mathrm{D}$ status. $\mathrm{CD}^{+} \mathrm{T}$ cells in the circulation produced relatively less pro- and more antiinflammatory cytokines in patients with a good vitamin $D$ status. We concluded that vitamin $\mathrm{D}$ appears to promote the regulation of T cell homeostasis in vivo in MS.

To investigate whether the role of vitamin $\mathrm{D}$ in calcium homeostasis was of primary importance, we investigated in chapter 5 in the same 29 patients whether $\mathrm{T}$ cell regulation was also correlated with the effects of vitamin D on calcium homeostasis. There was no correlation of either Treg suppressive function or $\mathrm{CD}^{+} \mathrm{T}$ cell cytokine balance with serum levels of 1,25-dihydroxyvitamin $D$, total calcium, and parathyroid hormone (PTH) levels. This observation suggests that the interaction between vitamin $\mathrm{D}$ status and T cells in vivo is not dependent on calcium metabolism.

The associations between vitamin $\mathrm{D}$ status and $\mathrm{CD} 4^{+} \mathrm{T}$ cell function suggest that supplementation of vitamin $D$ might be used to skew the T cell compartment to a more regulatory state in patients with MS. In preparation of a large intervention study, we performed a pilot study to assess both the safety of vitamin D supplementation and the effects of vitamin D supplementation on the $T$ cell compartment (described in chapter 6). We observed in 15 RRMS patients that supplementation of $500 \mu \mathrm{g} /$ day (20.000 IU/day) vitamin $D_{3}$ for 12 weeks did not affect the proportion of Treg in the circulation. The suppressive capacity of Treg was not enhanced significantly, and only a marginal trend towards improvement could be observed. However, after vitamin $\mathrm{D}$ supplementation, relatively more $\mathrm{CD} 4^{+} \mathrm{T}$ cells produced antiinflammatory cyokines (IL-4, IL-10), and relatively less cells produced proinflammatory cytokines (IFN- $\gamma$ ). This study suggests that the cytokine profile of pe- 
ripheral $\mathrm{CD}^{+} \mathrm{T}$ cells may form an interesting marker to monitor the immune modulating effects of vitamin $D$ in randomized placebo-controlled clinical trials. Additionally, we conclude that supplementation of high doses of vitamin $D_{3}$ was without side-effects in our cohort. Participants reported no side-effects, and the calcium levels in the circulation were unaffected.

In chapter 7, we assessed whether a functional genetic polymorphism of the vitamin $D$ receptor (VDR) gene was associated either with $M S$, or with vitamin $D$ status in patients with MS and healthy subjects. A genetic polymorphism is a common variation in the genome. In the case of this specific polymorphism, it leads to a longer or shorter VDR protein. We found no difference in the distribution of the polymorphism between 289 healthy subjects and 212 patients with MS. However, both in summer and in winter, lower vitamin D statuses were observed in carriers of the allele encoding the shorter VDR protein. The association was found both in patients and in healthy controls. We concluded that vitamin $D$ related genetic variation may be an important confounder in intervention studies on vitamin D in MS, and should therefore be taken into account.

All the knowledge collected in the previously described chapters was combined in the development of an international trial on vitamin D supplementation in MS, of which the protocol is described in chapter 8. In a multi-center trial in several European countries, 348 RRMS patients with a disease duration $<5$ years will be included. In a double-blind, randomized, placebo-controlled design, we will assess whether supplementation of either vitamin $\mathrm{D}_{3}$ or placebo aside regular MS therapy (Beta Interferon) has an additive inhibiting effect on disease activity of MS. In several sub-studies, the effects of this intervention on the peripheral immune system will be assessed. Additionally, potential genetic confounders of treatment effects will be taken into account.

In this thesis, we did not answer the question whether vitamin $D$ reduces disease activity of MS. However, this thesis did contribute significantly to the development of a trial which might provide answers to this question. Additionally, a mechanism was conceptualized by which vitamin D may influence the pathophysiology of MS. We conclude (chapter 9) that a poor vitamin D status is associated with a high level of both relapse rate and disability in our MS population. Furthermore, vitamin $D$ status correlates with the composition and function of the peripheral $\mathrm{CD}^{+}{ }^{+} \mathrm{T}$ cell compartment in patients with MS. In a small pilot study, patients displayed after supplementation a less pro-inflammatory cytokine profile, which at least supports the idea that vitamin $D$ supplementation may restore the imbalance in the peripheral $\mathrm{CD}^{+} \mathrm{T}$ cell compartment as is frequently found in MS. In a large clinical trial, we will investigate whether vitamin $D$ can be used as a disease and immune modulator in MS. 



\section{Dutch summary}

Nederlandse samenvatting
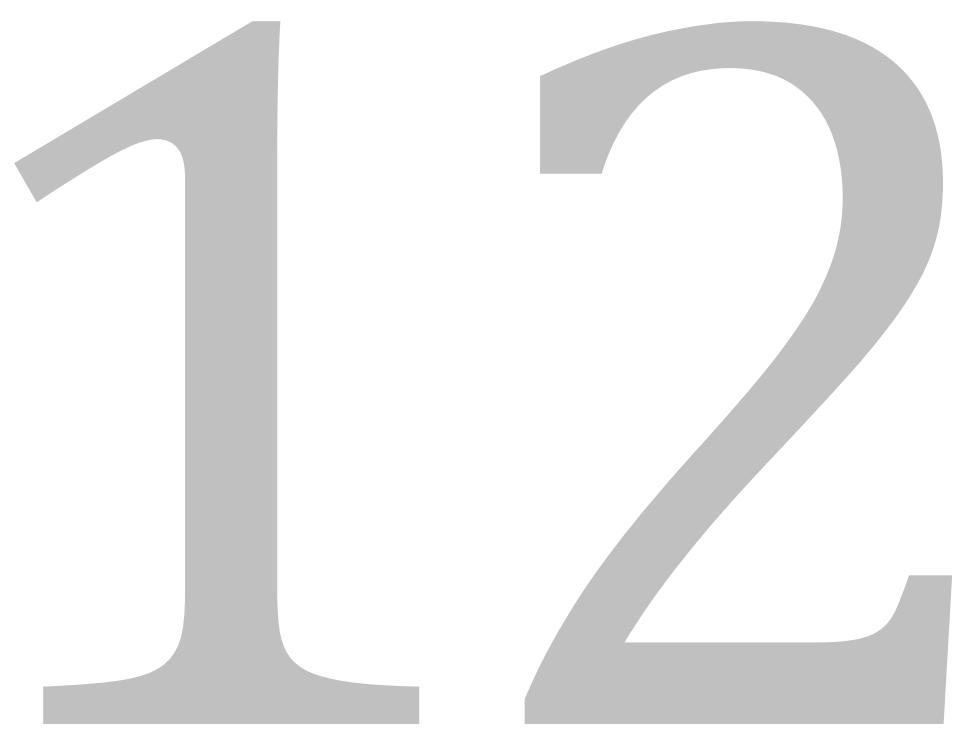

Multipele sclerose (MS) is een ernstige ontstekingsziekte van het centrale zenuwstelsel. In MS patiënten valt het immuunsysteem de isolatielaag rond zenuwen, het myeline, aan en zorgt ervoor dat deze isolatielaag beschadigd wordt. Hierdoor kunnen deze zenuwen niet meer goed functioneren en ervaart de patiënt uitval van lichaamsfuncties. De reden waarom het afweersysteem in de aanval gaat is niet duidelijk.

In de ontstekingreactie bij MS spelen $\mathrm{CD}^{+}$T cellen een belangrijke rol. Deze cellen zijn een essentieel onderdeel van de verworven immuun respons. Als een antigeen presenterende cel een pathogeen (bijvoorbeeld een bacterie) oppikt, laat hij deze aan de $\mathrm{CD}^{+}{ }^{+} \mathrm{T}$ cel zien. Als de $\mathrm{CD} 4^{+} \mathrm{T}$ cel dit pathogeen herkent, reageert deze hierop door te gaan delen en door ontstekingsstoffen (cytokines) te maken. Dit zorgt ervoor dat het pathogeen door andere cellen opgeruimd wordt. Het is belangrijk dat een $\mathrm{T}$ cel normaal gesproken alleen bij indringers van buiten voor ontsteking zorgt, en niet bij het zien van lichaamseigen eiwitten. Hiervoor worden T cellen in hun ontwikkeling zorgvuldig geselecteerd, en zijn er speciale regulerende $\mathrm{T}$ cellen (Treg) in het lichaam, die de $\mathrm{T}$ cel respons in bedwang houden wanneer nodig. Bij MS patiënten denkt men dat dit proces mis gaat, en dat het lichaam een afweerreactie tegen een lichaamseigen stof veroorzaakt (auto-immuunziekte). Welke stof dit precies is, is onbekend. Wel wordt bij MS patiënten een instabiel T cel compartiment gevonden, met minder goed werkende Treg en $\mathrm{CD}^{+} \mathrm{T}$ cellen die relatief gezien meer ontstekingsstoffen maken.

Vitamine D komt uit het voedsel en het zonlicht, en kennen we vooral als een belangrijke speler in de calcium huishouding. Verschillende studies suggereren een verband tussen een beperkte blootstelling aan vitamine $D$, en een toegenomen mate van beperking door MS. Dit zou kunnen betekenen dat vitamine $D$ wellicht een remmende werking op de ziekteactiviteit van MS zou kunnen hebben. Met het vitamine $D$ project waar dit proefschrift de start van is, willen we onderzoeken i) of we met het toedienen van vitamine $D$ de ziekteactiviteit van MS kunnen remmen, en ii) welke biologische mechanismen hieraan ten grondslag liggen.

In hoofdstuk 2 beschrijven we een literatuurstudie. Hierin hebben we onderzocht hoe stevig de aanwijzingen voor een ziektemodulerend effect van vitamine $D$ op MS zijn, en welke rol vitamine $D$ in het afweersysteem heeft. Experimentele studie in proefdieren en plastic schaaltjes ('in vitro') laten zien dat vitamine $D$ een essentiële rol in de verworven immuun respons speelt, en een sterke promotor van $\mathrm{T}$ cel homeostase is. $\mathrm{T}$ cel proliferatie en productie van ontstekingsbevorderende cytokines worden geremd, de productie van ontstekingsremmende cytokines en de ontwikkeling van Treg worden gestimuleerd. In proefdiermodellen van MS voorkomt en remt vitamine D ook de ziekteverschijnselen. Interessant genoeg correleert vitamine D status, of afgeleiden hiervan, negatief met het risico op het ontwikkelen van MS. Ook een grote ziekteactiviteit van MS is geassocieerd met een beperkte vitamine $\mathrm{D}$ status. Echter, naast veiligheidsstudies zijn geen grote interventiestudies 
met vitamine $D$ verricht. We concluderen dat vitamine $D$ een immuun modulator is, maar of vitamine $\mathrm{D}$ ook een immuun en ziekte modulator in MS is, is op dit moment onzeker.

In hoofdstuk 3 hebben we in een cross-sectionele studie onder 267 patiënten uit onze MS populatie onderzocht of er een verband tussen ziekteactiviteit van MS en vitamine $D$ status is. Lage vitamine $D$ statussen werden gevonden in oudere patienten en in patiënten met een grote mate van beperking. Hiernaast hadden RRMS patiënten met een korte ziekteduur ( $<5$ jaar) die relapsvrij waren voor bloedafname, een betere vitamine $D$ status dan patiënten die relapsen hadden. Deze laatste observatie is suggestief voor het idee dat een goede vitamine D status het risico op relapsen van MS zou kunnen verlagen.

Omdat in het cohort RRMS patiënten met een korte ziekteduur vooral een verstoring van perifere $\mathrm{CD}^{+}{ }^{+} \mathrm{T}$ cel homeostase wordt gevonden, en vitamine $\mathrm{D}$ in vitro een belangrijke promotor van $\mathrm{T}$ cel homeostase is, onderzochten we in dit cohort cross-sectioneel of er een correlatie tussen vitamine $D$ status en functie en samenstelling van het perifere $\mathrm{CD}^{+} \mathrm{T}$ cel compartiment was (beschreven in hoofdstuk 4). In 29 RRMS patiënten hing het aantal Treg in de circulatie niet samen met vitamine $D$, maar de Treg leken wel minder goed te werken in patiënten met een beperkte vitamine $\mathrm{D}$ status. $\mathrm{CD} 4^{+} \mathrm{T}$ cellen in de circulatie maakten bij patiënten met een hoge vitamine $D$ status relatief minder ontstekingsbevorderende en meer ontstekingsremmende cytokines. Vitamine $\mathrm{D}$ lijkt dus in vivo in MS patiënten dus de regulatie van $\mathrm{T}$ cel homeostase te bevorderen.

Om te onderzoeken of de rol van vitamine $D$ in de calcium huishouding voor deze interactie primair belangrijk is, bekeken we in hoofdstuk 5 in dezelfde 29 patiënten of $T$ cel regulatie ook samenhangt met afgeleiden van de effecten van vitamine $D$ op de calcium huishouding. Zowel serum waarden van 1,25-dihydroxy vitamine $D$, totaal calcium, en parathyroïd hormoon (PTH) correleerden niet met Treg functie en $\mathrm{CD}^{+} \mathrm{T}$ cel cytokine balans. Deze observatie suggereert dat de interactie tussen vitamine $\mathrm{D}$ en $\mathrm{T}$ cellen ook in vivo onafhankelijk van het calcium metabolisme is.

De associaties tussen vitamine $\mathrm{D}$ status en $\mathrm{CD}^{+} \mathrm{T}$ cel functie suggereren dat met vitamine $D$ suppletie het $T$ cel compartiment gestuurd zou kunnen worden. Als voorbereiding op een grote studie verrichtten we een pilotstudy om naar zowel de veiligheid van vitamine $D$, als naar de effecten van vitamine $D$ op de T cellen te kijken (beschreven in hoofdstuk 6). We vonden in 15 RRMS patiënten dat suppletie van $500 \mu \mathrm{g} /$ dag vitamine $D$ voor 12 weken geen effect had op het aantal Treg in de circulatie. Hiernaast werd ook de Treg functie niet significant beïnvloed, en leek deze hooguit marginaal gestimuleerd te worden. Wel vonden we na vitamine $D$ suppletie relatief gezien meer $\mathrm{CD}^{+} \mathrm{T}$ cellen die ontstekingsremmende cytokines maakten (IL-4, IL-10), en minder die ontstekingsbevorderende cytokines maakten (IFN- $\gamma$ ). Deze studie suggereert dat perifere $\mathrm{CD}^{+}{ }^{+} \mathrm{T}$ cellen een interessante marker vormen om de immuun modulerende gevolgen van vitamine $D$ suppletie in grote 
gerandomiseerde en placebo gecontroleerde studies te onderzoeken. Verder concluderen we dat suppletie van hoge dosis vitamine D zonder bijwerkingen was. Deelnemers rapporteerden geen bijwerkingen, en de calcium waarden in het bloed bleven onveranderd.

In hoofdstuk 7 onderzochten we de associatie van een functioneel vitamine D receptor (VDR) gen polymorfisme met MS, én met vitamine D status in MS patiënten en gezonde proefpersonen. Een genetisch polymorfisme is een veel voorkomende variatie in het erfelijk materiaal, dat in het geval van dit polymorfisme tot een langer of korter VDR eiwit leidt. Er was geen verschil in het voorkomen van het polymorfisme tussen 289 gezonde proefpersonen en 212 patiënten met MS. Wel werden zowel in de zomer als in de winter lagere vitamine D statussen gemeten in patiënten met het allel dat met een korter VDR eiwit geassocieerd is. In de gezonde proefpersonen vonden we dit verband ook. We concluderen dat vitamine $\mathrm{D}$ gerelateerde genetische variatie mogelijk een belangrijke confounder is in interventiestudies met vitamine $D$ en daarom in deze studies meegenomen moet worden.

Alle opgedane kennis uit de verschillende hoofdstukken hebben we gecombineerd in de ontwikkeling van het protocol voor een grote internationale studie naar vitamine D suppletie in MS dat beschreven staat In hoofdstuk 8. In een Multicenter studie in verschillende Europese landen wordt in 348 patiënten met RRMS en een korte ziekteduur onderzocht of suppletie van vitamine $D$ of placebo naast reguliere MS therapie (Interferon Beta) een toegevoegd remmend effect op de ziekteactiviteit van MS heeft. Hiernaast zal in verschillende substudies het effect op het perifere immuunsysteem onderzocht worden. Verder worden in de trial ook genetische variabelen meegenomen.

Met dit proefschrift hebben we niet de vraag beantwoord of vitamine D de ziekteactiviteit van MS kan remmen. Wel heeft dit proefschrift bijgedragen aan de ontwikkeling van een klinische studie die dit wel kan doen. Daarnaast heeft het een mechanisme uitgekristalliseerd waardoor vitamine D de pathofysiologie van MS kan beïnvloeden. We concluderen (hoofdstuk 9) dat een slechte vitamine D status samenhangt met een grote relaps activiteit en een grote mate van beperking in onze patiëntenpopulatie. Verder hangen de samenstelling en functie van het perifere $\mathrm{CD}^{+}{ }^{+} \mathrm{T}$ cel compartiment samen met vitamine $\mathrm{D}$ status in de circulatie van MS patienten. In een kleine openlabel interventiestudie hadden patiënten na vitamine $D$ suppletie een minder ontstekingsbevorderend $\mathrm{CD}^{+} \mathrm{T}$ cel cytokine profiel, wat op $z^{\prime} n$ minst de suggestie wekt dat vitamine $D$ suppletie de imbalans in het perifere $\mathrm{CD}^{+}{ }^{\mathrm{T}}$ cel compartiment bij patiënten met MS kan herstellen. In een grote interventiestudie gaan we onderzoeken of vitamine $D$ als ziekte en immuun modulator in MS ingezet kan worden. 



\title{
Acknowledgements
}

\author{
Dankwoord
}



Het verkleinwoord 'boekje' is summier voor een proefschrift, omdat deze in de regel veel tijd en energie van veel mensen kost. Daarom wil ik iedereen bedanken die op welke manier dan ook aan de totstandkoming van dit proefschrift heeft bijgedragen. Allereerst de patiënten. Zonder uw belangeloze deelname aan de studies was er geen vitamine $D$ en MS project in Sittard en Maastricht mogelijk.

Ik ben trots dat mijn paranimfen Arjen en Steven mij vandaag ter zijde staan. Arjen: onze studententijd op het Aubeldomein was geweldig! Steven: jij weet als geen ander wat promotieonderzoek op een immunologie lab inhoudt.

Verder wil ik heel graag mijn co-promotor Jan Damoiseaux bedanken. Jan, als ik één persoon aan het eind van mijn promotie als mentor aan moet wijzen, dan ben jij dat. Dank voor alle feedback, correcties, ideeën, en vooral voor het leren hoe de wetenschap werkt.

Mijn promotoren Raymond Hupperts en Jan Willem Cohen Tervaert ben ik veel dank verschuldigd. Raymond: tijdens onze eerste afspraak zei je al dat je een grote mate van zelfstandigheid verwachtte. We hebben een zeer vruchtbare manier van samenwerken gevonden en hebben de zaakjes goed voor elkaar gekregen. Ik hoop dat onze samenwerking blijft voortduren! Jan Willem: dank voor je oprechte betrokkenheid, voor je klinische input, voor je schat aan wetenschappelijke ervaring, en voor het aan willen gaan van confrontaties.

Dr. Menheere, dank voor uw expertise en onmisbare ondersteuning in dit project. Ook dank aan de laboranten die de vitamine $D$ bepalingen hebben gedaan, met speciale dank aan Nancy en Marie-José.

Mariëlle Thewissen. Ik ben geen hardcore immunoloog, maar jij gelukkig wel! Dank voor je torenhoge paniekdrempel, en dat je al je T cel expertise naast het $\mathrm{M}$ (et)S project ook in het MS project hebt willen investeren! Verder speciaal woord van dank aan Evelyn: dank voor je inzet en vooral voor je grenzeloze geduld. Ook dank aan 'B cel' Stephanie en de drie HLO-musketiers Dennis, Mark en Mike, die een grote bijdrage aan het project hebben geleverd. Josien, bedankt voor alle uren die je voor mij achter de Aria hebt door gebracht! Verder dank aan de collega's in het lab de afgelopen jaren: (Steven,) José, Maria; Ruud, Luciënne, Henk, Petra, Neele; Annelien, Bejamin, Santosh en Marcella (Porto was inderdaad top!). Dank natuurlijk ook aan alle andere medewerkers van de afdeling klinische en experimentele immuunologie!

Fons Kessels. Beste Fons, tijdens onze korte samenwerking heb ik veel van je geleerd. Dank hiervoor.

De MS verpleegkundigen, eerst in Maastricht, later in Sittard: Bertine, Riny, Tiny, Judith, Ingrid, en Sandra. Jullie enthousiasme, adequaatheid en alertheid zijn een onmisbare kracht voor het vitamine D project! Bedankt klinisch chemici Mario Vogt en Joop ten Kate, ziekenhuis apotheker Rob Janknegt, en psycholoog Yvonne Bol (allen Orbis MC Sittard) voor de enthousiaste samenwerking! 
Furthermore I would like to thank Lizette Ghazi and Manolo Beelke of Merck Serono. Our collaboration for the SOLAR-trial shows that an unbiased collaboration between academia and pharma is very well possible! Thanks for your trust in Raymond and me on this study. Additionally, I would like to thank all the members of the steering committee of SOLAR for joining us in this project.

Ook buiten de onderzoekssetting hebben velen bijgedragen aan dit onderzoek. In het bijzonder te noemen mijn collega hoornisten van de Koninklijke Harmonie van Heer en het Universiteitsorkest Maastricht: Frank, Jaap, Olav , Stijn, Willemien, Carmen en Paul. Mijn irritatiedrempel is laag, maar mijn waardering voor jullie des te hoger! Frank (en Linda en Rolo), Jaap (en Elena), ik waardeer onze vriendschap zeer en ben blij dat dit ook op pubmed vastgelegd is. Dank ook aan alle andere musici van beide orkesten, in het bijzonder de 'studenten' van de Koninklijke Harmonie van Heer: de weekendjes-weg waren een feest!

Aan de geneeskundeopleiding heb ik een aantal zeer dierbare vrienden overgehouden: (Arjen,) Petri, Argonde en Ad. Al was het houden van contact moeilijk vanuit het verre zuiden, ik waardeer jullie vriendschap enorm! Het is boeiend om te zien dat we allemaal op onze eigen manier onze plaats binnen de medische sector vinden. Onze vakantie in Les Deux Alps geldt als absoluut hoogtepunt van mijn studententijd! Bjorn, wij delen dezelfde zieke humor. Gelukkig is dit zeldzaam, dit maakt onze vriendschap extra bijzonder. Floris: ons gemeenschapelijke staartje van de geneeskunde opleiding schiep een band.

Mijn broers Tom en Bram. Tom: het is goed dat we beiden onze eigen weg gegaan zijn, en dat we elkaar na een aantal jaren ook weer teruggevonden hebben. Het is leuk zo. Bram: jij bent het lichtend voorbeeld van een echte 'family-man,' en dat bewonder ik zeer.

Verder dank aan mijn familie en schoonfamilie voor de warme omgeving vroeger en nu. Bijzonder dank aan Mirthe, Koen, Simon en Hannah. Tijdens het maken van dit proefschrift zijn jullie allemaal geboren, en met jullie erbij is de wereld nog leuker geworden!

$\mathrm{Pa}$ en Ma. Jullie hebben drie zonen adequaat opgevoed en altijd alles ervoor over gehad om ons zo goed mogelijk terecht te laten komen. Zonder jullie jarenlange liefde en toewijding had hier geen proefschrift gelegen. Ik hoop dat we hier op onze eigen gezellige Brabantse manier van kunnen genieten!

Als laatste Lies. ¡Hola! Dit stukje is af, nu kunnen we verder gaan. 
Publications 

1 Schreuder A, Smolders J, Engelshove H, Koehler P. [Balance disorder and subacute hydrocephalus due to haemorrhage in a cerebral cavernous malformation]. Nederlands Tijdschrift voor Geneeskunde 2005;149(46):2577-2581.

2 Smolders J, Damoiseaux J, Menheere P, Hupperts R. Vitamin D as an immune modulator in multiple sclerosis, a review. Journal of Neuroimmunology 2008;194(1-2):7-17.

3 Smolders J, Damoiseaux J, Hupperts R. Vitamin D and autoimmune diseases: observations in multiple sclerosis. Revista Española de Esclerosis Múltiple 2008;1(7):20-26.

4 Smolders J, Menheere P, Kessels A, Damoiseaux J, Hupperts R. Association of vitamin $\mathrm{D}$ metabolite levels with relapse rate and disability in multiple sclerosis. Multiple Sclerosis 2008;14(9):1220-1224.

5 Smolders J, Damoiseaux J, Menheere P, Cohen Tervaert JW, Hupperts R. Fok-I vitamin $D$ receptor gene polymorphism ( $r$ 10735810) and vitamin D metabolism in multiple sclerosis. Journal of Neuroimmunology 2009;207(1-2):117-121.

6 Smolders J, Damoiseaux J, Menheere P, Cohen Tervaert JW, Hupperts R. Association study on two vitamin D receptor polymorphisms and vitamin D metabolites in multiple sclerosis. Annals of the New York Academy of Sciences 2009;1173(1):515-520.

7 Smolders J, Peelen E, Thewissen M, Menheere P, Cohen Tervaert JW, Hupperts $\mathrm{R}$, Damoiseaux J. The relevance of vitamin $\mathrm{D}$ receptor gene polymorphisms for vitamin D research in multiple sclerosis. Autoimmunity Reviews 2009;8(7): 621626.

8 Smolders J, Thewissen M, Peelen E, Menheere P, Cohen Tervaert JW, Damoiseaux J, Hupperts R. Vitamin D status is positively correlated with regulatory T cell function patients with multiple sclerosis. PLoS One 2009;4(8):e6635.

9 Van den Biggelaar F, Smolders J, Jansen J. Complementary and alternative medicine in alopecia areata. American Journal of Clinical Dermatology 2010; 11(1):11-20.

10 Smolders J, Menheere P, Thewissen M, Peelen E, Cohen Tervaert JW, Hupperts $\mathrm{R}$, Damoiseaux J. Regulatory $\mathrm{T}$ cell function correlates with 25-hydroxyvitamin $D$, but not with 1,25-dihydroxyvitamin D, parathyroid hormone, and calcium levels in patients with relapsing remitting multiple sclerosis. Journal of Steroid Biochemistry \& Molecular Biology 2010;121(1-2):243-246.

11 Smolders J, Peelen E, Thewissen M, Cohen Tervaert JW, Menheere P, Hupperts $R$, Damoiseaux J. Safety and T cell modulating effects of high dose vitamin $D_{3}$ supplementation in multiple sclerosis. PLoS One 2010;5(12):e15235. 
12 Knippenberg S, Bol Y, Damoiseaux J, Hupperts R, Smolders J. Vitamin D status in patients with MS is negatively correlated with depression, but not with fatigue. Acta Neurologica Scandinavica 2011. Published online September $29^{\text {th }}, 2010$ as doi:10.1111/j.1600-0404.2010.01447.x.

13 Smolders J. Vitamin D and multiple sclerosis: correlation, causality, and controversy. Autoimmune Diseases 2011;article ID 629538:1-3.

14 Smolders J, Thewissen M, Damoiseaux J. Control of T cell activation by vitamin D. Nature Immunology 2011;12(1):3.

15 Smolders J, Damoiseaux J (2011). Vitamin D as a T-cell modulator in multiple sclerosis. In: Litwack G (ed.), Vitamins and Hormones, volume 86: vitamins and the immune system (Chapter 18, pp. 401-428), Elsevier, London (United Kingdom).

16 Smolders J, Thewissen M, Theunissen R, Peelen E, Knippenberg S, Menheere P, Cohen Tervaert JW, Hupperts R, Damoiseaux J. Vitamin D-related gene expression profiles in immune cells of patients with relapsing remitting multiple sclerosis. Submitted for publication.

17 Smolders J, Hupperts R, Barkhof F, Grimaldi L, Holmøy T, Killestein J, Rieckmann $P$, Schluep M, Vieth R, Hostalek $U$, Ghazi-Visser L, Beelke $M$, on behalf of the SOLAR study group. Efficacy of vitamin $\mathrm{D}_{3}$ as add-on therapy in patients with relapsing-remitting multiple sclerosis receiving subcutaneous interferon beta-1a: a phase II, multicentre, double-blind, randomized, placebo-controlled trial. Submitted for publication.

18 Smolders J, Moen SM, Damoiseaux J, Huitinga I, Holmøy T. Vitamin D in the healthy and inflamed central nervous system. Submitted for publication. 
Curriculum Vitae 

Joost Smolders werd op 28 maart 1983 geboren in Tilburg. Hij behaalde zijn VWO diploma in 2001 aan het Koning Willem II college te Tilburg. Hierna studeerde hij geneeskunde aan de Universiteit Maastricht, waar hij in 2007 cum laude afstudeerde. Tijdens zijn laatste studiejaar startte hij bij professor Hupperts (Maastricht Universitair Medisch Centrum (MUMC), Maastricht) met het onderzoek naar vitamine D in MS patiënten. Inmiddels is dit project uitgegroeid tot een voorname onderzoekslijn van het Academisch MS Centrum Limburg (Orbis MC, Sittard en MUMC) en de onderafdeling Immunologie van de afdeling Interne Geneeskunde (MUMC). In dit proefschrift is het onderzoek uiteengezet dat hij verrichtte bij de School for Mental Health and Neuroscience (MUMC) onder supervisie van professor Hupperts en professor Cohen Tervaert. Joost is mede-initiator en steering committee lid van de SOLAR trial, een internationale klinische studie naar vitamine D suppletie in MS. Als coordinating investigator werkt hij aan een immunologische substudie van SOLAR, de SOLAR(IUM). Momenteel onderzoekt hij de activiteit van vitamine $D$ in het centrale zenuwstelsel van MS patiënten bij de Neuroimmunologie onderzoeksgroep van dr. Huitinga (Nederlands Instituut voor Neurowetenschappen, Amsterdam). Joost woont samen met Marlies Kaal in Utrecht.

Joost Smolders was born on March $28^{\text {th }}, 1983$ in Tilburg (The Netherlands). He graduated from grammar school at Koning Willem II College (Tilburg) in 2001. Subsequently, he studied medicine at Maastricht University (Maastricht, The Netherlands), were he graduated with distinction in 2007. During the last year of his medical training, he started under supervision of prof. dr. Hupperts (Maastricht University Medical Center (MUMC), Maastricht, The Netherlands) his research on vitamin $D$ in MS. This vitamin D project has become an important research-line of the Academic MS Center Limburg (Orbis Medical Center, Sittard, The Netherlands; MUMC) and the division Immunology of the department of Internal Medicine (MUMC). This thesis comprises the research he performed at the School for Mental Health and Neuroscience (MUMC) under supervision of professor Hupperts and professor Cohen Tervaert. Joost is co-initiator and steering committee member of the SOLAR study, a clinical study on vitamin D supplementation in MS. As coordinating investigator, he contributes to an immunological sub-study of the SOLAR trial, the SOLAR(IUM). At present, he works on the activity of vitamin $D$ in the central nervous system of MS patients at the Neuroimmunology research group of dr. Huitinga (Netherlands Institute for Neuroscience, Amsterdam, The Netherlands). Joost lives together with Marlies Kaal in Utrecht (The Netherlands). 